\title{
SÍNTESIS GEOCRONOLÓGICA DEL MAGMATISMO, METAMORFISMO Y METALOGENIA DE COSTA RICA, AMÉRICA CENTRAL
}

\author{
GEOCHRONOLOGICAL SYNTHESIS OF MAGMATISM, METAMORPHISM AND \\ METALLOGENY OF COSTA RICA, CENTRAL AMERICA
}

\author{
Guillermo E. Alvarado ${ }^{1,2 *} \&$ Phillipe B. Gans ${ }^{3}$ \\ ${ }^{1}$ Instituto Costarricense de Electricidad, Apdo. 10032, 1000 San José, Costa Rica \\ ${ }^{2}$ Centro de Investigaciones Geológicas, Apdo. 35-2060 \\ Universidad de Costa Rica, San José, Costa Rica \\ ${ }^{3}$ Department of Geological Sciences, University of California, \\ Santa Barbara, CA 93106, USA \\ *Autor para contacto: galvaradoi@ice.go.cr
}

(Recibido: 15/10/2011; aceptado: 11/06/2012)

\begin{abstract}
A comprehensive compilation of 651 (since 1968) radiometric ages determinations $\left(415{ }^{40} \mathrm{Ar} /{ }^{39} \mathrm{Ar}, 211\right.$ $\mathrm{K} / \mathrm{Ar}, 5 \mathrm{U} / \mathrm{Th}, 4 \mathrm{Rb} / \mathrm{Sr}, 2 \mathrm{U} / \mathrm{Pb}$, and 13 fission track thermochronology ages using zircon) provides a complete picture of the igneous stratigraphy of Costa Rica, and information about the age of the major metamorphic and metalogenic events in the region. Igneous rocks of Late Jurassic to Middle Eocene age $(\sim 160$ to $\sim 41 \mathrm{Ma})$, mainly accreted ophiolites. At the beginning of Campanian time $(\sim 71 \mathrm{Ma})$, the actual subduction zone was established, represented by volcanosedimentary rocks of basic to felsic composition. However, voluminous subalkaline, primary volcanic rocks appeared only after $\sim 29 \mathrm{Ma}$. Intrusive to hypabyssal granitic to gabboic plutons, stocks, equivalent dykes and sills, are widely exposed in the Talamanca range $(\sim 12.4$ - 7.8 Ma), Cerros de Escazú $(\sim 6.0$ - 5.9 Ma), and Fila Costeña $(\sim 18.3-16.8$ and $\sim 14.8$ - $11.1 \mathrm{Ma})$, Tapantí-Montes del Aguacate-Carpintera $(\sim 4.2$ - $2.2 \mathrm{Ma})$ and Guacimal $(\sim 6.4-5.2 \mathrm{Ma})$. Arc rocks between 29 and $11 \mathrm{Ma}$ are known in the San Carlos plains and in southern Costa Rica. The location and age of the igneous rocks indicated that there was a $20^{\circ}$ counterclockwise rotation of the arc (termed as Proto-Volcanic Front) between 15 and $8 \mathrm{Ma}$, with a pole of rotation centered on southern Costa Rica. This rotation is attributed to deformation in the overriding plate (shortening in the south coeval with extension in the NW), accompanied by trench retreat in the south. At $\sim 3.45 \mathrm{Ma}$ arc-related volcanism shut off in southern part of the region, but local acid-adakite volcanism persisted in the Talamanca range (4.2- $0.95 \mathrm{Ma})$ due to the subduction of the Cocos Ridge. The Paleo-Volcanic Front is represented by arc-related rocks ( $8-3.5 \mathrm{Ma}$ ) along the length of Costa Rica, parallel to but in front of the modern arc. This activity was followed by the Monteverde (2.1 - 1.1 Ma) andesitic/basaltic effusive event, which progressively
\end{abstract}


retreated to the NE. Thus, the Neo-Volcanic Front was established between 2.1 and the present, in which the modern volcanoes grew mainly during the last $0,6 \mathrm{Ma}$. In general, modern volcanoes represent three volcanic episodes: ancestral cone/shield building at $\sim 1,61$ - 0,85 Ma (Proto-Cordillera), overlapping in part with Monteverde volcanism; a major constructive event at $\sim 0,74-\sim 0,2 \mathrm{Ma}$ (Paleo-Cordillera), and a relatively small but still active volcanism at 0,25 - $0 \mathrm{Ma}$ (Neo-Cordillera). Submarine volcanism in the Pacific is represented by the Fisher Ridge (30.0 and 19.2 $\mathrm{Ma})$, the Cocos Ridge (14,5 - 0,6 Ma), including the sub-aerial volcanism of Cocos Island (2,2 - 1,5 Ma). The major magmatic, metamorphic and metallogenic events are clearly related to major geotectonic events, including regional unconformities, at Upper Cretaceous ( $\sim 82 \mathrm{Ma})$, Middle Eocene ( $45 \mathrm{Ma})$ and Upper Miocene ( $~ 8 \mathrm{Ma})$.

Key words: Central America, Costa Rica, geochronology, magmatism, metamorphism, metallogeny

RESUMEN: Una recopilación completa de 651 determinaciones de edades radiométricas desde 1968 (415 dataciones ${ }^{40} \mathrm{Ar} /{ }^{39} \mathrm{Ar}, 211 \mathrm{~K} / \mathrm{Ar}, 5 \mathrm{U} / \mathrm{Th}, 4 \mathrm{Rb} / \mathrm{Sr}, 2 \mathrm{U} / \mathrm{Pb}$ y de fisión termocronología con zircón), tanto aquellas publicadas desde 1968 como muchas nuevas, proporcionan un marco completo de la estratigrafía ígnea de Costa Rica y las inferencias acerca de la edad del metamorfismo y los eventos metalogenéticos. Las rocas ígneas del Jurásico Superior temprano al Eoceno Medio ( $160 \mathrm{a} \sim 41 \mathrm{Ma})$, corresponden principalmente con acreciones ofiolíticas. Durante el Campaniano $(\sim$ $71 \mathrm{Ma}$ ) comienza a establecerse la actual zona de subducción, conformada por rocas volcano-sedimentarias, con una composición desde básica a félsica. Sin embargo, las rocas volcánicas primarias, subalcalinas, in situ y abundantes, aparecen hasta después de los $\sim 29$ Ma. Los intrusivos e hipoabisales de granitoides hasta gabroides (plutones, stocks, diques y sills), están presentes de SE a NW en: la cordillera de Talamanca ( 12,4 a 7,8 Ma), cerros de Escazú ( 6,0 a 5,9 Ma), fila Costeña ( 18,3 a 16,8 y 14,8 a 11,1 Ma), Tapantí-montes del Aguacate-Carpintera $(\sim 4,2$ a 2,2 Ma) y Guacimal ( 6,4 a 5,2 Ma). Las rocas asociadas al arco con edades entre los 29 y $11 \mathrm{Ma}$ (denominado Frente ProtoVolcánico), están presentes en la llanura de San Carlos y en el sur de Costa Rica. La ubicación y la edad de las rocas ígneas indican que el arco dio un giro de $20^{\circ}$ al NW entre 15 y $8 \mathrm{Ma}$, con un polo de rotación que se centró en el sur de Costa Rica. Esta rotación se atribuye a la deformación en la placa superior (acortamiento en el sur y extensión en el noroeste), acompañado por el retroceso de la trinchera hacia el sur. A los 3,45 Ma, el arco volcánico en el sur cesó su actividad, mientras que el vulcanismo adakítico localizado persistió en la cordillera de Talamanca (4,2 - 0,95 Ma) debido a la subducción de las Placa Cocos. El Frente Paleo-Volcánico está representada por rocas del arco (8 - 3,5 Ma) que se extienden a lo largo de Costa Rica, de forma paralela al arco volcánico moderno y fue seguido por el evento efusivo Monteverde (2,1 - 1,1 Ma), que progresivamente se retrocedió hacia el NE. El Frente Neovolcánico se estableció entre el 2,1 y el presente, con el crecimiento de los actuales volcanes, mayoritariamente hace unos 0,6 Ma y, en general, están representados por tres episodios, no isocrónicos entre volcanes: volcanes ancestrales entre 1,61 y 0,85 Ma (Proto-Cordillera), en parte coetánea con Monteverde; un evento importante cerca de $\sim 0,74-\sim 0,2 \mathrm{Ma}$ (Paleo-Cordillera), y una actividad volcánica relativamente pequeña, pero activa aún en 0,25 - $0 \mathrm{Ma}$ (Neo-Cordillera). El vulcanismo submarino en aguas del Pacífico costarricense, está representado por la serranía Fisher (30,0 Ma y 19,2 Ma), la cordillera del Coco (14,5 - 0,6 Ma) y el vulcanismo subaéreo de la isla del Coco (2,2 - 1,5 Ma). Los principales eventos magmáticos, metamórficos y metalogéneticos están relacionados con los principales eventos geotectónicos, incluyendo discordancias regionales en Cretácico Superior ( $\sim 82 \mathrm{Ma})$, Eoceno Medio ( $\sim 5 \mathrm{Ma})$ y el Mioceno Superior $(\sim 8 \mathrm{Ma})$.

Palabras clave: América Central, Costa Rica, geocronología, magmatismo, metamorfismo, metalogenia

\section{INTRODUCCIÓN}

Las dataciones radiométricas son una herramienta importante para el geólogo, de modo que en diversa investigaciones se incluyen dataciones como apoyo para el establecimiento de diversas hipótesis tectónicas y para sustentar la cronoestratigrafía. Con el avance tecnológico, se han cambiado los métodos en la búsqueda de una mejor precisión, por ejemplo, el tener un mejor control de la edad en rocas deficientes en potasio. Las dataciones hechas en rocas de Costa Rica se encuentran en diversos informes y publicaciones, lo que hace muy difícil su acceso. Por esto ya se había realizado una primera compilación, trabajo que se inició en 1986 y culminó en 1990 con la publicación de los 160 resultados disponibles hasta ese momento (Alvarado et al., 1992). Sin embargo, entre estos años, ya se ha superado estos números y existe un considerable número de datos, en informes internos y particularmente en publicaciones, además de la voluminosa base de datos no publicados, hechos bajo el marco 
de un proyecto de la National Science Fundation. En esta publicación se ponen por primera vez todos los datos de una manera fácil de localizar y que puedan ser comparativos.

La campaña de dataciones se inició en diciembre de 1998 y culminó en el 2000, aunque la compilación de todas las dataciones costarricenses fue posible concluirla hasta finales de 2011. Todo este banco de datos permite presentar un cuadro cronoestratigráfico de la evolución de las rocas ígneas en el tiempo y el espacio, así como sus relaciones estratigráficas. Se realiza, además, una travesía histórica sobre el uso de los diferentes métodos, sus limitaciones y virtudes. Igualmente, se aportan comentarios sobre la "calidad y tipo" de los datos con base en el estado del conocimiento al día de hoy.

En la presente investigación se compila, revisa y analiza sinópticamente todas las dataciones $\mathrm{K} / \mathrm{Ar},{ }^{40} \mathrm{Ar} /{ }^{39} \mathrm{Ar},{ }^{238} \mathrm{U} /{ }^{230} \mathrm{Th}, \mathrm{U} / \mathrm{Pb}, \mathrm{Rb} / \mathrm{Sr} \mathrm{y}$ de termocronología de trazas de fisión utilizando zircón, realizadas en rocas ígneas y metaígneas de Costa Rica desde 1968 hasta 2011, para contabilizar una cifra para nada despreciable de 651 edades. Cerca de un $40 \%$ de las muestras son de edad Cuaternaria, lo que evidencia una preferencia en los estudios por las rocas del eje neovolcánico. No se incluyen las de ${ }^{14} \mathrm{C}$ o las de $\mathrm{Sr} /$ $\mathrm{Sr}$ en rocas sedimentarias. Se presenta, además, un banco de datos uniforme de 203 dataciones ${ }^{40} \mathrm{Ar} /{ }^{39} \mathrm{Ar}$ colectadas y realizadas en su mayoría entre diciembre de 1998 y 2000, hasta el momento mencionadas solo una pequeña fracción de ellas (Gans et al., 2003, 2004; Vogel et al., 2004) y publicadas con todo su detalle (localización, tipo de roca, detalles cronológicos, etc.) tan solo 49 edades (MacMillan et al., 2004; Pérez et al. 2006), por lo que en su mayoría se mantenían inéditas hasta el presente trabajo. Estas muestras, procesadas en el Departamento de Ciencias Geológicas de la Universidad de California en Santa Bárbara (EE. UU.), representan el 35,6\% del total de muestras analizadas para Costa Rica, aportando información valiosa.

A pesar de las eventuales limitaciones que presenta cada método radiométrico y sus incertidumbres, aspectos que se tratarán extensamente en los apartados que siguen, la gran cantidad de edades disponibles en un territorio pequeño como el nuestro (51 $\left.100 \mathrm{~km}^{2}\right)$, permiten definir un marco cronoestratigráfico y de evolución ígnea de Costa Rica, así como realizar comparaciones detalladas, inclusive dentro de la misma unidad y, mejor aún, en el mismo afloramiento. En otros casos, se dispone de un control geológico o estratigráfico (unidades sobre- e infrayacentes, diques cortando unidades ígneas, dataciones paleontológicas), geomorfológicas (grado de disección y meteorización), o tectónico (basculamiento, grado de fracturamiento, discordancias), que permite complementar la historia geológica del territorio.

\section{Antecedentes históricos}

En la década de los setentas y ochentas del siglo pasado, las edades radiométricas, denominadas dataciones absolutas, proporcionaban los puntos de apoyos fijos para establecer la cronología ígnea de una secuencia estratigráfica. Al ser definido como absolutas (las paleontológicas $\mathrm{u}$ otras son relativas), se consideraban en cierto modo, incuestionables, es decir, que toda la geología (estratigrafía, geomorfología, tectónica e historia geológica) debían de girar en torno a ellas, sin cuestionarse si las evidencias geológicas las apoyaban. Claramente, gran parte de la tabla geológica del tiempo nace de estos métodos isotópicos, pero apoyada en regiones claves en donde existían muchas dataciones y fases mineralógicas que, conjunto con la micropaleontología, justificaban una secuencia u orden lógico. Pero en nuestro contexto, originalmente con pocas edades, este concepto de "absoluto" y su validez nacían por desconocimiento del método. Hoy en día se sabe que las dataciones radiométricas poseen limitaciones, por lo que los datos merecen analizarse con precaución.

Las dataciones radiométricas isotópicas eran, hasta hace escasamente dos décadas, un método que estaba fuera del alcance de la mayoría de los grupos de investigación en América Central, por lo que cualquier dato era considerado -y aún lo es- muy valioso.

La primera datación radiométrica de una roca ígnea procedente de un territorio costarricense 
fue realizada por Dalrymple \& Cox (1968) en la isla de Coco, y las primeras en territorio continental fueron realizadas por Barr \& Escalante (1969) en el Complejo de Nicoya. Después llegaron los primeros resultados sistemáticos de dataciones, que se enmarcaban principalmente en un volcán en particular, por ejemplo el Irazú, dado que adquirió relevancia mundial después de su actividad de 1963-65 (Krushensky, 1972; Allegre \& Condomines, 1976). Otras se encuentran en reportes internos del Instituto Costarricense de Electricidad (Mainieri, 1976, ICE, 1985, 1987; ICE-ENEL, 1983, 1989), aplicadas primordialmente a estudios goetérmicos de la región de Guanacaste.

En el Diagnóstico del Sector Minero de Costa Rica, se incluyen los resultados preliminares de 18 dataciones inéditas de 22 hechas por el petrólogo Jean Tournon (Anónimo, 1978, pp. 3, 4 y 91). En ese mismo año, se publicaron formalmente solo 19 (Bellon \& Tournon, 1978), de las cuales únicamente 10 concuerdan con las citadas en Anónimo (1978), porque probablemente los autores excluyeron datos por considerarlos poco confiables o bien, fueron recalculadas para su posterior publicación. Aunque Dengo (1962) es el primero que plantea una evolución tectonomagmática de Costa Rica por correlaciones estratigráficas (principalmente paleontológicas), pero son Hervé Bellon y Jean Tournon quienes por primera vez presentan un cuadro cronológico de eventos desde el Cretácico al Pleistoceno basado en 16 datos isotópicos. Parte de estas dataciones fueron republicadas con algunas modificaciones y agregados por Weyl (1980). Sáenz (1982) igualmente publica una compilación preliminar de 43 datos, sin comentario alguno, en donde incluye los resultados de Barr \& Escalante (1969), Krushenshy (1972), Allegre \& Condomines (1976), Berrangé \& Whittecker (1977), informes inéditos del ICE y de RECOPE, así como nuevamente comunicaciones escritas de Jean Tournon y verbales de Enrique Malavassi. Sin embargo, tal y como se comentó, algunos de los resultados suministrados por Tournon no llegaron a ser publicados por él por ser considerados en ese momento como poco confiables (dado su bajo contenido en $\mathrm{K}$ ), o por arrojar una edad que para ese entonces no estaba acorde con el cuadro estratigráfico que se manejaba. Tal y como se aclaró, los datos finales se publicaron en Bellon \& Tournon (1978) y en Bellon et al. (1983) y, finalmente, Tournon (1984) publica en su tesis doctoral algunos nuevos resultados inéditos, detallando la localización y petroquímica de sus dataciones anteriores. Los datos originalmente suministrados por E. Malavassi en forma verbal (p.ej., Sáenz, 1982), fueron formalmente publicados por Bergoeing (1982).

Por todo lo anterior, en la presente compilación se ha tenido el cuidado de verificar las fuentes originales y se han seleccionado solo los datos que se consideran confiables y basados en las fuentes primarias.

Berrangé \& Whittecker (1977) y WoodwardClyde (1980, en de Boer et al., 1995) realizaron valiosos detalles de las intrusiones de Talamanca y fila Costeña, o bien Schulz et al. (1987) así como Amos \& Rogers (1983) sobre las rocas de la cordillera de Tilarán. Para ese entonces, algunos investigadores publican datos aislados pero igualmente valiosos, dentro del contexto magmatogénico, con el fin de ir llenando paulatinamente los vacíos (p.ej., Bergoeing, 1982; Kesel, 1983; Cassell, 1986; Sen Gupta et al., 1986; Alvarado, 1990).

Posteriores dataciones K/Ar, se enfocaron en tratar de precisar más la historia magmática, en particular en regiones sin o poca información geocronológica como Nicoya, Osa y Burica, así como algunos eventos volcánicos Neógenos y Cuaternarios de importancia, para los cuales se contaron con campañas que iniciaron en 1987 y culminaron con varios trabajos, entre ellos se pueden citar: Berrangé et al. (1989), Appel (1990), Appel et al. (1994) y Gillot et al. (1994). Los resultados de los trabajos publicados hasta 1990, fueron compilados y enmarcados dentro de un contexto cronoestratigráfico por Alvarado et al. (1992), que incluyó 166 resultados radiométricos. Otros trabajos posteriores con algunos resultados K/Ar, son los de Obando (1995), Sigarán (2001) y Gazel et al. (2005).

Con el desarrollo de la técnica de datación ${ }^{40} \mathrm{Ar} /{ }^{39} \mathrm{Ar}$ y su mejor precisión geocronológica, así como el hecho de que este método permite verificar si existe contaminación o eventos térmicos, 
al no presentar un plateau, se entró en una nueva fase dentro de la historia geocronológica de Costa Rica. Las primeras dataciones de este tipo fueron realizadas por Thomas Gardner y Brent Turrin en 1990, pero no fueron publicadas por ellos, aunque se incluyeron en el trabajo de Alvarado et al. (1992), gracias a la autorización dada por Gardner en su momento. Sin embargo, Alvarado y sus colaboradores desconocían que esos datos eran, en realidad, edades ${ }^{40} \mathrm{Ar} /{ }^{39} \mathrm{Ar}$ (B. Turrin, com. escrita, 2006, 2010) y se tomaron más bien como resultados K/Ar (ídem para Marshall, 2000). Otra datación ${ }^{40} \mathrm{Ar} /{ }^{39} \mathrm{Ar}$, incluida en un informe interno, fue la realizada por Woodward-Clyde (1993) durante el proyecto MYRVIS para la capa de pómez Tibás, y no se conoció de su existencia hasta varios años después.

Nuevas campañas de dataciones ${ }^{40} \mathrm{Ar} /{ }^{39} \mathrm{Ar}$ se realizaron a principios de la década de los noventa del siglo XX e inicios del XXI, focalizadas a esclarecer el problema de los complejos ígneos básicos (ofiolitas), mediante los trabajos sistemáticos de Sinton et al. (1997, 2009), Alvarado et al. (1997), Hauff et al. (2000), Hoernle et al. (2002, 2004). Las dataciones de Hauff et al. (2000) se realizaron por medio del método de fusión total (en los cuadros como f.t.), que no produce una edad plateau, sino una edad media aparente (e.m.a.) similar a la K/Ar, mientras que las dataciones de Sinton et al. $(1997,1999)$ y Alvarado et al. (1997), sí se realizaron mediante la técnica de calentamiento por etapas (step-heating), las cuales producen resultados más confiables. Después, la técnica fue mejorada en el laboratorio de Geomar (Kiel, Alemania) para poder realizar dataciones por etapas, siendo sus resultados publicados por Hoernle et al. (2002, 2004), comparables con los previos obtenidos.

Un trabajo similar de campo fue realizado a finales del siglo XX para los eventos magmáticos del Cenozoico, pero cuyos resultados estuvieron disponibles hasta el nacimiento del nuevo milenio, con los estudios de Marshall (2000) y Marshall et al. (2003), a las que se vienen a sumar la campaña de Phillipe B. Gans y su nutrido grupo de colaboradores (Gans et al., 2003, 2004; MacMillan et al., 2004; Vogel et al., 2004; Pérez et al. 2006), así como por Mike J. Carr, Brent Turrin, Carl
Swisher, Kaj Hoernle, Esteban Gazel, Pablo Ruiz y colaboradores (Alvarado et al., 2006; Carr et al., 2007; Gazel et al., 2004, 2009, 2011; Ruiz et al., 2010a, b).

Contemporáneamente, del piso del fondo oceánico Pacífico fueron dragados basaltos y traquitas subordinadas, que junto con las lavas subaéreas de la isla del Coco, suministraron nuevas edades ${ }^{40} \mathrm{Ar} /{ }^{39} \mathrm{Ar}$ de la placa del Coco en aguas territoriales costarricenses. Dicha información fue procesada en la Universidad de Kiel y el Instituto Geomar, adscrito a dicha universidad (Werner et al., 1999; O'Connor et al., 2007), y realizadas por Paul van den Bogaard o por John M. O'Connor, en conjunto con sus colaboradores cercanos.

El grado de precisión de las edades obtenidas con el método ${ }^{40} \mathrm{Ar} /{ }^{39} \mathrm{Ar}$ ha llegado a ser tal, que se ha podido cotejar en muchos casos con dataciones ${ }^{14} \mathrm{C}$, representa un avance enorme dado que no siempre existe material orgánico carbonizado disponible en los afloramientos. Algunas edades obtenidas llegaren a ser tan jóvenes como $3 \pm 3 \mathrm{ka}$ (ver Alvarado et al., 2006; Carr et al., 2007; Ruiz et al., 2010b). Previamente, Gillot et al. (1994) habían obtenidos resultados igualmente dentro del rango del radiocarbono, pero con un refinamiento del método $\mathrm{K} / \mathrm{Ar}$ (ver más adelante).

Muchos años después de realizados los análisis, J. Tournon y H. Bellon publican otra serie de dataciones $\mathrm{K} / \mathrm{Ar}$, que en su momento consideraron que podían ser erradas dado su bajo contenido en $\mathrm{K}$, pero que se enmarcaban bien dentro de las propuestas cronoestratigráficas aportadas por Sinton et al. (1997) y Hauff et al. (2000), por lo que vienen a complementar los cuadros cronoestratigráficos de los complejos oceánicos ígneos básicos y ultrabásicos (Tournon \& Bellon, 2009).

Nuevos estudios radiométricos K/Ar y particularmente aquellos que utilizaron por primera vez en Costa Rica las técnica del $\mathrm{U} / \mathrm{Pb}, \mathrm{Rb} / \mathrm{Sr}$ y de termocronología de trazas de fisión del zircón, se compararon los resultados con los de K/Ar y ${ }^{40} \mathrm{Ar} /{ }^{39} \mathrm{Ar}$, entre ellos: Defant et al. (1992), de Boer et al. (1995), Drummond et al. (1995), Gräfe (1998), Gräfe et al. (2002), Kycl et al. (2010) y Žaček et al. (2011).

El presente trabajo compila toda esta valiosa información generada durante 43 años, a la vez 
que aporta una visión histórica, crítica y sinóptica de todas las dataciones y del estado del arte de la geocronología y cronoestratigrafía ígnea en Costa Rica.

\section{Base de datos, metodología y abreviaciones}

La base de datos consta de 569 muestras de roca, para un total de 651 determinaciones de edades radiométricas: 415 dataciones ${ }^{40} \mathrm{Ar} /{ }^{39} \mathrm{Ar}, 211$ $\mathrm{K} / \mathrm{Ar}, 5 \mathrm{U} / \mathrm{Th}, 4 \mathrm{Rb} / \mathrm{Sr}, 2 \mathrm{U} / \mathrm{Pb}$ y 13 de fisión termocronología con zircón.

Las dataciones radiométricas se agruparon por contexto geográfico y geológico, de más antigua a más joven y se indica la fuente original o primaria. Se incluyeron muestras que dan edades no acordes con la edad asumida de la roca, para que queden como dato de referencia, lo cual se especifica en los comentarios de los cuadros, pero, se tomaron únicamente las edades que se consideran más precisas o acordes con la estratigrafía (unidades superiores e inferiores) o con el paradigma geológico prevaleciente al día de hoy, incluyendo una amplia discusión sobre su significado geológico y su validez. Se excluyeron del análisis, aquellas edades que analíticamente son erróneas o cuya edad es más joven que lo que el método permite.

Hasta donde fue posible, se cita el método y el o los minerales utilizados (plag: plagioclasa; hb: anfíbol; kfd: felpespato potásico; biot: biotita, zir: zircón), así como si fue roca total (wr) o matriz (mtz). Mientras que en el método K/Ar, en la mayoría de los casos se molía la roca como un todo con poca separación de los elementos extraños (xenolitos, xenocristales, cumulados), en muchas de las dataciones ${ }^{40} \mathrm{Ar} /{ }^{39} \mathrm{Ar}$ se especifica la fase que fue datada (mineral, vidrio, matriz o roca total), y cuando se disponía de la información, se especifica en los cuadros si se utilizó el plateau (plat.) o la isócrona (iso.). También se incluyen aquellas edades obtenidas por trazas de fusión del zircón (zfta).

En los cuadros, los accidentes o rasgos geográficos fueron abreviados: bahía (Bah.), cerro (C.), carretera (ca.), este (E), fila (F.), hoja (H.), hacienda (Hda.), isla (I.), norte (N), península (Pe.), proyecto hidroeléctrico (P.H.), playa (Pl.), puerto (Pto.), quebrada (Queb.), río (R.), sur (S), volcán (V.) y oeste (W).

Para la confección de los cuadros con los datos, se consultó la literatura, informes internos y tesis, en la medida posible, la fuente primaria. Se trató de respetar la clasificación original del tipo de roca descrito los autores, aunque en muchos casos se aportaron notas adicionales o se renombró la roca, si el nombre no era el más apropiado con base en la petrografía (contenido mineralógico modal y/o normativo), geoquímica (diagramas petroquímicos clasificatorios) y contexto aportado por el mismo autor.

Referente a los nombres de las rocas, se utilizó la recomendación de la Subcomisión sobre la Sistemática de las Rocas Ígneas de la IUGS (Le Maitre, 1989), la de la Subcomisión sobre la Sistemática de las Rocas Metamórficas (Smulikowshi et al., 2007) y la propuesta para la clasificación de brechas de falla y rocas relacionadas (Woodcock \& Mort, 2008). Cuando se menciona tan solo la petrografía en los cuadros (p.ej., andesita, o andesita basáltica), suele corresponder con muestras procedentes de cuerpos lávicos (en su mayoría coladas de lava).

Para la tabla geológica del tiempo, se utilizó el trabajo de Walker \& Geissman (2009) y para la actualización del Pleistoceno y sus subdivisiones -envejecido ahora hasta los 2,58 Ma- se empleó el trabajo de Gibbard et al. (2010). Por ello, algunos rangos de edades o incluso el periodo geológico pueden variar con respecto a las publicaciones originales, basadas en tablas geológicas previas. Para la convención del uso del tiempo, se utilizó las recomendaciones dadas por Holden et al. (2011).

Las edades reportadas antes de 1977, deben de ser recalculadas usando la nueva constante de decaimiento de Steiger \& Jäger (1977). Dentro de ellas tenemos las edades aportadas por Dalrymple \& Cox (1968), Barr \& Escalante (1969), Krushensky (1972) y los reportes internos del Instituto Costarricense de Electricidad (Mainieri, 1976). El mayor problema radica en la carencia de los datos originales de laboratorio, por lo que no se pueden recalibrar las edades, caso de los trabajos de Krushensky (1972) y Mainieri (1976). Aunque dichas edades se mantienen en el presente trabajo (cuadros adjuntos) por 
su valor histórico, tiene que tenerse presente que no están recalibradas, más a la luz de que existen datos más recientes, en algunos casos duplicados, mejor controlados tanto geológica como geográficamente. La edad de Barr \& Escalante (1969) de una almohadilla basáltica de Nicoya $(75,5 \pm$ 4,0 Ma) fue recalculada por Frisch et al. (1992) en $85,5 \pm 4,7 \mathrm{Ma}$; sin embargo, se desconoce de dónde tomaron los datos de laboratorio, dado que no están incluidos en el trabajo original. De igual modo se desconoce si Berrangé \& Whittaker (1977) aplicaron esta calibración o no, dado que el trabajo se publicó en el mismo año en que aparece las nuevas constantes de recalibración de Steiger \& Jäger (1977), y muy probablemente las muestras fueron analizas previamente. Además, Berrangé \& Whittaker (1977) no aportan ningún comentario o tabla de los datos originales del laboratorio. La duda queda abierta y por ello, los datos deben de ser tomados con cautela, aunque queden dentro del rango de los intrusivos miocenos. Las tres lavas de la isla del Coco, reportadas por Dalrymple \& Cox (1968), pudieron ser recalculadas en el presente trabajo.

Algunos datos compilados por Alvarado et al. (1992), originalmente tomados como válidos, o algunos de los realizados por Appel et al. (1994), hoy día son cuestionados a la luz de nuevos estudios sistemáticos y confirmatorios mediante diferentes técnicas de laboratorio, además de controles cruzados. Muchos otros, sin embargo, se mantienen válidos.

Hay que tomar en consideración que los resultados radiométricos de Costa Rica, compilados en el presente trabajo, corresponden a muestras recolectadas por diferentes personas durante los últimos 43 años, en contextos geológicos variados, y que, a su vez, fueron analizados en laboratorios diferentes (en EE. UU., Francia, Alemania, Holanda, Noruega, Suiza e Inglaterra) y bajo técnicas $\left(\mathrm{K} / \mathrm{Ar},{ }^{238} \mathrm{U} /{ }^{230} \mathrm{Th},{ }^{40} \mathrm{Ar} /{ }^{39} \mathrm{Ar}, \mathrm{U} / \mathrm{Pb}\right.$ y $\mathrm{Rb} / \mathrm{Sr}$ ), muestras (roca total, fases mineralógicas y vidrio) y estándares variados. Por ello, para hacer las correlaciones, se requirió de un estudio sistemático, tanto en el campo como en el laboratorio, así como su evaluación estadística.

Algunos aspectos que se consideraron, son por ejemplo, que las tobas de caída y tobitas son desfavorables para datar, porque parte del Ar que está contenido en los líticos y en el vidrio de la matriz, que se transforma fácilmente en arcillas o recristaliza con el tiempo. De igual modo, los diques delgados no siempre son confiables de datar porque pueden contener exceso de gas atmosférico. Las rocas antiguas, por su parte, suelen perder parte del argón, por lo que los métodos suelen dar edades más antiguas, o en su defecto, rocas con poco contenido en potasio, pueden dar edades anómalamente jóvenes. Es por ello que los datos de los cuadros ofrecidos en este trabajo no pueden ser tomados con la misma confiabilidad y esta no se expresada simplemente por el error analítico reportado por el laboratorio. Todo ello se explica más adelante con mayor detalle en las metodologías y en el análisis de los resultados.

En tal caso, las rocas con textura lávica (principalmente coladas, pero también domos) fueron los mayoritariamente analizados, seguidos por las rocas plutónicas e ignimbritas, y en menor grado, los cuerpos hipoabisales, rocas volcaniclásticas y rocas metamórficas, incluyendo la alteración hidrotermal (Fig. 1).

Referente a las localizaciones de las muestras, en la medida de lo posible se citan aquellas aportadas en el trabajo original o bien aquellas deducidas de los mapas o figuras allí incluidos. En muchos casos, el primer autor tuvo participación directa en gran parte del trabajo de campo con los expertos y tesistas y en los resultados de laboratorio, tal y como es el caso de las dataciones realizadas por Thomas Gardner, Brent Turrin, Pierre-Yves Gillot, Holger Appel, Michael Abratis, Kaj Hoernle, Folmar Hauff, Paul van den Bogaard, Reinhard Werner, John M. O'Connor, Michael Carr, Thomas Vogel, Esteban Gazel, Pablo Ruiz, David Szymanski y Christofer Sinton, entre otros, o tuvo contacto directo con alguno de los autores de los trabajos, tal y como es el caso del petrólogo Jean Tournon, del geomorfólogo Jeffrey S. Marshall, o bien con los geólogos Petr Kycl, Vladimir Žaček, Alfredo Mainieri, Percy Denyer y Gerardo Soto.

De igual modo, en varios casos, la información básica, como el tipo de roca, contexto geológico o la geoquímica, no es clara o es incompleta, desconociéndose incluso si la roca es de tipo intrusiva o volcánica (p.ej., Jackson, 1991; de Boer 


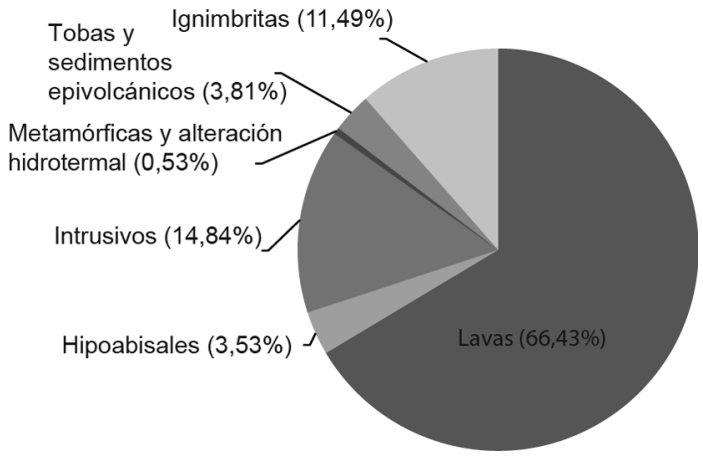

Fig. 1: Los tipos de rocas analizadas en forma porcentual por los metódos radiométricos incluidos en el presente trabajo.

et al., 1995), lo cual es dichosamente aclarado por Drummond et al. (1995), quienes utilizan los mismos datos de Boer y colaboradores. En muchos otros casos, no se aportaron coordenadas, tan solo direcciones generales (p.ej., Bergoeing, 1982, para citar un ejemplo) o mapas muy generales. Se tuvo entonces que consultar los trabajos originales para realizar control cruzado, tratando de extraer la información (análisis químicos, petrográficos, mapas, comentarios estratigráficos de los autores, fotografías en documentos) y cotejarla con los mapas geológicos disponibles y hacer giras de campo para corroboración, con el fin de deducir el tipo de roca y sus coordenadas aproximadas (en los cuadros se indican como aprox.). Se puso un signo de interrogación cuando la información litológica es dudosa o aproximada, o extrapolada de los reportes o cuando las coordenadas poseen un grado de incertidumbre de pocas decenas o centenares de metros, pero por lo general se estima que no supera los $2 \mathrm{~km}$ de radio. Nuevamente, dado que el primer autor participó en mucha de las recolecciones y con base en la información geológica disponible, o sus visitas al campo de verificación, la litología y las coordenadas fueron corregidas o mejoradas cuando así fue necesario. En otros casos, existen diferencias entre los datos citados en el texto con los aportados en las tablas de una misma publicación o tesis, debido a factores de corrección posteriores a partir de los estándares, errores tipográficos o descuidos, o por ser edades promedio dentro del texto. En estos casos se trató de contactar a los autores para tratar de clarificar y solventar el problema. En tal caso, siempre se puso la referencia original y el lector, en caso de requerirlo, podrá consultar la fuente primaria y tomar sus propias decisiones.

Para la base uniforme de dataciones presentadas en este trabajo, en su mayoría las muestras de roca fueron tomadas por ambos autores y el trabajo de laboratorio fue realizado por Gans y colaboradores, para un total de 203 muestras. La estrategia en el campo consistió, en el caso de las ignimbritas, por ejemplo, el de eliminar la mayor cantidad de fragmentos líticos accidentales posibles y recolectar los fragmentos de pómez pura (si eran lo bastante grandes), o concentrados de pómez. En el caso de las lavas, se trató de datar la matriz y separados de minerales para su comparación, lo mismo para diferentes fases mineralógicas de rocas intrusivas, siempre recolectándose las rocas más frescas posibles. Tras un análisis petrográfico, las mejores muestras fueron seleccionadas para trabajo geocronológico detallado. Inclusive, algunas muestras se obtuvieron de la misma localidad pero en diferentes partes de la sección. Además, se recolectaron fragmentos de rocas de coladas de lava subyacentes y sobreyacientes en varios lugares, para proporcionar soportes independientes de la edad. Las separaciones de minerales y los análisis isotópicos acá presentados, se realizaron en el Laboratorio de Geocronología de Argón en la Universidad de California, Santa Bárbara. Los concentrados purificados fueron triturados finamente, tamizados, y limpiados con ultrasónico.

Para la plagioclasa separada y de gran pure$\mathrm{za}$, las fracciones de diferentes tamaños se obtuvieron utilizando líquidos pesados estándares y técnicas de separación magnética. La plagioclasa separada y purificada, fue tratada en $5 \%$ de HF de 5 a 10 minutos, limpiada en baño ultrasónico, y los minerales contaminantes restantes fueron retirados manualmente bajo luz reflejada. $\mathrm{La}$ cantidad de mineral separado varió desde $50 \mathrm{mg}$ hasta varios cientos de $\mathrm{mg}$, en rangos de tamaño de $150-300 \mathrm{~mm}$ y $300-600 \mathrm{~mm}$ fueron empacadas en láminas de cobre, cargadas en un frasco de 
cuarzo e irradiado en un tubo de cadmio-alineado en el reactor de TRIGA de la Universidad Estatal de Oregón. Los análisis realizados por Gans y su grupo (Gans et al., 2003, 2004; MacMillan et al., 2004; Vogel et al., 2004; Pérez et al. 2006; presente trabajo), fueron obtenidos de tres irradiaciones por separado (dos de 40 min cada una y uno de $20 \mathrm{~min}$ ) realizado en un lapso de 2 años. El flujo de control utilizado en las tres irradiaciones fue Taylor Creek Rhyolite Sanidine, con una edad asignada de 27,92 Ma (Duffield \& Dalrymple, 1990). Para referencia, se obtuvieron edades de $747 \pm 4$ ka en Bishop Tuff Sanidine y 27,6 ka sobre Fish Canyon Tuff Sanidine como estándares. Los resultados incluyen las edades totales del gas, el promedio ponderado de la edad del plateau, y las edades inversas isocronas (o isócronas). Todos los errores de las edades estimadas (preferidas) de las distintas muestras fueron en general de \pm 2 sigmas ( $95 \%$ de confianza). La mayoría de los nuevos resultados incluidos en los cuadros de dataciones realizados en Universidad de California, corresponden con la mejor edad plateau.

Referente al sistema de coordenadas, se utilizó la tradicional Proyección Lambert, aportándose en los cuadros el nombre de la hoja topográfica para guía, y teniendo presente que si se encuentran al norte o sur del paralelo $9^{\circ} 40^{\prime}$, son Lambert Norte o Lambert Sur, respectivamente. Se aclara además, que primero se indica en las coordenadas el valor $\mathrm{x}$ o sea el $\mathrm{E}$, y el segundo valor corresponde con la $\mathrm{y}$, o sea $\mathrm{N}$, y que los valores de coordenadas están en unidades de kilómetros. Para muestras de rocas procedentes del océano Pacífico, se utilizaron las coordenadas geográficas tradicionales e internacionales.

Es bien conocido que el sistema Lambert es el utilizado por los geólogos desde hace décadas, siendo de fácil uso en el campo en conjunto con las hojas topográficas 1: 50000 del Instituto Geográfico Nacional. De modo contrario, el sistema de coordenadas geográficas por latitud y longitud, no es de uso práctico en el trabajo de campo. Claramente, hoy día existen los programas de cómputo que pueden transformar de un sistema a cualquier otro, aunque se evidenció que no siempre los mismos datos suelen dar el mismo resultado, aspecto no bien comprendido y fuera del alcance del presente trabajo. El nuevo sistema que se estableció en el país es el CRTM05, mediante un decreto que se firmó en el 2006 y es obligatorio para todas las instituciones. Un nuevo decreto (33797-MJ-MOTP) aparece el 30 de marzo del 2007 reafirmando el sustituir al sistema Lambert, pero como se dijo, no es práctico para el trabajo de campo con las hojas topográficas. Aunque las nuevas hojas cartográficas están en los tres sistemas, incluyendo el nuevo CRTM05, sus cuadrículas de kilómetros cuadrados y su georeferenciación está hecha solo para las Lambert. En resumen, en el país se utilizan:

a- Proyección Lambert Cónica Conforme Norte y Sur (los dos Datum o Fundamental de Ocotepeque, esferoide Clark 1866).

b- El sistema de coordenadas geográficas en grados y minutos por latitud y longitud.

c- CRTM05 (Proyección Costa Rica Transversal de Mercator y Sistema de Referencia CR05). El sistema CR05 es una red de 33 estaciones GPS de primer orden distribuidas en todo el territorio nacional con coordenadas geodésicas referidas al elipsoide WGS84.

\section{BASES TEÓRICAS DE LOS MÉTODOS RADIOMÉTRICOS}

A continuación se exponen algunos aspectos metodológicos, así como de sus virtudes y limitaciones de los seis métodos radiométricos utilizados. Evidentemente, la precisión de cada método será defendida en mayor o menor grado en función del laboratorista, de la afinidad y grado de conocimiento que tenga con el método, y de las tendencias imperantes en su momento. Lo que sí es claro es que un buen trabajo de campo sumado a una cuidadosa selección de las muestras (estudio petrográfico de detalle, grados de alteración, contexto geológico, estándares utilizados, etc.), y el grado de identificación que tenga el laboratorista con la problemática a resolver, favorece en gran parte el resultado final.

Para las bases teóricas, historia y fundamentos metodológicos, se recomienda, entre otros, el libro de Faure (1986). 


\section{Método K/Ar}

La técnica $\mathrm{K} / \mathrm{Ar}$ ha sido en los últimos 60 años muy utilizada a nivel mundial y puesto que sus precios son asequibles (unos $\$ 300$ - \$400) similares a los del radiocarbono, su uso es bastante generalizado. El método convencional se basa en la premisa de que la roca no contenía argón en el momento de su formación o que este no fue incorporado durante su cristalización, y que subsecuentemente todo el argón radiogénico producido fue cuantitativamente retenido. El potasio y el argón son analizados, siendo el K natural administrado por fotometría de llama, emisión de llama y absorción atómica, y el argón es medido isotópicamente por espectrometría de masas. En las formaciones geológicas relativamente modernas, la desintegración de un isótopo radiactivo del potasio, el ${ }^{40} \mathrm{~K}$, que espontáneamente se transforma en otro isótopo del argón, el ${ }^{40} \mathrm{Ar}$, permite determinar la edad absoluta mediante la relación ${ }^{40} \mathrm{~K} /{ }^{40} \mathrm{Ar}$ (en adelante como K/Ar), siendo ambos componentes medidos en muestras por separado (ver detalles en Faure, 1986). Sin embargo, bajo ciertas circunstancias, puede existir un exceso de argón radiogénico heredado y atrapado dentro de cristales (xenocristales y minerales cristalizados tempranamente, particularmente algunos anfíboles en nuestro caso) o xenolitos, resultando rocas con edades erróneamente muy antiguas. Así, el método provee en general poca indicación acerca del error potencial en el exceso de Ar en los minerales o la pérdida de éste debido a la meteorización o hidrotermalismo.

Las muestras de rocas volcánicas jóvenes son particularmente sensibles a estos problemas debido a la presencia de vidrio y al poco tiempo transcurrido para la producción de Ar radiogénico. Una edad anormalmente joven suele reflejar pérdida en ${ }^{40} \mathrm{Ar}$ debido a meteorización o al tránsito de fluidos que producen aperturas en las estructuras cristalinas. Igualmente, las edades $\mathrm{K} / \mathrm{Ar}$ tienen que ser consideradas con discreción, debido a la sensibilidad del método a la pérdida de $\mathrm{Ar}$ durante los procesos metamórficos (incluyendo el caso particular del hidrotermalismo), al ser un gas que se empieza a disipar a temperaturas elevadas $\left(>250^{\circ} \mathrm{C}\right) \mathrm{y}$, por el contrario, por el suministro de K extra durante la alteración hidrotermal. Los feldespatos potásicos de "baja temperatura" (i.e., ortoclasa, microclina y las variedades pertíticas) o rocas ricas en estos minerales, suelen dar edades algo más jóvenes, ya que no retienen el argón a la temperatura ambiente (Faure, 1986).

En Costa Rica, se utilizaron tanto roca total como separados de minerales (hornblenda, biotita, plagioclasa) utilizando el separador magnético Frantz y líquidos pesados. En general para las dataciones K/Ar (p.ej., Appel, 1990), se realizó un estudio petrográfico previo para comprobar no solo el tipo de roca sino si se encuentra sana sin minerales secundarios. Sin embargo, pese a ello, muchos resultados dieron anómalos o con un grado de error considerable.

Sin embargo, el método de K/Ar desarrollado en el Centre des Fiables Radiactivités (laboratorio conjunto CNRS-CEA) en Francia, aportó en el caso de Costa Rica edades congruentes con las ${ }^{40} \mathrm{Ar} /{ }^{39} \mathrm{Ar}$, dado que el análisis de argón fue adaptada para la datación de rocas jóvenes, mejorando la exactitud y precisión por estimaciones de los contaminantes de ${ }^{40} \mathrm{Ar}$, aplicando la técnica de Cassignol (Gillot \& Cornette, 1986). Consta de una comparación directa del argón atmosférico y el argón que se extrae de la muestra, bajo un riguroso control con condiciones idénticas de análisis, permitiendo una medición significativa de una proporción de argón radiogénico tan bajo como $0,12 \%$. Normalmente, esto corresponde con unos $10^{3}$ años en $1 \%$ de una lava potásica y permite datar lavas de alrededor de $50 \mathrm{ka}$, con una precisión del 10\%. Esta precisión se conserva en parte cuando se data material viejo, pero en muestras de más de 0,5 Ma, la incertidumbre relativa de la dosificación de los límites del potasio la exactitud es aproximadamente $1,7 \%$ del valor de edad. Con el fin de beneficiarse de este alto nivel de precisión, fue necesario seleccionar el material adecuado para la datación. En las muestras de rocas de coladas de lava, normalmente fue la matriz seleccionada, que corresponde con la parte del magma que se solidificó en el momento de su emplazamiento, en condiciones atmosféricas. Cuando fue posible, las diferentes fases minerales fueron separadas y comparadas con una prueba interna de la coherencia para la datación. Pequeñas discrepancias entre 
las distintas fases se interpreta como el resultado de una pequeña cantidad de ${ }^{40} \mathrm{Ar}$ radiogénico heredado en el mineral o el efecto de una ligera modificación con una posible migración de potasio y/o argón (Gillot et al., 1994).

En varios casos, debido a la dificultad de recoger muestras frescas en los complejos ígneos oceánicos $\mathrm{u}$ otras unidades, entonces se dataron cantos rodados, asumiendo que provienen de la cuenca y que poseen características petrográficas atribuibles a una unidad en particular, aunque no siempre fue el caso (p.ej., Berrangé et al., 1989, entre muchos otros autores).

Los errores aportados por las determinaciones de calibración de $\mathrm{K}$ y pico de ${ }^{38} \mathrm{Ar}$ establecen un mínimo de error de $\pm 1,5 \%(2 \sigma)$ de la edad - es decir, $\pm 0,9 \mathrm{Ma}$ en una roca de $60 \mathrm{Ma}$ de edad. Este error, sin embargo, normalmente es mayor por la corrección que debe hacerse al componente ${ }^{40} \mathrm{Ar}_{\text {atm }}$ (el argón radiogénico fue determinado por la diferencia). Así que, para estas muestras que las edades dan alrededor de $60 \mathrm{Ma}$, los errores serán de entre \pm 4 Ma y \pm 15 Ma si se analiza usando el espectrómetro MS.10. Estos errores pueden ser reducidos por análisis duplicados por un factor de $\sqrt{ } 1 / \mathrm{N}$, donde $\mathrm{N}$ es el número de análisis duplicados. Algunos de los procedimientos utilizados están explicados con mayor detalle en Bellon et al. (1981). Las edades fueron calculadas utilizando en la mayoría de los casos las constantes recomendadas por la Subcomisión de Geocronología de la IUGS (Steiger $\&$ Jäger, 1977) y $1 \sigma$ de error calculado según la ecuación de Mahood \& Drake (1982).

\section{Método ${ }^{40} \mathrm{Ar} /{ }^{39} \mathrm{Ar}$}

Este método fue establecido ya hace unos 50 años, pero no se difundió hasta en la década a los noventas del siglo pasado, aunque aún sigue siendo de uso casi exclusivo para los proyectos de investigación universitaria o de institutos de geociencias. Lo anterior es debido a que sus costos suelen rondar los $\$ 800$ - $\$ 1000$ por muestra, el doble o triple que para una datación $\mathrm{K} / \mathrm{Ar}$ convencional o comercial. La muestra de roca es irradiada con neutrones en un reactor nuclear que convierten parte del ${ }^{39} \mathrm{~K}$ a ${ }^{39} \mathrm{Ar}$ y es subsecuentemente fundida en el vacío (generalmente mediante pulsos de láser) y la proporción de ${ }^{40} \mathrm{Ar} /{ }^{40} \mathrm{~K}$ del gas desprendido es medida en un espectrómetro de gases nobles. Esta relación es proporcional $\mathrm{al}^{40} \mathrm{Ar} /{ }^{40} \mathrm{~K}$ y así a la edad (Faure, 1986; Hanes, 1987). Las muestras se irradian con estándares conocidos para monitorear el efecto del flujo de neutrones en el reactor nuclear (Factor-J).

El método ${ }^{40} \mathrm{Ar} /{ }^{39} \mathrm{Ar}$ provee, con respecto al $\mathrm{K} / \mathrm{Ar}$, una mejor versatibilidad y ventana en el proceso analítico para evaluar la contaminación con xenocristales, alteración (metamórfica, hidrotermal, meteórica) por pérdida o exceso de Ar (Faure, 1986). Mientras que el método K/ Ar requiere de un día o menos en el análisis, el ${ }^{40} \mathrm{Ar} /{ }^{39} \mathrm{Ar}$ tan solo requiere de unos 15 minutos, sin embargo, el tiempo mínimo entre la toma de la muestra y el análisis es de tan solo una semana en el $\mathrm{K} / \mathrm{Ar}$, en el ${ }^{40} \mathrm{Ar} /{ }^{39} \mathrm{Ar}$ es de 2 a 6 meses. Esto es debido a que la muestra debe enviarse a un reactor nuclear, donde el tiempo de espera es generalmente largo y luego debe dejarse en reposo, igualmente por varios meses, debido a su nivel de radiactividad, hasta que ciertos radionucleidos han decaído, siendo relativamente seguro el analizarla. Con estos números en concreto se entiende el por qué aún sea utilizado mucho el método $\mathrm{K} /$ $\mathrm{Ar}$, pese a las relativas desventajas en la incertidumbre del dato.

Para obtener edades confiables, los análisis deben cumplir con una serie de pruebas (ver detalles en Hauff et al., 2000; Alvarado et al., 1998, 2006; MacMillan et al., 2004; Carr et al., 2007; Gazel et al., 2009, 2011, Saginor et al., 2011b; entre otros). El primer criterio se deriva del paso de los espectros del calentamiento por etapas (step-heating). Resultados individuales de la edad aparente de los isótopos de argón liberados en pulsos de temperatura discreta se grafican en relación con el porcentaje acumulado de ${ }^{39} \mathrm{Ar}_{\mathrm{k}}$ liberado en cada incremento en relación con el ${ }^{39} \mathrm{Ar}_{\mathrm{k}}$ total liberado a partir del experimento completo. Estos experimentos, que resultan en la formación de patrones de edad del plateau, particularmente si los diferentes "escalones" definen una mesa lo más plana posible, siendo así considerados más confiables que los de las edades aparentes, puesto varían ampliamente con respecto a la temperatura. La edad del plateau se 
define por la liberación de gases de un mínimo de tres incrementos consecutivos de temperatura, cuyas edades relativas se superponen en un $95 \%$ del nivel de confianza y un total de $50 \%$ o más de los ${ }^{39} \mathrm{Ar}_{\mathrm{k}}$ totales liberados durante el experimento se consideran de mejor calidad y fiabilidad.

Los criterios del segundo grupo requiere graficar isótopos de Ar obtenidos en los experimentos de calentamiento gradual en los resultados de la isocrona inversa, donde el eje y $\left({ }^{36} \mathrm{Ar} /{ }^{40} \mathrm{Ar}\right)$ se refiere al componente atmosférico de los gases isotópicos medidos y el eje x $\left({ }^{39} \mathrm{Ar} /{ }^{40} \mathrm{Ar}\right)$ se relaciona con el componente de radiogénico de los gases medidos. Sin embargo, se considera que los análisis más confiables son aquellas isocronas que son analíticamente indistinguibles de la edad del plateau y la edad de fusión total (de la suma ponderada del incremento de las edades relativas). Además, la relación de ${ }^{40} \mathrm{Ar} /{ }^{39} \mathrm{Ar}$ inicial derivada de la intersección del eje y deben ser analíticamente indistinguible de la relación atmosférica de ${ }^{40} \mathrm{Ar} /{ }^{36} \mathrm{Ar} 295 \pm 1$, dado que se debe de tener presente que en las edades ${ }^{40} \mathrm{Ar} /{ }^{39} \mathrm{Ar}-\mathrm{al}$ igual que las $\mathrm{K} / \mathrm{Ar}$ - el cálculo de su edad se basa en un modelo cronológico, en que se asume que todo el argón atrapado en los cristales al momento en que el sistema se cerró (p.ej., momento de erupción), guarda dicha relación con respecto al argón atmosférico.

Un criterio adicional, que proporciona más confiabilidad sobre la edad de una muestra, es el orden en que los datos isotópicos aparecen en el diagrama isocrono relativo a aumentar o disminuir el ${ }^{36} \mathrm{Ar} /{ }^{40} \mathrm{Ar}$ y ${ }^{39} \mathrm{Ar} /{ }^{40} \mathrm{Ar}$ en las mediciones individuales del calentamiento por etapas. Estos puntos definen la línea de mezcla entre la relación de ${ }^{36} \mathrm{Ar} /{ }^{40} \mathrm{Ar}$ inicial y la relación de ${ }^{39} \mathrm{Ar} /{ }^{40} \mathrm{Ar}$ (edad) de la muestra. Al aumentar la temperatura, la composición isotópica comúnmente se mueve a lo largo de una línea de mezcla a través de la ${ }^{36} \mathrm{Ar}{ }^{/ 40} \mathrm{Ar}$ inicial (atmosférico) y la relación hacia el ${ }^{39} \mathrm{Ar} /{ }^{40} \mathrm{Ar}$ (radiogénico), la cual corresponde a la edad de la muestra hasta que esta alcance una temperatura única o nivel. En los casos donde el aumento de los componentes atmosféricos son liberados a altas temperaturas, la composición isotópica debe evolucionar hacia la intersección de
${ }^{36} \mathrm{Ar} /{ }^{40} \mathrm{Ar}$ inicial a lo largo de la línea de mezcla obtenida a partir de incrementos de temperatura más baja. Esto particularmente es válido cuando los plateaus están algo perturbados.

El caso ideal es donde existe una consistencia interna entre los resultados proporcionados por el plateau, la isocrona inversa, la fusión total y varianza inversa (abreviado en los cuadros como f.t., v.i.). En caso contrario, se aporta la 'edad preferida', que suele ser en primera instancia el plateau y en segundo lugar la isocrona inversa.

Edades precisas se pueden obtener en feldespatos (feldespatos potásicos y plagioclasas con cierto contenido en K), biotita, anfíbol y la matriz (en el caso de las lavas) a través de técnicas de láser de $\mathrm{CO}_{2}$ del calentamiento por etapas. Sin embargo, las edades jóvenes y de relativo bajo contenido de $\mathrm{K}$ de los basaltos y andesitas que conforman muchas de las lavas de los volcanes costarricenses, requieren una evaluación cuidadosa de los datos isotópicos de Ar utilizados para cálculos de edad. Por lo tanto, un enfoque riguroso de la selección de los resultados ${ }^{39} \mathrm{Ar} /{ }^{40} \mathrm{Ar}$ de dataciones se aplica, tal y como fue descrito previamente (ver Alvarado et al., 2006).

En algunos casos, el $\mathrm{K}$ de las biotitas se puede perder debido a la formación de clorita, por ello en estos casos, se deben de interpretar como edades mínimas del enfriamiento del cuerpo plutónico. De igual modo, los anfíboles se pueden transformar en cloritas y actinolitas, perdiendo igualmente el $\mathrm{K}$, aportando tan solo edades mínimas (Gräfe et al., 2002). Los diques por su parte, pueden contener exceso de argón y suelen dar un característico espectro con forma en $\mathrm{U}$, que suele ser interpretado como la edad máxima del dique (Hanes, 1987). Los pocos casos datados en Costa Rica, sin embargo han proporcionado edades y espectros confiables.

El grado de precisión del método ${ }^{40} \mathrm{Ar} /{ }^{39} \mathrm{Ar}$ ha llegado a permitir en muchos casos costarricenses el determinar edades tan jóvenes como aquellas obtenidas por el método de radiocarbono. Los dos campos de lavas de Cervantes, por ejemplo, se dataron y sus resultados fueron comparados con los de otros métodos (ver Alvarado et al., 2006). De igual modo, una buena cantidad de lavas recientes 
del volcán Turrialba se lograron datar y comparar con resultados previos de ${ }^{14} \mathrm{C}$, llegándose a obtener una de las lavas más recientes con un grado de precisión, en el plateau, hasta el momento no logrado para una de las coladas de lava más jóvenes de América Central (Ruiz et al., 2010b).

\section{Métodos ${ }^{238} \mathrm{U} /{ }^{232} \mathrm{Th} y{ }^{238} \mathrm{U} /{ }^{206} \mathrm{~Pb}$}

Comprende varios procedimientos relacionados con las cadenas de desintegración del ${ }^{238} \mathrm{U}$, ${ }^{235} \mathrm{U}$ y ${ }^{232} \mathrm{Th}$, que tienen como elementos finales ${ }^{206} \mathrm{~Pb},{ }^{207} \mathrm{~Pb}$ y ${ }^{208} \mathrm{~Pb}$ y emitiendo partículas alfa. El método U/Th basa en el desequilibrio entre el ${ }^{238} \mathrm{U}$ que decae en ${ }^{232} \mathrm{Th}$. Fue aplicado en Costa Rica únicamente en el volcán Irazú por Allegre \& Condomines (1976), pero en general dejó de usarse. Sin embargo, el afinamiento del método permite dar excelentes resultados, siempre que se date una fase alta en $\mathrm{U}$ y $\mathrm{Pb}$, tales como zircones, monasita, etc. La incertidumbre es, en general, mucho menor que el ${ }^{40} \mathrm{Ar} /{ }^{39} \mathrm{Ar}$, por que ahora se hacen in situ con láser o SHRIPM.

$\mathrm{El} \mathrm{U} / \mathrm{Pb}$ es un método muy utilizado -pero igualmente limitado en nuestro país- que se basa en el estudio de los minerales con contenido de uranio presentes en las rocas ígneas, que se suponen de primera formación. $\mathrm{El}{ }^{238} \mathrm{U}$ da como producto final de su desintegración ${ }^{236} \mathrm{~Pb}$, y dosificando la proporción ${ }^{238} \mathrm{U} / 236 \mathrm{~Pb}$, se puede calcular con bastante aproximación la edad de roca en millones de años. Debido a que el comportamiento geoquímico del uranio, torio y plomo no son similares, si las edades resultantes son parecidas, puede asegurarse que el sistema permaneció cerrado, siendo un caso por lo general muy raro (Faure, 1986).

En Costa Rica tan solo se ha aplicado al Intrusivo de Guacimal mediante separados de cristales de zircón y utilizando ablación laser con datación ICP-MS; para detalles sobre la metodología de las únicas muestras datadas en Costa Rica, consultar el trabajo de Žaček et al. (2011). Sin embargo, las rocas volcánicas jóvenes, poseen bajas concentraciones de ${ }^{236} \mathrm{~Pb}$, por lo que el método está limitado en ese sentido, siendo más útil en rocas pre-cuaternarias.

\section{Método ${ }^{87} \mathbf{R b} /{ }^{87} \mathbf{S r}$}

Otro método empleado es la dosificación de ciertos isótopos como por ejemplo que el ${ }^{87} \mathrm{Rb}$ decae en ${ }^{87} \mathrm{Sr}$ de su mismo peso atómico emitiendo partículas beta, de esta forma la relación ${ }^{87} \mathrm{Sr} /{ }^{87} \mathrm{Rb}$ resulta en un verdadero cronómetro. Dado que no hay minerales de rubidio en la naturaleza, este suele encontrarse asociado principalmente con minerales que contienen potasio (p.ej., micas, feldespatos potásicos, anfíboles, etc.) y estos contienen pequeñas cantidades de $\mathrm{Sr}$ no radiogénico. Este método se utiliza mucho para rocas cristalinas así como en interpretación de problemas petrogenéticos. Si las rocas fueron químicamente alteradas, entonces el $\mathrm{Rb}$ y/o el $\mathrm{Sr}$ puede adicionarse o perderse, por lo que la edad no sería válida (para detalles ver Faure, 1986 y Hanes, 1987).

Este método solo ha sido aplicado hasta el momento en Costa Rica por Gräfe (1998) y Gräfe et al. (2002).

\section{Método de termocronología de trazas de fisión}

Cuando una partícula nuclear viaja e impacta a través de un medio sólido, ellas dejan un camino de daño de 10-20 micrones de ancho, resultado de la transferencia de energía desde la partícula a los átomos del medio, y su número incrementa con el tiempo. Estas trazas resultantes de la desintegración de ${ }^{238} \mathrm{U},{ }^{235} \mathrm{U}$ y ${ }^{232} \mathrm{U}$ (también de Th y K, por ejemplo) pueden observarse en el microscopio óptico bajo el ataque de ciertas soluciones. Su edad se determina por el simple recuento de las trazas de desintegración espontánea de estos núcleos atómicos pesados. $\mathrm{La}$ termocronología utiliza la datación radiométrica con las temperaturas de cierre de los minerales estudiados (zircón, apatito, esfena, muscovita, flogopita, lepidolita, epidota, hornblenda) o sobre el vidrio volcánico, pero a su vez se usa para comprender la historia térmica de una roca o mineral; por eso los datos de trazas de fisión son, en cierto grado, edades de enfriamiento. 
La toma de muestras se realiza generalmente a lo largo de un perfil geológico o cañón. El mineral se concentra mediante un separador magnético de barrera y finalmente se utiliza diometano como líquido denso. Los minerales se pulen y las trazas del impacto se ponen de manifiesto al tratar el mineral mediante ciertos reactivos como el ácido fosfórico calentado a $480^{\circ} \mathrm{C}$, o un fundido eutéctico de $\mathrm{NaOH}$ y $\mathrm{KOH}$ a $226^{\circ} \mathrm{C}$ o una fuente radiactiva (p.ej., el Cf o californio), para atacar a los cristales, que se irradiarán con neutrones termales en un reactor nuclear, para así determinar las densidades de huellas o trazas espontáneas e inducidas (Faure, 1986; Reiners et al., 2005). Las trazas de cada elemento son calibradas experimentalmente, y la diferencia entre antes y después de la radiación, define la edad de la roca. El costo de la datación es de unos 500 euros.

Este método solo ha sido aplicado hasta el momento en Costa Rica por Gräfe (1998) y Gräfe et al. (2002) utilizando zircones.

\section{COMPARACIÓN DE LOS DIFERENTES MÉTODOS EN MUESTRAS Y UNIDADES SIMILARES EN COSTA RICA}

Una vez expuestos los aspectos teóricos y metodológicos de los diferentes métodos de dataciones radiométricos, y previo a plantear el cuadro geocronológico de las dataciones en Costa Rica, se considera conveniente el hacer una discusión sobre la comparación de los diferentes métodos, tomando ejemplos costarricenses.

Cuando se realiza una datación radiométrica de una roca ígnea, lo más conveniente es que tenga un contexto estratigráfico restringido, es decir, que se presente entre rocas de edad conocida, $o$ intruyendo en rocas sedimentarias bioestratigráficamente controladas, que permitan establecer una edad máxima y/o mínima. Sin embargo, no siempre es el caso. Por ello, muchas veces la edad resultante puede contradecir los paradigmas estratigráficos, dado que resultó ser más antigua o más joven de lo esperado. Surge entonces las preguntas de ifue la muestra contaminada por algún proceso de los descritos en los apartados anteriores? o ¿serán las edades asumidas de las rocas sedimentarias correctas? o más bien, ¿será necesario ver con más detalle el afloramiento para buscar evidencias que nos indiquen que el cuerpo ígneo fue contemporáneo con la sedimentación?

Tal y como se dijo antes, las dataciones $\mathrm{K} /$ Ar poseen el inconveniente con respecto a las ${ }^{40} \mathrm{Ar} /{ }^{39} \mathrm{Ar}$, en que no podemos verificar, dada la ausencia de un plateau, de si existe alguna contaminación o complicación en la muestra, por lo que siempre existirá una incertidumbre en la datación, más allá del rango de error reportado por el laboratorio.

Buchs et al. (2009) argumentan que hay que tener mucho cuidado con la credibilidad de las dataciones radiométricas realizadas en Osa e incluso en otros complejos ígneos básicos u ofiolitas en Costa Rica (p.ej., Sinton et al., 1997; Hauff et al., 2000; Hoernle et al., 2002, 2004), dado que las muestras datadas mediante ${ }^{40} \mathrm{Ar} /{ }^{39} \mathrm{Ar}$ pueden tener pérdida del Ar debido al tectonismo y metamorfismo de bajo grado, y las muestras K/Ar pueden ser pobres en K. Aunque esto es técnicamente factible y hay ejemplos al respecto dentro de la presente base de datos, sus argumentos están basados en que las edades biocronológicas no coinciden, y que algunos basaltos suelen ser más jóvenes que las rocas sedimentarias sobreyacentes y, por lo tanto, la edad reportada por el método radiométrico no representa la edad magmática. Este argumento es válido únicamente si los sedimentos sobreyacentes están directamente en contacto sedimentario con las coladas datadas. Sin embargo, Buchs et al. (2009) no considera la posibilidad de que se trate de un cuerpo hipoabisal dentro de los sedimentos o si existe una falla entre ellos, entonces no necesariamente la datación es errada.

En Costa Rica, tal y como se dijo previamente, varias muestras de roca de unidades estratigráficas similares e incluso del mismo afloramiento, fueron analizadas por diversos laboratorios y bajo diversos métodos, mostrándose en ciertos casos consistencias positivas, pero en varias otras desviaciones considerables, interesantes de recalcar y analizar.

Por ejemplo, las lavas del cerro Sardinal en las llanuras de San Carlos, fueron tomadas prácticamente en la misma localidad evidenciándose similitudes entre la edad ${ }^{40} \mathrm{Ar} /{ }^{39} \mathrm{Ar}$ reportada en 
este trabajo versus la $\mathrm{K} / \mathrm{Ar}$ reportada por Obando (1995) y publicadas por Gazel et al. (2005): 17,70 $\pm 0,30 \mathrm{Ma}$ vs. $17,20 \pm 0,8 \mathrm{Ma}$, respectivamente. Una similitud relativa también se observa para las lavas del domo del cerro 152: 15,2 \pm 0,04 Ma vs. $14,3 \pm 0,5 \mathrm{Ma}$, respectivamente. En cambio si se presentan diferencias notorias entre las muestras del cerro Blanco para los mismos autores: $17,10 \pm$ 0,25 Ma vs. 15,4 $\pm 0,6$ Ma y las del flanco SE del cerro 152: 15,30 \pm 0,10 Ma vs. 10,9 $\pm 0,4 \mathrm{Ma}$.

Otro caso es el conocido tajo Jaboncillo (carretera Interamericana, cerro de La Muerte), que corresponde a un cuerpo de andesita vidriosa transición a dacita, muy visitada por los geólogos y estudiantes desde hace más de cinco décadas. Fue datada por K/Ar en 16,9 $\pm 2,5 \mathrm{Ma}$ (Bellon \& Tournon, 1978) y posiblemente corresponde (por su descripción y localización) con la muestra datada por K/Ar en 9,40 \pm 0,47 Ma (Jackson, 1991), que igualmente fue datada por ${ }^{40} \mathrm{Ar} /{ }^{39} \mathrm{Ar}$ en 11,98 $\pm 0,06 \mathrm{Ma}$ (MacMillian et al., 2004). Vemos como existe una diferencia notoria de 7,5 millones de años entre los extremos de los resultados, aunque todas ellos son del Mioceno. Claramente, como se aclaró en la introducción, con el método ${ }^{40} \mathrm{Ar} /{ }^{39} \mathrm{Ar}$ tenemos más seguridad sobre el resultado radiométrico.

De modo similar, otro afloramiento muy visitado por los geólogos son las lavas medianamente alcalinas, localizadas en un tajo abandonado a la par del histórico puente La Garita. Originalmente datadas por Bellon \& Tournon (1978) en 2,8 \pm $0,4 \mathrm{Ma}$, sin embargo, las nuevas dataciones porveen edades más antiguas, tales como 5,52 $\pm 0,08$ Ma (Marshall et al., 2003), 6,10 $\pm 0,15$ (presente trabajo) y 6,47 $\pm 0,21 \mathrm{Ma}$ (Gazel et al., 2009). Aunque pueden ser varias fases subvolcánicas y puede presentar problemas de ceolizitación (presencia de analcima), las edades nos indican consistentemente una edad superior a los $5 \mathrm{Ma}$.

Un caso ejemplar de cómo la estratigrafía volcánica se invirtió con los nuevos datos isotópicos, corresponde con las dataciones de la andesita afírica y de la ignimbrita del Valle Central, las conocida lava de Intracañón o Colima Superior y las rocas de Avalancha Ardiente o Tiribí, que originalmente fueron datadas por K/Ar en $1 \mathrm{y}$ 0,7 Ma, respectivamente, siendo más antiguas que las lavas de los cerros Zurquí datadas en 0,5 Ma (Bellon \& Tournon, 1978). Sin embargo, los nuevos estudios isotópicos de ${ }^{40} \mathrm{Ar} /{ }^{39} \mathrm{Ar}$, se concluye que poseen edades de 0,33 y 0,32 Ma, respectivamente (Pérez et al., 2006), mucho más jóvenes que las propuestas. Su localización (aportada por J. Tournon, com. escrita, 2010), descripción (Tournon, 1984) y mapa geológico (Echandi, 1981) apoyan que no corresponde con coladas o ignimbritas más antiguas. En cambio, la edad reportada para el Zurquí por Bellon \& Tournon (1978), si da próxima y dentro del rango de la serie de edades aportadas en el presente trabajo.

Otra colada de lava, que consistentemente se ha datado varias veces por diversos autores por el mismo método $\left({ }^{40} \mathrm{Ar} /{ }^{39} \mathrm{Ar}\right)$, es la andesita de Monteverde que forma la base del cerro Chopo, en el camino entre Cañas y Tilarán, que aflora en el sector derecho de la carretera sobre la cuesta previo al tajo del Chopo. Gardner \& Turrin (en Alvarado et al., 1992) aportaron la primera edad para este afloramiento resultando en 1,16 $\pm 0,18$ Ma, seguida por Marshall (2000) en 1,90 $\pm 0,05$ Ma para la isocrona y 2,08 $\pm 0,26 \mathrm{Ma}$ (plateau), siendo esta última congruente con las tres muestras de la misma colada aportadas en presente trabajo, con resultados dentro de un estrecho rango de 2,040 - 2,030 $\pm 0,020$ - 0,010 Ma.

Otros ejemplos en los cuales la misma localidad fue datada $\operatorname{con}^{40} \mathrm{Ar} /{ }^{39} \mathrm{Ar}$ por diferentes autores y laboratorios, y pese a ello, las edades dieron muy similares, corresponden con la localidad tipo de la Fm. Grifo Alto (la Cruz de Guatuso, Puriscal) con resultados de 5,01 $\pm 0,11 \mathrm{Ma}$ (Marshall, 2000) vs. $5,10 \pm 0,10 \mathrm{Ma}$ (MacMillan et al., 2004) o el cerro Bola (río Abrojo, Ciudad Neily) con 3,51 $\pm 0,02$ Ma (MacMillan et al., 2004) y 3,64 $\pm 0,05 \mathrm{Ma}$ (Gazel et al., 2011).

De igual modo, resulta muy interesante que todas las edades K/Ar determinadas por Gillot et al. (1994), tanto para las lavas de Monteverde, las ignimbritas de Guanacaste e incluso las lavas del Pleistoceno Superior Tardío del Chato, aportan edades muy similares a las ${ }^{40} \mathrm{Ar} /{ }^{39} \mathrm{Ar}$ (presente trabajo), hecho que nos indica que una adecuada y cuidadosa selección y preparación de la muestra puede aportar edades $\mathrm{K} / \mathrm{Ar}$ igualmente valiosas. 
De varias unidades que parecen corresponder con eventos isócronos, como ignimbritas bien extendidas y correlacionables entre sí mediante criterios de campo, petrografía, geoquímica y estratigrafía, se tienen en varios casos muestras de diferentes localidades e incluso de la misma localidad, datadas por diversos autores, ya sea por $\mathrm{K} / \mathrm{Ar}$ o por ${ }^{40} \mathrm{Ar} /{ }^{39} \mathrm{Ar}$. A estas muestras se les practicó un filtro con el fin de eliminar los datos que se salen de la campana gaussiana; a las muestras restantes, se les aplicó los métodos estadísticos recomendados por Long \& Rippeteau (1974), que aunque son aplicados por ellos para dataciones de radiocarbono, son matemáticamente válidos para nuestras dataciones.

También, algunas muestras datadas con ${ }^{40} \mathrm{Ar} /{ }^{\beta 9} \mathrm{Ar}$ en clara posición estratigráfica continua y sin falla inversa, ya sea a nivel de afloramiento o de perforación con recuperación de núcleo, se observan inversiones relativas de edades (ligeramente más jóvenes las de abajo con respecto a las superiores) con diferencias de algunas decenas de miles de años, hecho que tan solo nos indica que las fases eruptivas o explosivas se originaron en un tiempo corto, construyéndose el edificio en un lapso dentro del rango de error del método, no necesariamente de la incertidumbre reportada por el laboratorio.

En síntesis, y tal y como se dijo al inicio, el método $\mathrm{K} / \mathrm{Ar}$ es más rápido, económico y más fácilmente ofrecido en el comercio, pero presenta el problema de que no se tiene un control sobre la calidad y, peor aún, la veracidad de la edad, aspecto algo más controlable con el método ${ }^{40} \mathrm{Ar} /{ }^{39} \mathrm{Ar}$. Sin embargo, claramente aún con el método ${ }^{40} \mathrm{Ar} /{ }^{39} \mathrm{Ar}$ hay que tener cuidado en el trabajo de campo y petrográfico, en la selección y preparación de la muestra, la escogencia de las fases petrográficas (tipo de minerales o matriz), su grado de conservación y alteración (exclusión de xenocristales, alteración meteórica e hidrotermal), contexto geológico, así como la escogencia entre una edad aportada por el plateau o por la isocrona, factores cruciales en el resultado de la edad (Saginor et al., 2011b; presente trabajo). Un adecuado conocimiento geológico de previo, resulta muy favorable a la hora de ponderar los resultados.

\section{Dataciones radiométricas infructuosas o no contempladas en el presente trabajo}

El costo elevados de las dataciones y el tiempo invertido (viajes, trabajo de campo, exportación de las muestras, secciones delgadas, selección y separación de fases a datar y análisis), muchas veces ha motivado a los autores a utilizarlas, pese a que su escasa confiabilidad. A continuación mencionaremos algunas de ellas que fueron desechadas en la base de datos y el análisis del presente trabajo.

Barr \& Escalante (1969), manifiestan sus dudas respecto a diferentes muestras debido al bajo contenido en potasio. Sin embargo, aunque dicha afirmación es válida para dos de las tres muestras costarricenses, merecen re-evaluarse sus datos con respecto a las muestras nicaragüenses, dado que quizás resulte interesante el re-considerarlas dentro de los nuevos conceptos estratigráficos. Y no solo eso, la edad de las muestras nicaragüenses deberían de recalcularse con la constante $\lambda_{\mathrm{K}}=$ $4,962 \times 10^{-10} \mathrm{a}^{-1}$.

Krushensky (1972) igualmente realizó un esfuerzo en efectuar dataciones $\mathrm{K} / \mathrm{Ar}$, pero varias de ellas presentan rangos de errores cercanos a la edad de la roca (p.ej., ignimbritas de río Conejo y de Aguacaliente) por lo que no fueron consideradas en el presente estudio (Cuadro 1).

El ICE por su parte, también realizó varias campañas para proyectos geotérmicos y en menor grado para proyectos hidroeléctricos. Algunos de los resultados que fueron compilados por Alvarado et al. (1992), no fueron tomados en consideración en la presente compilación por poseer errores muy elevados (p.ej., la muestra 23 del tajo La Ese, ICE, 1985). Durante el proyecto ICEENEL (1989, 1990), de las aproximadamente 15 dataciones $\mathrm{K} / \mathrm{Ar}$ realizadas en el Laboratorio de Geología Isotópica de la Universidad de Berna (Suiza), solamente unas cuatro proporcionaron resultados confiables, en dos más, el rango de variación resultó muy elevado y en las restantes 10 procedentes del Tenorio, Platanar, Poás, entre otros, no se pudo distinguir entre el ${ }^{36} \mathrm{Ar}$ en exceso del ${ }^{36} \mathrm{Ar}$ en el aire, por lo que se tradujo 
Cuadro 1

Dataciones radiométricas de la literatura no utilizadas en el presente trabajo, pero algunas de ellas utilizadas en trabajos previos (como complemento, ver Alvarado et al., 1992)

\begin{tabular}{|c|c|c|c|c|}
\hline MUESTRA & LITOLOGÍA & UBICACIÓN & $\begin{array}{l}\text { EDAD } \\
(\mathrm{Ma})\end{array}$ & REFERENCIA \\
\hline \multicolumn{5}{|c|}{ LAVAS Y PIROCLASTOS DE LA FM. LA CRUZ } \\
\hline 11 & "Aglomerado" & $\begin{array}{l}8 \text { km SSE de Cañas, H. Cañas, } \\
420,7-260,5\end{array}$ & $\begin{array}{c}71,8 \pm 5,4 \\
(\mathrm{~K} / \mathrm{Ar})\end{array}$ & $\begin{array}{l}\text { Amos \& Rogers } \\
\quad(1983)\end{array}$ \\
\hline 6.1 .95 .3 & Basalto & $\begin{array}{l}\text { C. La Mona, H. Cutris, 511,750- } \\
\qquad 301,250\end{array}$ & $\begin{array}{l}65,5 \pm 2,7 \\
(\mathrm{~K} / \mathrm{Ar})\end{array}$ & Obando (1985) \\
\hline NIC-038 & Basalto & $\begin{array}{c}\text { Intersección camino P1. del Coco } \\
\text { con Pl. Hermosa, H. Carrillo } \\
\text { Norte, } 353,4-280,2\end{array}$ & $\begin{array}{c}57,2 \pm 6,9 \\
(\mathrm{~K} / \mathrm{Ar})\end{array}$ & Appel 1990 \\
\hline 9 & "Aglomerado" andesítico & $\begin{array}{l}\text { Queb. Caballos, H. Cañas, } \\
419,6-265,2\end{array}$ & $\begin{array}{c}55,1 \pm 3,6 \\
(\mathrm{~K} / \mathrm{Ar})\end{array}$ & $\begin{array}{l}\text { Amos \& Rogers } \\
\quad(1983)\end{array}$ \\
\hline \multicolumn{5}{|c|}{ ROCAS ALCALINAS } \\
\hline GAR-1 & Basanita analcímica & $\begin{array}{c}\text { Puente La Garita, H. R. Grande, } \\
498,598-218,916\end{array}$ & $\begin{array}{c}2,8 \pm 0,4 \\
(\mathrm{~K} / \mathrm{Ar})\end{array}$ & $\begin{array}{l}\text { Bellon \& Tournon } \\
\text { (1978) }\end{array}$ \\
\hline C-la & Basanita & $\begin{array}{l}\text { C. Coronel, zona Caribe, } \mathrm{H} \text {. } \\
\text { Colorado, 575,3-297,0 }\end{array}$ & $\begin{array}{c}1,2 \pm 0,4 \\
(\mathrm{~K} / \mathrm{Ar})\end{array}$ & $\begin{array}{l}\text { Bellon \& Tournon } \\
\text { (1978) }\end{array}$ \\
\hline \multicolumn{5}{|c|}{ GUANACASTE } \\
\hline Santa Rosa & Toba (vitrófiro alterado a seudo-toba?) & $\begin{array}{l}\text { Parte basal Fm. Bagaces, por Santa } \\
\quad \text { Rosa (similar a } 990720 \text { - 12?) }\end{array}$ & $\begin{array}{l}7,5 \pm 2 \\
(\mathrm{~K} / \mathrm{Ar})\end{array}$ & Mainieri (1976) \\
\hline 226 & Seudotoba, vitrófiro dacítico con hb & $\begin{array}{l}\text { C. Górgona H. Curubandé, } \\
380,85-305,35\end{array}$ & $\begin{array}{l}4,3 \pm 1 \\
(\mathrm{~K} / \mathrm{Ar})\end{array}$ & Mainieri (1976) \\
\hline 132 & $\begin{array}{l}\text { Toba dacítica (descrita como parte } \\
\text { de Bagaces Superior, no de Liberia) }\end{array}$ & $\begin{array}{l}\text { Ca. Liberia-La Cruz, entrada } \\
\text { a Hda Coyolar, H. Curubandé, } \\
\text { 373,35-295,6 }\end{array}$ & $\begin{array}{c}0,637 \pm \\
0,04 \\
(\mathrm{~K} / \mathrm{Ar})\end{array}$ & Mainieri (1976) \\
\hline MU-10 & $\begin{array}{l}\text { Ignimbrita dacítica }(\mathrm{qz}+\mathrm{hb}) \text {, masi- } \\
\text { va, blanca medianamente soldada, } \\
\text { petrográfica y geoquímicamente } \\
\text { similar a la Unidad Buena Vista }\end{array}$ & $\begin{array}{l}\text { Base del V. Orosí, H. Murciélado, } \\
\qquad 367,5-325,3\end{array}$ & $\begin{array}{c}0,6 \pm 0,2 \\
(\mathrm{~K} / \mathrm{Ar})\end{array}$ & $\begin{array}{l}\text { Bellon \& Tournon } \\
\text { (1978) }\end{array}$ \\
\hline TM14a & $\begin{array}{c}\text { Toba rosada con biotita sobreyacida } \\
\text { por tobas pumíceas blancas }\end{array}$ & $\begin{array}{l}\text { Ca. Bagaces-Guayabo, cerca del } \\
\text { Torno, H. Miravalles, 401,3-288,6 } \\
\text { (relocalizada: 401,069-288,063) }\end{array}$ & $\begin{array}{l}0,5 \pm 0,15 \\
(\mathrm{~K} / \mathrm{Ar})\end{array}$ & $\begin{array}{l}\text { Bellon \& Tournon } \\
\text { (1978) }\end{array}$ \\
\hline 21 & Lava & $\begin{array}{l}\text { C. Espíritu Santo, H. Miravalles, } \\
\qquad 412,0-295,9\end{array}$ & $\begin{array}{l}0,27 \pm 0,1 \\
(\mathrm{~K} / \mathrm{Ar})\end{array}$ & ICE (1985) \\
\hline 2 & Lava & $\begin{array}{l}\text { C. Gota de Agua, H. Miravalles, } \\
\text { aprox. } 413,0-296,5\end{array}$ & $\begin{array}{l}0,22 \pm 0,1 \\
(\mathrm{~K} / \mathrm{Ar})\end{array}$ & ICE-ELC (1983) \\
\hline \multicolumn{5}{|c|}{ FM. GRIFO ALTO } \\
\hline AGU-064 & Brecha tobácea de flujo & $\begin{array}{l}\text { Queb. Concepción, H. Río Gran- } \\
\text { de, apox. 485,2-214,5 }\end{array}$ & $\begin{array}{c}3,0 \pm 1,7 \\
(\mathrm{~K} / \mathrm{Ar})\end{array}$ & Appel (1990) \\
\hline AGU-055 & $\begin{array}{l}\text { Basalto (clasto en flujo piroclás- } \\
\text { tico) }\end{array}$ & $\begin{array}{l}\text { Tajo La Cima, H. Naranjo, 487,2- } \\
\qquad 228,4\end{array}$ & $\begin{array}{c}2,1 \pm 1,3 \\
(\mathrm{~K} / \mathrm{Ar})\end{array}$ & Appel (1990) \\
\hline AGU-060 & Andesita & $\begin{array}{l}\text { H. R. Grande, H. R. Grande, } \\
\text { apox. } 485,3-212,6\end{array}$ & $\begin{array}{c}1,9 \pm 1,3 \\
(\mathrm{~K} / \mathrm{Ar})\end{array}$ & Appel (1990) \\
\hline
\end{tabular}


Cuadro 1 (continuación)

Dataciones radiométricas de la literatura no utilizadas en el presente trabajo, pero algunas de ellas utilizadas en trabajos previos (como complemento, ver Alvarado et al., 1992)

\begin{tabular}{|c|c|c|c|c|}
\hline MUESTRA & LITOLOGÍA & UBICACIÓN & $\begin{array}{l}\text { EDAD } \\
(\mathrm{Ma})\end{array}$ & REFERENCIA \\
\hline \multicolumn{5}{|c|}{ CORDILLERA Y VALLE CENTRAL } \\
\hline PLA-30 & Pómez (hornblenda) & $\begin{array}{l}\text { Sur de Zarcero, H. Quesada, } \\
493,6-239,3\end{array}$ & $\begin{array}{c}11,1 \pm 1,2 \\
(\mathrm{~K} / \mathrm{Ar})\end{array}$ & $\begin{array}{l}\text { ICE (1987, en Alvara- } \\
\quad \text { do et al., 1992) }\end{array}$ \\
\hline Q-36 & Andesita & $\begin{array}{l}\text { Colada Sucre, H. Quesada, 489,3- } \\
252,0\end{array}$ & $\begin{array}{c}1,5 \pm 0,2 \\
(\mathrm{~K} / \mathrm{Ar})\end{array}$ & $\begin{array}{l}\text { ICE (1987, en Alvara- } \\
\text { do et al., 1992) }\end{array}$ \\
\hline BB-1 & $\begin{array}{l}\text { Ignimbrita pumícea con muchas } \\
\text { inclusiones y fragmentos de roca } \\
(7 \%)\end{array}$ & $\begin{array}{c}\text { San Pablo de Turrubares, Hacien- } \\
\text { da los Vargas, H. Río Grande, } \\
\text { aprox. 486,5-210,6 }\end{array}$ & $\begin{array}{l}1,38 \pm 0,05 \\
(\mathrm{~K} / \mathrm{Ar})\end{array}$ & Bergöeing (1982) \\
\hline $\mathrm{AB}-20$ & Andesita afírica & $\begin{array}{l}\text { Valle Central Oriental, Puente de } \\
\text { Mulas, H. Abra, 566,1-217,3 }\end{array}$ & $\begin{array}{l}1,0 \pm 0,15 \\
(\mathrm{~K} / \mathrm{Ar})\end{array}$ & $\begin{array}{l}\text { Bellon \& Tournon } \\
\text { (1978) }\end{array}$ \\
\hline $\mathrm{AB}-21$ & Ignimbrita & $\begin{array}{l}\text { Valle Central Oriental, R. Bermu- } \\
\text { dez, cerca de Puente de Mulas, H. } \\
\text { Abra, 515,0-217,5 }\end{array}$ & $\begin{array}{c}0,7 \pm 0,2 \\
(\mathrm{~K} / \mathrm{Ar})\end{array}$ & $\begin{array}{l}\text { Bellon \& Tournon } \\
\text { (1978) }\end{array}$ \\
\hline MZ-75 & Andesita & $\begin{array}{c}\text { C. El Siete, H. Quesada, 496,7- } \\
246,3\end{array}$ & $\begin{array}{l}0,28 \pm 0,66 \\
\quad(\mathrm{~K} / \mathrm{Ar})\end{array}$ & ICE-ENEL (1988) \\
\hline$?$ & Ignimbrita soldada riodacítica & $\begin{array}{l}\text { Fm. "Orotina", edad promedio } \\
\text { de las muestras; CR90-SANK, } \\
\text { CR93-13 y CR93-23 }\end{array}$ & $\begin{array}{l}0,24 \pm 0,04 \\
\quad(4 \text { datos } \\
\left.{ }^{40} \mathrm{Ar}{ }^{39} \mathrm{Ar}\right)\end{array}$ & Fisher et al. (1994) \\
\hline
\end{tabular}

en edades negativas, posible indicador de edades muy jóvenes. De igual modo, una serie de muestras del volcán Turrialba dieron edades K/Ar no distinguibles de cero, por lo que Reagan et al. (2006) asumió que la edad de las rocas debía de ser más joven que $50 \mathrm{ka}$. Sin embargo, a criterio de los autores, la mayoría de las dataciones $\mathrm{K} / \mathrm{Ar}$ de la época (p.ej., Krushenshy, 1976; ICE, 1985; ICE-ELC, 1983), no podían precisar rocas más jóvenes que 0,2 Ma, con excepción de aquellas que aplicaban el método refinado de Cassignol (p.ej., Gillot et al., 1994).

Tres muestras de Appel (1990) de los Montes del Aguacate, que originalmente fueron incluidas por Alvarado et al. (1992) y Appel et al. (1994), no fueron incluidas en el presente trabajo por poseer un grado de error apreciable (Cuadro 1): la toba AGU-064 de la quebrada Concepción (3,0 \pm 1,7 Ma), la brecha AGUA-055 del tajo Alto La
Cima $(2,1 \pm 1,3 \mathrm{Ma})$ y la andesita AGU-60 de la quebrada Concepción (1,9 \pm 1,3 Ma). Lo mismo sucedió con una serie de muestras que fueron presentadas por Appel y colaboradores como edades máximas, pero que en realidad no lo son dado que el argón radiogénico 40 está por debajo del límite de detección.

Obando (1995) no utilizó 4 edades radiométricas, dado que tres de ellas dieron resultados negativos y una edad muy antigua $(65,5 \mathrm{Ma})$ por exceso de argón atmosférico.

Algunas muestras muy jóvenes, como las de los conos piroclásticos Tortuguero y la Loma Buenos Aires, resultaron con una edad "cero", es decir muy joven para ser datada por ${ }^{40} \mathrm{Ar} /{ }^{39} \mathrm{Ar}$ (Gazel et al., 2011), con probabilidad inferior a $60 \mathrm{ka}$.

Finalmente, en el presente trabajo, al menos unos 38 resultados no fueron incluidos por poseer errores muy grandes y "plateaus" no estables. 


\section{CUADRO CRONOSTRATIGRÁFICO}

La estratigrafía ígnea de Costa Rica se puede resumir en 5 grandes grupos con sus variantes y subdivisiones (Fig. 2): a) las ofiolitas (complejos oceánicos acrecionados) y rocas sedimentarias y tectónicas asociadas, extendidos entre unos $200 \mathrm{y}$ 40 millones de años atrás con diversos orígenes, b) el magmatismo de arcos de islas, representado por las rocas intrusivas y volcánicas in situ (no como clastos sedimentarios), entre unos 30 y 2 millones de años, c) el vulcanismo de fondo oceánico sobre la placa del Coco (entre 30 y 0,6 $\mathrm{Ma}$ ), d) las rocas alcalinas (entre $6 \mathrm{Ma}$ y el presente), y e) el arco magmático activo (entre $1 \mathrm{Ma}$ y el presente), rodeado de cuencas sedimentarias coetáneas y con diferente grado de tectonismo y metamorfismo de bajo grado (ver Tournon \& Alvarado, 1997; Bundschuh \& Alvarado, 2007; Denyer \& Alvarado, 2007).

A continuación se expone un análisis cronoestratigráfico de los resultados radiométricos acorde con el contexto geológico, empezando por las unidades más antiguas.

\section{LOS COMPLEJOS ÍGNEOS BÁSICOS/ ULTRABÁSICOS OCEÁNICOS (OFIOLITAS)}

En Costa Rica afloran rocas ígneas básicas y ultrabásicas con diferentes grados de metamorfismo, que a lo largo de más de 50 años de estudios se han ido paulatinamente agrupado en diferentes unidades con base en su geoquímica elemental e isotópica, geocronología y correlaciones con las rocas suprayacentes, a las que intruyen o que las envuelven a modo de matriz (sedimentaria, tectónica o ígnea). De norte a sur las expondremos brevemente, pero aquel lector que desee profundizar, se le recomienda los trabajos recientes y sinópticos de Hauff et al. (2000), Baumgartner et al. (2008), Alvarado et al. (2009a), Denyer \& Gazel (2009) y Tournon \& Bellon (2009), así como la extensa literatura allí citada. Todo este ensamblaje de rocas ígneas (básicas y ultrabásicas) y sedimentarias asociadas, representantes de una litosfera oceánica anexada al continente, generalmente producto de una dorsal medio-oceánica, pero que puede ser de cualquier ambiente geotectónico -en la mayoría de los casos incompleta y desmembrada por tectonismo- , posteriormente emplazada y expuesta por tectonismo, es lo que se agrupa dentro de las ofiolitas (Figs. 2 y 3; ver discusiones en Alvarado et al., 2009; Dilek \& Furnes, 2011).

\section{Península de Santa Elena}

El complejo ultramáfico de Santa Elena (300 $\mathrm{km}^{2}$ ) consiste en un nappe constituido por lherzolitas espinélicas y raras lherzolitas plagioclásicas, harzburgitas diopsídicas, dunitas, wehrlitas, piroxenitas y cromititas (Tournon, 1984; Tournon \& Bellon, 2009), relacionadas con una placa de subducción (Hauff et al., 2000; Gazel et al., 2006; Zaccarini et al., 2011). La peridotita serpentinizada está cortada por doleritas con anfíbol y anfibolitas, que aportan diferentes edades para los eventos magmáticos -más antiguos- y metamórficos -más jóvenes- entre 101 y 80 Ma (Bellon \& Tournon, 1978; Tournon \& Bellon, 2009). Ver cuadro 2 y más adelante el cuadro 38 .

El complejo ultramáfico sobreyace por contacto por falla al Complejo Acrecionado de Santa Rosa (Baumgartner \& Denyer, 2006) o un mélange (Tournon \& Bellon, 2009), constituido por basaltos alcalinos (masivos y en almohadillas), radiolaritas, tobitas, calizas pelágicas, lutitas negras, areniscas y microconglomerados del Calloviano-Oxfordiano y del Aptiano a Cenomaniano (De Wever et al., 1985; Baumgartner et al., 2008). Numerosos sills de basaltos alcalinos potásicos y de lamprófidos intruyen las radiolaritas, que a su vez forman parte de este complejo; se prefieren las edades obtenidas por los anfíboles tipo kaersutita a las aportadas por la roca total o matriz: 159 - 150 


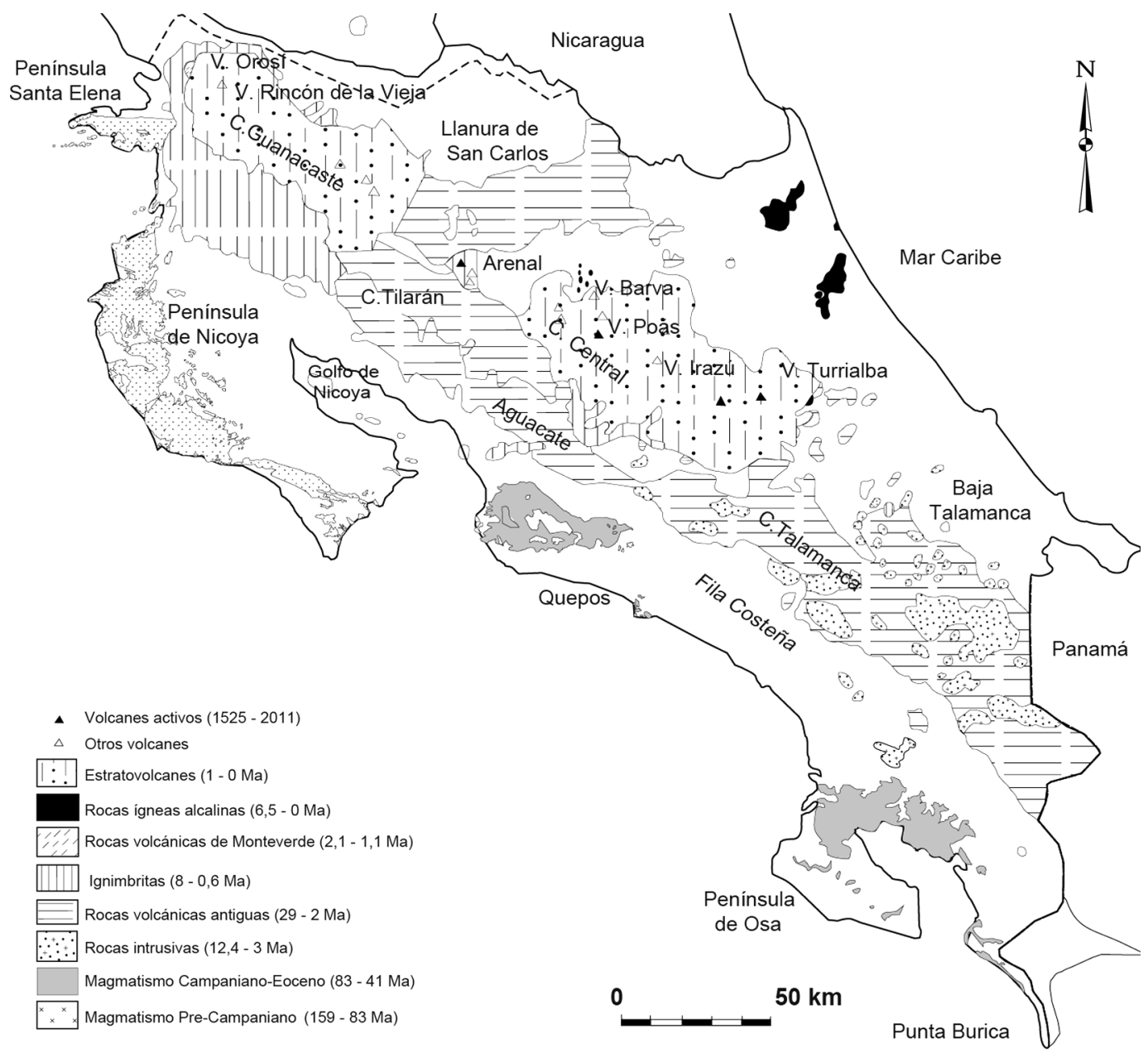

Fig. 2: Mapa geológico generalizado de Costa Rica (simplificado de Denyer \& Alvarado, 2007).

Ma. Los basaltos basaltos y las traquitas aportan edades más jóvenes, entre 127 y $80,7 \pm 2,5 \mathrm{Ma}$ (Tournon \& Bellon, 2009).

El complejo ultramáfico igualmente cabalga al cuerpo ígneo estratificado (megabloque?) de Bahía Nancite (al menos 500 x 50 m), constituido por gabros, plagiogranitos, peridotitas plagioclásicas y piroxenitas, cortadas para varias generaciones de diques (Tournon, 1984; Arias, 2002) con afinidad de cámaras magmáticas de arco de isla, datados entre 133 y 124 Ma (Hauff et al., 2000; Arias, 2002; Tournon \& Bellon, 2009). Ver cuadro 2 y figura 3 .
Las islas Murciélago ofrecen aún múltiples problemas para ubicarlas tectono-estratigráficamente dentro de la historia de Santa Elena, dado que su química difiere a las rocas de Santa Elena y de Nicoya (Hauff et al., 2000; Gazel et al., 2006). Las islas e isletas están conformadas por basaltos en almohadillas y masivos así como traquibasaltos, pero sus playas poseen cantos de rocas sedimentarias que no afloran en las islas (Tournon, 1984). Posiblemente corresponde con un escama tectónica asociada de algún modo con la tectónica de sobrecorrimiento de Santa Elena (ver discusión y detalles en Tournon \& Bellon, 2009), y los 


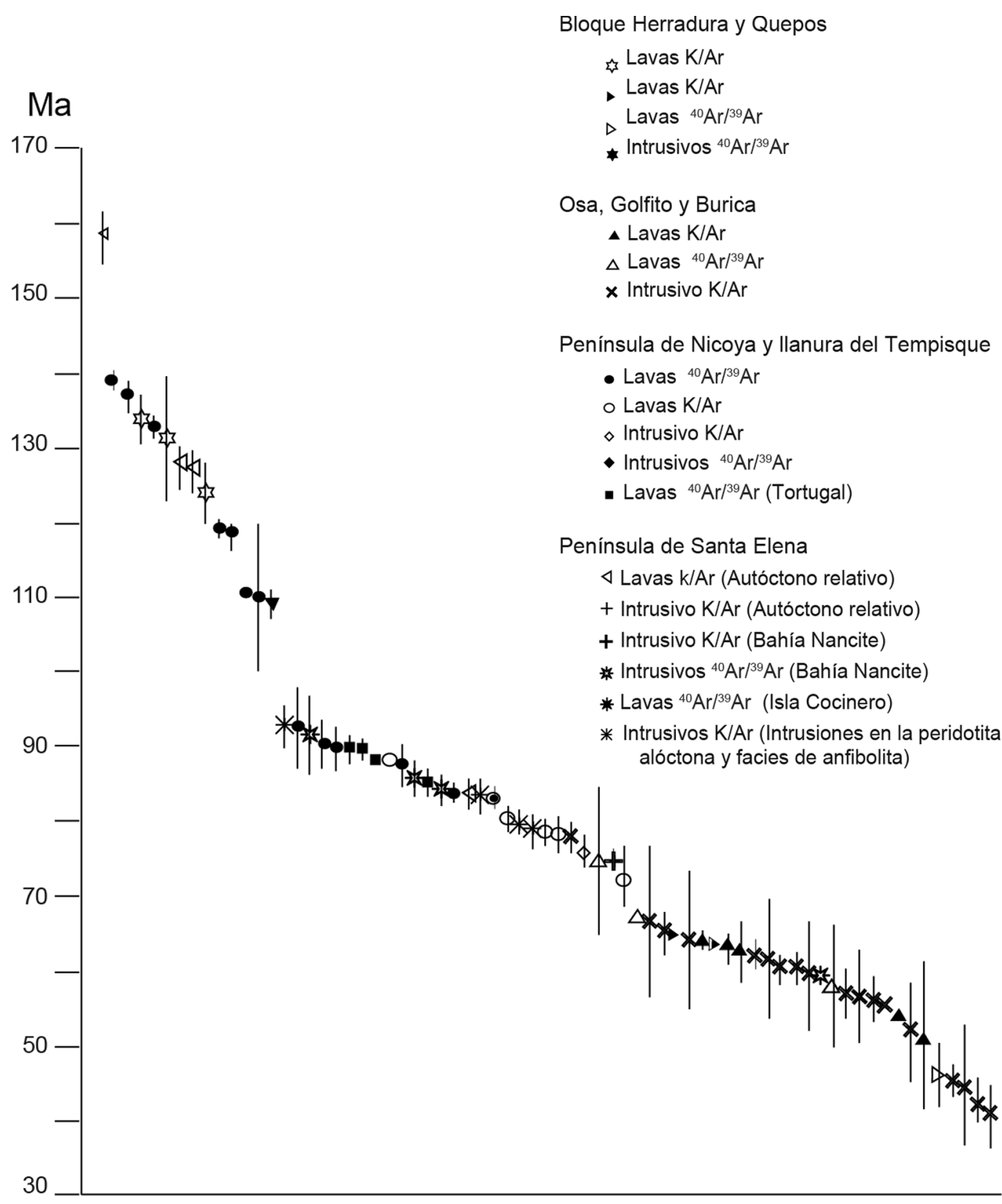

\section{Muestras}

Fig. 3: Número de dataciones de los complejos ofiolíticos costarricenses (Santa Elena, Nicoya, Herradura-Quepos, Golfito-OsaBurica), ordenados de mayor a menor edad. Si las muestras tomadas en diferentes sectores se presentan relativamente horizontales, indica eventos sincrónicos, mientras que si presenta una pendiente, sugiere continuidad en el magmatismo. Los saltos en las edades indican brechas en el magmatismo o en la toma de muestras. La barra vertical indica el rango de error analítico, sin embargo, existen muestras $\mathrm{K} / \mathrm{Ar}$ a las cuales no se les reportó el rango de error. 
cantos extraños podrían representar un depósito tsunaminogénico, hipótesis por demostrarse. Una edad suministrada por Hauff et al. (2000), sitúa al evento basáltico en $109 \mathrm{Ma}$ (Cuadro 2). Otros basaltos más jóvenes y ligeramente alcalinos asociados con traquitas, son los de Respingue, que suministran edades promedio de 86,5 Ma (Tournon \& Bellon, 2009).

La historia, en breve, se puede resumir en:

a. Intrusiones ácidas a ultrabásicas cumuladas y estratificadas de Bahía Nancite presentan edades compartidas entre el lapso de 133 y $140 \mathrm{Ma}$ (Hauff et al., 2000; Tournon \& Bellon, 2009).

b. Dos generaciones de gabros pegmatíticos la intruyen cuando aún la peridotita estaba caliente, en un medio de zona de subducción (Gazel et al., 2006).

c. Varias intrusiones tardías dentro de la peridotita de diques doleríticos (basaltos, andesitas basálticas y traquibasaltos) y doleritas con anfíbol, algunas anfibolitas gneísicas, de toleitas de arco a calcoalcalinos, cuya fase magmática quizás se remonta entre 101 y $93 \mathrm{Ma}$ (Bellon \& Tournon, 1978; Tournon \& Bellon, 2009).

d. Formación del complejo ígneo-sedimentario acrecionado o mélange de Santa Rosa, en el margen austral del bloque Chortis, posiblemente en el Cenomaniano.

e. Emplazamiento (obducción) de la peridotita de Santa Elena en algún momento entre el postCenomaniano y el Campaniano Tardío (Tournon \& Bellon, 2009).

\section{Península de Nicoya y la cuenca del Tempisque}

El basamento de la península de Nicoya está conformado por basaltos en almohadilla, basaltos masivos, e intrusiones doleríticas, gabroicas y más localmente, plagiograníticas, todos ellos más antiguos que el Campaniano (Alvarado \& Denyer, 1988). Secuencias radiolaríticas con edades usualmente más antiguas, enriquecidas en Mn y algunas contemporáneas con los basaltos, enriquecidas en
$\mathrm{Fe}$, son en su mayoría intruidas y sobreyacidas por varias fases magmáticas (Cuadro 3). Hasta el momento no se ha encontrado el basamento magmático de las radiolaritas más antiguas del Jurásico Medio, es decir unos 170 Ma (Denyer \& Baumgartner, 2006). En Nicoya existen rocas ígneas claramente asociadas con el Caribbean Large Igneous Province (CLIP), evento que principalmente se desarrolló a los 92 - 80 Ma, y rocas pre-CLIP (Baumgartner et al., 2008).

En la parte interna del golfo de Nicoya, cerca de Colorado de Abangares, se presentan afloramientos de picritas a lo largo de $14 \mathrm{~km}$ con características geoquímicas similares a komatiítas, que están cortadas por diques de traquibasaltos alcalinos, algunos con anfíbol (Alvarado et al., 1997). La edad media de las picritas komatíticas (Alvarado et al., 1997; Sinton et al., 2009) es de $88,4 \pm 0,57 \mathrm{Ma}$, asumiendo que se trate de un evento relativamente simultáneo (Cuadro 3). No se trata de cumulados (sensu Hauff et al., 2000) dado que el la matriz desvitrificada es rica en magnesio $(\mathrm{MgO}>32 \%$; Tournon \& Bellon, 2009), los olivinos son altos en $\mathrm{MgO}\left(\mathrm{Fo}_{71-85}\right)$, y presentan textura micro-spinifer común en picritas/komatiitas de alta temperatura. Aunque cerca se presentan basaltos masivos y en almohadillas, similares a los de la península de Nicoya, estas rocas ultrabásicas no se han llegado a reportar en dicha área. Se han localizado en la península de Santa Elena sills y diques alcalinos con una firma geoquímica muy similar a los que intruyen a las picritas komatiíticas de Tortugal (Hauff et al., 2000; Denyer \& Gazel, 2009; Tournon \& Bellon, 2009). Todavía queda por establecer mejor la relación entre sí de las rocas ultrabásicas, básicas a intermedias (basaltos hasta traquitas) e intrusivas de Tortugal, así como entre éstas últimas y los complejos de Santa Elena y Nicoya.

Finalmente, a partir del Campaniano Tardío, los sedimentos volcánicos subalcalinos suelen ser abundantes, indicio del establecimiento de una zona de subducción (Küypers, 1979; Denyer \& 
Cuadro 2

Dataciones radiométricas de la península de Santa Elena

\begin{tabular}{|c|c|c|c|c|}
\hline MUESTRA & LITOLOGÍA & UBICACIÓN & $\operatorname{EDAD}(\mathrm{Ma})$ & REFERENCIA \\
\hline \multicolumn{5}{|c|}{ AUTÓCTONO RELATIVO } \\
\hline SE 78 & $\begin{array}{l}\text { Sill, lamprófido alcalino } \\
\text { dentro de radiolaritas }\end{array}$ & $\begin{array}{l}\text { H. Sta. Elena, 330,95-318,30. } \\
\text { La edad de la roca estaría dada } \\
\text { por los anfíboles; las edades } \\
\text { más jóvenes (roca total y la ma- } \\
\text { triz), en algunos casos indicaría } \\
\text { un evento térmico }\end{array}$ & $\begin{array}{c}159,5 \pm 3,5 \\
155,4 \pm 3,6 \\
149,9 \pm 3,0 \\
(\mathrm{~K} / \mathrm{Ar}: \mathrm{hb}) \\
\\
84,7 \pm 1,4 \\
74,7 \pm 1,4 \\
\text { (K/Ar: mtz) }\end{array}$ & $\begin{array}{l}\text { Tournon \& Bellon } \\
\qquad(2009)\end{array}$ \\
\hline CR 774 & $\begin{array}{l}\text { Lamprófido alcalino } \\
\text { dentro de radiolaritas }\end{array}$ & H. Sta. Elena, 330,85-318,20 & $158,7 \pm 3,6(\mathrm{~K} / \mathrm{Ar}: \mathrm{hb})$ & $\begin{array}{l}\text { Tournon \& Bellon } \\
\qquad(2009)\end{array}$ \\
\hline CR 573 & Lamprófido alcalino & H. Sta. Elena, 330,85-318,20 & $\begin{array}{l}130,5 \pm 2,8 \\
126,9 \pm 2,7 \\
\text { (K/Ar: wr) }\end{array}$ & $\begin{array}{l}\text { Tournon \& Bellon } \\
\text { (2009) }\end{array}$ \\
\hline CR 564 & $\begin{array}{l}\text { Basalto alcalino dentro } \\
\text { de radiolaritas }\end{array}$ & H. Sta. Elena, 330,50-310,35 & $127,4 \pm 2,7$ (K/Ar: wr) & $\begin{array}{l}\text { Tournon \& Bellon } \\
\qquad(2009)\end{array}$ \\
\hline CR 580 & Traquita & $\begin{array}{l}\text { Respinge, H. Sta. Elena, } \\
332,25-317,60\end{array}$ & $\begin{array}{c}87,4 \pm 1,9 \\
86,2 \pm 2,0 \\
3,4 \pm 1,9 \\
83,7 \pm 1,9 \\
\text { (K/Ar: wr) } \\
\\
99,2 \pm 3,3 \\
0,7 \pm 2,5 \\
\text { (K/Ar: k-feld) }\end{array}$ & $\begin{array}{l}\text { Tournon \& Bellon } \\
\text { (2009) }\end{array}$ \\
\hline \multicolumn{5}{|c|}{ COMPLEJO DE BAHÍA NANCITE } \\
\hline SE 17 & Gabro & $\begin{array}{l}\text { Bah. Nancite, H. Ahogados, } \\
347,10-310,60\end{array}$ & $\begin{array}{l}133,8 \pm 3,4 \\
130,0 \pm 8,5 \\
\text { (K/Ar: wr) }\end{array}$ & $\begin{array}{l}\text { Tournon \& Bellon } \\
\qquad(2009)\end{array}$ \\
\hline SE 9 & Basalto & $\begin{array}{l}\text { Bah. Nancite, H. Ahogados, } \\
\text { 347,10-310,60 }\end{array}$ & $\begin{array}{l}131,3 \pm 8,3 \\
122,5 \pm 10 \\
\text { (K/Ar: wr) }\end{array}$ & $\begin{array}{l}\text { Tournon \& Bellon } \\
\qquad(2009)\end{array}$ \\
\hline SE2 & Gabro & $\begin{array}{l}\text { Bah. Nancite, Ahogados, } \\
346,50-311,00\end{array}$ & $\begin{array}{c}124,2 \pm 4,1 \\
\left({ }^{40} \mathrm{Ar} /{ }^{39} \mathrm{Ar} \text { : plag: iso. }\right) \\
24,0 \pm 4,0 \\
\left({ }^{40} \mathrm{Ar} /{ }^{39} \mathrm{Ar} \text { : e.m.a. }\right)\end{array}$ & Hauff et al. (2000) \\
\hline \multicolumn{5}{|c|}{ ISLA COCINERO } \\
\hline SE6 & Basalto toleítico & $\begin{array}{l}\text { Santa Elena, I. Cocinero, H. Sta. } \\
\text { Elena, 327,50-315,60 }\end{array}$ & $\begin{array}{c}105,4 \pm 6,2 \\
\left({ }^{40} \mathrm{Ar} /{ }^{39} \mathrm{Ar} \text { : iso. }\right) \\
109,0 \pm 2,0 \\
\left({ }^{40} \mathrm{Ar} /{ }^{39} \mathrm{Ar} \text { : e.m.a. }\right)\end{array}$ & Hauff et al. (2000) \\
\hline
\end{tabular}


Cuadro 3

Dataciones radiométricas de la península de Nicoya

\begin{tabular}{|c|c|c|c|c|}
\hline MUESTRA & LITOLOGÍA & UBICACIÓN & $\operatorname{EDAD}(\mathrm{Ma})$ & REFERENCIA \\
\hline \multicolumn{5}{|c|}{ NICOYA/BASALTOS } \\
\hline AN8 & $\begin{array}{l}\text { Vidrio basáltico de una } \\
\text { brecha basáltica masiva }\end{array}$ & $\begin{array}{l}\text { P. Cacique, N de Pl. del } \\
\text { Coco, H. Carrillo Norte, } \\
350,90-283,40\end{array}$ & $139,1 \pm 1,1\left({ }^{40} \mathrm{Ar} /{ }^{39} \mathrm{Ar}:\right.$ iso. $)$ & Hoernle et al. (2004) \\
\hline AN10 & $\begin{array}{l}\text { Corteza de hialoclastita, } \\
\text { basalto en almohadilla }\end{array}$ & $\begin{array}{l}\text { P. Cacique, norte de Pl. del } \\
\text { Coco, H. Carrillo Norte, } \\
351,10-283,50\end{array}$ & $\begin{array}{c}137,6 \pm 1,8 \text { (iso.) } \\
137 \pm 2\left({ }^{40} \mathrm{Ar} /{ }^{39} \text { Ar: plat. }\right)\end{array}$ & Hoernle et al. (2004) \\
\hline AN3 & $\begin{array}{c}\text { Vidrio basáltico } \\
\text { (corteza de basalto en } \\
\text { almohadilla) }\end{array}$ & $\begin{array}{l}\text { Playita Blanca, NW Pl. del } \\
\text { Coco, H. Carrillo Norte, } \\
349,00-282,15\end{array}$ & $132,9 \pm 1,5\left({ }^{40} \mathrm{Ar} /{ }^{39} \mathrm{Ar}\right.$ : iso. $)$ & Hoernle et al. (2004) \\
\hline AN34 & $\begin{array}{l}\text { Vidrio basáltico de } \\
\text { almohadilla }\end{array}$ & $\begin{array}{l}\text { Pl. Cocal, San Juanillo, H. } \\
\text { Cerro Brujo, 345,55-224,05 }\end{array}$ & $\begin{array}{c}119,4 \pm 1,1\left({ }^{40} \mathrm{Ar} /{ }^{39} \mathrm{Ar}: \text { iso }\right) \\
118 \pm 5\left({ }^{40} \mathrm{Ar} /{ }^{39} \mathrm{Ar} \text { : plat. }\right)\end{array}$ & Hoernle et al. (2004) \\
\hline AN40 & $\begin{array}{l}\text { Vidrio basálticode } \\
\text { almohadilla }\end{array}$ & $\begin{array}{l}\text { Pto. Carrillo, H. Cerro Azul, } \\
\quad 373,40-205,30\end{array}$ & $118,2 \pm 1,8\left({ }^{40} \mathrm{Ar} /{ }^{39} \mathrm{Ar}\right.$ : iso. $)$ & Hoernle et al. (2004) \\
\hline $\mathrm{BN} 22$ & Basalto (matriz) & $\begin{array}{l}3 \text { km E de Potrero, Belén. } \\
\text { H. Belén, 345,10-272,00 }\end{array}$ & $110,6 \pm 0,9\left({ }^{40} \mathrm{Ar} /{ }^{39} \mathrm{Ar}:\right.$ iso. $)$ & Hoernle et al. (2004) \\
\hline AN86 & Basalto toleítico & $\begin{array}{l}\text { Nicoya, } 1.4 \text { km W de Tambor, } \\
\text { H. R. Ario, 426,45-188,75 }\end{array}$ & $\begin{array}{c}110 \pm 10\left({ }^{40} \mathrm{Ar} /{ }^{39} \mathrm{Ar}: \text { iso. }\right) \\
94,7 \pm 0,9 \text { (e.m.a. })\end{array}$ & Hauff et al. (2000) \\
\hline NC93-3 & $\begin{array}{l}\text { Basalto grano fino- } \\
\text { medio }\end{array}$ & $\begin{array}{c}\text { Loma Sabanilla, } 2,5 \mathrm{~km} \\
\text { W del Sardinal H. Carrillo } \\
\text { Norte, } 353,6-277,3\end{array}$ & $92,5 \pm 5,4\left({ }^{40} \mathrm{Ar} /{ }^{39} \mathrm{Ar}:\right.$ plat. $)$ & Sinton et al. (1997) \\
\hline NC93-2 & Basalto masivo & $\begin{array}{l}\text { R. Brasil, Pilas. H. Belén, } \\
\text { 351,4-273,0 }\end{array}$ & $90,3 \pm 3,2\left({ }^{40} \mathrm{Ar} /{ }^{39} \mathrm{Ar}:\right.$ plat. $)$ & Sinton et al. (1997) \\
\hline NC93-20 & Basalto grano fino & $\begin{array}{c}\text { Corte de carretera, C. Vista } \\
\text { al Mar H. Cerro Brujo, } \\
\text { 357,9-234,0 }\end{array}$ & $89,9 \pm 2,8\left({ }^{40} \mathrm{Ar} /{ }^{39} \mathrm{Ar}:\right.$ plat. $)$ & Sinton et al. (1997) \\
\hline NC93-18 & $\begin{array}{l}\text { Basalto sobreyacido o } \\
\text { intruyendo radiolaritas }\end{array}$ & $\begin{array}{l}\text { Tajo } 2 \text { km W de Coyolito, } \\
\text { H. Belén, 353,7-260,8 }\end{array}$ & $89,7 \pm 1,7\left({ }^{40} \mathrm{Ar} /{ }^{39} \mathrm{Ar}:\right.$ plat. $)$ & Sinton et al. (1997) \\
\hline NC93-34 & $\begin{array}{c}\text { Dique de diabasa cor- } \\
\text { tando radiolaritas rojas } \\
\text { y grices }\end{array}$ & $\begin{array}{l}\text { P. Sabana, NNW Pl. } \\
\text { Conchal, H. Matapalo, } \\
\text { 337,0-266,0 }\end{array}$ & $88,0 \pm 0,7\left({ }^{40} \mathrm{Ar} /{ }^{39} \mathrm{Ar}:\right.$ plat. $)$ & Sinton et al. (1997) \\
\hline GE-53 & Basalto en almohadilla & $\begin{array}{l}\text { Ca. Nicoya-Sámara, aprox. } \\
2 \text { km sur de Nicoya, C. La } \\
\text { Cruz, H. Matambú, aprox. } \\
\quad 378,4-234,8\end{array}$ & $\begin{array}{c}72,5 \pm 4,0 \text { (recalculado: } \\
85,5 \pm 4,7(\mathrm{~K} / \mathrm{Ar})\end{array}$ & $\begin{array}{l}\text { Barr \& Escalante } \\
\text { (1969); } \\
\text { recalibrada por Frisch } \\
\text { et al. (1992) }\end{array}$ \\
\hline \multicolumn{5}{|c|}{ INTRUSIVOS } \\
\hline BN6 & Plagiogranito & $\begin{array}{l}\text { P. Ostional, N Pl. Potrero, } \\
\text { H. Matapalo, 341,90-271,30 }\end{array}$ & $\begin{array}{c}87,4 \pm 2,8\left({ }^{40} \mathrm{Ar} /{ }^{39} \mathrm{Ar}: \text { plag: }\right. \\
\text { iso.) } 87,5 \pm 1,8 \text { (e.m.a.) }\end{array}$ & Hauff et al.(2000) \\
\hline NC93-14B & Gabro & $\begin{array}{c}\text { Al N del Edén, loma } \\
\text { siguiendo la Queb. Salto, H. } \\
\text { Belén, 354,4-265,0 }\end{array}$ & $83,8 \pm 1,1\left({ }^{40} \mathrm{Ar} /{ }^{39} \mathrm{Ar}:\right.$ plat. $)$ & Sinton et al. (1997) \\
\hline NC93-26 & Plagiogranito & $\begin{array}{l}\text { Extremo NE de Pl. Panamá, } \\
\text { H. Carrillo Norte, 355,7-287,4 }\end{array}$ & $83,2 \pm 1,3\left({ }^{40} \mathrm{Ar} /{ }^{39} \mathrm{Ar}:\right.$ plat. $)$ & Sinton et al. (1997) \\
\hline
\end{tabular}


Cuadro 3 (continuación)

Dataciones radiométricas de la península de Nicoya

\begin{tabular}{|c|c|c|c|c|}
\hline MUESTRA & LITOLOGÍA & UBICACIÓN & $\operatorname{EDAD}(\mathrm{Ma})$ & REFERENCIA \\
\hline N226 B & Gabro fayalítico & $\begin{array}{c}\text { Ocotal, H. Carrillo Norte, } \\
347,35-281,20\end{array}$ & $80,5 \pm 1,9$ (K/Ar: wr) & $\begin{array}{c}\text { Tournon \& Bellon } \\
\text { (2009) }\end{array}$ \\
\hline N $220 \mathrm{~B}$ & Dolerita & $\begin{array}{c}\text { Ocotal, H. Carrillo Norte, } \\
348,00-281,30\end{array}$ & $78,4 \pm 2,3$ (K/Ar: wr) & $\begin{array}{l}\text { Tournon \& Bellon } \\
\qquad(2009)\end{array}$ \\
\hline $\mathrm{CN} 11 \mathrm{C}$ & $\begin{array}{l}\text { Gabro ferro-hortono- } \\
\text { lítico }\end{array}$ & $\begin{array}{c}\text { Ocotal, H. Carrillo Norte, } \\
347,45-281,10\end{array}$ & $78,5 \pm 1,7$ (K/Ar: plag) & $\begin{array}{l}\text { Tournon \& Bellon } \\
\text { (2009) }\end{array}$ \\
\hline $\begin{array}{l}\text { N } 284(\mathrm{CR} \\
284)\end{array}$ & Ferrogabro & $\begin{array}{l}\text { Pl. Matapalito, stock de P. } \\
\text { Gorda, H. P. Gorda, 342,95- } \\
280,10\end{array}$ & $76,2 \pm 2,1(\mathrm{~K} /$ Ar: plag $)$ & $\begin{array}{l}\text { Tournon \& Bellon } \\
\text { (2009) }\end{array}$ \\
\hline \multicolumn{5}{|c|}{ TORTUGAL } \\
\hline $1-15-12-94$ & Picrita komatiítica & $\begin{array}{c}\text { Pueblo Nuevo, H. Abanda- } \\
\text { res, } 414,5-245,7\end{array}$ & $\begin{array}{c}89,7 \pm 1,4\left({ }^{40} \mathrm{Ar} /{ }^{39} \mathrm{Ar}: \text { plag: }\right. \\
\text { plat. })\end{array}$ & Alvarado et al. (1997) \\
\hline CR98-27 & Picrita komatiítica & $\begin{array}{l}\text { Calle Línea, entre Quebs. } \\
\text { Barbudal y Coyol, H. Aban- } \\
\text { gares, 417,0-242,5 }\end{array}$ & $\begin{array}{c}88,5 \pm 0,7\left({ }^{40} \mathrm{Ar} /{ }^{39} \mathrm{Ar}: \text { plag: }\right. \\
\text { plat. })\end{array}$ & Sinton et al. (2009) \\
\hline CR98-58 & Picrita komatiítica & $\begin{array}{l}\text { Queb. Piñuela, H. Abanga- } \\
\text { res, } 416,4-244,35\end{array}$ & $\begin{array}{c}85,4 \pm 1,4\left({ }^{40} \mathrm{Ar} /{ }^{39} \mathrm{Ar}: \text { plag: }\right. \\
\text { plat. })\end{array}$ & Sinton et al. (2009) \\
\hline
\end{tabular}

Alvarado, 2007). Algunos clastos datados, parecen provenir de este evento (Cuadro 4).

De manera simplificada, la historia tectonomagmática se puede resumir a:

a. Sedimentación de una espesa secuencia de radiolaritas pelágicas en el Paleopacífico en conexión con el Tethys durante el Jurásico Medio, unos $170 \mathrm{Ma}$ (Denyer \& Baumgartner, 2006).

b. Efusiones basálticas a los $139-133 \mathrm{Ma}$ (Hoernle et al., 2004; Denyer \& Baumgartner, 2006).

c. Efusiones basálticas a los 119 - $110 \mathrm{Ma}$ (Denyer \& Baumgartner, 2006).

d. Intrusiones subvolcánicas de magmas basálticos a los 92 - $88 \mathrm{Ma}$ (Denyer \& Baumgartner, 2006; presente trabajo).

e. Picritas komatíticas $(88,4 \mathrm{Ma})$ intruidas por diques alcalinos (Alvarado et al., 1997; Sinton et al., 2009).

f. Intrusiones gabroicas y plagiograníticas a los 87 - 80 Ma.

g. Establecimiento de la zona de subducción aproximadamente a los 71 Ma.

\section{Promontorios de Herradura-Jacó-Quepos}

En el extremo SE del bloque Herradura $\left(1000 \mathrm{~km}^{2}\right)$ afloran radiolaritas y basaltos con una geoquímica (Hauff et al., 2000; Arias, 2003) y edad (91 - $84 \mathrm{Ma}$ ) similares a la de Nicoya (Sinton et al., 1997; Hauff et al., 2000; Tournon \& Bellon, 2009), es decir asociados con el CLIP. Sobre esta secuencia, se presentan basaltos vesiculares, masivos y en almohadillas, gabros, doleritas, picritas y brechas hialoclastíticas con calizas asociadas del Maastrichtiano al Eoceno Medio, e intepretados como un monte submarino con afinidad geoquímica de Basaltos de Islas Oceánicas o Basaltos oceánicos Intraplaca (OIB y WPB, en sus acrónimos en inglés) según Arias (2003). Constituyen la Fm. Tulín (Arias, 2003) o la unidad Turrubares (Tournon \& Bellon, 2009).

Similares litologías y facies de un monte submarino con afinidad OIB, se presentan en el promontorio de Quepos (Hauff et al., 2000; Arias, 2003; Tournon \& Bellon, 2009), que estuvo parcialmente emergido previo a ser tectónicamente 
Cuadro 4

Dataciones radiométricas de rocas volcaniclásticas antiguas del inicio del vulcanismo andesítico

\begin{tabular}{ccccc}
\hline MUESTRA & LITOLOGÍA & UBICACIÓN & EDAD (Ma) & REFERENCIA \\
\hline NIC-048-1 & Canto de andesita basáltica & Extremo W de Pl. Carrillo, & $61,3 \pm 4,7$ (K/Ar) & Appel (1990) \\
& dentro de turbidita del Pa- & al N de P. Indio, H. Garza, & & \\
leoceno Superior & $372,0-206,1$ & \\
R-241 & Toba basáltica & Sur P. Cacique, H. Carrillo & $56,8 \pm 6,0(\mathrm{~K} /$ Ar) & Berrangé et al. \\
& & Norte, 350,55-283,50 & & $(1989)$ \\
\hline
\end{tabular}

emplazado (Hauff et al., 2000; Denyer \& Gazel, 2009). Allí tenemos rocas básicas intrusivas (gabros feldespatoidocos) y volcánicas y subvolcánicas (basaltos, ankaramitas, picritas, diabasas y sus productos fragmentarios: brechas de almohadillas, depósitos de hialoclastitas) asociadas con sedimentos del Daniano (entre 65,5 y 61,7 Ma, Azema et al., 1979) a modo de peperitas, en justa concordancia con las edades ${ }^{40} \mathrm{Ar} /{ }^{39} \mathrm{Ar}$ entre $65 \mathrm{y}$ $61 \mathrm{Ma}$ (Cuadro 5).

La cronología de los eventos puede resumirse de manera simplicada como:

a. Desarrollo de rocas equivalentes al complejo de Nicoya con edades entre 91 y $83 \mathrm{Ma}$, que constituirían el basamento del bloque Herradura.

b. Formación de montes submarinos entre el Maastrichtiano y el Eoceno inferior sobre dicho basamento.

c. Arribo a la zona de subducción y acreción/ obducción al final del Eoceno Medio.

\section{Golfito-Osa-Burica}

En la región sur de Costa Rica afloran rocas máficas de origen submarino pero con una histórica geológica muy compleja, todavía en investigación. Se interpreta como fragmentos acrecionados de un plateau o parte del CLIP (Denyer et al., 2006; Denyer \& Gazel, 2009), pero se diferencia del Complejo de Nicoya en varios aspectos, entre ellos la presencia de: a) cuerpos básicos intruyendo o intercalados, deformando sedimentos del Campaniano Tardío hasta por lo menos el Eoceno (Berrangé \& Thorpe, 1988; Berrangé et al., 1989; Di Marco, 1994), b) basaltos vesiculares y picritas, así como gabros pegmatíticos (Berrangé \&
Thorpe, 1988; Berrangé et al., 1989; Buchs et al., 2009, 2010), c) rocas similares a los granófiros formados a partir de fundidos enriquecidos en fluidos y sílice (Buchs et al., 2010) y d) abundancia de vetillas de cuarzo en contraposición con Nicoya (presente trabajo) enriquecidas en $\mathrm{Au}$ (Berrangé \& Thorpe, 1988).

Se distinguen entre cuatro y seis terrenos exóticos acrecionados (Di Marco et al., 1995; Buchs et al., 2009), que conforman el complicado rompecabezas de esta región austral pacífica de Costa Rica. Sin embargo, su comprensión no es sencilla, tanto por la complejidad geológica intrínseca de región, como por los cambios constantes en los límites de las unidades en los mapas geológicos y sus rangos de edades, aún dentro de los mismos grupos de trabajo (Di Marco et al., 1995; Buchs et al., 2009, 2010).

Berrangé \& Thorpe (1988) son los primeros que plantean, basándose en la geoquímica de las rocas y piroxenos, la dificultad de definir el origen geotectónico de las rocas ofiolíticas de la zona sur. Sin embargo, tomando las rocas analizadas como un todo (Osa-Golfito), encuentran afinidad de MORB, aunque empobrecidas en elementos HFS durante episodios tempranos de fusión y enriquecidas en elementos LIL por episodios tardíos de subducción. Tan solo dos muestras son alcalinas, asociadas con vulcanismo intraplaca o de monte submarino (WPB u OIB), por sus enriquecimientos en $\mathrm{TiO}_{2}, \mathrm{Zr}$, Ta y $\mathrm{Nb}$ en comparación con otros elementos LIL y HFS, o una lava en almohadilla por poseer ferrosalita enriquecida en titanio, un clinopiroxeno cálcico de la serie diópsido-hedenbergita (Tournon, 1984). Aunque Berrangé \& Thorpe (1988) concluyen 
Cuadro 5

Dataciones radiométricas de los promontorios de Herradura y Quepos

\begin{tabular}{|c|c|c|c|c|}
\hline MUESTRA & LITOLOGÍA & UBICACIÓN & EDAD (Ma) & REFERENCIA \\
\hline \multicolumn{5}{|c|}{ HERRADURA } \\
\hline CR 366 & Colada basáltica masiva & $\begin{array}{l}\text { Extremo N Pl. Herradura, H. } \\
\text { Herradura, 390,35-400,35 }\end{array}$ & $\begin{array}{l}91,8 \pm 5,2 \\
91,7 \pm 5,2 \\
\text { (K/Ar: wr) }\end{array}$ & $\begin{array}{l}\text { Tournon \& Bellon } \\
\qquad(2009)\end{array}$ \\
\hline \multirow[t]{2}{*}{ AH1 } & Basalto toleítico & $\begin{array}{l}\text { P. Guapinol, corte de Ca. SSE de } \\
\text { Jacó, H. Herradura 394,65-393,65 }\end{array}$ & $\begin{array}{c}85,9 \pm 2,4\left({ }^{40} \mathrm{Ar} /{ }^{39} \mathrm{Ar}:\right. \\
\text { iso. })\end{array}$ & Hauff et al. (2000) \\
\hline & & & $\begin{array}{c}86,0 \pm 2,0\left({ }^{40} \mathrm{Ar} /{ }^{39} \mathrm{Ar}:\right. \\
\text { e.m.a. })\end{array}$ & \\
\hline \multirow[t]{2}{*}{ JC-93-1 } & Basalto & $\begin{array}{c}\text { Corte de Ca. } 1,2 \mathrm{~km} \text { al } \mathrm{S} \text { de la } \\
\text { última entrada a Pl. Jacó, H. } \\
\text { Herradura, 394,7-393,8N }\end{array}$ & $\begin{array}{l}84,2 \pm 1,8\left({ }^{40} \mathrm{Ar} /{ }^{39} \mathrm{Ar}:\right. \\
\text { plat. })\end{array}$ & Sinton et al. (1997) \\
\hline & & QUEPOS & & \\
\hline AQ66 & Basalto toleítico & $\begin{array}{c}\text { Quepos, H. Quepos, 446,9- } \\
370,3\end{array}$ & $\begin{array}{l}65,0 \pm 0,4\left({ }^{40} \mathrm{Ar} /{ }^{39} \mathrm{Ar}:\right. \\
\text { mtz, f.t., v.i. })\end{array}$ & Hoernle et al. (2002) \\
\hline QP93-1 & Basalto afírico columnar & $\begin{array}{c}\text { Sur del la Pl. } 1 \text { de Manuel } \\
\text { Antonio, basalto columnar, H. } \\
\text { Quepos, 446,9-371,0 }\end{array}$ & $\begin{array}{l}63,9 \pm 0,5\left({ }^{40} \mathrm{Ar} /{ }^{39} \mathrm{Ar}:\right. \\
\text { plat. })\end{array}$ & Sinton et al. (1997) \\
\hline \multirow[t]{2}{*}{ BQ32 } & Gabro & $\begin{array}{c}\text { Cerca de la entrada al Parque } \\
\text { Nacional Manuel Antonio, H. } \\
\text { Quepos, } 446,85-370,88\end{array}$ & $\begin{array}{l}52 \pm 8,0\left({ }^{40} \mathrm{Ar} /{ }^{39} \mathrm{Ar}:\right. \\
\quad \text { plag, f.t., v.i. })\end{array}$ & Hauff et al. (2000) \\
\hline & & & $\begin{array}{l}59,4 \pm 1,8\left({ }^{40} \mathrm{Ar} /{ }^{39} \mathrm{Ar}:\right. \\
\text { e.m.a. })\end{array}$ & \\
\hline QUE-020 & Brechas basáltica & $\begin{array}{l}\text { P. Quepos, extremo oeste P1. Es- } \\
\text { padilla, H. Quepos, 444,9- 371,9 }\end{array}$ & $46,2 \pm 4,4(\mathrm{~K} / \mathrm{Ar})$ & Appel (1990) \\
\hline
\end{tabular}

que en general estas rocas ígneas se formaron en un ambiente de cuenca tras-arco, si dejan en claro su cercanía o afinidad con una zona de subducción. Más estudios de detalles son requeridos, pero en términos generales se interpretan como fragmentos de montes submarinos, posiblemente parte de una cordillera asísmica del CLIP, también con presencia de rocas con afinidad N-MORB, E-MORB y OIB (Berrangé \& Thorpe, 1998; Hauff et al., 2000; Hoernle et al., 2002; Buchs et al., 2009; Denyer \& Gazel, 2009; Tournon \& Bellon, 2009).

Mediante el estudio original de 24 edades $\mathrm{K} / \mathrm{Ar}$ de rocas máficas extrusivas e intrusivas (Cuadro 6), Berrangé et al. (1989) concluyen que existen tres eventos magmáticos principales: el más antiguo y pobremente definido de $78 \pm 2$ Ma (Campaniano Medio), un segundo evento bien definido alrededor de 60,2 $\pm 7,6 \mathrm{Ma}$ (Maaestrichtiano Tardío al Eoceno Temprano) y un tercer evento aproximadamente a 44,1 $\pm 4,4$ Ma (Eoceno Medio). Si tomamos los propios datos de Berrangé y colaboradores (su figura 3) e independientemente de su disposición geográfica le aplicamos el criterio de la acronoza concurrente (utilizado en paleontología con edades de fósiles), entonces tenemos que se agrupan en 4 eventos principales, en concordancia con los mencionados pero mejor restringidos: 80 - $76 \mathrm{Ma}$ (Campaniano Medio), 64 - 60 Ma (Paleoceno Temprano a los albores del Medio), 56,7 - 54,7 Ma (Paleoceno Tardío) y 47,5 - 43,5 Ma (Eoceno Medio). Las edades anteriores están soportadas por el hecho de que existen evidencias de que gran parte de este magmatismo intruyó y se intercaló con sedimentos silíceos y calcáreos, en su mayoría aún 
en estado plástico, que aportan igualmente edades Campaniano a Eoceno Medio (Berrangé \& Thorpe, 1988; Berrangé et al., 1989; Di Marco et al., 1995). Sin embargo, la mayoría de las edades de los basaltos y gabros in situ se sitúan entre $\sim 65$ y $55 \mathrm{Ma}$, mientras que la de los basaltos y gabros asociados o cercanos al mélange, poseen edades primordialmente entre $\sim 60$ y $45 \mathrm{Ma}$.

Buchs et al. $(2009,2010)$ encuentra radiolaritas datadas del Coniaciano-Santoniano (aprox. 89 - $84 \mathrm{Ma}$ ), por lo que asumen que las rocas ígneas poseen dichas edades, aduciendo que las dataciones poseen problemas por pérdida de Ar. Sin embargo, aunque hablan que estas radiolaritas están intercaladas con la secuencia efusiva, no queda claro si efectivamente es así o si se trata de xenolitos. Pone como argumento adicional una lava datada en $54,5 \pm 1,5 \mathrm{Ma}$ en punta Burica, que en realidad pertenece a Osa (ver Hoernle et al., 2002), la cual es mucho más joven que los sedimentos que presumiblemente la cubren del Paleoceno Tardío-Eoceno Temprano (aprox. 59 $56 \mathrm{Ma}$ ) correspondientes a la Fm. Pavones. Sin embargo, al contrario de invalidar la edad, en el campo se observa que los basaltos intruyen a los sedimentos que aún estaban en estado plástico y, por ello, la edad de algunos basaltos es contemporánea y efectivamente algo más joven que la de los sedimentos. No obstante, el basalto en almohadilla datado por Hoernle et al. (2002) en Burica, con una edad de 64,2 Ma, procede de la desembocadura del río Claro, y se presentan volcados, indicando una tectónica considerable que aconteció entre el Paleoceno Inferior basal y el Paleoceno Tardío, previo a la Fm. Pavones.

Basaltos hasta traquiandesitas fluyeron e intruyeron a las calizas hemipelágicas tobáceas del Campaniano Tardío al Maastrichtiano (Fm. Golfito), magmatismo al que se le asocia con un arco de islas primitivo (alto contenido de $\mathrm{Pb}$, empobrecimiento de $\mathrm{Nb}$ y Ti y anomalías de $\mathrm{Eu}$ ). $\mathrm{La}$ Fm. Fila Achiote está representa una secuencia volcaniclástica con enriquecimiento de tobitas ácidas del Maastrichtiano al Paleoceno (Buchs et al., 2010).

Si tomamos en cuenta todas las dataciones radiométricas y paleontológicas, su ubicación geográfica y contexto geológico (Tournon, 1984;
Di Marco et al., 1995; Hauff et al., 2000; Hoernle et al., 2002; Tournon \& Bellon, 2009; Buchs et al., 2009, 2010), la cronología se puede resumir en:

a. Un magmatismo tipo CLIP pre-Campaniano, en equivalencia con el Complejo de Nicoya, que conformaría el basamento.

b. Posiblemente un magmatismo de arco de islas incipiente sobre este basamento, de edad del Campaniano Tardío a Maastrichtiano (75-70 Ma).

c. Un magmatismo de dorsal oceánica con montes submarinos aislados (tipo CLIP, MORB, N-MORB, E-MORB y OIB), del Campaniano al Eoceno Medio (80-76; 64-60; 56,7-54,7 y 47,543,5 Ma), que son paulatinamente acrecionados al margen convergente, e incluso desmembrados (mélange) junto con secuencias sedimentarias entre el Paleoceno y el Mioceno.

\section{El vulcanismo basáltico submarino de Talamanca}

Una serie de basaltos en almohadilla, vesiculares, muy alterados, pero posiblemente de composición alcalina (presencia de titanoaugitas) y una posición estratigráfica posiblemente entre Paleoceno a Eoceno Inferior a Medio, afloran en diversas partes de la raíz de la cordillera de Talamanca (ríos Boyei y Pacuare, quebradas Terciopelo y Grande). Se desconoce si corresponden con un vulcanismo alcalino in situ, o con montes submarinos emplazados tectónicamente y ahora cubiertos por series sedimentarias posteriores (Tournon, 1984; Tournon \& Alvarado, 1997; Tournon \& Bellon, 2009).

\section{EL MAGMATISMO DE ARCO OLIGO-PLIOCENO}

\section{Plutonismo Oligo-Plioceno}

Las rocas plutónicas de Talamanca (batolitos hasta stocks) son ampliamente conocidos desde hace más de un siglo (Gabb, 1874, 1875). Las rocas en su mayoría son granitos alcalinos a gabros, predominando los monzogabros y monzodioritas cuarcíferas, seguidas por los gabros, que en términos generales -no siempre- suelen 
Cuadro 6

Dataciones radiometricas de la peninsula de Osa, Golfito y punta Burica

\begin{tabular}{|c|c|c|c|c|}
\hline MUESTRA & LITOLOGÍA & UBICACIÓN & EDAD (Ma) & REFERENCIA \\
\hline \multicolumn{5}{|c|}{ INTRUSIVOS/HIPOABISALES } \\
\hline $\mathrm{R}-152$ & $\begin{array}{l}\text { Gabro estratificado (parte mar- } \\
\text { ginal: R-292) }\end{array}$ & $\begin{array}{c}\text { A 16,6 km de Rincón a Chacarita, } \\
\text { H. Rincón, } 528,00-300,50\end{array}$ & $78,0 \pm 2(\mathrm{~K} / \mathrm{Ar})$ & Berragé et al. (1989) \\
\hline $\mathrm{R}-161$ & $\begin{array}{l}\text { Basalto-dolerita alterado (parte } \\
\text { del intrusivo R-162) }\end{array}$ & $\begin{array}{l}\text { I. Violines, H. Sierpe, } \\
504,30-304,65\end{array}$ & $\begin{array}{l}66,7 \pm 10 \\
(\mathrm{~K} / \mathrm{Ar})\end{array}$ & Berrangé et al., 1989 \\
\hline $\mathrm{R}-283$ & Gabro (bloque) & $\begin{array}{l}\text { R. Agujas, H. Golfo Dulce, } \\
526,00-277,50\end{array}$ & $65,3 \pm 3(\mathrm{~K} / \mathrm{Ar})$ & Berragé et al. (1989) \\
\hline $\mathrm{R}-216$ & Gabro fresco (bloque) & $\begin{array}{l}\text { R. Brazo Izquierda, } 200 \text { m sobre } \\
\text { R. Piedras Blancas, H. Golfo } \\
\text { Dulce, 527,55-273,58 }\end{array}$ & $64,2 \pm 9(\mathrm{~K} / \mathrm{Ar})$ & Berragé et al. (1989) \\
\hline $\mathrm{R}-74$ & $\begin{array}{l}\text { Gabro pegmatítico con anfíbol } \\
\text { (bloque) }\end{array}$ & $\begin{array}{l}\text { P. Carbonera, H. Carate, } \\
542,40-262,30\end{array}$ & $\begin{array}{c}62,1 \pm 2 \\
(\mathrm{~K} / \mathrm{Ar}: \mathrm{hb})\end{array}$ & Berragé et al. (1989) \\
\hline $\mathrm{R}-252$ & Gabro (bloque) & $\begin{array}{c}\text { R. Coyunda, H. Carate, } 538,45- \\
262,30\end{array}$ & $61,8 \pm 8(\mathrm{~K} / \mathrm{Ar})$ & Berragé et al. (1989) \\
\hline $\mathrm{R}-240$ & $\begin{array}{l}\text { Dolerita (borde del intrusivo } \\
\text { R-239) }\end{array}$ & $\begin{array}{l}\text { Ca. Golfito-R. Claro, } 200 \text { m E } \\
\text { de la intersección a Trenzas, H. } \\
\text { Golfito, 566,0-284,1 }\end{array}$ & $60,3 \pm 8(\mathrm{~K} / \mathrm{Ar})$ & Berragé et al. (1989) \\
\hline $\mathrm{R}-292$ & $\begin{array}{l}\text { Microgabro alterado (borde } \\
\text { intrusivo R-152) }\end{array}$ & $\begin{array}{l}\text { A 16,6 km de Rincón a Chacarita, } \\
\text { H. Rincón, } 528,00-300,50\end{array}$ & $60,3 \pm 2(\mathrm{~K} / \mathrm{Ar})$ & Berragé et al. (1989) \\
\hline $\mathrm{R}-168$ & Dolerita (bloque) & $\begin{array}{l}\text { I. Violines, H. Sierpe, } \\
504,15-306,85\end{array}$ & $59,6 \pm 7(\mathrm{~K} / \mathrm{Ar})$ & Berragé et al. (1989) \\
\hline $\mathrm{R}-246$ & Gabro (bloque) & $\begin{array}{l}\text { R. Coyunda, H. Carate, 538,10- } \\
\qquad 261,55\end{array}$ & $57,2 \pm 3(\mathrm{~K} / \mathrm{Ar})$ & Berragé et al. (1989) \\
\hline $\mathrm{R}-239$ & $\begin{array}{l}\text { Gabro (borde grano fino en } \\
\text { R-240) }\end{array}$ & $\begin{array}{l}\text { Ca. Golfito-R. Claro, } 200 \text { m E } \\
\text { de la intersección a Trenzas, H. } \\
\text { Golfito, } 566,0-284,1\end{array}$ & $\begin{array}{l}56,0 \pm 3,0 \\
(\mathrm{~K} / \mathrm{Ar})\end{array}$ & $\begin{array}{l}\text { Berrangé et al. } \\
\text { (1989) }\end{array}$ \\
\hline $\mathrm{R}-32$ & Gabro (bloque) & $\begin{array}{l}\text { Queb. Pizote, H. Golfo Dulce, } \\
527,80-275,05\end{array}$ & $55,7 \pm 1(\mathrm{~K} / \mathrm{Ar})$ & Berragé et al. (1989) \\
\hline $\mathrm{R}-120$ & Gabro (bloque) & $\begin{array}{l}\text { R. Conte, H. Golfo Dulce, } \\
521,75-281,20\end{array}$ & $55,3 \pm 6(\mathrm{~K} / \mathrm{Ar})$ & Berragé et al. (1989) \\
\hline $\mathrm{R}-162$ & $\begin{array}{l}\text { Dolerita masiva (parte intrusivo } \\
\text { R-161) }\end{array}$ & $\begin{array}{l}\text { I. Violines, H. Sierpe, 504,30- } \\
\text { 304,65 }\end{array}$ & $52,0 \pm 7(\mathrm{~K} / \mathrm{Ar})$ & Berragé et al. (1989) \\
\hline 950 & $\begin{array}{l}\text { Dique de dolerita dentro de } \\
\text { radiolaritas (melange) }\end{array}$ & $\begin{array}{l}\text { San Pedrillo, H. Llorona, } \\
492,1-286,2\end{array}$ & $\begin{array}{l}45,6 \pm 2,5 \\
45,5 \pm 2,5 \\
\text { (K/Ar: wr) }\end{array}$ & $\begin{array}{l}\text { Tournon (1984); } \\
\text { Tournon \& Bellon } \\
\text { (2009) }\end{array}$ \\
\hline $\mathrm{R}-89$ & Gabro (bloque) & $\begin{array}{l}\text { R. Conte, H. Golfo Dulce, } \\
523,00-281,75\end{array}$ & $\begin{array}{l}45,6 \pm 2,0 \\
(\mathrm{~K} / \mathrm{Ar})\end{array}$ & Berragé et al. (1989) \\
\hline $\mathrm{R}-295$ & Dique dolerítico vertical & $\begin{array}{c}\text { A } 40 \text { km de Rincón a Chacarita, } \\
\text { H. Rincón, 543,35-302,88 }\end{array}$ & $\begin{array}{l}44,8 \pm 8,0 \\
(\mathrm{~K} / \mathrm{Ar})\end{array}$ & Berragé et al. (1989) \\
\hline $\mathrm{R}-106$ & Leucogabro (bloque) & $\begin{array}{l}\text { R. Brazo Izquierda, H. Golfo } \\
\text { Dulce, 528,80-275,05 }\end{array}$ & $\begin{array}{c}42,5 \pm 3,0 \\
(\mathrm{~K} / \mathrm{Ar})\end{array}$ & Berragé et al. (1989) \\
\hline $\mathrm{R}-80$ & Dolerita (bloque) & $\begin{array}{l}\text { Confluencia R. Pavón-Rincón, H. } \\
\text { Golfo Dulce, 518,50-284,35 }\end{array}$ & $\begin{array}{c}40,8 \pm 4,0 \\
(\mathrm{~K} / \mathrm{Ar})\end{array}$ & Berragé et al. (1989) \\
\hline
\end{tabular}


Cuadro 6 (continuación)

Dataciones radiometricas de la peninsula de Osa, Golfito y punta Burica

\begin{tabular}{|c|c|c|c|c|}
\hline MUESTRA & LITOLOGÍA & UBICACIÓN & $\operatorname{EDAD}(\mathrm{Ma})$ & REFERENCIA \\
\hline \multicolumn{5}{|c|}{ BASALTOS } \\
\hline R-296 & $\begin{array}{c}\text { Basalto (roca caja) del dique } \\
\text { dolerítico R-295 }\end{array}$ & $\begin{array}{l}\text { A } 40 \text { km de Rincón a Chacarita, } \\
\text { H. Rincón, 543,35-302,88 }\end{array}$ & $\begin{array}{l}74,8 \pm 10 \\
(\mathrm{~K} / \mathrm{Ar})\end{array}$ & Berragé et al. (1989) \\
\hline CR 929 & Basalto & $\begin{array}{l}\text { Boca R. Sierpe H. Sierpe, 503,0- } \\
303,25\end{array}$ & $67,0(\mathrm{~K} / \mathrm{Ar})$ & Tournon (1984) \\
\hline BUR5 (G5) & $\begin{array}{l}\text { Lava en alhomadilla basáltica } \\
\text { toleítica }\end{array}$ & $\begin{array}{c}\text { Boca del R. Claro, Pavones, H. } \\
\text { Pavón, 558,00-261,15 }\end{array}$ & $\begin{array}{c}64,2 \pm 1,1 \\
\left({ }^{40} \mathrm{Ar} r{ }^{39} \mathrm{Ar}: \text { f.t. }\right. \\
\text { v.i. })\end{array}$ & Hoernle et al. (2002) \\
\hline OS6 & Basalto toleítico & $\begin{array}{l}\text { P. Ganado, H. Sierpe, } \\
502,40-298,90\end{array}$ & $\begin{array}{c}63,4 \pm 1,8 \\
\left({ }^{40} \mathrm{Ar} /{ }^{39} \mathrm{Ar}: \text { iso. }\right)\end{array}$ & Hauff et al. (2000) \\
\hline & & & $\begin{array}{c}62,1 \pm 0,6 \\
\left({ }^{40} \mathrm{Ar}{ }^{\beta 9} \mathrm{Ar} \text {.e.m.a. }\right)\end{array}$ & \\
\hline $\mathrm{R}-182$ & Basalto & $\begin{array}{l}\text { Catarata de la Queb. Arepa, H. } \\
\text { Rincón, 541,50-303,335 }\end{array}$ & $62,8 \pm 4(\mathrm{~K} / \mathrm{Ar})$ & Berragé et al. (1989) \\
\hline $\mathrm{R}-251$ & Basalto (bloque) & $\begin{array}{l}\text { R. Coyunda, H. Carate, } \\
538,45-262,30\end{array}$ & $58,1 \pm 8(\mathrm{~K} / \mathrm{Ar})$ & $\begin{array}{l}\text { Berrangé et al. } \\
\text { (1989) }\end{array}$ \\
\hline OS4 & Basalto toleítico & $\begin{array}{l}\text { P. Violín, I. Violín, H. Sierpe, } \\
501,833-305,869\end{array}$ & $\begin{array}{c}54,5 \pm 1,5 \\
\text { (40Ar/39Ar: } \\
\text { mtz: f.t., v.i.) }\end{array}$ & Hoernle et al. (2002) \\
\hline $\mathrm{R}-156$ & Basalto alterado (bloque) & $\begin{array}{l}\text { Queb. China, I. Violines, H. } \\
\text { Sierpe, 503,50-305,90 }\end{array}$ & $\begin{array}{l}51,2 \pm 10 \\
(\mathrm{~K} / \mathrm{Ar})\end{array}$ & Berragé et al. (1989) \\
\hline
\end{tabular}

ser más antiguos o contenidos como enclaves en los granitoides (Figs. 2 y 4). También se presentan granodioritas, tonalitas, monzogranitos y monzonitas cuarcíferas (Kussmaul, 1987; presente trabajo). Algunos enclaves y venillas de diabasa, también pueden estar presentes. La mayoría de las rocas cristalizaron entre 800 y $860^{\circ} \mathrm{C}$ y a una profundidad $\leq 3$ - $5 \mathrm{~km}$ (Drummond et al., 1995; Gräfe, 1988; Gräfe et al., 2002; Ulloa \& Delgado, 2010).

Existen algunas dataciones $\mathrm{K} / \mathrm{Ar}$ que indican edades entre 35 y unos $19 \mathrm{Ma}$, pero existen dudas de si corresponden con muestras alteradas y/o con rocas toleíticas empobrecidas en potasio (Cuadro 7). Posiblemente, equivalente en edad, se tiene el leucogabro con olivino de Boca Tapada (llanura de San Carlos), pese a que carece de edad radiométrica, por su contexto (rodeado de lavas con edades entre 16,7 y $17,1 \mathrm{Ma}$, pero sin relaciones claras con respecto al intrusivo), por su geoquímica (similar a los basaltos del Hito Sar, Gazel et al., 2005) y razón de los isótopos de estroncio, se puede inferir una edad cercana o superior a los $17 \mathrm{Ma}$, posiblemente de alrededor de los $22 \mathrm{Ma}$.

Las edades que suelen ser más consistentes en Talamanca y que, sin lugar a dudas por los diferentes métodos y sus traslapes $\left(\mathrm{K} / \mathrm{Ar},{ }^{40} \mathrm{Ar}{ }^{\beta 9} \mathrm{Ar}, \mathrm{Rb} /\right.$ Sr y huellas de fisión en zircón), muestran una serie de fases intrusivas que se extendieron en forma continua desde 12,8 hasta 7,8 Ma (5 Ma de lapso). La vereda que conduce a la cumbre del cerro Chirripó (3820 m) a través de la fila Cementerio de la Máquina, pasa por rocas plutónicas con edades entre 10,6 y 7,5 Ma, para culminar con el macizo del Chirripó con rocas plutónicas e hipoabisales entre 10,1 y 7,8 Ma (Mioceno Medio hasta Inferior), rodeado de rocas volcánicas (lavas y brechas) con edades no determinadas isotópicamente (Cuadro 8). 


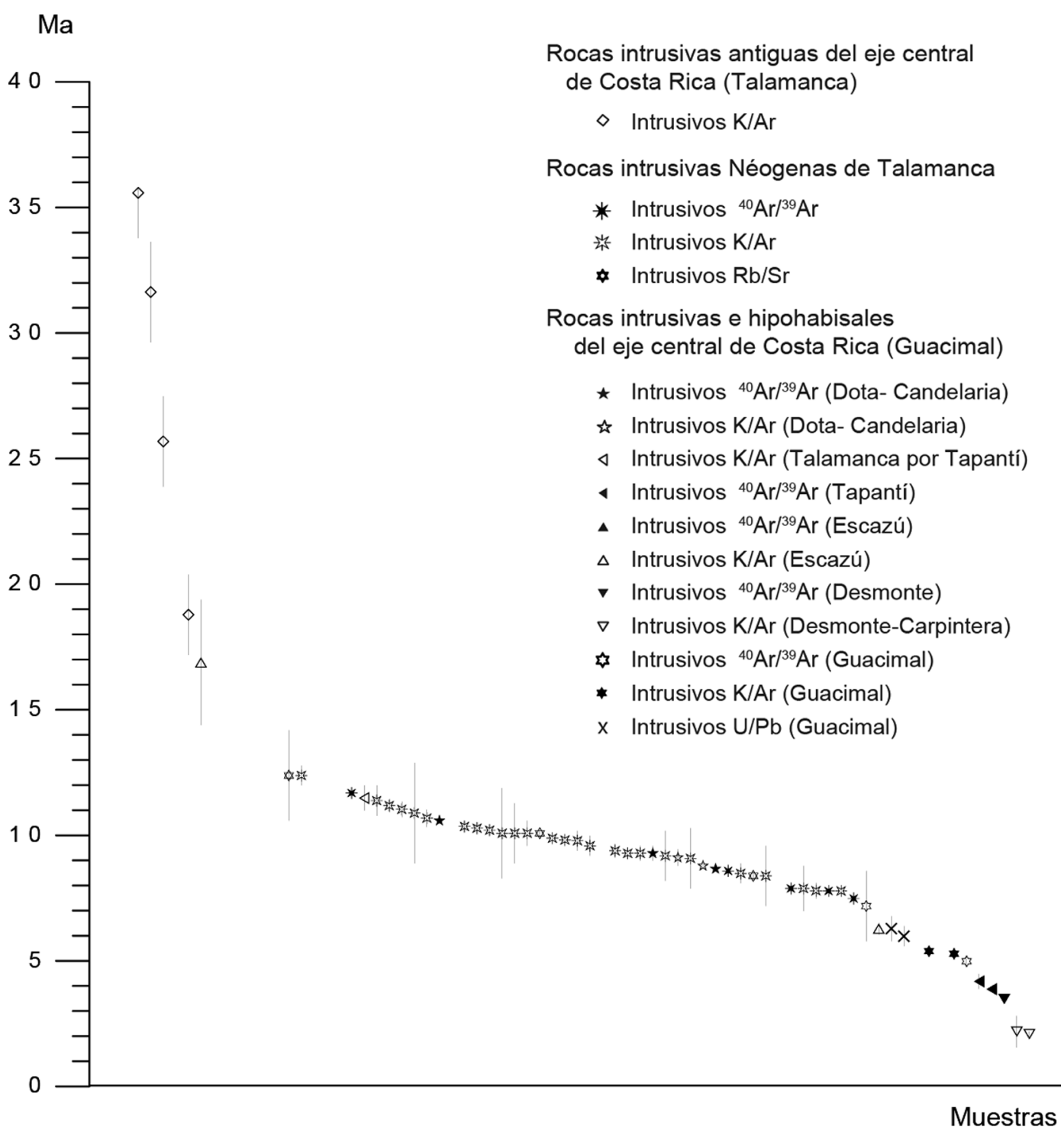

Fig. 4: Número de dataciones de los cuerpos intrusivos con textura plutónica (desde Talamanca hasta Guacimal), ordenados de mayor a menor edad.

En la fila Costeña afloran varios kilómetros de espesor de turbiditas ricas en clastos volcánicos (Fm. Descartes y Fm. Térraba, Paleoceno al Mioceno Medio; Mora, 1979; Alvarado et al., 2009b; Obando, 2011), intruidas por cuerpos predominantemente básicos y sus diferenciados (gabros y monzogabros, doleritas, aplitas, andesitas, basaltos) de la Fm. Puerto Nuevo (Mora, 1979; Kussmaul, 1987). Las primeras dataciones radiométricas de este sector (Woodward-Clyde, 1980; Heywood, 1984), relacionadas con las rocas intrusivas que allí afloran, permanecieron en su mayor parte desconocidas para la comunidad científica por años, hasta que de Boer et al. (1995) la dio 
Cuadro 7

Dataciones radiométricas de las rocas intrusivas antiguas (¿raíz?) de Talamanca (intrusivos de Talamanca)

\begin{tabular}{ccccc}
\hline MUESTRA & LITOLOGÍA & UBICACIÓN & EDAD (Ma) & REFERENCIA \\
\hline A-43 & $\begin{array}{c}\text { Granito con hornblenda } \\
\text { cloritizada }\end{array}$ & $\begin{array}{c}\text { Alto Lari, Queb. Shurida, H. Siola, } \\
\text { aprox. 376,3-568,0 }\end{array}$ & $\begin{array}{c}35,6 \pm 1,8 \\
\text { (K/Ar) }\end{array}$ & $\begin{array}{c}\text { RECOPE en Sáenz } \\
(1982)\end{array}$ \\
CR27 & Gabro toleítico con & Alto Macho Mora, cerca de Divi- & $31,65 \pm 2,00$ & de Boer et al. (1995); \\
& olivino & sión, H. Cuericí, aprox. 496,0-386,4 & (K/Ar) & Drummond et al. (1995) \\
A-57 & Gabro toleítico? & A 5,5 km de Amubri, sobre el R. & $25,7 \pm 1,8$ & RECOPE em Sáenz \\
& & Lari, H. Sukut, aprox. 573,3-383,1 & (K/Ar) & $(1982)$ \\
KAM-052 & Rodado de gabro con & Queb. cerca de localidad Sukut, H. & $18,8 \pm 1,6$ & Appel (1990), Appel et \\
& clorita, muscovita y & Sukut, aprox. 576,3-373,3 & (K/Ar: hb: 22,7 & al. (1994) \\
& sericita secundarias & & & \\
\hline
\end{tabular}

nuevamente a conocer. Appel (1991) y Appel et al. (1994) igualmente dató un clasto rodado de dolerita en 16,8 Ma. Un nuevo grupo de dataciones fue proporcionado por MacMillan et al. (2004) complementado con una datación de Gazel et al. (2009). Las rocas gabroicas en los alrededores de la localidad tipo, por el antiguo sitio de presa de Boruca y por Puerto Nuevo, consistentemente poseen edades entre 14,8 y 11,1 Ma, muy similares al gabro aflorante en la carretera Interamericana (12,8 Ma) y a un dique andesítico co-magmático (11,7 Ma), pero difieren en ser algo más jóvenes que los diques andesíticos hasta diabásicos aflorantes por Dominical (entre 18,3 y 16,8 Ma). Pese a que desconocemos los rangos de error de las dataciones de Woodward-Clyde (1980, en de Boer et al., 1995) y Heywood (1984, en de Boer et al., 1995), se pueden inferir dos grandes pulsos intrusivos: a los 18 - 17 Ma por Dominical y 15 - $11 \mathrm{Ma}$ por Boruca (Cuadro 9). Sin embargo, los trabajos de campo posteriores realizados por el primer autor y otros colegas, evidencian que en el sector central y sur de la fila Costeña, se presentan abundantes cuerpos hipoabisales todavía no mapeados en toda su extensión, por lo que la aparente brecha en las edades podría deberse a la ausencia de dataciones de estos lugares, para lo que se requieren estudios radiométricos adicionales.

Cuerpos hipoabisales más recientes, los encontramos en la fila Costeña por China Kichá en el sill (?) diabásico del cerro Las Bolas (6,4 - 6,2 $\mathrm{Ma})$ y en un dique andesítico rico en plagioclasa con marcada estructura fluidal (6,1 Ma), presente en la quebrada La Danta (MacMillan et al., 2004). Ver cuadro 9.

Referente al intrusivo de Escazú, se reconoce una facies marginal gabroica y una central monzonítica (Obando, 1983, 1985), aunque también se reportan monzodioritas-adamelitas, cuarzomonzonitas, granodioritas, monzogabros, así como diabasas olivínicas, aplitas o monzodioritas cuarcíferas (Rivier, 1979; Kussmaul, 1987). Las edades $\mathrm{K} / \mathrm{Ar}$ dan un rango relativamente entre 6,30 y 5,33 Ma (Bergoeing, 1982; de Boer et al., 1995), siendo mucho más restringido con las ${ }^{40} \mathrm{Ar} /{ }^{39} \mathrm{Ar}$ entre 5,95 y $5,90 \mathrm{Ma}$ (presente trabajo). Ver cuadro 10.

El intrusivo de Guacimal, compuesto por granitos (predominantemente leucogranitos) hasta gabros, pasando por monzodioritas y monzogabros cuarzosos (Kussmaul, 1987; Žáček et al., 2011), pero sin tonalitas; al parecer se emplazó a $<5 \mathrm{~km}$ y a temperaturas de $715-800{ }^{\circ} \mathrm{C}$ (Žáček et al., 2011). Posee edades K/Ar, ${ }^{40} \mathrm{Ar} /{ }^{39} \mathrm{Ar}$ y U/Pb, que se agrupan a los 6,4 - 5,8 Ma y 5,6-5,2 Ma, estando la mayoría del traslape en 5,8 - 5,2 Ma (Schulz et al., 1987; Appel et al., 1994; Žáček et al., 2011; presente trabajo). Ver cuadro 10 .

Los plutones e hipoabisales alcalinos del Plioceno (Cuadros 34 y 35) serán tratados por aparte junto con sus equivalentes efusivos.

Las cuerpos plutónicos más recientes, corresponden con stocks de leucomonzogabros hasta microgabros monzoníticos aflorantes en Tapantí 


\section{Cuadro 8}

Dataciones radiométricas de las rocas plutónicas Neógenas de Talamanca

\begin{tabular}{|c|c|c|c|c|}
\hline MUESTRA & LITOLOGÍA & UBICACIÓN & $\operatorname{EDAD}(\mathrm{Ma})$ & REFERENCIA \\
\hline $78 \mathrm{~A}$ & Granito con hb & $\begin{array}{c}\text { R. Ceibo, H. Buenos Aires, } \\
540,163-359,157\end{array}$ & $\begin{array}{c}12,4 \pm 1,8(\mathrm{zfta}) \\
10,0 \pm 0,1(\mathrm{Rb} / \mathrm{Sr})\end{array}$ & $\begin{array}{c}\text { Gräfe (1998); Gräfe et al. } \\
\text { (2002) }\end{array}$ \\
\hline$?$ & Roca plutónica & $\begin{array}{l}\text { Cerca de División, H. Cueri- } \\
\text { cí, aprox. } 495,0-384,8\end{array}$ & $12,4 \pm 0,40(\mathrm{~K} / \mathrm{Ar})$ & $\begin{array}{l}\text { de Boer (1981, en de } \\
\text { Boer et al., 1995) }\end{array}$ \\
\hline CR-299 & Gabro & $\begin{array}{l}\text { Pequeña intrusión, C. Páramo, } \\
\text { H. Vueltas, 490,851-390,657 }\end{array}$ & $\begin{array}{c}11,70 \pm 0,20\left({ }^{40} \mathrm{Ar} /{ }^{39} \mathrm{Ar}:\right. \\
\text { plag })\end{array}$ & MacMillan et al. (2004) \\
\hline 22 & $\begin{array}{l}\text { Leucomonzodiorita } \\
\text { cuarzosa con } \mathrm{hb}\end{array}$ & $\begin{array}{c}\text { Cerca de San Gerardo, H. } \\
\text { San Isidro, 506,985-379,382 }\end{array}$ & $\begin{array}{l}11,4 \pm 1,4(\mathrm{zfta}) \\
8,4 \pm 0,1(\mathrm{Rb} / \mathrm{Sr})\end{array}$ & $\begin{array}{c}\text { Gräfe (1998); Gräfe et al. } \\
\text { (2002) }\end{array}$ \\
\hline CR-88-73 & Gabro & $\begin{array}{l}\text { C. Boruca, H. San Isidro, } \\
\text { aprox. 497,4-382,0 }\end{array}$ & $11,4 \pm 0,6(\mathrm{~K} / \mathrm{Ar})$ & $\begin{array}{l}\text { Berrangé \& Whittaker } \\
\text { (1977) }\end{array}$ \\
\hline$?$ & Roca plutónica & $\begin{array}{l}\text { Cerca de División, H. Cueri- } \\
\text { cí, aprox. 495,3-384,0 }\end{array}$ & $11,2 \pm 0,27(\mathrm{~K} / \mathrm{Ar})$ & $\begin{array}{l}\text { de Boer (1981, en de } \\
\text { Boer et al., 1995) }\end{array}$ \\
\hline CR13M & Monzonita cuarcífera & $\begin{array}{l}\text { Finca Helechales, H. Ca- } \\
\text { bagra, aprox. 564,6-336,3 }\end{array}$ & $11,05 \pm 0,31(\mathrm{~K} / \mathrm{Ar})$ & $\begin{array}{l}\text { de Boer et al. (1995); } \\
\text { Drummond et al. (1995) }\end{array}$ \\
\hline 77 & $\begin{array}{l}\text { Leucomonzonita } \\
\text { cuarzosa }\end{array}$ & $\begin{array}{c}\text { R. Kuiyé, H. Buenos Aires, } \\
541,113-355,379\end{array}$ & $10,9 \pm 2,0(\mathrm{zfta})$ & $\begin{array}{c}\text { Gräfe (1998); Gräfe et al. } \\
\text { (2002) }\end{array}$ \\
\hline 48 & $\begin{array}{l}\text { Leucomonzodiorita } \\
\text { cuarzosa con } \mathrm{hb}\end{array}$ & $\begin{array}{c}\text { Confluencia R. Chirripó } \\
\text { Pacífico con R. Talari, H. San } \\
\text { Isidro, 506,924-378,737 }\end{array}$ & $\begin{array}{c}10,7 \pm 2,0 \text { (zfta) } \\
8,7 \pm 0,2 \\
\left({ }^{40} \mathrm{Ar}{ }^{39} \mathrm{Ar}: \mathrm{hb}\right) \\
8,6 \pm 0,1\left({ }^{40} \mathrm{Ar}{ }^{\beta 9} \mathrm{Ar}: \text { biot }\right) \\
8,5 \pm 0,4(\mathrm{Rb} / \mathrm{Sr})\end{array}$ & $\begin{array}{c}\text { Gräfe (1998); Gräfe et al. } \\
\text { (2002) }\end{array}$ \\
\hline$?$ & Roca plutónica & $\begin{array}{l}\text { Cerca de División, H. Cueri- } \\
\text { cí, aprox. 496,0-383,5 }\end{array}$ & $10,7 \pm 0,35(\mathrm{~K} / \mathrm{Ar})$ & $\begin{array}{l}\text { de Boer (1981, en de } \\
\text { Boer et al., 1995) }\end{array}$ \\
\hline $55 \mathrm{~A}$ & Leucogranodiorita & $\begin{array}{c}\text { F. Cementerio de la Máquina, } \\
\text { H. San Isidro, } 509,334- \\
379,474\end{array}$ & $\begin{array}{c}10,6 \pm 2,2(\mathrm{zfta}) \\
7,5 \pm 0,1\left({ }^{40} \mathrm{Ar} /{ }^{39} \mathrm{Ar}: \text { biot }\right)\end{array}$ & $\begin{array}{c}\text { Gräfe (1998); Gräfe et al. } \\
\text { (2002) }\end{array}$ \\
\hline 55 & Leucogranodiorita & $\begin{array}{l}\text { F. Cementerio de la Máquina, } \\
\text { H. San Isidro, 509,340- } \\
379,471\end{array}$ & $\begin{array}{c}10,3 \pm 1,6(\mathrm{zfta}) \\
7,9 \pm 0,1\left({ }^{40} \mathrm{Ar}{ }^{39} \mathrm{Ar}: \mathrm{hb}\right)\end{array}$ & $\begin{array}{c}\text { Gräfe (1998); Gräfe et al. } \\
\text { (2002) }\end{array}$ \\
\hline CR9 & Canto de granodiorita & $\begin{array}{l}\text { Buenos Aires, H. Buenos } \\
\text { Aires, aprox. 537,0-347,0 }\end{array}$ & $10,37 \pm 0,21(\mathrm{~K} / \mathrm{Ar})$ & $\begin{array}{l}\text { de Boer et al. (1995); } \\
\text { Drummond et al. (1995) }\end{array}$ \\
\hline$?$ & Roca plutónica & $\begin{array}{c}\text { Cerca de División, H. Cueri- } \\
\text { cí, aprox. } \\
496,0-383,5\end{array}$ & $10,3 \pm 0,21(\mathrm{~K} / \mathrm{Ar})$ & $\begin{array}{l}\text { de Boer (1981, en de } \\
\text { Boer et al., 1995) }\end{array}$ \\
\hline CR10 & $\begin{array}{l}\text { Canto de monzonita } \\
\text { cuarcífera }\end{array}$ & $\begin{array}{c}\text { Por Cañas de Buenos Aires, } \\
\text { H. Buenos Aires, aprox. } \\
527,5-350,0\end{array}$ & $10,22 \pm 0,20(\mathrm{~K} / \mathrm{Ar})$ & $\begin{array}{l}\text { de Boer et al. (1995); } \\
\text { Drummond et al. (1995) }\end{array}$ \\
\hline 59 & Tonalita & $\begin{array}{l}\text { C. Pirámide, H. Durika, } \\
\text { 519,521-381,014 }\end{array}$ & $10,1 \pm 1,8(\mathrm{zfta})$ & $\begin{array}{c}\text { Gräfe (1998); Gräfe et al. } \\
\text { (2002) }\end{array}$ \\
\hline 79 & $\begin{array}{l}\text { Lecucomonzodiorita } \\
\text { cuarzosa }\end{array}$ & $\begin{array}{c}\text { Cerro entre los ríos Chubugra } \\
\text { y Kuiye, H. Buenos Aires, } \\
543,489-360,051\end{array}$ & $10,1 \pm 1,2(\mathrm{zfta})$ & $\begin{array}{c}\text { Gräfe (1998); Gräfe et al. } \\
\text { (2002) }\end{array}$ \\
\hline
\end{tabular}


Cuadro 8 (continuación)

Dataciones radiométricas de las rocas plutónicas Neógenas de Talamanca

\begin{tabular}{|c|c|c|c|c|}
\hline MUESTRA & LITOLOGÍA & UBICACIÓN & $\operatorname{EDAD}(\mathrm{Ma})$ & REFERENCIA \\
\hline TA-1 & Leucogranófiro & $\begin{array}{l}\text { División, H. Cuericí, 495,3- } \\
\text { 384,0 }\end{array}$ & $10,1 \pm 0,5(\mathrm{~K} / \mathrm{Ar})$ & $\begin{array}{l}\text { Bellon \& Tournon, } \\
\text { (1978) }\end{array}$ \\
\hline 78 & $\begin{array}{l}\text { Lecucomonzonita } \\
\text { cuarzosa }\end{array}$ & $\begin{array}{c}\text { Queb. afluente R. Ceibo, H. } \\
\text { Buenos Aires, 540,527-360,847 }\end{array}$ & $\begin{array}{c}10,0 \pm 1,2(\mathrm{zfta}) \\
10,1 \pm 0,1(\mathrm{Rb} / \mathrm{Sr})\end{array}$ & $\begin{array}{c}\text { Gräfe (1998); Gräfe et al. } \\
\text { (2002) }\end{array}$ \\
\hline 80 & Granito & $\begin{array}{l}\text { Alto Helechales, H. Buenos } \\
\text { Aires, 530,641-358,810 }\end{array}$ & $\begin{array}{c}9,9 \pm 0,1(\mathrm{Rb} / \mathrm{Sr}) \\
9,4 \pm 1,4(\mathrm{zfta})\end{array}$ & $\begin{array}{c}\text { Gräfe (1998); Gräfe et al. } \\
\text { (2002) }\end{array}$ \\
\hline CR-090 & Granodiorita & $\begin{array}{l}\text { Ujarraz, confluencia ríos } \\
\text { Ceibo y Kuiyé, H. Buenos } \\
\text { Aires, 541,950-355,750 }\end{array}$ & $\begin{array}{c}9,90 \pm 0,10\left({ }^{40} \mathrm{Ar} /{ }^{39} \mathrm{Ar}:\right. \\
\mathrm{kfd})\end{array}$ & MacMillan et al. (2004) \\
\hline CR8B & Gabro & $\begin{array}{l}\text { C. Kai H. Kámuk, } \\
548,5-359,2\end{array}$ & $9,83 \pm 0,23(\mathrm{~K} / \mathrm{Ar})$ & $\begin{array}{l}\text { de Boer et al. (1995); } \\
\text { Drummond et al. (1995) }\end{array}$ \\
\hline CR-87B-73 & $\begin{array}{l}\text { Roca plutónica rica } \\
\text { en hb }\end{array}$ & $\begin{array}{l}\text { Cerca Corte Fuentes, H. Cue- } \\
\text { ricí, aprox. 494,8-387,8 }\end{array}$ & $9,8 \pm 0,4$ (K/Ar: plag) & $\begin{array}{c}\text { Berránge \& Whittaker } \\
\text { (1977) }\end{array}$ \\
\hline CR-87-73 & Diorita con hb & $\begin{array}{l}\text { Cerca Corte Fuentes, H. Cue- } \\
\text { ricí, aprox. 494,8-388,4 }\end{array}$ & $9,6 \pm 0,4$ (K/Ar: kfd) & $\begin{array}{c}\text { Berránge \& Whittaker } \\
\text { (1977) }\end{array}$ \\
\hline$?$ & Roca plutónica & $\begin{array}{l}\text { Cerca de División, H. Cueri- } \\
\text { cí, aprox. 496,2-383,4 }\end{array}$ & $9,4 \pm 0,28(\mathrm{~K} / \mathrm{Ar})$ & $\begin{array}{l}\text { de Boer (1981, en de } \\
\text { Boer et al., 1995) }\end{array}$ \\
\hline$?$ & Roca plutónica & $\begin{array}{l}\text { Cerca de División, H. Cueri- } \\
\text { cí, aprox. 496,1E-383,3 }\end{array}$ & $9,3 \pm 0,34(\mathrm{~K} / \mathrm{Ar})$ & $\begin{array}{l}\text { de Boer (1981, en de } \\
\text { Boer et al., 1995) }\end{array}$ \\
\hline $14-3-90$ & Diorita & $\begin{array}{l}3,7 \mathrm{~km} \text { aguas arriba de la } \\
\text { confluencia del Talari con el } \\
\text { R. Chirripó Pacífico, H. San } \\
\text { Isidro, } 509,8-378,4\end{array}$ & $9,3 \pm 0,18(\mathrm{~K} / \mathrm{Ar})$ & $\begin{array}{l}\text { de Boer et al. (1995); } \\
\text { Drummond et al. (1995) }\end{array}$ \\
\hline CR-87A-73 & $\begin{array}{c}\text { Roca plutónica rica en } \\
\text { biot. }\end{array}$ & $\begin{array}{l}\text { Siberia, H. Cuericí, aprox. } \\
\qquad 494,8-389,0\end{array}$ & $9,3 \pm 0,3$ (K/Ar: kfd) & $\begin{array}{c}\text { Berrangé \& Whittaker } \\
\text { (1977) }\end{array}$ \\
\hline 57 & $\begin{array}{l}\text { Leucomonzodiorita } \\
\text { cuarzosa }\end{array}$ & $\begin{array}{c}\text { C. Piedra Pintada, H. Siola, } \\
565,979-379,466\end{array}$ & $9,2 \pm 1,0(\mathrm{zfta})$ & $\begin{array}{c}\text { Gräfe (1998); Gräfe et al. } \\
\text { (2002) }\end{array}$ \\
\hline 20 & Tonalita & $\begin{array}{l}\text { F. Cementerio de la Máquina, H. } \\
\text { San Isidro, } 510.218 \mathrm{E}-379.106 \mathrm{~N}\end{array}$ & $9,1 \pm 1,2(\mathrm{zfta})$ & $\begin{array}{c}\text { Gräfe (1998); Gräfe et al. } \\
\text { (2002) }\end{array}$ \\
\hline 49 & Diorita cuarcífera & $\begin{array}{c}\text { División, H. Cuericí, aprox. } \\
\text { 494,9-385,0 }\end{array}$ & $8,5 \pm 0,4(\mathrm{~K} / \mathrm{Ar})$ & Bellon \& Tournon (1978) \\
\hline 58 & $\begin{array}{l}\text { Leucomonzodiorita } \\
\text { cuarzosa }\end{array}$ & $\begin{array}{l}\text { C. Chirripó, H. Durika, } \\
\text { 519,582-381,536 }\end{array}$ & $8,4 \pm 1,2(\mathrm{zfta})$ & $\begin{array}{c}\text { Gräfe (1998); Gräfe et al. } \\
\text { (2002) }\end{array}$ \\
\hline CR-305 & $\begin{array}{l}\text { Granodiorita con hb } \\
\text { y biot. }\end{array}$ & $\begin{array}{c}\text { San Gerardo, H. San Isidro, } \\
507,320-379,597\end{array}$ & $\begin{array}{c}8,30 \pm 0,20\left({ }^{40} \mathrm{Ar} /{ }^{39} \mathrm{Ar}:\right. \\
\text { biot }) \\
7,80 \pm 0,10\left(\left(^{40} \mathrm{Ar} /{ }^{\beta 9} \mathrm{Ar}: \mathrm{kfd}\right)\right.\end{array}$ & MacMillan et al. (2004) \\
\hline KAM-066 & $\begin{array}{l}\text { Bloque de granodiorita } \\
\text { con cloritas secundarias }\end{array}$ & $\begin{array}{l}\text { Flanco C. Kámuk, H. Ká- } \\
\text { muk, aprox. 567,0-357,0 }\end{array}$ & $\begin{array}{l}7,9 \pm 0,9 \text { (K/Ar: biot: } 9,2 \\
\pm 1,2 \text { ) (plag: } 30,1 \pm 0,9)\end{array}$ & $\begin{array}{c}\text { Appel (1990), Appel et } \\
\text { al. (1994) }\end{array}$ \\
\hline $18-3-90$ & Diorita & C. Chirripó H. Durika, 520,1-381,9 & $7,81 \pm 0,31(\mathrm{~K} / \mathrm{Ar})$ & $\begin{array}{l}\text { de Boer et al. (1995); } \\
\text { Drummond et al. (1995) }\end{array}$ \\
\hline CR-304 & Granodiorita & $\begin{array}{l}\text { F. Cementerio de la Máquina, } \\
\text { H. San Isidro, 507,320-379,597 }\end{array}$ & $7,80 \pm 0,10\left({ }^{40} \mathrm{Ar} /{ }^{\beta 9} \mathrm{Ar}: \mathrm{hb}\right)$ & MacMillan et al. (2004) \\
\hline
\end{tabular}


( 4,2 - 3,9 Ma), Desmonte (3,5 Ma) y en la Carpintera $(2,2 \pm 0,63 \mathrm{Ma})$ (Bellon \& Tournon, 1978; Bergoeing, 1982, presente trabajo).

La historia intrusiva puede resumirse a:

a. Stocks aislados en el núcleo de Talamanca, edad por verificarse: ¿35,6 - 18,8 Ma?

b. Stock de Boca Tapada, en las llanuras de San Carlos: ¿22 - 17 Ma?

c. Stocks, sills y diques de Puerto Nuevo: 18,3 - 16,8 Ma y 14,8 - 11,1 Ma.

d. Batolitos y stocks de Talamanca: 12,4 - 7,8 Ma.

e. Stocks, sills y apófisis en la fila Costeña: 6,4 - 6,1 Ma.

f. Stock de Escazú: 6,0 - 5,9 Ma.

g. Stocks, diques y sills alcalinos: 6,49 - 4,4 Ma.

h. Stock de Guacimal: 6,4 - 5,2 Ma, predominantemente entre 5,8 y 5,2 Ma.

i. El batolito de Tapantí y los stocks de Desmonte y la Carpintera: 4,2 - 2,2 Ma.

\section{Vulcanismo en la cordillera de Talamanca}

Mientras que el plutonismo en la cordillera de Talamanca está relativamente bien estudiado, aunque no con detalle dentro de los propios cuerpos plutónicos, no así lo está el vulcanismo, que es más desconocido. Es más, existe la predisposición estratigráfica a que la mayoría de las rocas volcánicas por default, deben de ser más jóvenes que las intrusivas, conclusión muchas veces sin soporte sólido de campo (ver Alvarado \& Aguilar, 2008). Contrariamente, existen sin lugar a dudas rocas volcánicas (lavas y cuerpos hipoabisales) contemporáneas con la sedimentación y con el tectonismo antiguo, evidencia de lo cual no solo son las propias dataciones radiométricas, sino el hecho de estar tectónicamente basculadas en la misma dirección que las secuencias sedimentarias antiguas y por el hecho de presentar localmente peperitas en sus contactos. En algunos sectores de Talamanca, incluso las lavas están intruidas por diques diabásicos y stocks gabroicos-granitoides del Mioceno Superior. Por ello, la edad de una buena parte del vulcanismo tiene que ser mayor que la de los intrusivos y coetánea con la sedimentación. Ya esta conclusión había sido externada por Malavassi et al. (1971). Estudios de detalle de campo y de los contactos son fundamentales, y no puede asumirse que un cuerpo es una colada de lava simplemente por el hecho de que tenga textura lávica.

Afloramientos aislados de lavas antiguas los tenemos para un basalto cerca de La Ese $(21,61$ \pm 1,08 Ma; Jackson, 1991; de Boer et al., 1995), en Alturas, cerca de Panamá (16,87 Ma) y el vitrófiro del Jaboncillo (11,98 Ma, MacMillan et al., 2004). Justo las lavas del Jaboncillo están cortadas por un dique basáltico alterado, similar a otros que afloran cerca del cerro Buena Vista (Malavassi et al., 1971). Una andesita vitrofírica por el cerro Páramo (11,80 Ma, MacMillan et al., 2004) y un posible rodado de dacita vidriosa colectado en la confluencia del río General con el Pacuar (11,79 Ma, Jackson, 1991), nos hablan de eventos de andesitas ácidas-dacitas alrededor de 12 - 11,8 Ma. Las rocas muy sanas allá expuestas, no fueron afectadas por la alteración hidrotermal y su posición geopetal no es fácil de establecerse posiblemente por tratarse de cuerpos subvolcánicos someros (criptodomos?). La mayoría de las lavas y diques andesíticos hasta basálticos poseen edades comprendidas entre 14,10 y $8,3 \mathrm{Ma}$, con una clara concentración entre 13 y $11 \mathrm{Ma}$ (Cuadro 11).

En general, se observa que el vulcanismo subalcalino antiguo, hoy día expuesto como cuerpos lávicos, se concentra en dos fases eruptivas: a) 21 - 17 Ma y b) $14,1-8,3 \mathrm{Ma}$, por lo que fue ligeramente anterior y contemporáneo a los grandes cuerpos intrusivos (12,4 - 7,8 Ma). Rocas sedimentaria detríticas, también reportan la existencia de dicho vulcanismo andesítico (Yuan, 1984).

Un vulcanismo más reciente, post-plutónico, está representado por basaltos hasta dacitas, algunas con anfíbol y biotita, agrupadas dentro del término adakitas, término bajo discusión en la nomenclatura petrológica. Estos magmas se interpretan como derivados de la fusión parcial de la placa subducida y su subsecuente reacción con los 
Cuadro 9

Dataciones radiométricas de las rocas ígneas Neógenas sin-intrusivas de la fila Costeña

\begin{tabular}{|c|c|c|c|c|}
\hline MUESTRA & LITOLOGÍA & UBICACIÓN & $\operatorname{EDAD}(\mathrm{Ma})$ & REFERENCIA \\
\hline \multicolumn{5}{|c|}{ PLUTONES E HIPOABISALES DE PUERTO NUEVO } \\
\hline TC-10a & Dique andesítico & $\begin{array}{l}\text { Dominical, Q. Grande, cerca de P. Uvi- } \\
\text { ta, H. Coronado, 494,390-343,005 }\end{array}$ & $\begin{array}{c}18,32 \pm 0,33 \\
\left({ }^{40} \mathrm{Ar} /{ }^{/ 9} \mathrm{Ar}: \text { plag }\right)\end{array}$ & Gazel et al. (2009) \\
\hline CR-094 & Gabro & $\begin{array}{l}\text { Entre P. Q. Grande y P. Chimenea, H. } \\
\quad \text { Coronado, } 494,250-342,250\end{array}$ & $\begin{array}{c}17,50 \pm 0,10 \\
\left({ }^{40} \mathrm{Ar} /{ }^{39} \mathrm{Ar}: \text { plag }\right)\end{array}$ & $\begin{array}{l}\text { MacMillan et al. } \\
\text { (2004) }\end{array}$ \\
\hline \multirow[t]{2}{*}{ DOM-028 } & Rodado de dolerita & $\begin{array}{l}\text { Q. al sur de P. Puertecito, Dominical, } \\
\text { H. Dominical, } 484,5-350,8\end{array}$ & $16,8 \pm 1,1(\mathrm{~K} / \mathrm{Ar})$ & Appel (1990) \\
\hline & Gabro? & $\begin{array}{c}\text { Sitio de Presa de Boruca, H. Chángüe- } \\
\text { na, aprox. 537,5-323,1 }\end{array}$ & $14,8(\mathrm{~K} / \mathrm{Ar})$ & $\begin{array}{l}\text { Woorward-Clyde } \\
\text { (1980, en de Boer et } \\
\text { al., 1995) }\end{array}$ \\
\hline CR-087 & Basalto & $\begin{array}{l}\text { Sabana de Mano de Tigre, H. General, } \\
\qquad 542,145-331,695\end{array}$ & $\begin{array}{c}14,10 \pm 0,15 \\
\left({ }^{40} \mathrm{Ar} /{ }^{39} \mathrm{Ar}: \mathrm{mtz}\right)\end{array}$ & $\begin{array}{l}\text { MacMillan et al. } \\
\text { (2004) }\end{array}$ \\
\hline & & & $\begin{array}{c}14,07 \pm 0,12 \\
\left({ }^{40} \mathrm{Ar} /{ }^{39} \mathrm{Ar}: \text { plag }\right)\end{array}$ & \\
\hline$?$ & Gabro? & $\begin{array}{l}\text { Sitio de Presa de Boruca, H. Chángüe- } \\
\text { na, aprox. 537,5-323,1 }\end{array}$ & $13,1(\mathrm{~K} / \mathrm{Ar})$ & $\begin{array}{l}\text { Woorward-Clyde } \\
\text { (1980, en de Boer et } \\
\text { al., 1995) }\end{array}$ \\
\hline CR-084 & Gabro & $\begin{array}{l}\text { Ca. Interamericana, cerca de Pto. Nue- } \\
\text { vo, H. Chángüena, 539,6-325,0 }\end{array}$ & $\begin{array}{c}12,80 \pm 0,10 \\
\left({ }^{40} \mathrm{Ar}{ }^{39} \mathrm{Ar}: \text { plag }\right)\end{array}$ & $\begin{array}{l}\text { MacMillan et al. } \\
\qquad(2004)\end{array}$ \\
\hline CR-093 & $\begin{array}{l}\text { Dique andesítico } \\
\text { porfirítico }\end{array}$ & $\begin{array}{l}\text { Alto Montura, H. Chángüena, } \\
525,657-326,152\end{array}$ & $\begin{array}{c}11,76 \pm 0,12 \\
\left({ }^{40} \mathrm{Ar} /{ }^{39} \mathrm{Ar}: \text { plag }\right)\end{array}$ & $\begin{array}{l}\text { MacMillan et al. } \\
\qquad(2004)\end{array}$ \\
\hline$?$ & Gabro? & $\begin{array}{l}\text { Sitio de Presa de Boruca, H. Chángüe- } \\
\text { na, aprox. 537,5-323,1 }\end{array}$ & $11,6(\mathrm{~K} / \mathrm{Ar})$ & $\begin{array}{c}\text { Woorward-Clyde } \\
\text { (1980, en de Boer et } \\
\text { al., 1995) }\end{array}$ \\
\hline$?$ & Gabro? & $\begin{array}{l}\text { Sitio de Presa de Boruca, H. Chángüe- } \\
\text { na, aprox. 537,5-323,1 }\end{array}$ & $11,1(\mathrm{~K} / \mathrm{Ar})$ & $\begin{array}{c}\text { Heywood (1984, en de } \\
\text { Boer et al., 1995) }\end{array}$ \\
\hline \multicolumn{5}{|c|}{ HIPOABISALES DEL CERRO LAS BOLAS } \\
\hline CR-076 & Diabasa o basalto & $\begin{array}{l}\text { C. Las Bolas, Q. Los Congos, Pueblo } \\
\text { Nuevo, H. General, 522,6-342,5 }\end{array}$ & $\begin{array}{c}6,40 \pm 0,10 \\
\left({ }^{40} \mathrm{Ar} /{ }^{39} \mathrm{Ar}: \mathrm{mtz}\right)\end{array}$ & $\begin{array}{l}\text { MacMillan et al. } \\
\text { (2004) }\end{array}$ \\
\hline CR-074B & Diabasa o basalto & $\begin{array}{l}\text { C. Las Bolas, naciente Q. Las Bolas, H. } \\
\text { General, 520,5-341,2 }\end{array}$ & $\begin{array}{c}6,25 \pm 0,10 \\
\left({ }^{40} \mathrm{Ar} /{ }^{39} \mathrm{Ar}: \mathrm{mtz}\right)\end{array}$ & $\begin{array}{l}\text { MacMillan et al. } \\
\text { (2004) }\end{array}$ \\
\hline CR-077 & $\begin{array}{c}\text { Dique andesítico } \\
\text { porfirítico rico en } \\
\text { plagioclasa }\end{array}$ & $\begin{array}{l}\text { Q. La Danta, } 350 \mathrm{~m} \text { al NE de la laguna, } \\
\text { H. General, 524,2-341,0 }\end{array}$ & $\begin{array}{c}6,12 \pm 0,02 \\
\left({ }^{40} \mathrm{Ar}{ }^{39} \mathrm{Ar}: \text { plag }\right)\end{array}$ & $\begin{array}{l}\text { MacMillan et al. } \\
\text { (2004) }\end{array}$ \\
\hline
\end{tabular}

fluidos de la cuña astenosférica metasomatizada (Defant et al., 1992; Gazel et al., 2011 y referencias allí citadas). Estas rocas se presentan en la zona sur, al parecer en varios pulsos eruptivos que produjeron coladas de lava, domos e inclusive pequeños estratovolcanes, hoy día fuertemente derruidos por erosión y estructuras de colapso sectorial con desarrollo de depósitos de debris avalanches y sus facies de retrabajo fluvial (p.ej., San Vito de Java). Las edades de las lavas (domos, coladas y bloques) se ubican mayoritariamente entre los 4,23 y los 0,95 Ma (Bellon \& Tournon, 1978; Tournon, 1984; Jackson, 1991; Defant et al., 1992; de Boer et al., 1995; Drummond et al., 1995; Abratis, 1998; MacMillan et al., 2004; Gazel et al., 2011; presente trabajo). Ver cuadro 12. 
Cuadro 10

Dataciones radiométricas de las rocas intrusivas (plutónicas e hipoabisales) Neógenas desde Dota a Guacimal

\begin{tabular}{|c|c|c|c|c|}
\hline MUESTRA & LITOLOGÍA & UBICACIÓN & $\operatorname{EDAD}(\mathrm{Ma})$ & REFERENCIA \\
\hline \multicolumn{5}{|c|}{ INTRUSIVO DE TALAMANCA POR TAPANTÍ } \\
\hline CR-86-73 & $\begin{array}{l}\text { Diorita o gabro } \\
\text { rico en } \mathrm{hb}\end{array}$ & $\begin{array}{c}\text { Sitio presa Tapantí, H. Tapantí, aprox. } \\
\qquad 185,9-563,2\end{array}$ & $\begin{array}{c}11,5 \pm 0,5(\mathrm{~K} / \mathrm{Ar}: \\
\text { plag })\end{array}$ & $\begin{array}{c}\text { Berrangé \& Whittaker } \\
\text { (1977) }\end{array}$ \\
\hline \multicolumn{5}{|c|}{ INTRUSIVO DE DOTA-CANDELARIA } \\
\hline CR-248 & Granodiorita & $\begin{array}{c}\text { Flanco WNW C. Vueltas, R. Pedrego- } \\
\text { so, H. Vueltas, } \\
476,644-396,561\end{array}$ & $\begin{array}{c}10,60 \pm 0,10 \\
\left({ }^{40} \mathrm{Ar} /{ }^{39} \mathrm{Ar}: \mathrm{kfd}\right)\end{array}$ & $\begin{array}{l}\text { MacMillan et al. } \\
\qquad(2004)\end{array}$ \\
\hline CR-227 & $\begin{array}{l}\text { Granodiorita con } \\
\mathrm{hb}+\text { biot }\end{array}$ & $\begin{array}{l}\text { Buenavista, cerca R. Grande de Cande- } \\
\text { laria, H. Caraigres, 523,772-194,410 }\end{array}$ & $\begin{array}{l}9,30 \pm 0,30\left(\left(^{40} \mathrm{Ar} /{ }^{\beta 9} \mathrm{Ar}: \text { biot }\right)\right. \\
8,90 \pm 0,04\left({ }^{40} \mathrm{Ar}{ }^{\beta 9} \mathrm{Ar}: \mathrm{kfd}\right)\end{array}$ & $\begin{array}{l}\text { MacMillan et al. } \\
\qquad(2004)\end{array}$ \\
\hline $\begin{array}{l}\text { BREN-1 } \\
(\mathrm{B}-4)\end{array}$ & $\begin{array}{l}\text { Leucomonzoga- } \\
\text { bro cuarcífero } \\
\text { con } \mathrm{hb}\end{array}$ & $\begin{array}{l}\text { Santa María de Dota, H. Vueltas, } \\
\text { aprox. 541,866-182,080 }\end{array}$ & $9,13 \pm 0,33(\mathrm{~K} / \mathrm{Ar})$ & Bergoeing (1982) \\
\hline CR-226 & $\begin{array}{l}\text { Sill granofírico } \\
\quad \text { (granito) }\end{array}$ & $\begin{array}{l}\text { Santa María de Dota, H. Vueltas, } \\
\text { aprox. } 541,866-182,080\end{array}$ & $\begin{array}{c}8,80 \pm 0,03\left({ }^{40} \mathrm{Ar} /{ }^{39} \mathrm{Ar}:\right. \\
\mathrm{kfd})\end{array}$ & $\begin{array}{l}\text { MacMillan et al. } \\
\qquad(2004)\end{array}$ \\
\hline CR-225 & $\begin{array}{l}\text { Granodiorita con } \\
\mathrm{hb}+\mathrm{biot}\end{array}$ & $\begin{array}{l}\text { Santa María de Dota, H. Vueltas, } \\
\text { aprox. 541,866-182,080 }\end{array}$ & $\begin{array}{c}8,90 \pm 0,04\left({ }^{40} \mathrm{Ar} /{ }^{39} \mathrm{Ar}:\right. \\
\mathrm{kfd}) \\
8,68 \pm 0,02\left({ }^{40} \mathrm{Ar} /{ }^{39} \mathrm{Ar}:\right. \\
\text { biot })\end{array}$ & $\begin{array}{l}\text { MacMillan et al. } \\
\text { (2004) }\end{array}$ \\
\hline \multicolumn{5}{|c|}{ INTRUSIVO DE GUACIMAL } \\
\hline GUA-011 & Diorita cuarcífera & $\begin{array}{l}\text { Q. Machos, Mina La Unión, H. Mira- } \\
\text { mar, 457,2-237,6 }\end{array}$ & $7,2 \pm 1,4(\mathrm{~K} / \mathrm{Ar})$ & $\begin{array}{l}\text { Appel (1990), Appel } \\
\quad \text { et al. (1994) }\end{array}$ \\
\hline Ju311 & $\begin{array}{l}\text { Leucogranodiorita } \\
\text { con hb y biotita }\end{array}$ & C. San Antonio, H. Juntas, 451,4-246,5 & $6,3 \pm 0,5(\mathrm{U} / \mathrm{Pb}: \mathrm{zir})$ & Žáček et al. (2011) \\
\hline Ju346 & $\begin{array}{l}\text { Leucogranito con } \\
\text { flogopita y hb }\end{array}$ & $\begin{array}{l}\text { San Martín Norte, afluente Q. Chan- } \\
\text { chera, H. Juntas, 454,108-246,443 }\end{array}$ & $6,0 \pm 0,4(\mathrm{U} / \mathrm{Pb}:$ zir $)$ & Žáček et al. (2011) \\
\hline CR-172 & Roca plutónica & $\begin{array}{l}\text { Margen derecha R. Aranjuez, por } \\
\text { Claraboya, H. Juntas, aprox. 452,500- } \\
239,300\end{array}$ & $\begin{array}{c}5,59 \pm 0,04\left({ }^{40} \mathrm{Ar} /{ }^{39} \mathrm{Ar}:\right. \\
\text { biot })\end{array}$ & Presente trabajo \\
\hline & & & $\begin{array}{c}5,40 \pm 0,10\left({ }^{40} \mathrm{Ar} /{ }^{39} \mathrm{Ar}:\right. \\
\mathrm{kfd})\end{array}$ & \\
\hline CR-176 & Canto granítico & $\begin{array}{l}\text { R. Aranjuez, H. Chapernal, 447,575- } \\
\qquad 231,550\end{array}$ & $\begin{array}{c}5,30 \pm 0,20\left({ }^{40} \mathrm{Ar} /{ }^{39} \mathrm{Ar}:\right. \\
\mathrm{kfd})\end{array}$ & Presente trabajo \\
\hline CR062ASL & Roca plutónica & $\begin{array}{l}\text { Bajo Caliente, H. San Lorenzo, 456,5- } \\
\qquad 242,6\end{array}$ & $5,0 \pm 0,2(\mathrm{~K} / \mathrm{Ar}: \mathrm{kfd})$ & Schulz et al. (1987) \\
\hline \multicolumn{5}{|c|}{ INTRUSIVO DE ESCAZÚ } \\
\hline CR-34 & $\begin{array}{l}\text { Leucomonzo- } \\
\text { diorita }\end{array}$ & $\begin{array}{l}\text { Cerros de Escazú, H. Abra, aprox. } \\
\text { 523,0-207,0 }\end{array}$ & $6,30 \pm 0,24(\mathrm{~K} / \mathrm{Ar})$ & $\begin{array}{l}\text { de Boer et al. (1995); } \\
\text { Drummond et al. } \\
\text { (1995) }\end{array}$ \\
\hline CR-316 & Granodiorita & $\begin{array}{l}\text { Cerros de Escazú, H. Abra, aprox. } \\
\text { 523,0-206,3 }\end{array}$ & $\begin{array}{c}5,95 \pm 0,05\left({ }^{40} \mathrm{Ar} /{ }^{39} \mathrm{Ar}:\right. \\
\text { biot })\end{array}$ & Presente trabajo \\
\hline & & & $\begin{array}{c}5,90 \pm 0,10\left({ }^{40} \mathrm{Ar} /{ }^{39} \mathrm{Ar}:\right. \\
\mathrm{kfd})\end{array}$ & \\
\hline
\end{tabular}


Cuadro 10 (continuación)

Dataciones radiométricas de las rocas intrusivas (plutónicas e hipoabisales) Neógenas desde Dota a Guacimal

\begin{tabular}{|c|c|c|c|c|}
\hline MUESTRA & LITOLOGÍA & UBICACIÓN & $\operatorname{EDAD}(\mathrm{Ma})$ & REFERENCIA \\
\hline 72 & $\begin{array}{l}\text { Leucomonzoga- } \\
\text { bro con augita } \\
\text { transición a mon- } \\
\text { zodiorita }\end{array}$ & $\begin{array}{c}\text { Flanco E del Cerro La Cruz, H. Abra, } \\
\text { aprox. 523,0-206,2 }\end{array}$ & $5,33 \pm 0,61(\mathrm{~K} / \mathrm{Ar})$ & Bergoing (1982) \\
\hline \multicolumn{5}{|c|}{ INTRUSIVO DE TAPANTÍ } \\
\hline CR-223 & $\begin{array}{l}\text { Bloque de gabro } \\
\text { hornbléndico }\end{array}$ & $\begin{array}{l}\text { R. Grande de Orosi, Tapantí, H. Tapan- } \\
\text { tí, } 558,518-194,452\end{array}$ & $\begin{array}{c}4,20 \pm 0,30\left({ }^{40} \mathrm{Ar} /{ }^{39} \mathrm{Ar}:\right. \\
\mathrm{hb})\end{array}$ & $\begin{array}{l}\text { MacMillan et al. } \\
\text { (2004) }\end{array}$ \\
\hline \multirow[t]{2}{*}{ CR-221 } & $\begin{array}{l}\text { Bloque de } \\
\text { granodiorita con } \\
\text { hb+biot }\end{array}$ & $\begin{array}{l}\text { R. Grande de Orosi, Tapantí, H. Tapan- } \\
\text { tí, } 558,518-194,452\end{array}$ & $\begin{array}{c}4,08 \pm 0,02\left({ }^{40} \mathrm{Ar} /{ }^{39} \mathrm{Ar}:\right. \\
\mathrm{kfd})\end{array}$ & $\begin{array}{l}\text { MacMillan et al. } \\
\text { (2004) }\end{array}$ \\
\hline & & & $\begin{array}{c}3,89 \pm 0,02\left({ }^{40} \mathrm{Ar} /{ }^{39} \mathrm{Ar}:\right. \\
\text { biot })\end{array}$ & \\
\hline \multicolumn{5}{|c|}{ INTRUSIVO DE DESMONTE-CARPINTERA } \\
\hline CR-158 & Monzogabro & $\begin{array}{c}\text { Ca. Atenas-Desmonte, H. Río Grande, } \\
485,914-216,200\end{array}$ & $\begin{array}{c}3,50 \pm 0,10\left({ }^{40} \mathrm{Ar} /{ }^{39} \mathrm{Ar}:\right. \\
\mathrm{kfd})\end{array}$ & Presente trabajo \\
\hline A1 & $\begin{array}{l}\text { Leucomonzo- } \\
\text { gabro }\end{array}$ & $\begin{array}{c}\text { Finca "El Banco", entre Alto Rich- } \\
\text { mond y Juan Montoya, N de los C. La } \\
\text { Carpintera, H. Istarú, Aprox. aprox. } \\
\text { 536,7-207,0? }\end{array}$ & $2,2 \pm 0,63(\mathrm{~K} / \mathrm{Ar})$ & Bergoeing (1982) \\
\hline 15624 & $\begin{array}{l}\text { Microgabro mon- } \\
\text { zonítico }\end{array}$ & Desmonte, H. Río Grande, 485,5-215,5 & $2,1 \pm 0,1(\mathrm{~K} / \mathrm{Ar})$ & $\begin{array}{c}\text { Bellon \& Tournon } \\
\text { (1978) }\end{array}$ \\
\hline
\end{tabular}

Un afloramiento de una andesita rica en potasio por El Empalme, carretera Interamericana, reportado por de Boer et al. (1995) y Drummond et al. (1995), no solo muestra una edad relativamente joven de 3,37 Ma (Cuadro 12), sino que presenta un enriquecimiento en $\mathrm{Sr}$ (1200 ppm), y muy bajos contenidos en $\mathrm{Y}$ e $\mathrm{Yb}$, indicadores de un magma adakítico. Valga mencionarse que Sapper (1937) consideraba a la laguna Chonta (aprox. $2350 \mathrm{~m}$ s.n.m.), localizada a escasos kilómetros al sur de El Empalme, como el cráter de un volcán. Aunque resulta poco viable un crater volcánico en dicho sector, si parecen existir rocas volcánicas del Plioceno Superior sobre un basamento ígneo y sedimentario pre-plioceno, tal y como lo deja entreveer la morfología del área. Esta área merece re-estudiarse y ser geológicamente cartografiado.

En general, las rocas que se agrupan como adakitas aparecen en asocio con la migración hacia el SE de la Zona de Fractura de Panamá (Alvarado, 1984; Gazel et al., 2011).
La historia magmática de Talamanca puede resumirse en:

a. Vulcanismo basáltico de fondo oceánico del Eoceno.

b. Profuso vulcanismo subalcalino desde el Oligoceno al Mioceno representado por clastos volcánicos (esquirlas de vidrio, lapilli acrecional, pómez alteradas, arenas volcánicas).

c. Rocas plutónicas aisladas con cierto grado de duda por su alteración o bajo contenido en K: $35,6-18,8 \mathrm{Ma}$

d. Afloramientos aislados de lavas (p.ej., 21- $17 \mathrm{Ma})$.

d. Vulcanismo basáltico y andesítico de arco con cuerpos hipoabisales: 14,1 - 8,3 Ma, particularmente entre 13 y 11 Ma.

e. Intrusiones gabroides y granitoides: 12,4 - 7,8 Ma.

f. Vulcanismo post-intrusivo basáltico-dacítico ("adakítico") en cuerpos lávicos menores: 4,23 - 0,95 Ma. 
Cuadro 11

Dataciones radiométricas de las rocas volcánicas antiguas de la cordillera de Talamanca

\begin{tabular}{|c|c|c|c|c|}
\hline MUESTRA & LITOLOGIA & UBICACIÓN & $\operatorname{EDAD}(\mathrm{Ma})$ & REFERENCIA \\
\hline \multicolumn{5}{|c|}{ VULCANISMO PRE- Y SIN-INTRUSIVO } \\
\hline C4-47-88 & Basalto augítico & $\begin{array}{l}\text { Cerca de La Ese, camino a San Isidro, } \\
\text { H. San Isidro, aprox. 494,5-377,0 }\end{array}$ & $21,61 \pm 1,08(\mathrm{~K} / \mathrm{Ar})$ & $\begin{array}{l}\text { Jackson (1991); Defant } \\
\text { et al. (1992); de Boer et } \\
\text { al. (1995) }\end{array}$ \\
\hline ALT 16 & $\begin{array}{l}\text { Andesita basáltica } \\
\text { toleítica }\end{array}$ & $\begin{array}{c}3 \mathrm{~km} \text { al NE de Alturas, cerca frontera } \\
\text { con Panamá, H. Unión, 593,870- } \\
322,500\end{array}$ & $\begin{array}{c}16,87 \pm 0,27 \\
\left({ }^{40} \mathrm{Ar} /{ }^{39} \mathrm{Ar} \text { Furnace- }\right. \\
\text { largest step: hb) }\end{array}$ & $\begin{array}{l}\text { Abratis (1998); Abratis } \\
\text { \& Wörner (2001) }\end{array}$ \\
\hline $\begin{array}{l}\text { EG-1 (TA- } \\
021206-3)\end{array}$ & Basalto olivínico & $\begin{array}{c}\text { C. Asunción, H. Vueltas, 489,380- } \\
392,452\end{array}$ & $\begin{array}{c}14,10 \pm 1,0\left({ }^{40} \mathrm{Ar} /{ }^{39} \mathrm{Ar}:\right. \\
\mathrm{mtz})\end{array}$ & Gazel et al. (2009) \\
\hline TC-2 & $\begin{array}{l}\text { Dique basáltico } \\
\quad \text { (diabasa) }\end{array}$ & $\begin{array}{l}\text { C. de la Muerte, H. San Isidro, } \\
\qquad 495,296-379,380\end{array}$ & $\begin{array}{c}13,77 \pm 0,86 \\
\left({ }^{40} \mathrm{Ar} /{ }^{39} \mathrm{Ar}: \mathrm{mtz}\right)\end{array}$ & Gazel et al. (2009) \\
\hline CR-307 & Andesita basáltica & $\begin{array}{l}\text { Finca Mina, Linda Arriba, H. San } \\
\text { Isidro, 503,661-370,380 }\end{array}$ & $\begin{array}{c}13,00 \pm 1,50 \\
\left({ }^{40} \mathrm{Ar} /{ }^{39} \mathrm{Ar}: \mathrm{mtz}\right)\end{array}$ & MacMillan et al. (2004) \\
\hline CR-003 & Andesita & C. Páramo, H. Vueltas, 490,1E-390,0 & $\begin{array}{c}13,00 \pm 0,20 \\
\left({ }^{40} \mathrm{Ar} /{ }^{39} \mathrm{Ar}: \mathrm{mtz}\right)\end{array}$ & MacMillan et al. (2004) \\
\hline CR-298 & Andesita basáltica & $\begin{array}{l}\text { La Georgina, Siberia, H. Cuericí, } \\
494,510-388,813\end{array}$ & $\begin{array}{c}13,00 \pm 0,20 \\
\left({ }^{40} \mathrm{Ar} /{ }^{39} \mathrm{Ar}: \mathrm{mtz}\right)\end{array}$ & MacMillan et al. (2004) \\
\hline CR-002 & $\begin{array}{l}\text { Andesita piroxé- } \\
\text { nica }\end{array}$ & $\begin{array}{c}\text { C. Buenavista, H. Vueltas, } \\
\text { 494,150-390,600 }\end{array}$ & $\begin{array}{c}12,50 \pm 0,20 \\
\left({ }^{40} \mathrm{Ar} /{ }^{39} \mathrm{Ar}: \mathrm{mtz}\right)\end{array}$ & MacMillan et al. (2004) \\
\hline CR-300 & $\begin{array}{l}\text { Andesita vitro- } \\
\quad \text { fírica }\end{array}$ & $\begin{array}{l}\text { C. Páramo, H. Vueltas, 490,100- } \\
\text { 390,400 }\end{array}$ & $\begin{array}{c}11,80 \pm 0,20 \\
\left({ }^{40} \mathrm{Ar} /{ }^{39} \mathrm{Ar}: \mathrm{mtz}\right)\end{array}$ & MacMillan et al. (2004) \\
\hline $\mathrm{C} 4-6-88$ & $\begin{array}{l}\text { Rodado de dacita } \\
\text { vidriosa piroxé- } \\
\text { nica }\end{array}$ & $\begin{array}{l}\text { Confluencia R. General con el Pacuar, } \\
\text { Bajos de Pacuar, H. Repunta, } \\
\text { 503,5-356,5 }\end{array}$ & $11,79 \pm 0,59(\mathrm{~K} / \mathrm{Ar})$ & $\begin{array}{l}\text { Jackson (1991); de } \\
\text { Defant et al. (1992); } \\
\text { Boer et al. (1995) }\end{array}$ \\
\hline CR-302 & Andesita & $\begin{array}{l}\text { C. Buena Vista, H. Cuericí, 490,850- } \\
\qquad 388,813\end{array}$ & $\begin{array}{c}10,50 \pm 0,90 \\
\left({ }^{40} \mathrm{Ar} /{ }^{39} \mathrm{Ar}: \mathrm{mtz}\right)\end{array}$ & MacMillan et al. (2004) \\
\hline PA-4 & $\begin{array}{l}\text { Andesita piroxé- } \\
\text { nica }\end{array}$ & $\begin{array}{l}\text { Vuelta Ventolera, a } 6 \text { km de El Em- } \\
\text { palme, H. Tapantí, 538,2-195,2 }\end{array}$ & $8,3 \pm 0,4(\mathrm{~K} / \mathrm{Ar})$ & $\begin{array}{l}\text { Bellon \& Tournon } \\
\text { (1978) }\end{array}$ \\
\hline \multicolumn{5}{|c|}{ CERRO JABONCILLO, 11,98 Ma } \\
\hline PA-12 & $\begin{array}{l}\text { Vitrófiro andesí- } \\
\quad \text { tico }\end{array}$ & C. Jaboncillo, H. Vueltas, 486,3-394,9 & $16,9 \pm 2,5(\mathrm{~K} / \mathrm{Ar})$ & $\begin{array}{l}\text { Bellon \& Tournon } \\
\text { (1978) }\end{array}$ \\
\hline CR-072 & $\begin{array}{l}\text { Vitrófiro andesíti- } \\
\text { co piroxénico }\end{array}$ & $\begin{array}{l}\text { C. Jaboncillo, H. Vueltas, } \\
\text { 487,193-394,344 }\end{array}$ & $\begin{array}{c}11,98 \pm 0,06 \\
\left({ }^{40} \mathrm{Ar} /{ }^{39} \mathrm{Ar}: \text { plag }\right)\end{array}$ & MacMillan et al. (2004) \\
\hline $\mathrm{C} 4-1-88$ & $\begin{array}{l}\text { Dacita piroxénica } \\
\text { vidriosa }\end{array}$ & $\begin{array}{l}\text { C. Jaboncillo, H. Vueltas, aprox. } \\
\qquad 486,5-395,0\end{array}$ & $9,40 \pm 0,47(\mathrm{~K} / \mathrm{Ar})$ & $\begin{array}{l}\text { Jackson (1991); Defant et al. } \\
\text { (1992); de Boer et al. (1995) }\end{array}$ \\
\hline
\end{tabular}

\section{Vulcanismo de la fila Costeña}

El vulcanismo (efusivo y explosivo) en la fila Costeña es muy restringido lo mismo que los cuerpos hipoabisales, que se tratan en el apartado del plutonismo. Hay dudas sobre la edad de los basaltos de Mano de Tigre (Cuadros
9 y 12), desconociéndose si coexisten ambas edades o si se trata de un error en la toma de muestras: 14,1 - 14,0 Ma (McMillan et al., 2004 ) versus 4,23 (Gazel et al., 2011). La roca analizada por Gazel et al. (2011) tiene una clara afinidad adakítica, consistente con las edades de las adakitas de Talamanca. 
Cuadro 12

Dataciones radiométricas de rocas volcánicas post-intrusivas, básicas a ácidas con tendencias "adakíticas" en la cordillera de Talamanca y fila Costeña

\begin{tabular}{|c|c|c|c|c|}
\hline MUESTRA & LITOLOGÍA & UBICACIÓN & $\operatorname{EDAD}(\mathrm{Ma})$ & REFERENCIA \\
\hline \multicolumn{5}{|c|}{ FM. PASO REAL } \\
\hline R-3969 & Basalto (bloque) & $\begin{array}{c}\text { Queb. Cabuya, Ca. Interamericana, } \\
\text { cerca de Paso Real, H. Cabagra, } \\
478,5-207,1\end{array}$ & $5,0 \pm 0,4(\mathrm{~K} / \mathrm{Ar})$ & Kesel (1983) \\
\hline C3-16-89 & Andesita & $\begin{array}{l}\text { F. Mojones, entre Boruca y San An- } \\
\text { tonio, H. General, aprox. 539,0-330,6 }\end{array}$ & $4,31 \pm 0,07(\mathrm{~K} / \mathrm{Ar})$ & $\begin{array}{l}\text { de Boer et al. (1995); } \\
\text { Drummond et al. (1995) }\end{array}$ \\
\hline $\begin{array}{c}\text { GE- } \\
021306-8\end{array}$ & $\begin{array}{l}\text { Basalto con tendencia } \\
\text { adakítica }\end{array}$ & $\begin{array}{l}\text { Volcancito, Mano de Tigre, } \mathrm{H} \text {. } \\
\text { General, 541,763-332,080 }\end{array}$ & $\begin{array}{c}4,23 \pm 0,02 \\
\left({ }^{40} \mathrm{Ar} /{ }^{39} \mathrm{Ar}: \mathrm{mtz}\right)\end{array}$ & Gazel et al. (2011) \\
\hline TC-3 & $\begin{array}{l}\text { Brecha de basalto con } \\
\text { tendência adakítica }\end{array}$ & $\begin{array}{l}\text { Loma Ceiba, R. General, H. Gene- } \\
\text { ral, 543,439-338,041 }\end{array}$ & $\begin{array}{c}3,98 \pm 0,20 \\
\left({ }^{40} \mathrm{Ar} /{ }^{39} \mathrm{Ar}: \mathrm{mtz}\right)\end{array}$ & Gazel et al. (2011) \\
\hline CR-088 & $\begin{array}{l}\text { Brecha basáltica } \\
\text { monolítica }\end{array}$ & $\begin{array}{l}\text { Bajo el puente El Brujo, Fm. Paso } \\
\text { Real, H. General, 543,250-338,350 }\end{array}$ & $\begin{array}{c}3,87 \pm 0,02 \\
\left({ }^{40} \mathrm{Ar} /{ }^{39} \mathrm{Ar}: \mathrm{mtz}\right)\end{array}$ & MacMillan et al. (2004) \\
\hline CR-085 & Bloques andesíticos & $\begin{array}{l}\text { Paso Real, H. Cabagra, } \\
548,372-328,458\end{array}$ & $\begin{array}{c}3,65 \pm 0,30 \\
\left({ }^{40} \mathrm{Ar}{ }^{\beta 9} \text { Ar: plag }\right)\end{array}$ & MacMillan et al. (2004) \\
\hline & & & $\begin{array}{c}3,59 \pm 0,06 \\
\left({ }^{40} \mathrm{Ar} /{ }^{39} \mathrm{Ar}: \mathrm{mtz}\right)\end{array}$ & \\
\hline \multicolumn{5}{|c|}{ ANDESITAS-DACITAS (“ADAKITAS ”) } \\
\hline TC-5A & Andesita & Juntas, H. Unión, 579,361-311,455 & $\begin{array}{c}4,54 \pm 0,64 \\
\left({ }^{40} \mathrm{Ar} /{ }^{39} \mathrm{Ar}: \mathrm{mtz}\right)\end{array}$ & Gazel et al. (2011) \\
\hline TC-8 & $\begin{array}{l}\text { Lamprófido con bioti- } \\
\text { ta (latita o kersantita) }\end{array}$ & $\begin{array}{l}\text { C. Bola, H. Canoas, } 582,426- \\
286,800\end{array}$ & $\begin{array}{c}3,64 \pm 0,05 \\
\left({ }^{40} \mathrm{Ar} /{ }^{39} \mathrm{Ar}: \mathrm{mtz}\right)\end{array}$ & Gazel et al. (2011) \\
\hline C4-39-88 & $\begin{array}{l}\text { Bloque de andesita vi- } \\
\text { driosa rica en potasio } \\
\text { dentro de sedimentos? }\end{array}$ & $\begin{array}{l}\text { Loma Ceiba, R. General, H. Gene- } \\
\text { ral, aprox. 542,0-337,0 }\end{array}$ & $3,56 \pm 0,08(\mathrm{~K} / \mathrm{Ar})$ & $\begin{array}{l}\text { Jackson (1991); Drum- } \\
\text { mond et al. (1995); de } \\
\text { Boer et al. (1995) }\end{array}$ \\
\hline CR-092a & $\begin{array}{l}\text { Lamprófido con bioti- } \\
\text { ta (latita o kersantita) }\end{array}$ & $\begin{array}{l}\text { C. Bola, R. Abrojo, cerca de ciudad } \\
\text { Neily, H. Canoas, 582,350-286,850 }\end{array}$ & $\begin{array}{c}3,51 \pm 0,02 \\
\left({ }^{40} \mathrm{Ar} /{ }^{39} \mathrm{Ar}: \mathrm{mtz}\right)\end{array}$ & MacMillan et al. (2004) \\
\hline CR1 & $\begin{array}{l}\text { Andesita rica en } \\
\text { potasio }(\mathrm{Sr} 1200 \mathrm{ppm} \text {, } \\
\text { bajo } \mathrm{Y}, \mathrm{Lu} \text { e } \mathrm{Yb})\end{array}$ & $\begin{array}{l}\text { El Empalme, Ca. Interamericana, H. } \\
\text { Tapantí, aprox. 541,9-189,5 }\end{array}$ & $3,37 \pm 0,08(\mathrm{~K} / \mathrm{Ar})$ & $\begin{array}{l}\text { de Boer et al. (1995); } \\
\text { Drummond et al. } \\
\text { (1995) }\end{array}$ \\
\hline$?$ & Dacita & $\begin{array}{l}\text { Cuello o domo de Durika, H. Siola, } \\
\text { aprox. } 547,6-367,8\end{array}$ & $2,80 \pm 0,05(\mathrm{~K} / \mathrm{Ar})$ & $\begin{array}{l}\text { de Boer (1985, en de } \\
\text { Boer et al., 1995). }\end{array}$ \\
\hline $\operatorname{Pc} 2 \mathrm{c}$ & $\begin{array}{l}\text { Andesita con anfíbol } \\
\text { (brecha) }\end{array}$ & $\begin{array}{l}\text { Entre San Vito de Java y Sabalito, } \\
\text { H. Cañas Gordas, } 581.6 \mathrm{E}-307.1 \mathrm{~N}\end{array}$ & $2,6 \pm 0,4(\mathrm{~K} / \mathrm{Ar})$ & $\begin{array}{l}\text { Bellon \& Tournon } \\
\text { (1978) }\end{array}$ \\
\hline$?$ & Canto de lava & $\begin{array}{l}\text { Conglomerado antiguo entre Q. } \\
\text { Peje y R. Volcán, H. Buenos Aires, } \\
524,75-349,00\end{array}$ & $2,6(\mathrm{~K} / \mathrm{Ar})$ & Beaudet et al. (1982) \\
\hline $\mathrm{CH} 36$ & $\begin{array}{l}\text { Andesita básáltica } \\
\text { afírica con anfíbol }\end{array}$ & $\begin{array}{l}\text { R. Xikiari, vertiente W de F. Mata- } \\
\text { ma, H. Matama, 609,2-192,2 }\end{array}$ & 2,4 (K/Ar) & $\begin{array}{l}\text { Bellon, com. oral } \\
\text { (1983, en Tournon, } \\
\text { 1984) }\end{array}$ \\
\hline TAL 104 & Dacita & $\begin{array}{l}\text { Parte N del domo de Durika, H. } \\
\quad \text { Siola, } 546,900-368,450\end{array}$ & $\begin{array}{c}1,90 \pm 0,17 \\
\left({ }^{40} \mathrm{Ar} /{ }^{39} \mathrm{Ar}: \text { Laser }\right. \\
\text { weighted mean: } \mathrm{hb})\end{array}$ & $\begin{array}{l}\text { Abratis (1998); Abratis } \\
\quad \text { \& Wörner (2001) }\end{array}$ \\
\hline
\end{tabular}


Cuadro 12 (continuación)

Dataciones radiométricas de rocas volcánicas post-intrusivas, básicas a ácidas con tendencias "adakíticas" en la cordillera de Talamanca y fila Costeña

\begin{tabular}{|c|c|c|c|c|}
\hline MUESTRA & LITOLOGÍA & UBICACIÓN & EDAD (Ma) & REFERENCIA \\
\hline C4-4-88 & $\begin{array}{l}\text { Andesita vidriosa con } \\
\text { anfíbol }\end{array}$ & $\begin{array}{l}\text { Sabalito, H. Cañas Gordas, aprox. } \\
583,1-308,3\end{array}$ & $1,71 \pm 0,09(\mathrm{~K} / \mathrm{Ar})$ & $\begin{array}{c}\text { Jackson (1991); Defant } \\
\text { et al. (1992); de Boer et } \\
\text { al. (1995) }\end{array}$ \\
\hline CR-081B & $\begin{array}{l}\text { Andesita con mezcla } \\
\text { de basalto olivínico }\end{array}$ & $\begin{array}{l}\text { Tajo en el C. Pelón, H. Unión, } \\
596,8-318,9\end{array}$ & $\begin{array}{c}1,67 \pm 0,04 \\
\left({ }^{40} \mathrm{Ar} /{ }^{39} \mathrm{Ar}: \mathrm{mtz}\right)\end{array}$ & MacMillan et al. (2004) \\
\hline CR-082A & Andesita & $\begin{array}{l}\text { Tajo, La Lucha, H. Unión, 593,491- } \\
\qquad 315,193\end{array}$ & $\begin{array}{c}1,490 \pm 0,020 \\
\left({ }^{40} \mathrm{Ar} /{ }^{39} \mathrm{Ar}: \mathrm{mtz}\right)\end{array}$ & MacMillan et al. (2004) \\
\hline $\mathrm{C} 4-37-88$ & $\begin{array}{l}\text { Bloque de basalto } \\
\text { olivínico, dentro de } \\
\text { aluviones antiguos? }\end{array}$ & $\begin{array}{l}\text { Cerca de Paso Real, H. Cabagra, } \\
\text { aprox. } 548,4-329,0\end{array}$ & $1,25 \pm 0,03(\mathrm{~K} / \mathrm{Ar})$ & $\begin{array}{l}\text { Jackson (1991); Drum- } \\
\text { mond et al. (1995); de } \\
\text { Boer et al. (1995) }\end{array}$ \\
\hline C4-62-88 & $\begin{array}{l}\text { Andesita vidriosa con } \\
\text { anfíbol }\end{array}$ & $\begin{array}{l}\text { Por Maravilla de San Vito de Java, } \\
\text { H. Coto Brus, aprox. 573,0-315,3 }\end{array}$ & $1,10 \pm 0,06(\mathrm{~K} / \mathrm{Ar})$ & $\begin{array}{c}\text { Jackson (1991); Defant } \\
\text { et al. (1992); de Boer et } \\
\text { al. (1995) }\end{array}$ \\
\hline CR17A & Andesita & $\begin{array}{l}\text { Por Maravilla de San Vito de Java, } \\
\text { H. Coto Brus, aprox. 571,2-315,9 }\end{array}$ & $1,07 \pm 0,04(\mathrm{~K} / \mathrm{Ar})$ & $\begin{array}{l}\text { de Boer et al. (1995); } \\
\text { Drummond et al. } \\
(1995)\end{array}$ \\
\hline$?$ & Colada dacítica & $\begin{array}{l}\text { Domos de Durika, H. Siola, aprox. } \\
546,9-367,9\end{array}$ & $0,95 \pm 0,01(\mathrm{~K} / \mathrm{Ar})$ & $\begin{array}{l}\text { de Boer (1985, en de } \\
\text { Boer et al., 1995) }\end{array}$ \\
\hline
\end{tabular}

Lo que sí es claro es que existe un vulcanismo muy localizado (Fm. Paso Real, equivalente o sinónimo de Fm. Grifo Alto; Dengo, 1962; Henningsen, 1965; Mora, 1979; Alvarado et al., 2009b), representado por brechas basálticas monomícticas, aisladas coladas de lava (basaltos en su mayoría, escasas andesitas) y diques casuales, infrayaciendo a los conglomerados polimícticos de la Fm. Valle del General. Su edad predominante está comprendida entre 4,6 y 3,45 Ma (Kesel, 1983; de Boer et al., 1985; Drummond et al., 1995; McMillan et al., 2004; Gazel et al., 2011; presente trabajo). Ver cuadro 12 y figura 5.

El cerro Bola se ubica en la zona Sur, cerca de Ciudad Nelly, en la carretera interamericana, a la par del río Abrojo. Fue datado en 3,51 Ma (MacMillan et al., 2004) o en 3,64 Ma (Gazel et al., 2011), siendo su edad promedio de 3,57 Ma. Está ubicado en la intersección entre la falla Longitudinal de Costa Rica y la proyección de la Zona de Fractura de Panamá. Este cuerpo abovedado fue mencionado por primera vez por Henningsen (1965) como una leucoaugita-andesitabasalto porfirítica con hornblenda, después como un lamprófido dacítico con megacristales de biotita (Tournon \& Alvarado, 1997) con algo de piroxeno. Aunque Abratis (1998) reporta sodalita euhedral y nefelina intersticial $(i ?)$, entre otros minerales de la matriz, la química de esta lava es, sin embargo, subalcalina, con cuarzo e hipersteno normativos y una tendencia adakítica (Gazel et al., 2011). La roca corresponde geoquímicamente con una latita, aunque su petrografía indica un lamprófido con biotita llamado kersantita.

En resumen, en la fila Costeña se tiene una migración del magmatismo desde la costa, donde afloran las rocas más antiguas hacia la vecindad su límite con el pie de monte de la cordillera de Talamanca, donde se tienen cuerpos volcánicos y subvolcánicos más recientes (ver complemento en el apartado de rocas intrusivas). La historia se resume:

a. Diques andesíticos hasta diabásicos por Dominical (Fm. Puerto Nuevo): 18,3 - 16,8 Ma.

b. Gabros por Puerto Nuevo: 14,8 - 11,1 Ma.

c. Hipoabisales andesíticos y diabásicos del cerro Las Bolas: 6,4 - 6,1 Ma. 


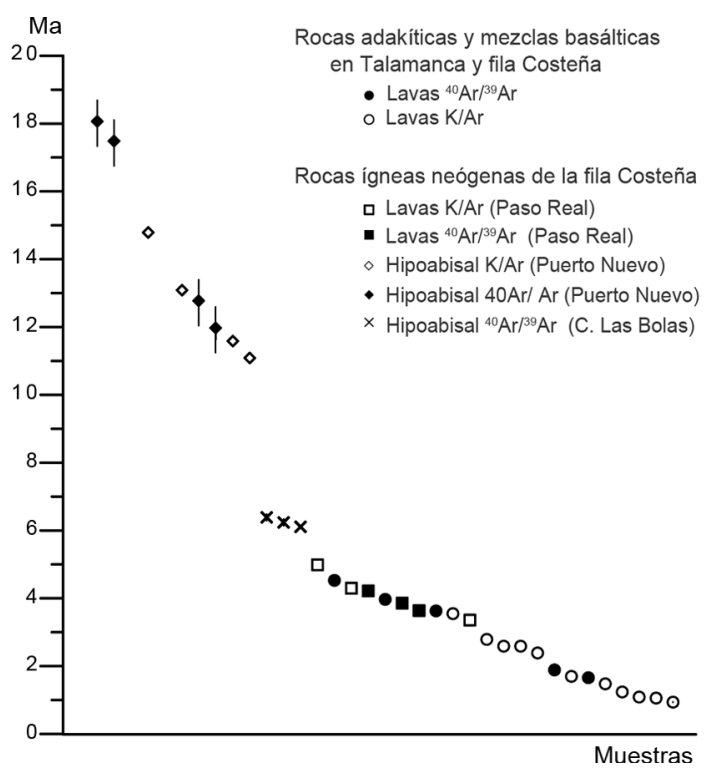

Fig. 5: Número de dataciones del magmatismo de la fila Costeña, ordenados de mayor a menor edad.

d. Coladas, cuerpos dómicos (¿criptodomos o domos?), brechas basálticas monomícticas y diques con tendencia adakítica: 4,6 - 3,45 Ma.

\section{Vulcanismo de Sarapiquí}

En las llanuras de San Carlos (Fig. 2) se levantan unos cerros y lomas bajas (40 - 370 m s.n.m.), hasta el grado que parte de ellos fueron mapeados en los mapas antiguos como llanuras aluviales, estando constituidos por coladas de lavas (andesíticas piroxénicas, basaltos, dacitas y riolitas), además de tobas y brechas de diversos orígenes, entre ellos depósitos de flujos piroclásticos (ignimbritas y depósitos de flujos de bloques y cenizas) e intruidos por pequeños cuerpos intrusivos (p.ej., el gabro de Boca Tapada). En algunos sectores conforman térrazas litológicas, evidenciando una posible peneplanización con espesos suelos lateríticos (50 $\mathrm{m}$ de espesor). Este vulcanismo fue descrito por primera vez por Malavassi \& Chávez (1970), Malavassi \& Madrigal (1970), Alvarado (1984) y Tournon (1984), pero no fue mapeado y estudiado petrológica, geocronológica y vulcanológicamente hasta en la década de los noventas y presente siglo (Obando, 1995; Sigarán, 2001;
Gazel et al., 2005, 2009). Fue incluido dentro de la Fm. Cureña (Malavassi \& Madrigal, 1970), que sería la continuidad de las estribaciones meridionales de la cordillera de Chontales en Nicaragua, el equivalente del Grupo Coyol (Malavassi \& Madrigal, 1970; Gazel et al., 2005; Alvarado et al., 2007).

Dicho vulcanismo presenta fases claramente definidas datadas por ${ }^{40} \mathrm{Ar} /{ }^{39} \mathrm{Ar}$, iniciando con las efusiones basálticas, mayoritariamente entre 29,2 y $24 \mathrm{Ma}$ (Cuadro 13, Fig. 6). Sin embargo, el vulcanismo basáltico toleítico antiguo (29,2 - 28,4 Ma) reportado por Gazel et al. (2009) aflora en la margen izquierda del río San Juan, por lo que estrictamente hablando no corresponde con territorio costarricense. La parte interesante es que la rocas cercanas datadas en el territorio costarricense tanto por Gazel y colaboradores como en el presente trabajo, suelen poseer edades máximas de 24,3 Ma y más jóvenes (brecha cronológica de $4,1 \mathrm{Ma}$ ), por lo que surge la duda de si se trata de un faltante de muestras por datar o si existe una gran falla a lo largo del río, en tentadora correspondencia con el escarpe de Hess.

Las dataciones $\mathrm{K} / \mathrm{Ar}$ de coladas de basaltos relativamente más jóvenes de 22,2 $\pm 2,7$ Ma y de 20,8 \pm 3,0 (Obando, 1995 y Sigarán, 2001, respectivamente), se ubicarían dentro de éste lapso al tomar en cuenta sus rangos de error, y al considerar que una de ellas fue datada en la misma localidad con ${ }^{40} \mathrm{Ar} /{ }^{39} \mathrm{Ar}$ y la otra fue un dique en el prospecto aurífero, recalcándose el problema ya expuesto que presentan los diques con los gases y su hidrotermalismo posterior.

Este vulcanismo basáltico fue seguido por efusiones andesíticas (28,43 Ma pero particularmente 23 - $21 \mathrm{Ma}$ ) en concomitancia con domos riolíticos (22,75 - 22,2 Ma). La edad de 11,4 Ma para la colada de andesita del pozo Chamorro (Obando, 1995) se sale de la campana de datos. A esta actividad se sobrepusieron extensas efusiones andesíticas y un vulcanismo explosivo (18-16 $\mathrm{Ma}$ ), así como por cuerpos dacíticos y riolíticos (17,5 -15,2 Ma) contemporáneos (Cuadros 13 y 14; Fig. 6).

La alteración hidrotermal, obtenidas a partir de rocas con alteración potásica, nos indican dos fases de mineralización epitermal en coincidencia 


\section{Cuadro 13}

Dataciones radiométricas de las rocas basálticas y andesíticas de Sarapiquí

\begin{tabular}{|c|c|c|c|c|}
\hline MUESTRA & LITOLOGÍA & UBICACIÓN & EDAD (Ma) & REFERENCIA \\
\hline \multicolumn{5}{|c|}{ BASALTOS } \\
\hline P-126 & Basalto & $\begin{array}{l}\text { E1 Castillito, R. San Juan (margen de Nicara- } \\
\text { gua), H. Trinidad, 548,986-300,449 }\end{array}$ & $\begin{array}{c}29,20 \pm 1,3 \\
\left({ }^{40} \mathrm{Ar} /{ }^{39} \mathrm{Ar}: \mathrm{mtz}\right)\end{array}$ & Gazel et al. (2009) \\
\hline CR-256 & Basalto & $\begin{array}{l}\text { R. San Carlos, } 1 \mathrm{~km} \text { al norte de I. Canacas, misma } \\
\text { localidad 29.1.95.3, H. Cutris, 516,025-303,925 }\end{array}$ & $\begin{array}{c}24,39 \pm 0,18 \\
\left({ }^{40} \mathrm{Ar} /{ }^{39} \mathrm{Ar}: \mathrm{mtz}\right)\end{array}$ & Presente trabajo \\
\hline CR-255 & Basalto & $\begin{array}{l}\text { El Recreo-I. Los Castaños, R. San Carlos, H. } \\
\text { Cutris, 514,270-301,150 }\end{array}$ & $\begin{array}{c}23,83 \pm 0,14 \\
\left({ }^{40} \mathrm{Ar} /{ }^{39} \mathrm{Ar}: \mathrm{mtz}\right)\end{array}$ & Presente trabajo \\
\hline 29.1 .95 .3 & Basalto & $\begin{array}{c}\text { Hacienda La Flor, R. San Carlos, margen } \\
\text { derecha (misma localidad CR-256), H. Cutris, } \\
515,900-304,000\end{array}$ & $22,2 \pm 2,7(\mathrm{~K} / \mathrm{Ar})$ & Obando (1995) \\
\hline $\begin{array}{l}\text { CO-262 } \\
\text { UHip }\end{array}$ & Dique basáltico & $\begin{array}{l}\text { Prospecto aurífero Conchudita, Perforación } \\
\text { CO, 262, a 92,3 m, H. Cutris, 510,330-309,870 }\end{array}$ & $20,8 \pm 3,0(\mathrm{~K} / \mathrm{Ar})$ & Sigarán (2001) \\
\hline \multicolumn{5}{|c|}{ ANDESITAS } \\
\hline P-127 & Andesita & $\begin{array}{l}\text { P. Petaca, R. San Juan (margen de Nicaragua), } \\
\text { H. Trinidad, 554,604-303,411 }\end{array}$ & $\begin{array}{c}28,43 \pm 0,44 \\
\left({ }^{40} \mathrm{Ar} /{ }^{39} \mathrm{Ar}: \text { plag }\right)\end{array}$ & Gazel et al. (2009) \\
\hline CR-294 & Andesita vitrofírica & $\begin{array}{l}2,3 \mathrm{~km} \text { al NE del caserío de Jocote, H. Poco- } \\
\text { sol, 497,700-323,620 }\end{array}$ & $\begin{array}{c}22,79 \pm 0,08 \\
\left({ }^{40} \mathrm{Ar} /{ }^{39} \mathrm{Ar}: \text { plag }\right)\end{array}$ & Presente trabajo \\
\hline CR-273 & $\begin{array}{l}\text { Bloque de andesita } \\
\text { vitrofírica }\end{array}$ & $\begin{array}{l}\text { 5,4 km al ESE de Chamorro, H. Infiernillo, } \\
\qquad 503,350-309,850\end{array}$ & $\begin{array}{c}21,66 \pm 0,16 \\
\left({ }^{40} \mathrm{Ar} /{ }^{39} \mathrm{Ar}: \text { plag }\right)\end{array}$ & Presente trabajo \\
\hline CR-268 & Andesita bandeada & $\begin{array}{l}\text { 4,7 km al SSE de Crucitas, H. Pocosol, } \\
\quad 501,700-314,900\end{array}$ & $\begin{array}{c}21,00 \pm 0,70 \\
\left({ }^{40} \mathrm{Ar} /{ }^{39} \mathrm{Ar}: \text { plag }\right)\end{array}$ & Presente trabajo \\
\hline & & & $\begin{array}{l}20,90 \pm 0,10 \\
(\mathrm{mtz})\end{array}$ & \\
\hline CR-239 & Andesita & $\begin{array}{l}\text { Muelle, Fm. Arrepentidos, H. Río Cuarto, } \\
\text { 534,5-272,9 }\end{array}$ & $\begin{array}{c}17,90 \pm 0,20 \\
\left({ }^{40} \mathrm{Ar} /{ }^{39} \mathrm{Ar}: \text { plag }\right)\end{array}$ & Presente trabajo \\
\hline CR-240 & Andesita basáltica & $\begin{array}{l}\text { Cerros Sardinal, cementerio de Chilamate, } \\
\text { misma localidad que } 8.1 .95 .1, \mathrm{H} \text {. Río Cuarto, } \\
528,600-270,300\end{array}$ & $\begin{array}{c}17,70 \pm 0,30 \\
\left({ }^{40} \mathrm{Ar} /{ }^{39} \mathrm{Ar}: \mathrm{mtz}\right)\end{array}$ & Presente trabajo \\
\hline CR-296 & Andesita & $\begin{array}{l}\text { Cerca de Pangola (C. Chaparrón), H. Chapa- } \\
\text { rrón, 521,050-284,400 }\end{array}$ & $\begin{array}{c}17,50 \pm 0,25 \\
\left({ }^{40} \mathrm{Ar} /{ }^{39} \mathrm{Ar}: \text { plag }\right)\end{array}$ & Presente trabajo \\
\hline 8.1 .95 .1 & Andesita basáltica & $\begin{array}{l}\text { C. Sardinal, misma localidad que CR-240, H. } \\
\text { Río Cuarto, } 528,650-270,350\end{array}$ & $\begin{array}{l}17,20 \pm 0,8(\mathrm{~K} / \\
\mathrm{Ar})\end{array}$ & $\begin{array}{l}\text { Obando (1995), } \\
\text { Gazel et al. (2005) }\end{array}$ \\
\hline CR-264 & $\begin{array}{l}\text { Andesita basáltica } \\
\text { lajeada }\end{array}$ & $\begin{array}{l}\text { 2,4 km al ENE del caserío de Jardín, H. Infier- } \\
\text { nito, } 508,075-304,200\end{array}$ & $\begin{array}{c}17,30 \pm 0,15 \\
\left({ }^{40} \mathrm{Ar} /{ }^{39} \mathrm{Ar}: \mathrm{mtz}\right)\end{array}$ & Presente trabajo \\
\hline CR-242 & $\begin{array}{l}\text { Brecha de flujo de } \\
\text { bloques (andesitas } \\
\text { vidriosas) y cenizas }\end{array}$ & $\begin{array}{l}\text { C. Blanco (C. Chaparrón), misma localidad } \\
\text { que 7.1.95.1, H. Chaparrón, 513,800-280,700 }\end{array}$ & $\begin{array}{c}17,10 \pm 0,25 \\
\left({ }^{40} \mathrm{Ar} /{ }^{39} \mathrm{Ar}: \text { plag }\right)\end{array}$ & Presente trabajo \\
\hline CR-253 & $\begin{array}{l}\text { Bloque andesítico } \\
\text { afírico }\end{array}$ & R. San Carlos, H. Cutris, 513,350-296,100 & $\begin{array}{c}17,10 \pm 0,10 \\
\left({ }^{40} \mathrm{Ar} /{ }^{39} \mathrm{Ar}: \mathrm{mtz}\right)\end{array}$ & Presente trabajo \\
\hline CR-292 & $\begin{array}{l}\text { Bloque andesítico } \\
\text { basáltico }\end{array}$ & $\begin{array}{l}1,5 \mathrm{~km} \text { al NW del caserío de Jocote, H. Poco- } \\
\text { sol, } 494,400-323,650\end{array}$ & $\begin{array}{c}17,05 \pm 0,10 \\
\left({ }^{40} \mathrm{Ar} /{ }^{39} \mathrm{Ar}: \mathrm{mtz}\right)\end{array}$ & Presente trabajo \\
\hline CR-263 & $\begin{array}{l}\text { Bloque andesítico } \\
\text { basáltico }\end{array}$ & $\begin{array}{l}1,75 \mathrm{~km} \text { al E del caserío de Jardín, H. Infierni- } \\
\text { to, } 507,400-303,500\end{array}$ & $\begin{array}{c}16,90 \pm 0,10 \\
\left({ }^{40} \mathrm{Ar} /{ }^{39} \mathrm{Ar}: \mathrm{mtz}\right)\end{array}$ & Presente trabajo \\
\hline
\end{tabular}


Cuadro 13 (continuación)

Dataciones radiométricas de las rocas basálticas y andesíticas de Sarapiquí

\begin{tabular}{|c|c|c|c|c|}
\hline MUESTRA & LITOLOGÍA & UBICACIÓN & $\operatorname{EDAD}(\mathrm{Ma})$ & REFERENCIA \\
\hline CR-274 & Andesita basáltica & $\begin{array}{l}5 \mathrm{~km} \text { al ESE de Chamorro, H. Infiernito, } \\
503,800-310,750\end{array}$ & $\begin{array}{c}16,85 \pm 0,10 \\
\left({ }^{40} \mathrm{Ar} /{ }^{39} \mathrm{Ar}: \mathrm{mtz}\right)\end{array}$ & Presente trabajo \\
\hline CR-295 & Andesita basáltica & $\begin{array}{l}\text { 4,5 km al WSW de Crucitas, H. Pocosol, } \\
4496,250-318,750\end{array}$ & $\begin{array}{c}16,80 \pm 0,30 \\
(40 \mathrm{Ar} / 39 \mathrm{Ar}: \mathrm{mtz})\end{array}$ & Presente trabajo \\
\hline CR-262 & Andesita basáltica & $\begin{array}{l}1,2 \mathrm{~km} \text { al E del caserío de El Jardín ,H. Infier- } \\
\text { nito, 506,900-303,750 }\end{array}$ & $\begin{array}{c}16,90 \pm 0,90 \\
\left({ }^{40} \mathrm{Ar} /{ }^{39} \mathrm{Ar}: \text { pla }\right) \\
\\
16,78 \pm 0,15 \\
\left({ }^{40} \mathrm{Ar} /{ }^{39} \mathrm{Ar}: \mathrm{mtz}\right)\end{array}$ & Presente trabajo \\
\hline CR-261 & $\begin{array}{l}\text { Bloques andesíticos } \\
\text { afíricos }\end{array}$ & $\begin{array}{l}\text { 0,7 km WSW Caserío de El Jardín, H. Infier- } \\
\text { nito, 505,100-303,450 }\end{array}$ & $\begin{array}{c}16,75 \pm 0,20 \\
\left({ }^{40} \mathrm{Ar} /{ }^{39} \mathrm{Ar}: \mathrm{mtz}\right)\end{array}$ & Presente trabajo \\
\hline CR-265 & $\begin{array}{l}\text { Lava andesítica vi- } \\
\text { trofírica en flujo de } \\
\text { bloques y cenizas }\end{array}$ & $\begin{array}{l}2 \mathrm{~km} \text { al SSW de Chamorro, H. Infiernito, } \\
\quad 497,600-309,275\end{array}$ & $\begin{array}{c}16,45 \pm 0,09 \\
\left({ }^{40} \mathrm{Ar} /{ }^{39} \mathrm{Ar}: \text { plag }\right)\end{array}$ & Presente trabajo \\
\hline CR-242 & $\begin{array}{l}\text { Clastos vitrofíricos } \\
\text { en flujos de bloques } \\
\text { y cenizas }\end{array}$ & C. Chaparrón, H. Chaparrón, 513,8-280,7 & $\begin{array}{c}16,10 \pm 0,25 \\
\left({ }^{40} \mathrm{Ar} /{ }^{39} \mathrm{Ar}: \mathrm{mtz}\right)\end{array}$ & Presente trabajo \\
\hline 7.1.95.1 & $\begin{array}{c}\text { Andesitas vidriosas } \\
\text { en flujos de bloques } \\
\text { y cenizas }\end{array}$ & $\begin{array}{l}\text { C. Blanco (C. Chaparrón) misma localidad } \\
\text { que CR-242, H. Chaparrón, 513,8-280,7 }\end{array}$ & $\begin{array}{l}15,4 \pm 0,6(\mathrm{~K} / \\
\text { Ar: wr) }\end{array}$ & $\begin{array}{l}\text { Obando (1995), } \\
\text { Gazel et al. (2005) }\end{array}$ \\
\hline CR-272 & Andesita basáltica & $\begin{array}{l}2,5 \mathrm{~km} \text { al ESE del Carmen, Crucitas, } \mathrm{H} \text {. } \\
\text { Infiernito, 503,800-307,250 }\end{array}$ & $\begin{array}{c}15,10 \pm 0,40 \\
\left({ }^{40} \mathrm{Ar} /{ }^{39} \mathrm{Ar}: \mathrm{mtz}\right)\end{array}$ & Presente trabajo \\
\hline $\begin{array}{l}\text { DHCham- } \\
280.4\end{array}$ & Andesita & $\begin{array}{c}\text { Pozo Chamorro (RECOPE), a } 2,5 \mathrm{~km} \text { al N } \\
\text { de Chamorro, lava a } 280,4 \mathrm{~m} \text {, H. Infiernito, } \\
498,300-313,200\end{array}$ & $11,4 \pm 0,4(\mathrm{~K} / \mathrm{Ar})$ & $\begin{array}{l}\text { Obando (1995), } \\
\text { Gazel et al. (2005) }\end{array}$ \\
\hline
\end{tabular}

con el vulcanismo intermedio-ácido: 22,9 - 22,2 Ma (Sigarán, 2001) y 16,4 - 15,3 Ma (Obando, 1995). El dique basáltico CO-282, aportó una edad de 20,8 $\pm 3,0 \mathrm{Ma}$ con un rango de error elevado $(14,4 \%)$, posiblemente debido a un bajo contenido de $\mathrm{K}$ así como a una contaminación de Ar atmosférico (Sigarán, 2001).

Una secuencia de plataforma marina hasta parálica (Fm. Venado; Malavassi \& Madrigal, 1970), representada por calizas bioclásticas (lumaquelas), lutitas, areniscas fosilíferas, tobitas, conglomerados y capas de carbón (de hasta $2 \mathrm{~m}$ de espesor), que afloran en el área de San Rafael y Venado, sobreyacen a las rocas volcánicas previamente descritas. Las areniscas tienen a menudo niveles pumíceos gruesos con hornblenda y cuarzo, así como probables ignimbritas (Obando, 1986). La abundante macro- y microfauna indica un ambiente marino somero del Mioceno
Medio pero predominantemente Mioceno Tardío (N17: Messiniano) e incluso Plioceno Tardío (Sen Gupta et al., 1986; Pizarro, 1993): 14 hasta $3 \mathrm{Ma}$, pero predominantemente entre 7 y $3 \mathrm{Ma}$. Los dos pozos profundos realizados en la zona (Pataste y Tonjibe) perforaron 728 y 1007 m, respectivamente, de rocas correlacionables con la Fm. Venado, que sobreyacían a una secuencia de rocas volcánicas antiguas (Fm. Cureña). Están a su vez sobreyacidas por coladas de lava del Plioceno-Cuaternario (Obando, 1986) y rocas piroclásticas del Cuaternario (Pizarro, 1993). Sen Gupta et al. (1986), Obando (1986) y Calvo \& Bolz (1987) concluyen que el aporte de sedimentos volcánicos (pómez y areniscas ricas en plag \pm $\mathrm{qz} \pm \mathrm{hb}$; Obando, 1986) se realizaba desde el norte, noroeste y oeste. El vulcanismo como fuente de aporte no se ha establecido geoquímicamente, pero es probable que provenga del vulcanismo 


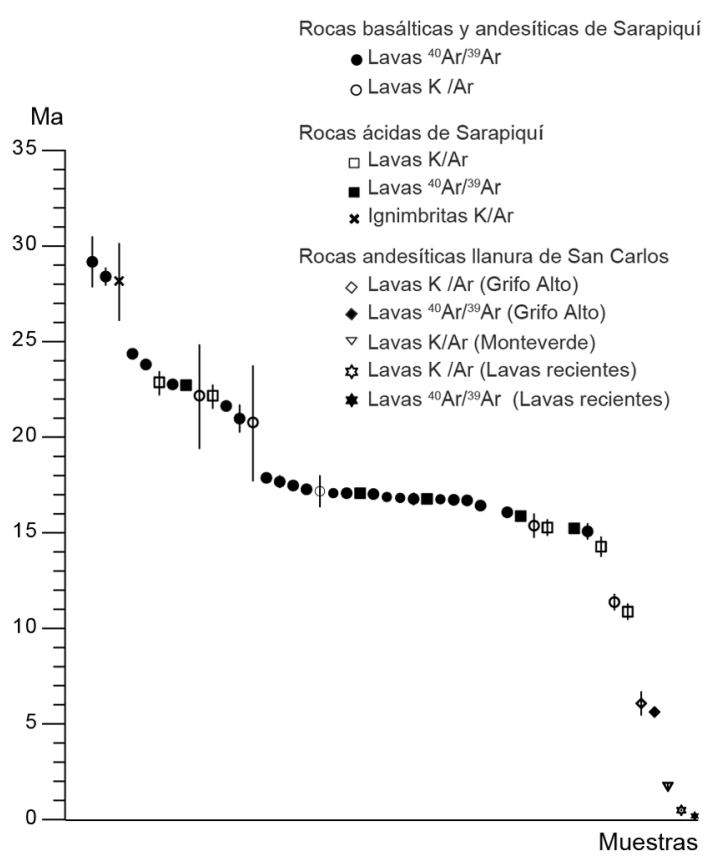

Fig. 6: Número de dataciones de las rocas en las llanuras de San Carlos, ordenados de mayor a menor edad.

ácido de Nicaragua, en lugar del vulcanismo de la Fm. Bagaces (8 - $2 \mathrm{Ma}$ ), dada la poca abundancia de cuarzo y anfíbol en esta unidad.

Finalmente, un vulcanismo calcoalcalino aislado (lava del cerro La Mina, 6,1 Ma, Sen Gupta et al., 1986) y alcalino del Plioceno (5,3 y 3,2 Ma), culminando con un vulcanismo subordinado alcalino (2,0 - 1,2 y 0,6 - $0 \mathrm{Ma})$ y calcoalcalino reciente (lahares y coladas subordinadas: 1,73 y $0,5 \mathrm{Ma}$ ) en las cercanías con los volcanes Cuaternarios, cubren parcialmente a las rocas volcánicas y sedimentarias Oligo-Miocenas (Cuadro 15).

En resumen, el vulcanismo y sedimentación de las llanuras del Caribe se puede resumir a:

a. Vulcanismo basáltico toleítico: 29,2 - 24 Ma.

b. Intrusión gabroica de edad radiométrica no establecida: ¿22 Ma?

c. Primer vulcanismo andesítico: 28,4 y 23 $-21 \mathrm{Ma}$

d. Primero vulcanismo dacítico-riolítico: 22,75 - 22,2 Ma.

e. Primera alteración hidrotermal y mineralización aurífera: 22,9 - 22,2 Ma. f. Segundo vulcanismo andesítico: 18 - 16 Ma.

g. Segundo vulcanismo dacítico-riolítico: 17,5 - 15,2 Ma.

h. Segunda alteración hidrotermal y mineralización aurífera: 16,4 - 15,3 Ma.

i. Establecimiento de un estuario lagunar estuarino con barra arenosa carbonatada, y aportes volcaniclásticos desde el NW: aprox. 14 - $3 \mathrm{Ma}$, principalmente a los 7 - 3 Ma.

j. Tercer vulcanismo andesítico aislado del Plioceno: 6,1 Ma.

k. Vulcanismo alcalino (que se tratará en detalla más adelante) en cuatro fases sucesivas mayores $(5,3 ; 3,2 ; 2,0$ - 1,2 y 0,6 - $0 \mathrm{Ma})$.

1. Vulcanismo calcoalcalino contemporáneo con el de Monteverde (1,73 Ma).

M. Vulcanismo en sus facies distales de los estratovolcanes $(0,5-0,02 \mathrm{Ma})$.

\section{Magmatismo de los Montes del Aguacate y la cordillera de Tilarán}

Por años se ha enmarcado al vulcanismo que no se le asocia con los estratovolcanes cuaternarios ni con los complejos ofiolíticos, dentro del Grupo Aguacate, ya sea un vulcanismo que yace concordante o discordante sobre las secuencias sedimentarias marinas infrayacentes (Fig. 2). Esto fue aplicado para los Montes del Aguacate y la cordillera de Tilarán, pero también para otras serranías, entre ellas la cordillera de Talamanca (incluyendo la Fm. Paso Real, Fm. Doán) y las llanuras del Sarapiquí (Fm. Cureña). No fue sino hasta el trabajo de Denyer \& Arias (1991) en que se logró establecer que en la parte central de Costa Rica, en realidad existen dos grandes eventos volcánicos distintivos, uno más antiguo y concordante con la secuencia sedimentaria infrayacente (llamado Fm. La Cruz) y otro más reciente y sobreyaciendo mediante una marcada discordancia angular a las rocas sedimentarias y volcánicas (llamado Fm. Grifo Alto), hecho comprobado con una serie de dataciones del tipo ${ }^{40} \mathrm{Ar} /{ }^{39} \mathrm{Ar}$ (Marshall, 2000; Marshall et al., 2003; MacMillan et al., 2004; presente trabajo).

Efectivamente, se encontró que las coladas de lava antiguas y por lo general basculadas, 
Cuadro 14

Dataciones radiométricas de las rocas ácidas de Sarapiquí (domos riolíticos-dacíticos)

\begin{tabular}{|c|c|c|c|c|}
\hline MUESTRA & LITOLOGÍA & UBICACIÓN & EDAD (Ma) & REFERENCIA \\
\hline PLA-104 & $\begin{array}{l}\text { Flujo piroclástico gris } \\
\text { con hornblenda y biotita }\end{array}$ & $\begin{array}{l}\text { Cerca del hospital de Ciudad Quesa- } \\
\text { da, H. Aguas Zarcas, 486,4-259,8 }\end{array}$ & $28,2 \pm 2,0(\mathrm{~K} / \mathrm{Ar})$ & $\begin{array}{l}\text { ICE (1987, en Alvara- } \\
\text { do et al., 1992) }\end{array}$ \\
\hline CR-278 & Riolita con biotita & $\begin{array}{c}\text { Domo Crucitas, H. Pocosol, } \\
502,450-317,300\end{array}$ & $\begin{array}{c}22,75 \pm 0,08 \\
\left({ }^{40} \mathrm{Ar} /{ }^{39} \mathrm{Ar}: \text { plag }\right)\end{array}$ & Presente trabajo \\
\hline CO-282 Udac-i & Dacita algo alterada & $\begin{array}{l}\text { Conchudita, Perforación CO-282 a } \\
169,6 \text { m, H. Cutris, 510,670-309,780 }\end{array}$ & $22,2 \pm 0,6(\mathrm{~K} / \mathrm{Ar})$ & Sigarán (2001) \\
\hline \multirow[t]{2}{*}{ CR-297 } & Dacita & $\begin{array}{l}\text { Domo C. Mollejón, H. Chaparrón, } \\
524,700-286,500\end{array}$ & $17,50 \pm 0,25$ (plag) & Presente trabajo \\
\hline & & & $\begin{array}{c}17,10 \pm 0,10 \\
\left({ }^{40} \mathrm{Ar} /{ }^{39} \mathrm{Ar}: \mathrm{mtz}\right)\end{array}$ & \\
\hline CR-247 & Dacita hornbléndica & $\begin{array}{l}\text { Tajo Zarcero, Zarcero, H. Quesada, } \\
4493,20-241,050\end{array}$ & $\begin{array}{c}16,80 \pm 0,21 \\
\left({ }^{40} \mathrm{Ar} /{ }^{39} \mathrm{Ar}: \text { plag }\right)\end{array}$ & Presente trabajo \\
\hline CR-252 & Dacita hornbléndica & $\begin{array}{c}\text { Domo a } 1,3 \mathrm{~km} \text { al ENE de Boca } \\
\text { Tapada, margen izquierda del R. San } \\
\text { Carlos, H. Cutris, 512,150-295,500 }\end{array}$ & $\begin{array}{c}16,72 \pm 0,12 \\
\left({ }^{40} \mathrm{Ar} /{ }^{39} \mathrm{Ar}: \text { plag }\right)\end{array}$ & Presente trabajo \\
\hline CR-282 & Dacita hornbléndica & $\begin{array}{c}\text { Domo } 2 \text { km al WSW de Crucitas, H. } \\
\text { Pocosol, 498,750-318,350 }\end{array}$ & $\begin{array}{c}15,90 \pm 0,10 \\
\left({ }^{40} \mathrm{Ar} /{ }^{39} \mathrm{Ar}: \text { plag }\right)\end{array}$ & Presente trabajo \\
\hline CR-266 & $\begin{array}{l}\text { Dacita hornbléndica } \\
\text { vidriosa }\end{array}$ & $\begin{array}{c}\text { 3,5 km al SW de Crucitas, C. 152, } \\
\text { flanco SE, H. Pocosol, } \\
\text { 498,875-316,500 }\end{array}$ & $\begin{array}{c}15,30 \pm 0,10 \\
\left({ }^{40} \mathrm{Ar}{ }^{39} \text { Ar: plag }\right)\end{array}$ & Presente trabajo \\
\hline CR-281 & Riolita biotítica & $\begin{array}{l}\text { Domo C. } 152,4 \text { km al SW de Cruci- } \\
\text { tas, H. Pocosol, 498,050-316,225 }\end{array}$ & $\begin{array}{c}15,26 \pm 0,04 \\
\left({ }^{40} \mathrm{Ar} /{ }^{39} \mathrm{Ar}: \text { plag }\right)\end{array}$ & Presente trabajo \\
\hline 26.01 .95 .1 & Riolita biotítica & $\begin{array}{c}\text { Domo C. 152, similar localidad } \\
\text { a CR-281, H. Pocosol, 497,800- } \\
316,400\end{array}$ & $14,3 \pm 0,5(\mathrm{~K} / \mathrm{Ar})$ & $\begin{array}{c}\text { Obando (1995), Gazel } \\
\text { et al. (2005) }\end{array}$ \\
\hline 4.1 .95 .3 & $\begin{array}{l}\text { Dacita con horn- } \\
\text { blenda }\end{array}$ & $\begin{array}{c}\text { Flanco SE del C. 152, similar } \\
\text { localidad a CR-266, H. Pocosol, } \\
497,400-316,500\end{array}$ & $10,9 \pm 0,4(\mathrm{~K} / \mathrm{Ar})$ & $\begin{array}{c}\text { Obando (1995), Gazel } \\
\text { et al. (2005) }\end{array}$ \\
\hline
\end{tabular}

localizadas en la parte central del país, poseen edades de 11,3 - 10,9 Ma (MacMillan et al., 2004). También se dataron depósitos de cenizas plinianas vitrocristalinas distales dentro de las rocas asociadas con los sedimentos fluviales e ignimbritas de la Fm. Mata de Limón (19,9 Ma, Cuadro 16), equivalentes distales del vulcanismo intrasedimentario de la Fm. Pacacua (Alvarado \& Gamboa, 2008). Este vulcanismo estaría asociado con el profuso magmatismo presente en las llanuras de Sarapiquí (Fm. Cureña) datado entre 29 y 10,9 Ma (p.ej., Gazel et al., 2005, 2009) o aquel presente en la cordillera de Talamanca, primordialmente dentro del rango de 21,6 y 9,4 Ma, coetáneo con las intrusiones e incluso con muchas de las rocas sedimentarias marinas (de Boer et al., 1995; MacMillan et al., 2004).
Las dataciones que aportaron edades cerca de Cañas de 71,8 hasta más de 23,0 Ma (Amos \& Rogers, 1983), no fueron consideradas dado que al parecer son erróneas, posiblemente debido a su bajo contenido en potasio, tal y como se comprobó con fechas radiométricas posteriores realizadas en el área.

A los $8 \mathrm{Ma}$, el eje del magmatismo inició un cambio, virando contra-reloj unos $20^{\circ}$ grados con pivote en la parte sur de Costa Rica, para dar a un nuevo vulcanismo que se extendió hasta hace unos 3,3 Ma en correspondencia con lo que se conoce como Fm. Grifo Alto (Cuadro 17; también Cuadros 12 y 15). Sería contemporáneo con el vulcanismo y los hipoabisales más recientes de la fila Costeña (6,4 - 3,6 Ma; MacMillan et al., 
Cuadro 15

Dataciones radiométricas de las rocas andesíticas cerca de la llanura de San Carlos

\begin{tabular}{|c|c|c|c|c|}
\hline MUESTRA & LITOLOGÍA & UBICACIÓN & $\operatorname{EDAD}(\mathrm{Ma})$ & REFERENCIA \\
\hline \multicolumn{5}{|c|}{ LAVAS DE GRIFO ALTO } \\
\hline & Traquiandesita & $\begin{array}{l}\text { Cuello volcánico, C. La Mina, H. Mon- } \\
\text { terrey, } 453,4-283,2\end{array}$ & $6,1 \pm 0,6(\mathrm{~K} / \mathrm{Ar})$ & $\begin{array}{l}\text { Sen Gupta et al. } \\
\text { (1986); Obando } \\
\text { (1986) }\end{array}$ \\
\hline CR-MV-02-40 & Lava & $\begin{array}{l}\text { Colada en zona de falla, H. Upala, } \\
\qquad 410,923-314,553\end{array}$ & $\begin{array}{c}5,65 \pm 0,03 \\
\left({ }^{40} \mathrm{Ar} /{ }^{39} \mathrm{Ar} \text { : mtz: plat. }\right)\end{array}$ & Carr et al. (2007) \\
\hline \multicolumn{5}{|c|}{ LAVA DE FM. MONTEVERDE? } \\
\hline CR-212 & $\begin{array}{l}\text { Bloque monolítico } \\
\text { de andesita basáltica }\end{array}$ & $\begin{array}{c}1 \mathrm{~km} \text { al E de Delicias, H. Monterrey, } \\
460,186-285,850\end{array}$ & $\begin{array}{c}1,73 \pm 0,20 \\
\left({ }^{40} \mathrm{Ar} /{ }^{39} \mathrm{Ar}: \mathrm{mtz}\right)\end{array}$ & Presente trabajo \\
\hline \multicolumn{5}{|c|}{ LAVAS RECIENTES } \\
\hline CR-259 & $\begin{array}{l}\text { Bloque andesítico } \\
\text { dentro del suelo }\end{array}$ & $\begin{array}{l}3 \mathrm{~km} \text { al SW del caserío de Paso Real, H. } \\
\text { Infiernito, } 485,450-300,925\end{array}$ & $\begin{array}{c}0,512 \pm 0,024 \\
\left({ }^{40} \mathrm{Ar} /{ }^{39} \mathrm{Ar}: \mathrm{mtz}\right)\end{array}$ & Presente trabajo \\
\hline CR-TE-02-32 & $\begin{array}{l}\text { Bloque de lava } \\
\text { dentro del suelo }\end{array}$ & $\begin{array}{c}2,8 \mathrm{~km} \text { al NE del C. Olla de Carne, entre } \\
\text { los riós Caño Negro y Rito, H. Guatuso, } \\
432,013-307,130\end{array}$ & $\begin{array}{c}0,209 \pm 0,04 \\
\left({ }^{40} \mathrm{Ar} /{ }^{39} \mathrm{Ar}: \mathrm{mtz}: \text { iso. }\right)\end{array}$ & Carr et al. (2007) \\
\hline
\end{tabular}

2004, Cuadro 9), con las rocas alcalinas tras-arco, y con el vulcanismo explosivo de Bagaces y sus lavas intraignimbríticas $(8,05-2,0 \mathrm{Ma})$. Algunas lavas e ignimbritas antiguas asociadas con esta fase (particularmente aquellas más antiguas que $6 \mathrm{Ma}$ ), presentan cierto grado de basculamiento (Cuadro 17).

Esta actividad culminó con la construcción de la meseta de lavas andesíticas hasta basálticas de la Fm. Monteverde (2,1 - 1,1 Ma, Cuadro 18, ver también Cuadros 15 y 17), presumiblemente asociadas con un vulcanismo fisural pero podría corresponder también con escudos andesíticos (Gillot et al., 1994; Carr et al., 2007; presente trabajo). El contacto entre las lavas del Grupo Aguacate y las de la Fm. Monteverde es difícil de trazar en ciertos sectores, ya que tanto su composición petrográfica como química es muy parecida. Sin embargo, isotópicamente, las lavas de Monteverse se parecen más a los estratovolcanes y difiere a la del

Cuadro 16

Dataciones radiométricas del Grupo Aguacate (Fm. La Cruz) y la Fm. Mata de Limón, en la cordillera de Tilarán y montes del Aguacate

\begin{tabular}{|c|c|c|c|c|}
\hline MUESTRA & LITOLOGÍA & UBICACIÓN & EDAD (Ma) & REFERENCIA \\
\hline 1 & "Aglomerado" & $\begin{array}{l}\text { Por cementerio entre Macacona y San Jerónimo, H. } \\
\text { Miramar, 466,5-222,5 }\end{array}$ & $23,0 \pm 3,6(\mathrm{~K} / \mathrm{Ar})$ & $\begin{array}{l}\text { Amos \& Rogers } \\
\quad(1983)\end{array}$ \\
\hline CR-166 & $\begin{array}{c}\text { Tobita blanca } \\
\text { vítreo-cristalina } \\
\text { en Fm. Mata de } \\
\text { Limón }\end{array}$ & Ca. Caldera, H. Barranca, 461,512-210,894 & $\begin{array}{c}19,96 \pm 0,22 \\
19,88 \pm 0,36 \\
\left({ }^{40} \mathrm{Ar} /{ }^{39} \mathrm{Ar}: \text { plag }\right)\end{array}$ & Presente trabajo \\
\hline 4 & Andesita & Cerca de Guacimal, H. Juntas, 442,8-243,6 & $11,8 \pm 2,5(\mathrm{~K} / \mathrm{Ar})$ & $\begin{array}{c}\text { Amos \& Rogers } \\
\text { (1983) }\end{array}$ \\
\hline CR-137 & Basalto & $\begin{array}{l}\text { Cerca Alto La Cruz, base de la sección, localidad } \\
\text { tipo Fm. La Cruz, H. Caraigres, 512,800-196,248 }\end{array}$ & $\begin{array}{c}11,35 \pm 0,10 \\
\left({ }^{40} \mathrm{Ar} /{ }^{39} \mathrm{Ar}: \mathrm{mtz}\right)\end{array}$ & $\begin{array}{l}\text { MacMillan et al. } \\
\text { (2004) }\end{array}$ \\
\hline CR-136 & Basalto & $\begin{array}{l}\text { Localidad tipo Fm. La Cruz, H. Caraigres, } \\
\qquad 514,600-196,248\end{array}$ & $\begin{array}{c}10,90 \pm 0,10 \\
\left({ }^{40} \mathrm{Ar} /{ }^{39} \mathrm{Ar}: \mathrm{mtz}\right)\end{array}$ & $\begin{array}{l}\text { MacMillan et al. } \\
\text { (2004) }\end{array}$ \\
\hline
\end{tabular}


Cuadro 17

Dataciones radiométricas del Grupo Aguacate (Fm. Grifo Alto) en los montes de Aguacate y cordillera de Tilarán

\begin{tabular}{|c|c|c|c|c|}
\hline MUESTRA & LITOLOGÍA & UBICACIÓN & EDAD (Ma) & REFERENCIA \\
\hline 10 & Andesita & R. Jabilla, H. Cañas, 421,1-265,2 & $8,7 \pm 1,7(\mathrm{~K} / \mathrm{Ar})$ & $\begin{array}{c}\text { Amos \& Rogers } \\
\text { (1983) }\end{array}$ \\
\hline CR-171 & Riolita con biot y hb. & $\begin{array}{c}3,5 \mathrm{~km} \text { al } \mathrm{N} \text { de Guacimal, } 750 \mathrm{~m} \text { al } \\
\text { NE del cementerio de Guaria, } \mathrm{H} . \\
\text { Chapernal, } 443,500-247,050\end{array}$ & $\begin{array}{c}7,30 \pm 0,20 \\
\left({ }^{40} \mathrm{Ar}{ }^{\beta 9} \mathrm{Ar}: \mathrm{plag}\right)\end{array}$ & Presente trabajo \\
\hline 2 & Andesita & $\begin{array}{c}\text { Cerca de Sabana Bonita, H. Mira- } \\
\text { mar, 462,0-230,2 }\end{array}$ & $6,7 \pm 0,9(\mathrm{~K} / \mathrm{Ar})$ & $\begin{array}{c}\text { Amos \& Rogers } \\
\text { (1983) }\end{array}$ \\
\hline CR-175 & Riolita fluidal basculada & $\begin{array}{l}\text { Ca. Interamericana, R. Ciruelas, H. } \\
\text { Chapernal, 452,400-226,850 }\end{array}$ & $\begin{array}{c}6,50 \pm 0,10 \\
\left({ }^{40} \mathrm{Ar} /{ }^{39} \mathrm{Ar}: \text { plag }\right)\end{array}$ & Presente trabajo \\
\hline CR-062 & Andesita lajeada & $\begin{array}{c}\text { Tajo La Garita, H. Río Grande, } \\
498,450-218,350\end{array}$ & $\begin{array}{c}6,10 \pm 0,30 \\
\left({ }^{40} \mathrm{Ar} /{ }^{39} \mathrm{Ar}: \mathrm{mtz}\right)\end{array}$ & Presente trabajo \\
\hline 8 & Bloque rodado de andesita & $\begin{array}{l}\text { Por Vergel de Cañas, H. Cañas, } \\
\qquad 422,3-269,2\end{array}$ & $5,8 \pm 0,6(\mathrm{~K} / \mathrm{Ar})$ & $\begin{array}{c}\text { Amos \& Rogers } \\
\text { (1983) }\end{array}$ \\
\hline CR-170 & $\begin{array}{l}\text { Andesita basáltica porfirítica } \\
\text { basculado sobre aluviones }\end{array}$ & C. Eskameca, H. Cañas, 410,8-258,7 & $\begin{array}{c}5,80 \pm 0,10 \\
\left({ }^{40} \mathrm{Ar} /{ }^{39} \mathrm{Ar}: \mathrm{mtz}\right)\end{array}$ & Presente trabajo \\
\hline 12 & Andesita & $\begin{array}{c}4,5 \mathrm{~km} \text { al SSW del Cerro San José, } \\
\text { H. Junta, 431,0-256,9 }\end{array}$ & $5,6 \pm 0,8(\mathrm{~K} / \mathrm{Ar})$ & $\begin{array}{c}\text { Amos \& Rogers } \\
\text { (1983) }\end{array}$ \\
\hline CR-62087-12 & Lava intra-ignimbrítica & $\begin{array}{c}\text { Cerro a } 1 \mathrm{~km} \text { al N de Hda. Taboga, } \\
\text { H. Cañas, 407,6-259,9 }\end{array}$ & $\begin{array}{l}5,45 \pm 0,23 \\
\left({ }^{40} \mathrm{Ar} /{ }^{39} \mathrm{Ar}\right)\end{array}$ & $\begin{array}{l}\text { Gardner \& Tu- } \\
\text { rrin (en Alvarado } \\
\quad \text { et al., 1992) }\end{array}$ \\
\hline CR-184 & Brecha andesítica basáltica & $\begin{array}{l}\text { 1,65 km al W de Loma E1 Rey, H. } \\
\text { Cañas, 421,150-261,350 }\end{array}$ & $\begin{array}{c}5,20 \pm 0,30 \\
\left({ }^{40} \mathrm{Ar} /{ }^{39} \mathrm{Ar}: \mathrm{mtz}\right)\end{array}$ & Presente trabajo \\
\hline CR-185 & Brecha andesítica basáltica & $\begin{array}{c}1,7 \mathrm{~km} \text { al WNW de Loma El Rey, H. } \\
\text { Cañas, 421,0-260,5 }\end{array}$ & $\begin{array}{c}5,15 \pm 0,36 \\
\left({ }^{40} \mathrm{Ar} /{ }^{39} \mathrm{Ar}: \mathrm{mtz}\right)\end{array}$ & Presente trabajo \\
\hline CR-139A/C & $\begin{array}{l}\text { Bloques en brechas andesíti- } \\
\text { cas monomícticas }\end{array}$ & $\begin{array}{c}\text { Cruz de Guatuso, Puriscal Localidad } \\
\text { tipo Fm. Grifo Alto, H. Río Grande, } \\
494,515-203,619\end{array}$ & $\begin{array}{c}5,10 \pm 0,10 \\
\left({ }^{40} \mathrm{Ar} /{ }^{39} \mathrm{Ar}: \mathrm{mtz}\right)\end{array}$ & $\begin{array}{l}\text { MacMillan et al. } \\
\text { (2004) }\end{array}$ \\
\hline CR-186 & Brecha de andesita basáltica & $\begin{array}{l}\text { 1,1 km al SSW del C. Cúpula, H. } \\
\text { Cañas, 421,150-265,150 }\end{array}$ & $\begin{array}{c}5,05 \pm 0,22 \\
\left({ }^{40} \mathrm{Ar} /{ }^{39} \mathrm{Ar}: \mathrm{mtz}\right)\end{array}$ & Presente trabajo \\
\hline CR94-13 & $\begin{array}{l}\text { Bloques en brechas andesíti- } \\
\text { cas monomícticas }\end{array}$ & $\begin{array}{c}\text { Cruz de Guatuso, Puriscal Localidad } \\
\text { tipo Fm. Grifo Alto, H. Río Grande, } \\
494,515-203,619\end{array}$ & $\begin{array}{c}5,01 \pm 0,11 \\
\left({ }^{40} \mathrm{Ar} /{ }^{39} \mathrm{Ar}: \text { plat. }\right. \\
\text { mtz })\end{array}$ & Marshall (2000) \\
\hline Mi89 & Basalto & $\begin{array}{c}\text { Lava, Carrera Buena, H. Miramar, } \\
467,057-321,406\end{array}$ & $\begin{array}{l}4,99 \pm 0,36(\mathrm{~K} / \\
\text { Ar: wr) }\end{array}$ & $\begin{array}{l}\text { Kycl et al. } \\
\text { (2010) }\end{array}$ \\
\hline CR-181 & Andesita piroxénica & $\begin{array}{c}\text { Lava sobre flujo de pómez, C. Peña } \\
\text { Blanca, H. Abangares, 422,800- } \\
252,850\end{array}$ & $\begin{array}{c}4,90 \pm 0,40 \\
\left({ }^{40} \mathrm{Ar} /{ }^{39} \mathrm{Ar}: \mathrm{plag}\right)\end{array}$ & Presente trabajo \\
\hline CR-6208711 & Basalto & $\begin{array}{c}\text { C. Alta } 151 \text { Torre, Queb. Palo, } \\
\text { Ca. Interamericana, H. Chapernal, } \\
449,8-229,3\end{array}$ & $\begin{array}{l}4,89 \pm 0,25 \\
\left({ }^{40} \mathrm{Ar} /{ }^{39} \mathrm{Ar}\right)\end{array}$ & $\begin{array}{l}\text { Gardner \& Tu- } \\
\text { rrin (en Alvarado } \\
\quad \text { et al., 1992) }\end{array}$ \\
\hline Mi95 & Riolita fluidal & $\begin{array}{c}\text { Miramar, H. Miramar, } \\
456,064-229,606\end{array}$ & $\begin{array}{c}4,41 \pm 0,15(\mathrm{~K} / \\
\text { Ar: wr) }\end{array}$ & $\begin{array}{l}\text { Kycl et al. } \\
\text { (2010) }\end{array}$ \\
\hline CR-183 & Domo de dacita piroxénica & $\begin{array}{c}\text { Concepción, H. Abangares, } \\
426,85-253,80\end{array}$ & $\begin{array}{c}4,40 \pm 0,10 \\
\left({ }^{40} \mathrm{Ar} /{ }^{39} \mathrm{Ar}: \mathrm{mtz}\right)\end{array}$ & Presente trabajo \\
\hline
\end{tabular}


Cuadro 17 (continuación)

Dataciones radiométricas del Grupo Aguacate (Fm. Grifo Alto) en los montes de Aguacate y cordillera de Tilarán

\begin{tabular}{|c|c|c|c|c|}
\hline MUESTRA & LITOLOGÍA & UBICACIÓN & EDAD (Ma) & REFERENCIA \\
\hline AGU-062 & Andesita & $\begin{array}{l}\text { Queb. Concepción ,H. Río Grande, } \\
\text { aprox. 484,9-213,8 }\end{array}$ & $4,4 \pm 1,8(\mathrm{~K} / \mathrm{Ar})$ & Appel (1990) \\
\hline G-18 & Andesita & $\begin{array}{l}\text { Cerca del C. Pelado, por Jabilla } \\
\text { Arriba, H. Cañas, 424,6-265,2 }\end{array}$ & $\begin{array}{l}4,38 \pm 0,28(\mathrm{~K} / \mathrm{Ar}) \\
4,37 \pm 0,35(\mathrm{~K} / \mathrm{Ar})\end{array}$ & $\begin{array}{l}\text { ICE-ENEL } \\
(1989)\end{array}$ \\
\hline CR-140 & Basalto & $\begin{array}{l}\text { Tajo Grifo Alto, cerca de Pieda- } \\
\text { des de Santiago, H. Río Grande, } \\
494,525-205,462\end{array}$ & $\begin{array}{c}4,04 \pm 0,04 \\
\left({ }^{40} \mathrm{Ar} /{ }^{39} \mathrm{Ar}: \mathrm{mtz}\right)\end{array}$ & $\begin{array}{l}\text { MacMillan et al. } \\
\text { (2004) }\end{array}$ \\
\hline CR-616871 & $\begin{array}{c}\text { Bloque de lava dentro de } \\
\text { lahar }\end{array}$ & $\begin{array}{l}\text { Intersección Jacó-Caldera, H. Ba- } \\
\text { rranca, 472,5- 207,5 }\end{array}$ & $3,5\left({ }^{40} \mathrm{Ar} /{ }^{39} \mathrm{Ar}\right)$ & $\begin{array}{l}\text { Gardner \& Tu- } \\
\text { rrin (en Alvarado } \\
\quad \text { et al., 1992) }\end{array}$ \\
\hline CR-061 & Andesita basáltica & $\begin{array}{l}\text { Ca. cerca de Atenas, H. Río Grande, } \\
\qquad 497,100-218,050\end{array}$ & $\begin{array}{c}3,50 \pm 0,20 \\
\left({ }^{40} \mathrm{Ar} /{ }^{39} \mathrm{Ar}: \mathrm{mtz}\right)\end{array}$ & Presente trabajo \\
\hline $\mathrm{Na}-13$ & Basalto & $\begin{array}{l}\text { Tajo Alto Santiago, San Ramón, H. } \\
\text { Miramar, 481,5- 228,0 }\end{array}$ & $3,2 \pm 0,2(\mathrm{~K} / \mathrm{Ar})$ & $\begin{array}{l}\text { Bellon \& Tour- } \\
\text { non (1978) }\end{array}$ \\
\hline G-19 & Andesita & $\begin{array}{c}\text { Cerro a } 2 \mathrm{~km} \text { al S del C. Pelado, } \\
\text { H. Cañas, } 424,6-258,6\end{array}$ & $\begin{array}{c}3,01 \pm 0,86 \\
2,97 \pm 0,55 \\
(\mathrm{~K} / \text { Ar: plag) }\end{array}$ & $\begin{array}{l}\text { ICE-ENEL } \\
\text { (1989) }\end{array}$ \\
\hline \multicolumn{5}{|c|}{ BASAMENTO DEL VOLCÁN TURRIALBA (FM. GRIFO ALTO O MONTEVERDE $i)$} \\
\hline S-21 & Andesita con anfíbol & $\begin{array}{c}\text { Pascua, valle del Reventazón, base del } \\
\text { v. Turrialba, H. Bonilla, 579,3-222,9 }\end{array}$ & $\begin{array}{l}2,15 \pm 0,3 \\
(\mathrm{~K} / \mathrm{Ar})\end{array}$ & $\begin{array}{l}\text { Bellon \& Tour- } \\
\text { non (1978) }\end{array}$ \\
\hline
\end{tabular}

Aguacate (E. Gazel, com. escrita, 2011). Del mismo modo, sucede a la hora de establecer el contacto en el campo entre Monteverde y las lavas antiguas de los estratovolcanes Cuaternarios, por ejemplo, en el extremo sur y oriental del volcán Tenorio u occidental de la cordillera volcánica Central. No obstante, localmente se encuentran depósitos de flujos de pómez infrayaciendo a la Fm. Monteverde (Chaves \& Sáenz, 1974; Cigolini \& Chaves, 1986; Kycl et al., 2010). Uno de estos depósitos de flujos de pómez rico en biotita, fue datado por ${ }^{40} \mathrm{Ar} /{ }^{39} \mathrm{Ar}$ en $1,55 \pm 0,02 \mathrm{Ma}$, estando sobreyacido por una colada andesítica con una edad de 1,57 $\pm 0,03 \mathrm{Ma}$ (carretera de acceso a la planta hidroeléctrica Daniel Gutiérrez), que se traslapa en sus rangos entre 1,57 y 1,54 Ma, siendo este ámbito de edad el más probable para la colada de lava (ver y comparar Cuadros 18 y 31 ).

Infrayaciendo al cono piroclástico del cerro Chopo y en las vecindades de la presa de Sandillal por Cañas, las lavas de Monteverde, datadas por ${ }^{40} \mathrm{Ar} /{ }^{39} \mathrm{Ar}$ entre 1,7 y 2,0 Ma, sobreyacen igualmente a depósitos de flujos de pómez antiguos (4,1 Ma), estando separadas por paleosuelos y por depósitos fluviales. En el canal de Sandillal, camino a Upala, sin embargo, los depósitos de flujos de pómez poseen edades de 2,06 Ma.

La Fm. Monteverde, tanto en Tilarán como en los Montes del Aguacate, y en algunos cerros aislados (p.ej., cerro El Hacha) y por los montes del Aguacate, poseen lavas más sanas, en buena parte sin alteración hidrotermal en sus facies distales (lejos del foco eruptivo) ni mineralizaciones auríferas, y con su típica, pero no exclusiva, morfología de meseta o de escudo andesítico; además, posee su sonido metálico llamado "fonolítico", aunque claramente su petrografía es andesítica con subordinadas coladas basálticas.

Un vulcanismo más localizado está representado por los domos ácidos (Cuadro 18) de San 
Cuadro 18

Dataciones radiométricas del vulcanismo efusivo de Fm. Monteverde

\begin{tabular}{|c|c|c|c|c|}
\hline MUESTRA & LITOLOGIA & UBICACIÓN & $\operatorname{EDAD}(\mathrm{Ma})$ & REFERENCIA \\
\hline \multicolumn{5}{|c|}{ VULCANISMO EFUSIVO DE MONTEVERDE } \\
\hline 5 & Andesita & $\begin{array}{l}\text { Cerca de Queb. Alondra, C. Centinelas, H. } \\
\text { Juntas, 444,9-252,2 }\end{array}$ & $2,2 \pm 0,5(\mathrm{~K} / \mathrm{Ar})$ & $\begin{array}{l}\text { Amos \& Rogers } \\
\text { (1983) }\end{array}$ \\
\hline CR-TE-02-38 & Andesita & $\begin{array}{l}\text { Tajo C. Bambú, Tierras Morenas, H. Tierras } \\
\text { Morenas, 421,684-286,213 }\end{array}$ & $\begin{array}{l}2,174 \pm 0,040 \\
\left({ }^{40} \mathrm{Ar} /{ }^{39} \mathrm{Ar}: \mathrm{mtz}\right. \\
\quad \text { iso. })\end{array}$ & Carr et al. (2007) \\
\hline CR-025 & Andesita basáltica & $\begin{array}{l}\text { Basamento del C. Chopo, H. Cañas, } \\
\qquad 418,900-272,075\end{array}$ & $\begin{array}{c}2,030 \pm 0,020 \\
\left({ }^{40} \mathrm{Ar} /{ }^{39} \mathrm{Ar}: \mathrm{mtz}\right)\end{array}$ & Presente trabajo \\
\hline \multirow[t]{2}{*}{ CR97-1 } & Andesita & $\begin{array}{l}\text { Colada de lava bajo gravas aluviales, cerca } \\
\text { del Chopo, H. Cañas, } 419,717-271,913\end{array}$ & $2,08 \pm 0,26$ (plat.) & Marshall (2000) \\
\hline & & & $\begin{array}{c}1,90 \pm 0,05 \\
\left({ }^{40} \mathrm{Ar} /{ }^{39} \mathrm{Ar}: \text { iso.: }\right. \\
\quad \mathrm{mtz})\end{array}$ & \\
\hline CR-026 & Andesita basáltica & $\begin{array}{l}\text { Basamento del C. Chopo, H. Cañas, } \\
\qquad 418,900-272,075\end{array}$ & $\begin{array}{c}2,040 \pm 0,015 \\
\left({ }^{40} \mathrm{Ar} /{ }^{39} \mathrm{Ar}: \mathrm{mtz}\right)\end{array}$ & Presente trabajo \\
\hline CR-027 & Andesita basáltica & $\begin{array}{l}\text { Basamento del C. Chopo, H. Cañas, } \\
\qquad 418,750-271,750\end{array}$ & $\begin{array}{c}2,040 \pm 0,010 \\
\left({ }^{40} \mathrm{Ar} /{ }^{39} \mathrm{Ar}: \mathrm{mtz}\right)\end{array}$ & Presente trabajo \\
\hline PT-1/93 (JR-43) & $\begin{array}{l}\text { Colada de an- } \\
\text { desita dentro de } \\
\text { brechas }\end{array}$ & $\begin{array}{c}\text { Pozo de gradiente geotérmico }(92 \mathrm{~m}) \text {, } \\
\text { poblado de Paraíso, Queb. Casa, H. Tierras } \\
\text { Morenas, } 421,8-288,2\end{array}$ & $\begin{array}{c}\text { Aprox. } 1,96 \pm \\
0,03(\mathrm{~K} / \mathrm{Ar})\end{array}$ & $\begin{array}{l}\text { ICE-ENEL } \\
\quad(1990)\end{array}$ \\
\hline CR-169 & Andesita & $\begin{array}{l}\text { Cuesta Blanca, entre La Lindora y Llanos, } \\
\text { H. Juntas, 445,200-243,300 }\end{array}$ & $\begin{array}{c}1,92 \pm 0,04 \\
\left({ }^{40} \mathrm{Ar} /{ }^{39} \mathrm{Ar}: \mathrm{mtz}\right)\end{array}$ & Presente trabajo \\
\hline 6 & Andesita & E de Líbano, H. Tilarán, 431,4- 267,5 & $1,8 \pm 0,8(\mathrm{~K} / \mathrm{Ar})$ & $\begin{array}{l}\text { Amos \& Rogers } \\
\quad(1983)\end{array}$ \\
\hline CR-104 & Andesita basáltica & $\begin{array}{l}\text { P.H. Peñas Blancas sitio de Presa, tope per- } \\
\text { foración, H. Fortuna, 470,025-260,950 }\end{array}$ & $\begin{array}{c}1,79 \pm 0,04 \\
\left({ }^{40} \mathrm{Ar} /{ }^{39} \mathrm{Ar}: \mathrm{mtz}\right)\end{array}$ & Presente trabajo \\
\hline Mi245 & Andesita basáltica & $\begin{array}{l}\text { Tajo Bellavista, } 3 \text { km ENE Miramar, H. } \\
\text { Miramar, 459,811-231,291 }\end{array}$ & $\begin{array}{l}1,77 \pm 0,11(\mathrm{~K} / \\
\text { Ar: wr) }\end{array}$ & Kycl et al. (2010) \\
\hline CR-C-3-89 & Andesita & Presa Sandillal, H. Cañas, 415.7E- 271.4N & $\begin{array}{l}1,77 \pm 0,05 \\
\left({ }^{40} \mathrm{Ar} /{ }^{39} \mathrm{Ar}\right)\end{array}$ & $\begin{array}{l}\text { Gardner \& Turrin } \\
\text { (en Alvarado et } \\
\text { al., 1992) }\end{array}$ \\
\hline Mi343 & Andesita basáltica & $\begin{array}{l}\text { Finca Mirón, H. Miramar, 463.364E-222- } \\
.285 \mathrm{~N}\end{array}$ & $\begin{array}{l}1,71 \pm 0,22(\mathrm{~K} / \\
\text { Ar: wr })\end{array}$ & Kycl et al. (2010) \\
\hline CR-107 & Andesita basáltica & $\begin{array}{l}\text { P.H. Peñas Blancas sitio de Presa, parte basal } \\
\text { de la perforación, H. Fortuna, 470,025-260,950 }\end{array}$ & $\begin{array}{c}1,77 \pm 0,004 \\
\left({ }^{40} \mathrm{Ar} /{ }^{39} \mathrm{Ar}: \mathrm{mtz}\right)\end{array}$ & Presente trabajo \\
\hline CR-C-1-89 & Andesita & $\begin{array}{l}\text { Basamento del C. Chopo, H. Cañas, } \\
\qquad 418,8-271,8\end{array}$ & $\begin{array}{c}1,70 \pm 0,09 \\
(40 \mathrm{Ar} / 39 \mathrm{Ar})\end{array}$ & $\begin{array}{c}\text { Gardner \& Turrin } \\
\text { (en Alvarado et } \\
\text { al., 1992) }\end{array}$ \\
\hline CRO72ARK & Andesita & W San Ramón, H. Miramar, 479,0- 233,4 & $1,6 \pm 0,04(\mathrm{~K} / \mathrm{Ar})$ & $\begin{array}{l}\text { Schultz et al. } \\
1987\end{array}$ \\
\hline CR-213 & $\begin{array}{l}\text { Andesita sobre } \\
\text { flujo de pómez } \\
\text { CR-214 }\end{array}$ & $\begin{array}{l}\text { P.H. Daniel Gutiérrez, R. Balsa, H. San } \\
\text { Lorenzo, } 479,850-246,900\end{array}$ & $\begin{array}{c}1,57 \pm 0,03 \\
\left({ }^{40} \mathrm{Ar} /{ }^{39} \mathrm{Ar}: \mathrm{mtz}\right)\end{array}$ & Presente trabajo \\
\hline
\end{tabular}


Cuadro 18 (continuación)

Dataciones radiométricas del vulcanismo efusivo de Fm. Monteverde

\begin{tabular}{|c|c|c|c|c|}
\hline MUESTRA & LITOLOGIA & UBICACIÓN & $\operatorname{EDAD}(\mathrm{Ma})$ & REFERENCIA \\
\hline CR-C-2-89 & Basalto & Lavas "Las Pulgas", H. Cañas, 419,8-273,8 & $\begin{array}{l}1,38 \pm 0,04 \\
\left({ }^{40} \mathrm{Ar} /{ }^{39} \mathrm{Ar}\right)\end{array}$ & $\begin{array}{c}\text { Gardner \& Turrin } \\
\text { (en Alvarado et } \\
\text { al., 1992) }\end{array}$ \\
\hline CR-168 & Andesita & $\begin{array}{l}\text { Cuesta Blanca, entre La Lindora y Llanos, } \\
\text { H. Juntas, } 445,150-253,300\end{array}$ & $\begin{array}{c}1,350 \pm 0,020 \\
\left({ }^{40} \mathrm{Ar} /{ }^{39} \mathrm{Ar}: \mathrm{mtz}\right)\end{array}$ & Presente trabajo \\
\hline CR-177 & $\begin{array}{l}\text { Basalto gris } \\
\text { lajeada }\end{array}$ & $\begin{array}{l}\text { C. Tilarán (Tovar), H. Tilarán, } \\
\text { 429,200-271,600 }\end{array}$ & $\begin{array}{c}1,340 \pm 0,020 \\
\left({ }^{40} \mathrm{Ar} /{ }^{39} \mathrm{Ar}: \mathrm{mtz}\right)\end{array}$ & Presente trabajo \\
\hline G-49 Y & Andesita rica en $\mathrm{K}$ & $\begin{array}{l}500 \text { m NW laguna Poco Sol, H. Fortuna, } \\
\qquad 462,3-258,9\end{array}$ & $\begin{array}{c}1,313 \pm 0,04 \\
1,282 \pm 0,04(\mathrm{~K} / \\
\text { Ar: } \mathrm{mtz})\end{array}$ & $\begin{array}{l}\text { Gillot et al. } \\
\text { (1994) }\end{array}$ \\
\hline MZ-37 & Andesita rica en $\mathrm{K}$ & Monteverde, H. Juntas, 447,5E-254,6 & $\begin{array}{c}1,301 \pm 0,02 \\
1,281 \pm 0,02(\mathrm{~K} / \\
\text { Ar: } \mathrm{mtz})\end{array}$ & $\begin{array}{l}\text { Gillot et al. } \\
\text { (1994) }\end{array}$ \\
\hline G-49 Z & Basalto alumínico & $\begin{array}{l}\text { Por San Miguel de Poco Sol, R. Peñas Blan- } \\
\text { cas, H. Fortuna, 466,4- 259,9 }\end{array}$ & $\begin{array}{c}1,303 \pm 0,35 \\
1,275 \pm 0,35 \\
1,117 \pm 0,35(\mathrm{~K} / \\
\text { Ar: } \mathrm{mtz})\end{array}$ & $\begin{array}{l}\text { Gillot et al. } \\
\text { (1994) }\end{array}$ \\
\hline CR-C-6-89 & Andesita & $\begin{array}{l}\text { Basamento del C. Chopo, H. Cañas, 419,3- } \\
\qquad 272,4\end{array}$ & $\begin{array}{l}1,16 \pm 0,18 \\
\left({ }^{40} \mathrm{Ar} /{ }^{39} \mathrm{Ar}\right)\end{array}$ & $\begin{array}{c}\text { Gardner \& Turrin } \\
\text { (en Alvarado et } \\
\text { al., 1992) }\end{array}$ \\
\hline \multicolumn{5}{|c|}{ DOMOS ÁCIDOS } \\
\hline Mi39 & $\begin{array}{l}\text { Riolita con } \\
\text { anfíbol }\end{array}$ & $\begin{array}{l}\text { Cuesta La Danta, domo C. La Cruz, H. } \\
\text { Miramar, 465,233-233,405 }\end{array}$ & $\begin{array}{c}1,71 \pm 0,14(\mathrm{~K} / \\
\text { Ar: hb, biot) } 1,13 \\
\pm 0,06(\mathrm{~K} / \mathrm{Ar}: \mathrm{wr})\end{array}$ & Kycl et al. (2010) \\
\hline Mi236 & Dacita con anfíbol & $\begin{array}{l}\text { R. San Miguel, domo C. San Miguel, H. } \\
\text { Miramar, 459,770-222,289 }\end{array}$ & $\begin{array}{l}1,59 \pm 0,12(\mathrm{~K} / \\
\text { Ar: biot })\end{array}$ & Kycl et al. (2010) \\
\hline
\end{tabular}

Miguel y La Cruz (K/Ar 1,71 - 1,59 Ma; Kycl et al., 2010), que tendrían sus homónimos al pie del volcán Rincón de la Vieja (domos de Cañas Dulces, 1,6 - 1,4 Ma, Cuadro 22). La fase final del vulcanismo, más bien asociado con los estratovolcanes activos o recientes, procedentes de cuerpos dómicos de los cerros Los Perdidos en 86 y $83 \mathrm{ka}$, y una lava de la base del volcán cerro Chato en 48 - 38 ka (Gillot et al., 1994; presente trabajo).

Así, la historia magmática en la cordillera de Tilarán y montes del Aguacate puede resumirse de la siguiente manera:

a. Coetáneo con la sedimentación marina y las intrusiones, se tiene un vulcanismo de arco de islas: 19,9 - 10,9 Ma). Correspondería con las lavas asociadas con la Fm. Pacacua y la Fm. La Cruz.

b. Seguido a una fase de basculamiento, tenemos las lavas, brechas e ignimbritas asociadas con la Fm. Grifo Alto: 7,3 - 3,3 Ma.

c. Intrusión de Guacimal (aprox. 6,4 - 5,2 Ma) y Desmonte (3,5 Ma).

d. Ignimbritas dacíticas, en algún momento todavía no bien establecido: 3,3 - 2,1 Ma.

e. Profuso vulcanismo efusivo de Monteverde: 2,1 - 1,1 Ma.

f. Emplazamiento de domos ácidos: 1,71 1,59 Ma. 
Cuadro 19

Dataciones radiométricas del vitrófiro intraignímbritico de Carbonal (Fm. Bagaces Inferior)

\begin{tabular}{|c|c|c|c|c|}
\hline MUESTRA & LITOLOGIA & UBICACIÓN & $\operatorname{EDAD}(\mathrm{Ma})$ & REFERENCIA \\
\hline \multicolumn{5}{|c|}{ VITRÓFIRO CARBONAL $(8,05 \pm 0,09 \mathrm{Ma})$} \\
\hline $990720-12$ & Dacita Carbonal & $\begin{array}{l}\text { Parque Nacional Santa Rosa, H. Aho- } \\
\text { gados, 356,011-309,000 }\end{array}$ & $\begin{array}{c}8,60 \pm 0,70 \\
\left({ }^{40} \mathrm{Ar} /{ }^{39} \mathrm{Ar}: \text { plag }\right)\end{array}$ & Presente trabajo \\
\hline CR-179 & $\begin{array}{l}\text { Vitrófiro andesítico } \\
\text { piroxénico }\end{array}$ & $\begin{array}{l}\text { Loma a } 1 \mathrm{~km} \text { al W C. Eskameca, Hda. } \\
\text { Taboga, H. Cañas, 409,7- 258,2 }\end{array}$ & $\begin{array}{c}8,05 \pm 0,10 \\
\left({ }^{40} \mathrm{Ar} /{ }^{39} \mathrm{Ar}: \text { plag }\right)\end{array}$ & Presente trabajo \\
\hline G-49 S & Vitrófiro dacítico & C. Cabuyal, H. Ahogados, 356,9-295,8 & $\begin{array}{c}7,81 \pm 0,16 \\
7,99 \pm 0,16 \\
7,85 \pm 0,16 \\
\text { (K/Ar: mtz, plag) }\end{array}$ & Gillot et al. (1994) \\
\hline CR-62287-18 & Vitrófiro dacítico & C. Cabuyal, H. Ahogados, 357,3-295,2 & $6,5\left({ }^{40} \mathrm{Ar} /{ }^{39} \mathrm{Ar}\right)$ & $\begin{array}{l}\text { Gardner \& Turrin (en } \\
\text { Alvarado et al., 1992) }\end{array}$ \\
\hline
\end{tabular}

g. Emplazamiento de los domos de los cerros Los Perdidos (0,086 - $0.083 \mathrm{Ma})$, para finalmente dar paso a los volcanes Chato $(0,048-0,0038)$ y Arenal (0,007 - $0 \mathrm{Ma})$, montados sobre el flanco norte de la cordillera de Tilarán.

\section{CORDILLERAS VOLCÁNICAS Y SU PIE DE MONTE}

\section{Plataforma de ignimbritas}

\section{Meseta de Santa Rosa y abanico ignimbrítico de Liberia}

En Guanacaste se presente una extensa planicie o plateau volcánico originado por varias decenas de abanicos de ignimbritas (Fig. 2).

Un potente macizo rocoso ( $\geq 90 \mathrm{~m}$ de espesor) constituye los acantilados de Cabuyal, Carbonal y parte del camino de Santa Rosa a playa Naranjo. La roca es una dacita negra (plag $+\mathrm{cpx}$ ), vidriosa, con textura hialopilítica o perlítica, estructuras de flujo, pliegues, rosas de prismas por disyunción columnar, brechas locales, pocos xenolitos y clastos pumíceos, cuya base suele ser masiva pero su parte superior con marcada disyunción columnar. La discusión de si se trata de una reoignimibrita o un potente cuerpo lávico, parece inclinarse a favor de lo último. La dacitas de Carbonal sobreyacen a un flujo piroclástico que aflora en la base de los taludes que unen la Meseta de Santa Rosa con el llano aluvial del río Nisperal y cerca del cauce sur de la laguna El Limbo (Chiesa et al., 1987, 1998). Los vitrófiros de Carbonal están datados entre 8,6 $\pm 0,70$ hasta 7,85 $\pm 0,16 \mathrm{Ma}$, con una excepción de una edad de 6,5 Ma, pero al parecer las rocas están cargadas de xenocristales, por lo que su datación no ha sido del todo fácil según lo expresaron los laboratoristas. Una "toba" proveniente de la parte basal de la Fm. Bagaces y que en el mapa se dice como anotación que se le llama "Santa Rosa" (Cuadro 1), pero sin mayores detalles de su ubicación, aportó una edad de 7,5 \pm 2 Ma (Mainieri, 1976), que podría corresponder con esta unidad algo alterada, que por su carácter vidrioso, al meteorizarse, emula una toba. Tomando en cuenta las mejores dataciones y asumiendo que se trate de un único flujo o de varios cercanos en el tiempo, su edad media sería de 8,05 $\pm 0,06 \mathrm{Ma}$ (Cuadro 19).

Sobre Carbonal existe una potente serie de ignimbritas, intercaladas con coladas de lava y depósitos fluviales y fluvio-lacustrinos, para totalizar un espesor de al menos unos $200 \mathrm{~m}$ que conjunto con Carbonal constituye la llamada Fm. Bagaces, con una potencia total compuesta de $500 \mathrm{~m}$. Las coladas de lava intercaladas son de composición andesítico basáltica hasta dacítica (Chiesa et al., 1994), masivas o lajeadas. Algunas de las ignimbritas poseen fiammes bien desarrollados, mientras que otras son flujos de pómez no soldados o tobas de flujo ricas en lapilli (líticos, pómez, cristales); sus colores son grises, blancuzcos, rojizos e incluso amarillentos. Los minerales hidroxilados (biotita y 
anfíbol) así como el cuarzo, suelen estar completamente ausentes o en el caso de su presencia, no suelen ser abundantes a lo largo de la mayoría de los afloramientos. Las edades de la mayoría de los depósitos de flujo de Bagaces varían entre 4,87 y 2,0 Ma (Cuadro 20). Los sedimentos epiclásticos (fluviales en su mayoría, lacustrinos subordinados) e incluso marinos (Aguilar \& Alvarado, 2004; presente trabajo), pueden poseer espesores entre unos pocos decímetros hasta decenas de metros.

Un problema claro se establece cuando se pregunta ¿Qué ocurrió entre las dacitas de Carbonal

Cuadro 20

Dataciones radiométricas de las ignimbritas de Bagaces

\begin{tabular}{|c|c|c|c|c|}
\hline MUESTRA & LITOLOGÍA & UBICACIÓN & $\operatorname{EDAD}(\mathrm{Ma})$ & REFERENCIA \\
\hline \multicolumn{5}{|c|}{ BAGACES POR BARBUDAL } \\
\hline 020703-13a & Ignimbrita & $\begin{array}{l}\text { Tajo Pelón, Alto Mirador, H. Tempis- } \\
\text { que, } 382,5-274,0\end{array}$ & $\begin{array}{c}4,87 \pm 0,07 \\
\left({ }^{40} \mathrm{Ar} /{ }^{39} \text { Ar: plag }\right) \\
\end{array}$ & $\begin{array}{l}\text { Szymanski (com. } \\
\text { escrita, 2009) }\end{array}$ \\
\hline \multicolumn{5}{|c|}{ IGNIMBRITAS SANDILLAL } \\
\hline $990716-1 f$ & $\begin{array}{l}\text { Depósito de flujo de pó- } \\
\text { mez superior (Sandillal) }\end{array}$ & $\begin{array}{l}\text { Tajo camino entre el Chopo y Sandi- } \\
\text { 1lal, H. Cañas, } 418,5-273,1\end{array}$ & $\begin{array}{c}4,15 \pm 0,02 \\
\left({ }^{40} \mathrm{Ar} /{ }^{39} \text { Ar: plag }\right)\end{array}$ & Presente trabajo \\
\hline $990715-3 p$ & $\begin{array}{l}\text { Depósito de flujo de pó- } \\
\text { mez inferior (Sandillal) }\end{array}$ & $\begin{array}{l}\text { Tajo camino entre el Chopo y Sandi- } \\
\text { 1lal, H. Cañas, } 418,5-273,1\end{array}$ & $\begin{array}{c}4,10 \pm 0,04 \\
4,10 \pm 0,02 \\
\left({ }^{40} \mathrm{Ar} /{ }^{39} \mathrm{Ar}: \text { plag }\right)\end{array}$ & Presente trabajo \\
\hline \multicolumn{5}{|c|}{ OTRAS IGNIMBRITAS } \\
\hline $\mathrm{P} 1$ & $\begin{array}{l}\text { Toba gris, lítico-vidriosa } \\
\text { con estructura de flujo }\end{array}$ & $\begin{array}{l}\text { Parte media Fm. Bagaces, cerca del } \\
\text { R. Pijije, } 3,5 \mathrm{~km} \text { de la Hda. El Pelón } \\
\text { de la Bajura, H. Monteverde, aprox. } \\
\text { 383,6-277,3(?) }\end{array}$ & $3,8 \pm 0,5(\mathrm{~K} / \mathrm{Ar})$ & Mainieri (1976) \\
\hline $040704-5 d$ & Ignimbrita Pan de Azúcar & $\begin{array}{c}6 \mathrm{~km} \text { al sur de Bagaces, finca San } \\
\text { Gerardo, H. Tempisque, 398,4-271,7 }\end{array}$ & $\begin{array}{c}3,64 \pm 0,066 \\
\left({ }^{40} \mathrm{Ar} /{ }^{39} \text { Ar: plag }\right)\end{array}$ & $\begin{array}{l}\text { Szymanski (com. } \\
\text { escrita, 2009) }\end{array}$ \\
\hline $990721-3 j$ & $\begin{array}{l}\text { Pómez de caída con } \\
\text { anfíbol }\end{array}$ & $\begin{array}{l}\text { Tajo, sitio Abomal, Queb. Barbudal, } \\
\text { H. Carrillo Norte, 361,24-289,53 }\end{array}$ & $\begin{array}{c}3,21 \pm 0,06 \\
\left({ }^{40} \mathrm{Ar} /{ }^{39} \text { Ar: plag }\right)\end{array}$ & Presente trabajo \\
\hline BBCR-3 (B3) & Ignimbrita con algo de hb. & $\begin{array}{l}\text { Ignimbrita sobre colada de lava, } 4 \text { km } \\
\text { antes de la Hda. El Pelón de la Baju- } \\
\text { ra, H. Monteverde, } 383,8-277,6\end{array}$ & $3,06 \pm 0,2(\mathrm{~K} / \mathrm{Ar})$ & Bergoeing (1982) \\
\hline $990721-3 d$ & $\begin{array}{l}\text { Depósito de flujo piroclás- } \\
\text { tico con grandes pómez }\end{array}$ & $\begin{array}{l}\text { Tajo, sitio Abomal, Queb. Barbudal, } \\
\text { H. Carrillo Norte, 361,241-289,353 }\end{array}$ & $\begin{array}{c}2,97 \pm 0,03 \\
\left({ }^{40} \mathrm{Ar} /{ }^{39} \mathrm{Ar}: \text { plag }\right)\end{array}$ & Presente trabajo \\
\hline \multicolumn{5}{|c|}{ IGNIMBRITA RÍO COLORADO $(2,08 \pm 0,01 \mathrm{Ma})$} \\
\hline $99721-5$ & Ignimbrita & $\begin{array}{l}\text { Cuesta sitio Abomal, Queb. Barbudal, } \\
\text { H. Carrillo Norte, 361,396-289,503 }\end{array}$ & $\begin{array}{c}2,11 \pm 0,04 \\
\left({ }^{40} \mathrm{Ar} /{ }^{39} \mathrm{Ar}: \text { plag }\right)\end{array}$ & Presente trabajo \\
\hline CR-017 & Ignimbrita & $\begin{array}{c}\text { Ca. Interamericana, } 200 \mathrm{~m} \mathrm{SE} \\
\text { puente R. Villa Vieja, H. Tempisque, } \\
\quad 401,800-275,707\end{array}$ & $\begin{array}{c}2,11 \pm 0,02 \\
\left({ }^{40} \mathrm{Ar} /{ }^{39} \mathrm{Ar}: \text { plag }\right)\end{array}$ & Presente trabajo \\
\hline $990721-4$ & Ignimbrita & $\begin{array}{l}\text { Cuesta sitio Abomal, Queb. Barbudal, } \\
\text { H. Carrillo Norte, 361,272-289,610 }\end{array}$ & $\begin{array}{c}2,10 \pm 0,02 \\
\left({ }^{40} \mathrm{Ar} /{ }^{/ 9} \mathrm{Ar}: \text { plag }\right)\end{array}$ & Presente trabajo \\
\hline $020702-4 a$ & Ignimbrita & $\begin{array}{l}1 \mathrm{~km} \text { al sur de Aguacaliente de Baga- } \\
\text { ces, H. Cañas, 402,250-271,200 }\end{array}$ & $\begin{array}{l}1,87 \pm 0,05 \text { (iso: } \\
{ }^{40} \mathrm{Ar} /{ }^{39} \mathrm{Ar}: \text { plag) }\end{array}$ & $\begin{array}{l}\text { Szymanski (com. } \\
\text { escrita, 2009) }\end{array}$ \\
\hline \multicolumn{5}{|c|}{ IGNIMBRITA DE CAÑAS } \\
\hline $990716-6 b$ & $\begin{array}{l}\text { Depósito de flujo de } \\
\text { pómez de Cañas }\end{array}$ & $\begin{array}{l}\text { Canal de Sandillal, Ca. a Upala, H. } \\
\text { Cañas, } 411,900-273,425\end{array}$ & $\begin{array}{c}2,06 \pm 0,02 \\
\left({ }^{40} \mathrm{Ar} /{ }^{39} \mathrm{Ar}: \text { plag }\right)\end{array}$ & Presente trabajo \\
\hline
\end{tabular}


$(8,05 \mathrm{Ma})$ y la ignimbrita más antigua datada en este sector en 4,87 Ma? ¿Es el producto de una falta en la toma de muestras radiométricas o efectivamente representa una brecha en el vulcanismo de casi 3,18 Ma? Por otro lado, resulta ser que en el vulcanismo reciente del Aguacate $(=\mathrm{Fm}$. Grifo Alto) se tienen lavas datadas con confiabilidad entre 7,3 y $3 \mathrm{Ma}$, y algunas ignimbritas intercaladas entre 6,05 y 4,2 Ma, pero aún así la brecha entre el vulcanismo ignimbrítico sería de $2 \mathrm{Ma}$, es decir entre 8 y $6 \mathrm{Ma}$, por lo que se podría argumentar que las fases explosivas caldéricas fueron subodinadas en el territorio nacional. Sin embargo, en la Fm. Venado, durante el Messiniano (7,2 5,3 Ma), es justamente en donde aparecen niveles enriquecidos en pómez posiblemente producto de erupciones ignimbríticas y con una procedencia predominantemente desde el NW (cf. Obando, 1986; Sen Gupta et al., 1986; Calvo \& Bolz, 1987), por lo que podría argumentarse que corresponde con una falta de muestras radiométricas o bien, que dicho vulcanismo se desarrollóen el actual territorio nicaragüense, tal y como se expuso previamente.

Hoy día, a lo que Dengo (1962) definió como Fm. Liberia, consiste en realidad en una serie de depósitos de flujos de pómez con características petrográficas y geoquímicas bien diferenciables entre sí y que se extendieron entre 1,59 y 0,6 Ma, es decir por un lapso de casi un millón de años. De la base al techo las unidades o tobas de flujo pumíceas son: a) Río Liberia (para diferenciarla de Fm. Liberia), b) Salitral, c) Buena Vista y d) La Ese (Chiesa, 1991; Chiesa et al., 1992; Gillot et al., 1994). Estas unidades sobreyacen a la Fm. Bagaces por medio de un paleo-suelo rojizo regional. En la actualidad existe el consenso de que el extenso flujo de pómez rico en biotita y cuarzo de la unidad Río Liberia, debe de provenir de la caldera de Alcántaro-Guachipelín-Cañas Dulces. Lo anterior está fundamentado en el incremento en el tamaño de los líticos y pómez hacia dicho sector, en la existencia de brechas coignimbríticas cercanas, localizadas por la carretera Interamericana, y en que se han encontrado espesos paquetes de ignimbritas similares dentro de la citada caldera. Este depósito de flujo de pómez posee una amplia distribución espacial, aflorando también en la vertiente oriental, en el área de Upala y se caracteriza por ser dos unidades de flujos (uno blanco y otro rosado) de un depósito de pómez riolítica rica en biotita (Chiesa, 1991).

La edad de dicho depósito de flujo fue tomado originalmente como de 0,6 - 0,5 Ma por Chiesa et al. (1987) basado en dos dataciones K/ Ar (Mainieri, 1976; Bellon \& Tournon, 1978), que suministran edades anómalmente jóvenes (Cuadro 1). Una de ellas al parecer corresponde con una ignimbrita más antigua, al tope del la Fm. Bagaces, la unidad Río Colorado. Esto está basado en la localización de la muestra datada, asignada en el trabajo original como a Bagaces Superior y no a Liberia, y en que su química se asemeja más a la ignimbrita de Río Colorado (ver Mainieri, 1976, plano 2100-16A-15 y tabla 7). Debemos de recordar que las muestras $\mathrm{K} /$ Ar datadas por Mainieri (1976) no poseen recalibración. En campañas geocronológicas posteriores, se demostró que la edad de Río Liberia era al menos un millón de años más antigua, variando dentro de las mismas muestras con fases diferentes (vidrio, plagioclasa, biotita) entre 1,29 y 1,83 Ma, tomándose previamente como dato que mejor se ajustaba a la estratigrafía y promedio el de 1,6 $\pm 0,2 \mathrm{Ma}$ (Alvarado et al., 1992; Gillot et al., 1994). Una nueva edad ${ }^{40} \mathrm{Ar} /{ }^{39} \mathrm{Ar}$, aportadas por P. Gans, nos suministra una edad de 1,47 $\pm 0,02$ Ma (Vogel et al., 2004; presente trabajo), acorde con una edad previa de 1,45 $\pm 0,0$ Ma (Gardner y Turrin, en Alvarado et al., 1990) para la misma localidad, y que está estratigráficamente restringida en su parte superior por el flujo Salitral, rico en plagioclasas (1,36 \pm 0,02 Ma; Vogel et al., 2004) y por el depósito del flujo Buena Vista, rico en anfíboles (1,45 \pm 0,36 Ma en Gillot et al., 1994 y 1,31 $\pm 0,02 \mathrm{Ma}$ en Vogel et al., 2004). Otra edad que recientemente se sumó a esta lista, fue la de la muestra tomada por Bergoeing (1982) datada en 1,2 Ma, para la cual aporta una descripción petrográfica pero una ubicación geográfica muy general (Cuadro 21). Sin embargo, mediante unas fotografías y descripciones de campo (Bergoeing, 1998, p. 314 - 315) se puede ubicar la muestra con gran precisión como asociada a la toba verdosa con anfíbol y biotita, 
que infrayase al depósito de flujo de pómez ricas en biotita y sobreyace al suelo rojizo regional post-Bagaces. Así contaríamos con 12 edades para esta unidad, y solo una de ellas se salen de la campana de datos (la muestra de 0,5 Ma de Bellon \& Tournon, 1978). Si aplicamos para las 11 edades (Cuadro 21) el método de ponderación explicado en Long \& Rippeteau (1974), tendríamos una edad media $1,595 \pm 0,02 \mathrm{Ma}$, que es la que se toma como valedera para esta importante unidad estratigráfica y capa guía. Utilizando el mismo método, la edad media del depósito de flujo rico en anfíbol sobreyacente sería de 1,35 $\pm 0,01 \mathrm{Ma}$.

Cerca de la escuela de La Ese $(\mathrm{Km} 18+300)$ se observa una capa de pómez de caída, que posiblemente se depositó en un medio lacustrino, evidenciado por su gradación inversa, datada por ${ }^{40} \mathrm{Ar} /{ }^{39} \mathrm{Ar}$ en $1,18 \mathrm{Ma}$, sobreyacida por arenas y conglomerados pumíceos de origen fluvio-lacustrino y, finalmente, a través de una discordancia erosiva, dos tobas pumíceas de flujo separadas por paleosuelos, con edades invertidas, indicando la contemporaneidad de los eventos: la inferior $634 \pm 32$ ka y la superior en $652 \pm 24 \mathrm{ka}$. En este mismo sector, Gillot et al. (1994) dató con K/Ar dichos flujos y obtuvo edades similares: $620 \pm 10$ y $580 \pm 12 \mathrm{ka}$. Cerca de allí, en el tajo abandonado de La Ese, se tiene un depósito de flujo de pómez inferior (no se observa la base), cuya pómez se dató en $890 \pm 30$ ka y un clasto intrusivo comagmático dentro de la brecha coignimbrítica, en 824 $\pm 38 \mathrm{ka}$. Separado por depósitos coluvio-aluviales y un paleosuelo, se tiene un nuevo depósito de flujo de pómez datado en $665 \pm 24$ ka (presente trabajo). Se puede ver, que los eventos pumíceos, afíricos de La Ese, se pueden agrupar con edades medias en tres grupos: a) $1,18 \mathrm{Ma}$, b) $868 \pm 23 \mathrm{ka}$ y c) $622 \pm 0,006 \mathrm{ka}$ (Cuadro 21).

Con base en todo lo anterior, se podría hipotetizar la subdivisión de la Fomación Bagaces en:

a. Bagaces Basal o Carbonal, representado por la dacita de Carbonal y sus unidades ignimbríticas locales infrayacentes: 8,05 Ma.

b. Bagaces Inferior o Barbudal, representado por coladas de lava e ignimbritas: 4,87-3,64 Ma.

c. Bagaces Intermedio o fluvial, que correspondería con el Paleo-Tempisque: 3,64 y 3,21 Ma. d. Un Bagaces Superior: 3,21 - 2,0 Ma.

La Fm. Liberia se puede subdividir en 4 grandes eventos ignimbríticos (Chiesa et al., 1992):

a. La toba de Río Liberia con sus facies piroclásticas precedentes, la toba verde inferior y la brecha pumícea de Santa Fe (1,59 Ma).

b. La toba de Salitral (1,36 Ma).

c. La toba Buena Vista (1,35 Ma)

d. Después de un periodo de calma relativa, se tiene una pómez de caída $(1,18 \mathrm{Ma})$ contemporáneo con un lacustre, seguida por un paleosuelo y erosión local, coronado por los flujos de pómez de La Ese, representados por tres grandes eventos, en correspondencia con la caldera festoneada de Guayabo: a) 0,868 Ma y b) dos flujos a los 0,622 Ma.

\section{CORDILLERA DE GUANACASTE}

\section{Volcán Orosí}

La evolución del volcán Orosí es poco conocida (Chiesa et al., 1998) lo mismo que sus edades absolutas. Entre las haciendas El Hacha y la Orosí, aflora una ignimbrita riolítica, masiva, con textura perlítica (vidrio incoloro), vesicular y con cristales (plag $+\mathrm{qz}+\mathrm{mt} \pm \mathrm{hb} \pm \mathrm{opx}$ ) que fue datada en 0,6 \pm 0,2 Ma (Bellon \& Tournon, 1978; Tournon, 1984); su posición estratigráfica, química (similares contenidos en $\mathrm{CaO}, \mathrm{Sr}$ and $\mathrm{Zr}$, ligeramente alta en $\mathrm{TiO}_{2}$ ) y petrografía son similares a los flujos de pómez de Buena Vista (datado en $1,35 \mathrm{Ma}$ ), por lo que surge la duda sobre su edad. Sobre ellas se desarrolló parte del Neo-Orosí.

La historia puede resumirse como:

a. Vulcanismo probablemente equivalente al de Monteverde que da origen al Cerro Hacha y alrededores, posiblemente en el Pleistoceno Inferior.

b. Vulcanismo del Paleo-Orosí, representado por los restos del volcán Orosilito, entre otros.

c. Neo-Vulcanismo, representado por los conos Orosí y Cacao con derrames de lava al occidente.

d. Colapso sectoriales con el derrumbe y erosión de los conos principales hacia el oeste y suroeste.

e. Reactivación volcánica dando origen a domos y escasas coladas de lava en el Cacao. 
Cuadro 21

Dataciones radiométricas de las ignimbritas de la Fm. Liberia

\begin{tabular}{|c|c|c|c|c|}
\hline MUESTRA & LITOLOGÍA & UBICACIÓN & $\operatorname{EDAD}(\mathrm{Ma})$ & REFERENCIA \\
\hline \multicolumn{5}{|c|}{ IGNIMBRITA R. LIBERIA $(1,595 \pm 0,02 \mathrm{Ma})$} \\
\hline $\mathrm{G}-49 \mathrm{O}$ & $\begin{array}{l}\text { Depósito de flujo de } \\
\text { pómez riolítico rico en } \\
\text { biotita }\end{array}$ & $\begin{array}{l}\text { Camino a Hda. Ciruelas, H. } \\
\text { Monteverde, } 390,5-278,4\end{array}$ & $\begin{array}{c}1,83 \pm 0,03(\mathrm{~K} / \text { Ar: plag }) \\
1,61 \pm 0,06(\mathrm{~K} / \text { Ar: biot }) \\
1,42 \pm 0,03 \\
1,393 \pm 0,03(\mathrm{~K} / \mathrm{Ar}: \\
\text { vidrio })\end{array}$ & Gillot et al. (1994) \\
\hline G-49 A & $\begin{array}{l}\text { Depósito de flujo de } \\
\text { pómez riolítico rico en } \\
\text { biotita }\end{array}$ & $\begin{array}{l}\text { Por Salitral, H. Tierras More- } \\
\text { nas, } 400,0-286,3\end{array}$ & $\begin{array}{c}1,600 \pm 0,05 \\
1,551 \pm 0,06 \text { (vidrio) } \\
1,270 \pm 0,03 \\
1,310 \pm 0,03 \\
\text { (K/Ar: plag) }\end{array}$ & Gillot et al. (1994) \\
\hline CR-024A & $\begin{array}{l}\text { Depósito de flujo de } \\
\text { pómez riolítico rico en } \\
\text { biotita }\end{array}$ & $\begin{array}{c}\text { Km 4, Ca. Bagaces-Guayabo, } \\
\text { H. Monteverde, } 399,250- \\
282,250\end{array}$ & $\begin{array}{c}1,470 \pm 0,020\left({ }^{40} \mathrm{Ar}{ }^{39} \mathrm{Ar}:\right. \\
\text { plag })\end{array}$ & Presente trabajo \\
\hline CR-62187-15B & $\begin{array}{l}\text { Depósito de flujo de } \\
\text { pómez riolítico rico en } \\
\text { biotita }\end{array}$ & $\begin{array}{c}\text { Km 4, Ca. Bagaces-Guayabo, } \\
\text { H. Monteverde, 399,3-283,5 }\end{array}$ & $1,45 \pm 0,0\left({ }^{40} \mathrm{Ar} /{ }^{39} \mathrm{Ar}\right)$ & $\begin{array}{l}\text { Gardner \& Turrin (en } \\
\text { Alvarado et al., 1992) }\end{array}$ \\
\hline BBCR-2 (B2) & $\begin{array}{l}\text { Toba verdosa vitro- } \\
\text { clástica con algo de } \\
\text { hb. y biot. ( } 29 \% \\
\text { clastos), -erróneamen- } \\
\text { te interpretada como } \\
\text { lacustre- bajo el flujo } \\
\text { de pómez biotítica }\end{array}$ & $\begin{array}{l}\text { Hda. Ciruelas, H. Montever- } \\
\text { de, } 390,797-278,894\end{array}$ & $1,2 \pm 0,07(\mathrm{~K} / \mathrm{Ar})$ & Bergoeing (1982) \\
\hline \multicolumn{5}{|c|}{ IGNIMBRITA SALITRAL } \\
\hline $990718-02 \mathrm{c}$ & $\begin{array}{l}\text { Ignimbrita poco solda- } \\
\text { da rica en plagioclasa }\end{array}$ & $\begin{array}{c}\text { Ca. Bagaces-Guayabo, Km } \\
\text { 10,8, H. Tierras Morenas, } \\
401,250-289,050\end{array}$ & $\begin{array}{c}1,360 \pm 0,020\left({ }^{40} \mathrm{Ar} /{ }^{39} \mathrm{Ar}:\right. \\
\text { plag })\end{array}$ & Presente trabajo \\
\hline \multicolumn{5}{|c|}{ IGNIMBRITA BUENA VISTA $(1,35 \pm 0,01 \mathrm{Ma})$} \\
\hline H63 & $\begin{array}{l}\text { Depósito de flujo de } \\
\text { pómez rico en anfíbol }\end{array}$ & $\begin{array}{l}\text { Por el R. Blanco, } 0,5 \mathrm{~km} \text { al } \\
\text { NW cuesta el Jobo H. Tie- } \\
\text { rras Morenas, } 405,9-283,6\end{array}$ & $1,456 \pm 0,036(\mathrm{~K} / \mathrm{Ar}: \mathrm{hb})$ & Gillot et al. (1994) \\
\hline $990718-03 a$ & $\begin{array}{l}\text { Depósito de flujo de } \\
\text { pómez rico en anfíbol }\end{array}$ & $\begin{array}{c}\text { Ca. Bagaces-Guayabo, Km } \\
\text { 11,0, H. Miravalles, 401,3-289,2 }\end{array}$ & $\begin{array}{c}1,310 \pm 0,020\left({ }^{40} \mathrm{Ar} /{ }^{39} \mathrm{Ar}:\right. \\
\text { plag })\end{array}$ & Presente trabajo \\
\hline \multicolumn{5}{|c|}{ PÓMEZ DE CAÍDA } \\
\hline $990718-07$ & $\begin{array}{l}\text { Pómez de caída, bajo } \\
\text { lacustre, geoquímica- } \\
\text { mente similar a La Ese }\end{array}$ & $\begin{array}{l}0,5 \mathrm{~km} \text { al SE de La Ese, } \mathrm{H} . \\
\text { Miravalles, 400,800-294,850 }\end{array}$ & $\begin{array}{c}1,180 \pm 0,020\left({ }^{40} \mathrm{Ar} /{ }^{39} \mathrm{Ar}:\right. \\
\text { plag })\end{array}$ & Presente trabajo \\
\hline \multicolumn{5}{|c|}{ FLUJO DE PÓMEZ LA ESE ( $868 \pm 23$ ka) } \\
\hline $990718-09 a$ & $\begin{array}{l}\text { Depósito de flujo de } \\
\text { pómez afírico Inferior } \\
\text { de La Ese }\end{array}$ & $\begin{array}{c}\text { Tajo La Ese, H. Miravalles, } \\
400,600-295,700\end{array}$ & $\begin{array}{c}0,890 \pm 0,030 \text { : pómez, } 0,824 \\
\pm 0,038 \text { : intrusivo comag- } \\
\text { mático }\left({ }^{40} \mathrm{Ar} /{ }^{39} \mathrm{Ar} \text { : plag }\right)\end{array}$ & Presente trabajo \\
\hline
\end{tabular}


Cuadro 21 (continuación)

Dataciones radiométricas de las ignimbritas de la Fm. Liberia

\begin{tabular}{|c|c|c|c|c|}
\hline MUESTRA & LITOLOGÍA & UBICACIÓN & $\operatorname{EDAD}(\mathrm{Ma})$ & REFERENCIA \\
\hline \multicolumn{5}{|c|}{$622 \pm 0,006 \mathrm{ka}$} \\
\hline 990718-10a & $\begin{array}{l}\text { Depósito de flujo de } \\
\text { pómez afírico Superior } \\
\text { (2 unidades de flujo) }\end{array}$ & $\begin{array}{c}\text { Tajo La Ese, H. Miravalles, } \\
400,600-295,700\end{array}$ & $\begin{array}{c}0,665 \pm 0,024\left({ }^{40} \mathrm{Ar} /{ }^{39} \mathrm{Ar}:\right. \\
\text { plag })\end{array}$ & Presente trabajo \\
\hline $990718-05$ & $\begin{array}{l}\text { Depósito de flujo de } \\
\text { pómez afírico Supe- } \\
\text { rior sobre el depósito } \\
\text { lacustre }\end{array}$ & $\begin{array}{c}0,5 \mathrm{~km} \text { al SE de La Ese }(\mathrm{Km} \\
18+300), \mathrm{H} . \text { Miravalles, } \\
400,800-294,850\end{array}$ & $\begin{array}{c}0,652 \pm 0,024\left({ }^{40} \mathrm{Ar} /{ }^{39} \mathrm{Ar}:\right. \\
\text { plag })\end{array}$ & Presente trabajo \\
\hline 990718-06 & $\begin{array}{l}\text { Depósito de flujo de } \\
\text { pómez afírico Superior } \\
\text { (unidad de flujo infe- } \\
\text { rior) sobre lacustre }\end{array}$ & $\begin{array}{c}0,5 \mathrm{~km} \text { al SE de La Ese }(\mathrm{Km} \\
18+300), \mathrm{H} . \text { Miravalles } \\
400,800-294,850\end{array}$ & $\begin{array}{c}0,634 \pm 0,032\left({ }^{40} \mathrm{Ar} /{ }^{39} \mathrm{Ar}:\right. \\
\text { plag })\end{array}$ & Presente trabajo \\
\hline G 49P & $\begin{array}{l}\text { Depósito de flujo de } \\
\text { pómez afírico }\end{array}$ & $\begin{array}{l}0,5 \mathrm{~km} \text { al SE de La Ese H. } \\
\text { Miravalles, 400,5-295,0 }\end{array}$ & $\begin{array}{c}0,620 \pm 0,010(\mathrm{~K} / \mathrm{Ar}: \\
\text { plag) } 0,580 \pm 0,012(\mathrm{~K} / \\
\text { Ar: vidrio })\end{array}$ & Gillot et al. (1994) \\
\hline
\end{tabular}

\section{Volcán Rincón de la Vieja}

La evolución volcánica del macizo del Rincón de la Vieja es compleja, pero con los datos geocronológicos disponibles (particularmente Carr et al., 2007 y presente trabajo) y con el mapeo geológico de detalle (Zamora et al., 2004) es posible establecer un cronología más precisa. De los volcanes de la cordillera de Guanacaste sólo el Rincón de la Vieja está activo.

El paleo-volcán Alcántaro está constituido predominantemente por coladas de lava vidriosas piroxénicas ( $\sin$ minerales hidroxilados), lajeadas, con estructuras fluidal, perlítica, así como depósitos de flujos piroclásticos densos (¿reo-ignimbritas?), ambos con pliegues, fallas sineruptivas, conformando el borde festoneado de la caldera Alcántaro-Guachipelín-Cañas Dulces. La edad de las rocas del borde la caldera varían entre 2,17 y 1,79 Ma: 2,17 en Quebrada Tempisquito, 1,86 Ma en el cerro Atravesado, 1,81 Ma en la finca Aprecio (correlacionada con la Unidad Tibio de Zamora et al., 2004) y 1,78 - 1,79 Ma en Buena Vista. La ignimbrita Río Colorado (Kempter, 1987; Zamora et al., 2004), parece estar asociada con este paleovolcán y su edad media es de
2,08 Ma (Cuadro 22). Esto nos indica que volcán Alcántaro debió de haber colapsado en varios eventos menores y, finalmente, en una sucesión de eventos mayores, posterior a 1,78 Ma (edad más joven de las lavas) y antes de la formación de los domos y lavas post-caldéricas, cuyas edades más seguras se ubican alrededor de 1,4 Ma. Por ello, la edad de la formación de la caldera AlcántaroGuachipelín-Cañas Dulces debe de estar comprendida entre 1,78 y 1,4 Ma.

Las fechas más recientes ${ }^{40} \mathrm{Ar} /{ }^{39} \mathrm{Ar}$ de los domos nos indican una edad de 1,33 Ma para el cerro Fortuna, en acuerdo con las dataciones K/Ar antiguas del domo de Cañas Dulces de 1,55 Ma y 1,6 Ma para el cerro San Roque, cuyos rangos de error varían en ambas en 0,5 Ma (Mainieri, 1976; Bellon y Tournon, 1978). Las datación del cerro Góngora de 4,3 $\pm 2 \mathrm{Ma}$ (Mainieri, 1976), parecer ser errónea con base en el contexto local, y juventud morfológica de este domo.

Las lavas más antiguas del Rincón de la Vieja, definen un espeso campo de lavas (al menos $160 \mathrm{~m}$ ) con varios frentes morfológicamente visibles en el terreno, con edades entre 1,6 \pm 0,2 y $1,1 \pm 0,03$ Ma para las partes basales (cronológicamente correlacionables con el vulcanismo 
Cuadro 22

Dataciones radiométricas del macizo volcánico Rincón de la Vieja y la caldera de Alcántaro-Guachipelín-Cañas Dulces

\begin{tabular}{|c|c|c|c|c|}
\hline MUESTRA & LITOLOGIA & UBICACIÓN & $\operatorname{EDAD}(\mathrm{Ma})$ & REFERENCIA \\
\hline \multicolumn{5}{|c|}{ LAVAS PRE-CALDERA (PALEO-VOLCÁN ALCÁNTARO) } \\
\hline CR-RV-04-13 & Lava lajeada & $\begin{array}{l}\text { Queb. Tempisque, H. Curubandé, } \\
383,995-301,448\end{array}$ & $\begin{array}{c}2,176 \pm 0,019 \\
\left({ }^{40} \mathrm{Ar} /{ }^{39} \mathrm{Ar}: \text { mtz: iso. }\right)\end{array}$ & Carr et al. (2007) \\
\hline CR-206 & $\begin{array}{l}\text { Vitrófiro dacítico } \\
\text { piroxénico }\end{array}$ & $\begin{array}{l}\text { C. Atravesado, H. Curubandé, 374,825- } \\
\text { 306,200 }\end{array}$ & $\begin{array}{c}1,86 \pm 0,02 \\
\left({ }^{40} \mathrm{Ar} /{ }^{/ 9} \mathrm{Ar}: \text { plag }\right)\end{array}$ & Presente trabajo \\
\hline CR-204 & $\begin{array}{l}\text { Dacita piroxénico } \\
\text { rica en plagioclasa }\end{array}$ & $\begin{array}{c}\text { Finca Aprecio, H. Curubandé, } 377,375 \\
-304,375\end{array}$ & $\begin{array}{c}1,81 \pm 0,02 \\
\left({ }^{40} \mathrm{Ar} /{ }^{39} \mathrm{Ar}: \text { plag }\right)\end{array}$ & Presente trabajo \\
\hline CR-203 & $\begin{array}{l}\text { Dacita lajeada, } \\
\text { fluidal y plegada }\end{array}$ & $\begin{array}{l}\text { Tajo Buena Vista, H. Curubandé, } \\
\text { 376,450-303,575 }\end{array}$ & $\begin{array}{c}1,79 \pm 0,02 \\
\left({ }^{40} \mathrm{Ar} /{ }^{/ 9} \mathrm{Ar}: \text { plag }\right)\end{array}$ & Presente trabajo \\
\hline CR-202 & $\begin{array}{l}\text { Dacita piroxénico } \\
\text { rica en plagioclasa }\end{array}$ & $\begin{array}{l}\text { Buena Vista, H. Curubandé, } 375,400- \\
302,950\end{array}$ & $\begin{array}{c}1,78 \pm 0,04 \\
\left({ }^{40} \mathrm{Ar} /{ }^{39} \mathrm{Ar}: \text { plag }\right)\end{array}$ & Presente trabajo \\
\hline \multicolumn{5}{|c|}{ DOMOS POST-CALDÉRICOS } \\
\hline CU-38 & Dacita hornbléndica & $\begin{array}{l}\text { C. San Roque, H. Curubandé, 376,1- } \\
\qquad 306,2\end{array}$ & $1,6 \pm 0,5(\mathrm{~K} / \mathrm{Ar})$ & $\begin{array}{l}\text { Bellon \& Tour- } \\
\text { non (1978) }\end{array}$ \\
\hline $13 \mathrm{~A}$ & $\begin{array}{l}\text { "Andesita" horn- } \\
\text { bléndica }\end{array}$ & $\begin{array}{l}\text { C. Cañas Dulces, Torre ICE, H. Curuban- } \\
\text { dé, } 379,3-303,7\end{array}$ & $1,55 \pm 0,5(\mathrm{~K} / \mathrm{Ar})$ & Mainieri (1976) \\
\hline CR-207 & Dacita hornbléndica & $\begin{array}{l}\text { Flanco W C. Fortuna, H. Curubandé, } \\
\qquad 375,800-310,050\end{array}$ & $\begin{array}{c}1,330 \pm 0,020 \\
\left({ }^{40} \mathrm{Ar} /{ }^{39} \mathrm{Ar}: \text { plag }\right)\end{array}$ & Presente trabajo \\
\hline \multicolumn{5}{|c|}{ LAVAS PROTO-RINCÓN } \\
\hline CR-RV-02-66 & Lava & $\begin{array}{l}\text { Tajo entre las Quebs. Gata y Pacayal, H. } \\
\text { Curubandé, } 381,711-311,051\end{array}$ & $\begin{array}{c}1,611 \pm 0,200 \\
\left({ }^{40} \mathrm{Ar} /{ }^{39} \mathrm{Ar}: \mathrm{mtz}: \text { edad }\right. \\
\text { integrada })\end{array}$ & Carr et al. (2007) \\
\hline CR-RV-02-62 & Basalto & $\begin{array}{l}\text { Cuesta Diablo, H. Curubandé, 379,912- } \\
\text { 307,020 }\end{array}$ & $\begin{array}{c}1,138 \pm 0,030 \\
\left({ }^{40} \mathrm{Ar}{ }^{\beta 9} \mathrm{Ar}: \text { mtz: plat. }\right)\end{array}$ & Carr et al. (2007) \\
\hline CR-205 & Basalto & $\begin{array}{c}\text { Finca Dos Quebradas, H. Curubandé, } \\
376.900 \mathrm{~N}-307.750 \mathrm{E}\end{array}$ & $\begin{array}{c}0,850 \pm 0,050 \\
\left({ }^{40} \mathrm{Ar} /{ }^{39} \mathrm{Ar}: \mathrm{mtz}\right)\end{array}$ & Presente trabajo \\
\hline \multicolumn{5}{|c|}{ LAVAS PALEO-RINCÓN } \\
\hline CR-RV-04-12 & Lava & $\begin{array}{l}\text { Queb. Provisión, SE del Rincón de la } \\
\text { Vieja, H. Curubandé, 396,708-305,407 }\end{array}$ & $\begin{array}{c}0,564 \pm 0,005 \\
\left({ }^{40} \mathrm{Ar} /{ }^{39} \mathrm{Ar}: \text { mtz: plat. }\right)\end{array}$ & Carr et al. (2007) \\
\hline CR-RV-201 & Basalto & $\begin{array}{l}\text { Por Colonia Blanca, flanco SE Rincón de } \\
\text { la Vieja, H. Curubandé, } 398,765-307,398\end{array}$ & $\begin{array}{c}0,380 \pm 0,02 \\
\left({ }^{40} \mathrm{Ar}{ }^{39} \mathrm{Ar}: \text { mtz: plat. }\right)\end{array}$ & Carr et al. (2007) \\
\hline
\end{tabular}

del Proto-Rincón), y 0,85 \pm 0,05 Ma para las más recientes, incluso bifurcándose éstas al chocar con el domo cerro Fortuna. La edad de 1,6 posee un grado de error de 0,2 Ma, por lo que preferimos pensar que el campo de lavas del Diablo (Proto-Rincón) se formó entre 1,3 (edad del cerro Fortuna) y $0,85 \mathrm{Ma}$.

Resulta interesante que el campo de domos de Cañas Dulces (1,6 - 1,33 Ma; edad más probable: $\sim 1,4 \mathrm{Ma}$ ) posean una edad, petrografía y morfología similar a la de los domos de San
Miguel y La Cruz (1,71 - 1,59 Ma; ver apartado del vulcanismo en la cordillera de Tilarán, Cuadro 18), como de igual modo resulta interesante que las lavas basales del Rincón de la Vieja (1,6 - 1,1 Ma), sean similares a las lavas de Monteverde (comparar cuadros 18 y 22 ).

Las coladas de lava más recientes del PaleoRincón, aportan edades de 0,56 Ma para uno de los flancos antiguos del macizo más reciente (Cuadro 22). Claramente, existen coladas de lava morfológicamente más jóvenes, que pueden extenderse al 
Pleistoceno Superior Tardío e incluso Holoceno Temprano, pero no se han datado.

Un cuadro cronológico de los principales eventos sería:

a. Formación del volcán Alcántaro y la ignimbrita Río Colorado: 2,17 - 1,78 Ma.

b. Formación de varias calderas festoneadas (caldera Alcántaro-Guachipelín-Cañas Dulces) con varios depósitos de flujos de pómez asociados: 1,59 Ma (toba Río Liberia). La procedencia de los flujos de pómez que dieron origen a la toba Salitral $(1,36 \mathrm{Ma})$ y la toba Buena Vista $(1,35$ $\mathrm{Ma})$, todavía está bajo discusión de si proceden de esta caldera o de una caldera precedente a la de Guayabo.

c. Formación del campo de domos intracaldéricos y pericaldéricos de Cañas Dulces: alrededor de 1,4 Ma.

d. Inicio de la formación del Proto-Rincón de la Vieja: 1,6 - 0,85 Ma.

e. Continuo crecimiento del Paleo- y NeoRincón de la Vieja: 0,56 - 0 Ma.

\section{Volcán Miravalles}

Las nuevas dataciones radiométricas y los estudios de detalle, tanto locales como regionales, cambian substancialmente la evolución cronológica del macizo del Miravalles, dejando por fuera un gran número de dataciones previas, en su mayoría del tipo $\mathrm{K} / \mathrm{Ar}$.

Las lavas más antiguas datadas por medio de ${ }^{40} \mathrm{Ar} /{ }^{39} \mathrm{Ar}$ corresponden al antiguo volcán Guayabo, cuyas edades consistentemente dan entre 1,17 y $1,0 \mathrm{Ma}: 1,17$ (cerro Mogote) y 1,07 - 1,02 para los cerros Espíritu Santo y la Montañosa. La edad poco precisa de 2,1 $\pm 1 \mathrm{Ma}$ para el cerro Mogote (Mainieri, 1976) se ubica dentro del rango de error. Otras edades aportadas (ICE, 1985; ICE-ELEC, 1983) variaban substancialmente (p.ej., 0,22 Ma para el cerro Gota de Agua, 0,27 Ma para el Espíritu Santo y $\sim 0,62$ Ma para el Mogote) y no son consistentes con los nuevos resultados ni con el hecho de que la mayoría de las ignimbritas asociadas a la caldera poseen edades de 0,86 - 0,62 Ma (Cuadro 23).
Una posible capa pliniana, algo afectada por eventos fluvio-lacustrinos, documenta un evento explosivo alrededor de 1,18 Ma, posiblemente asociado con el paleo-volcán Guayabo, acaecidos prevos a su colapso principal (Cuadro 21).

A este gran pulso efusivo del volcán Guayabo, le siguió la formación de la caldera de Guayabo con el concomitando vaciado de su cámara magmática, generando los dos depósitos de flujos piroclásticos principales (el inferior son dos unidades de flujo), de pómez afíricas, separados por paleo-suelos, llamados La Ese, con edades medias de 0,86 y 0,62 Ma, respectivamente (Cuadro 21).

A este evento caldérico, le sigue la formación del volcán Cabro Muco y otras lavas coetáneas, con edades entre 0,57 y 0,40 Ma (ICE-ELC, 1983; Carr et al., 2007; presente trabajo). Varios colapsos sectoriales con desarrollo de depósitos de debris avalanche y crecimientos sucesivos del Paleo-Miravalles (o volcán Zapote) y del nuevo Miravalles propiamente dicho, pueden corresponder con la edad reportada para uno de los bloques dentro de la avalancha (0,28 Ma; ICE-ELC, 1983), y más recientemente para un depósito de flujo de bloques y cenizas presente por el poblado de Pata de Gallo (0,03 Ma o $30 \mathrm{ka})$ o una colada de lava por la quebrada Hornillas (77 ka; Carr et al., 2007).

Así, la cronología constructiva y destructiva del complejo Miravalles puede resumirse en:

a. Edificación del paleo-volcán Guayabo (Proto-Miravalles): 1,17 - 1,0 Ma

b. Colapso caldérico festoneado con la concomitante formación de depósitos de flujos piroclásticos: 0,86 y 0,62 Ma.

c. Formación del paleo-volcán Cabro Muco (Paleo-Miravalles): 0,57 - 0,28? Ma.

d. Formación de los volcanes Zapote y Miravalles (Neo-Miravalles): $\leq 0,28$ - 0 Ma.

\section{Volcán Tenorio}

Los estudios geológicos son muy generales $\mathrm{y}$ varias de las edades K/Ar presentaban incertidumbres muy altas (ICE-ENEL, 1990). Una serie de nuevas edades, todas ellas aportadas por 
Cuadro 23

Dataciones radiométricas del macizo volcánico de Guayabo y Miravalles

\begin{tabular}{|c|c|c|c|c|}
\hline MUESTRA & LITOLOGÍA & UBICACIÓN & $\operatorname{EDAD}(\mathrm{Ma})$ & REFERENCIA \\
\hline \multicolumn{5}{|c|}{ LAVAS PRE-CALDERA (PROTO-MIRAVALLES) } \\
\hline $187 \mathrm{~A}$ & $\begin{array}{l}\text { Andesita piroxéni- } \\
\text { ca lajeada }\end{array}$ & $\begin{array}{c}\text { Caldera de Guayabo, 1,3 km NNE C. Mogote, } \\
\text { H. Curumbandé, 399,1-302,9 }\end{array}$ & $2,3 \pm 1(\mathrm{~K} / \mathrm{Ar})$ & Mainieri (1976) \\
\hline CR-188 & Basalto & $\begin{array}{l}\text { Tajo a 1,1 km al SE del C. Mogote, H. Curu- } \\
\text { bandé, } 399,200-300,750\end{array}$ & $\begin{array}{c}1,17 \pm 0,04 \\
\left({ }^{40} \mathrm{Ar} /{ }^{39} \mathrm{Ar}: \mathrm{mtz}\right)\end{array}$ & Presente trabajo \\
\hline 22 & Lava & Espíritu Santo, H. Miravalles, 412,0-294,3 & $1,07 \pm 0,09(\mathrm{~K} / \mathrm{Ar})$ & ICE (1985) \\
\hline CR-196 & Andesita & $\begin{array}{l}\text { C. Gota de Agua, flanco W, H. Miravalles, } \\
\qquad 414,325-295,750\end{array}$ & $\begin{array}{c}1,050 \pm 0,050 \\
\left({ }^{40} \mathrm{Ar} /{ }^{39} \mathrm{Ar}: \mathrm{mtz}\right)\end{array}$ & Presente trabajo \\
\hline CR-194 & Domo andesítico & $\begin{array}{l}\text { C. Gota de Agua, flanco WNW, H. Mirava- } \\
\text { lles, 414,250-295,850 }\end{array}$ & $\begin{array}{c}1,020 \pm 0,020 \\
\left({ }^{40} \mathrm{Ar} /{ }^{39} \mathrm{Ar}: \mathrm{mtz}\right)\end{array}$ & Presente trabajo \\
\hline 5 & Lava & C. Mogote, H. Curubandé, aprox. 399,0-302,8 & $0,62 \pm 0,2(\mathrm{~K} / \mathrm{Ar})$ & ICE-ELC (1983) \\
\hline \multicolumn{5}{|c|}{ LAVAS DEL PALEO-MIRAVALLES } \\
\hline CR-201 & $\begin{array}{l}\text { Bloque de lava en } \\
\text { lahar antiguo }\end{array}$ & $\begin{array}{l}\text { Torre ICE, } 1 \mathrm{~km} \text { al WSW finca Armenia, H. } \\
\text { Miravalles, 411,325-309,800 }\end{array}$ & $\begin{array}{c}0,573 \pm 0,021 \\
\left({ }^{40} \mathrm{Ar} /{ }^{39} \mathrm{Ar}: \mathrm{mtz}\right)\end{array}$ & Presente trabajo \\
\hline $\begin{array}{l}\text { CR-MV- } \\
04-11\end{array}$ & Bloque de lava & $\begin{array}{l}\text { Queb. La Cabra, C. La Giganta, H. Mirava- } \\
\text { lles, 411,203-295,640 }\end{array}$ & $\begin{array}{c}0,548 \pm 0,011 \\
\left({ }^{40} \mathrm{Ar} /{ }^{39} \mathrm{Ar}: \text { mtz: plat. }\right)\end{array}$ & Carr et al. (2007) \\
\hline CR-193 & $\begin{array}{l}\text { Andesita en debris } \\
\text { avalanche }\end{array}$ & La Giganta, H. Miravalles, 414,250-295,800 & $\begin{array}{c}0,416 \pm 0,008 \\
\left({ }^{40} \mathrm{Ar} /{ }^{39} \mathrm{Ar}: \mathrm{mtz}\right)\end{array}$ & Presente trabajo \\
\hline 3 & Lava & Cabro Muco, H. Miravalles, aprox. 410,0-299,0 & $0,40 \pm 0,1(\mathrm{~K} / \mathrm{Ar})$ & ICE-ELC (1983) \\
\hline 12 & Lava & Pozo PH-35, 244 m, H. Miravalles, 404,479-297,010 & $0,48 \pm 0,1(\mathrm{~K} / \mathrm{Ar})$ & ICE-ELC (1983) \\
\hline 7 & $\begin{array}{c}\text { Bloque de lava } \\
\text { dentro de lahar } \\
\text { (debris avalanche) }\end{array}$ & H. Miravalles & 0,28 (K/Ar) & ICE-ELC (1983) \\
\hline \multicolumn{5}{|c|}{ LAVAS DEL NEO-MIRAVALLES } \\
\hline $\begin{array}{l}\text { CR-MV- } \\
04-9\end{array}$ & $\begin{array}{l}\text { Posible frente de } \\
\text { colada }\end{array}$ & $\begin{array}{l}\text { Queb. Hornillas, Santa Rosa, H. Miravalles, } \\
407,982-299,565\end{array}$ & $\begin{array}{c}0,075 \pm 0,04 \\
\left({ }^{40} \mathrm{Ar} /{ }^{39} \mathrm{Ar}: \text { mtz: plat. }\right)\end{array}$ & Carr et al. (2007) \\
\hline CR-199 & $\begin{array}{l}\text { Depósito de flujo de } \\
\text { bloques (basalto con } \\
\text { olivino) y cenizas }\end{array}$ & $\begin{array}{l}1,6 \mathrm{~km} \text { W de Pata de Gallo, H. Miravalles, } \\
\qquad 415,050-307,850\end{array}$ & $\begin{array}{c}0,030 \pm 0,012 \\
\left({ }^{40} \mathrm{Ar} /{ }^{39} \mathrm{Ar}: \mathrm{mtz}\right)\end{array}$ & Presente trabajo \\
\hline
\end{tabular}

el trabajo de Carr et al. (2004), permite dilucidar un mejor panorama. Claramente, el basamento local lo constituyen las lavas andesíticas de Monteverde (localmente 2,17 - 1,92 Ma) sobre las cuales se desarrolló el Paleo-Tenorio en dos fases: 0,74 - 0,54 Ma y 0,37 - 0,26 Ma, siendo parcialmente cubiertas por las lavas de los volcanes Tenorio-Montezuma iniciadas a los 94 - $90 \mathrm{ka}$ (Cuadro 24). Los domos y domos colada andesíticos de Bijagua indican una edad entre unas pocas decenas de millares y $140 \mathrm{ka}$, pero se mantienen las dudas de su confiabilidad (ICE-ENEL, 1990).
El presunto borde caldérico propuesto en el flanco sur del Tenorio (cerros Barrera, Bambú, Nubes; ICE-ENEL, 1990), al parecer se trata más bien de la continuidad del graben de Arenal cortando los relictos eruptivos que dieron origen a las lavas de Monteverde. Su contorno festoneado (a modo de seudo-caldera) se explica por la intersección de la falla cortando los cerros, otrora cónicos, generando fallas arqueadas en su proyección superficial. La inexistencia de depósitos de flujos de pómez importantes sobre dichas lavas soporta el hecho de que dicha estructura no corresponde con una caldera de colapso. 
Cuadro 24

Dataciones radiométricas del volcán Tenorio

\begin{tabular}{|c|c|c|c|c|}
\hline MUESTRA & LITOLOGIA & UBICACIÓN & $\operatorname{EDAD}(\mathrm{Ma})$ & REFERENCIA \\
\hline \multicolumn{5}{|c|}{ LAVAS PALEO-TENORIO } \\
\hline CR-TE-04-5 & Lava & $\begin{array}{l}\text { R. Madrigal, 2,2 km al N de Tierras More- } \\
\text { nas, H. Tierras Morenas, 423,912-286,096 }\end{array}$ & $\begin{array}{c}0,740 \pm 0,030 \\
\left({ }^{40} \mathrm{Ar} /{ }^{39} \mathrm{Ar}: \text { mtz: plat. }\right)\end{array}$ & Carr et al. (2007) \\
\hline CR-TE-04-6 & Lava & $\begin{array}{c}\text { Entre Queb. Casa y R. Mayra, } 3,8 \mathrm{~km} \\
\text { NNW de Tierras Morenas, H. Tierras } \\
\text { Morenas,, 422,799-287,666 }\end{array}$ & $\begin{array}{c}0,548 \pm 0,006 \\
\left({ }^{40} \mathrm{Ar} /{ }^{39} \mathrm{Ar}: \text { mtz: plat. }\right)\end{array}$ & Carr et al. (2007) \\
\hline CR-TE-04-8b & Lava & $\begin{array}{l}\text { Finca Choluteca, flanco SW del Tenorio, } \\
\text { H. Tierras Morenas, 421,723-289,142 }\end{array}$ & $\begin{array}{c}0,371 \pm 0,012 \\
\left({ }^{40} \mathrm{Ar} /{ }^{39} \mathrm{Ar}: \text { mtz: plat. }\right)\end{array}$ & Carr et al. (2007) \\
\hline CR-TE-02-32 & Bloque de lava & $\begin{array}{c}\text { Camino entre los ríos Caño Negro y Rito, } \\
\text { a unos } 2 \text { km al NE del C. Olla de Carne, } \\
\text { H. Guatuso, 432,003-307,046 }\end{array}$ & $\begin{array}{c}0,209 \pm 0,04 \\
\left({ }^{40} \mathrm{Ar} /{ }^{39} \mathrm{Ar}: \text { mtz: iso. }\right)\end{array}$ & Carr et al. (2007) \\
\hline CR-TE-04-8a & Lava & $\begin{array}{c}\text { Finca Choluteca, flanco SW del Tenorio, } \\
\text { H. Tierras Morenas, } 421,723-289,142\end{array}$ & $\begin{array}{c}0,266 \pm 0,019 \\
\left({ }^{40} \mathrm{Ar} /{ }^{39} \mathrm{Ar}: \text { mtz: plat. }\right)\end{array}$ & Carr et al. (2007) \\
\hline \multicolumn{5}{|c|}{ LAVAS NEO-TENORIO } \\
\hline CR-TE-O4-7 & Bloque de lava & $\begin{array}{c}\text { Paraíso, flanco SW del Tenorio, H. Tierras } \\
\text { Morenas, 422,195-288,211 }\end{array}$ & $\begin{array}{c}0,090 \pm 0,004 \\
\left({ }^{40} \mathrm{Ar} /{ }^{39} \mathrm{Ar}: \text { mtz: plat. }\right)\end{array}$ & Carr et al. (2007) \\
\hline CR-TE-02-31 & Bloque de andesita & $\begin{array}{c}\text { Flanco NE V. Tenorio, Ca. Guatuso, H. } \\
\text { Guatuso, 429,144-298,843 }\end{array}$ & $\begin{array}{c}0,095 \pm 0,008 \\
\left({ }^{40} \mathrm{Ar}{ }^{39} \mathrm{Ar}: \text { mtz: plat. }\right)\end{array}$ & Carr et al. (2007) \\
\hline
\end{tabular}

Así, la cronología del complejo Tenorio puede resumirse de manera muy simplificada como sigue:

a. Edificación de los edificios de Monteverde: 2,17 - 1,92 Ma.

b. Edificación de varios edificios del Tenorio en al menos tres grandes fases efusivas: 0,74 0,54, 0,37 - 0,26 y 0,09 - ? Ma.

\section{Domos cerros Los Perdidos y volcán Chato}

Gillot et al. (1994) dataron por medio de K/ Ar dos coladas de lava (andesitas con anfíbol) procedentes de cuerpos dómicos de los cerros Los Perdidos en 86 y 83 ka y una lava de la base del Cerro Chato en $38 \mathrm{ka}$. Un resultado similar fue realizado en el presente trabajo mediante ${ }^{40} \mathrm{Ar} /{ }^{39} \mathrm{Ar}$, en donde la lava bajo el puente sobre el río Fortuna y la catarata del mismo nombre, aportan edades prácticamente indistinguibles de 46 y $48 \mathrm{ka}$, respectivamente. Así tenemos, que estas lavas con un contenido en potasio intermedio (mayor que para la mayoría de las lavas del Chato y Arenal), marcan el inicio del vulcanismo de estratocono del Chato, que podría fijarse en $48 \mathrm{ka}$ (Cuadro 25).

Con base en las dataciones $\mathrm{K} / \mathrm{Ar},{ }^{40} \mathrm{Ar} /{ }^{35} \mathrm{Ar}$, así como de radiocarbono, se puede establecer la siguiente cronología:

a. Formación de los domos andesíticos del cerro Los Perdidos: 86 - 83 ka.

b. Edificación del volcán dormido cerro Chato: $48-3,5 \mathrm{ka}$.

c. Edificación del volcán Arenal: 7 - 0 ka.

\section{Volcán Platanar}

Constituye uno de los complejos eruptivos mayores, con sectores muy inaccesibles. Limita al oeste con la cordillera de Tilarán, al SE se interdigita con el complejo eruptivo del Poás y al norte está limitado por las llanuras de San Carlos.

Tres dataciones radiométricas inéditas, realizadas a través del ICE (1987) en el Geochron Laboratorios Inc. y otra incluida por Sáenz (1982), 
Cuadro 25

Dataciones radiométricas de los domos de los cerros Los Perdidos y del volcán Chato

\begin{tabular}{|c|c|c|c|c|}
\hline MUESTRA & LITOLOGIA & UBICACIÓN & EDAD (Ma) & REFERENCIA \\
\hline \multicolumn{5}{|c|}{ DOMOS LOS PERDIDOS } \\
\hline G-50 A & $\begin{array}{l}\text { Domo andesítico } \\
\text { con anfíbol }\end{array}$ & $\begin{array}{l}\text { Finca Bosque, confluencia Queb. } \\
\text { Flores con el R. Fortuna, H. Fortuna, } \\
462,2-267,4\end{array}$ & $\begin{array}{c}0,084 \pm 0,003 \\
0,083 \pm 0,003(\mathrm{~K} / \mathrm{Ar}: \mathrm{mtz})\end{array}$ & Gillot et al. (1994) \\
\hline G-50 B & $\begin{array}{l}\text { Domo andesítico } \\
\text { con anfíbol }\end{array}$ & $\begin{array}{l}\text { C. los Perdidos, H. Fortuna, } \\
462,0-265,3\end{array}$ & $\begin{array}{c}0,099 \pm 0,003 \\
0,094 \pm 0,003 \text { (K/Ar: mtz) }\end{array}$ & Gillot et al. (1994) \\
\hline \multicolumn{5}{|c|}{ VOLCÁN CHATO } \\
\hline CR-029 & Andesita & $\begin{array}{c}\text { Catarata, R. Fortuna, V. Chato, H. } \\
\text { Fortuna, 463,350-269,275 }\end{array}$ & $0,048 \pm 0,018\left({ }^{40} \mathrm{Ar} /{ }^{39} \mathrm{Ar}: \mathrm{mtz}\right)$ & Presente trabajo \\
\hline CR-015 & Andesita & $\begin{array}{l}\text { Puente R. Fortuna, V. Chato, H. } \\
\text { Fortuna, 466,100-270,850 }\end{array}$ & $0,046 \pm 0,006\left({ }^{40} \mathrm{Ar} /{ }^{39} \mathrm{Ar}: \mathrm{mtz}\right)$ & Presente trabajo \\
\hline G-50 C & Andesita & $\begin{array}{l}\text { Puente R. Fortuna, V. Chato, H. } \\
\text { Fortuna, } 461,8-271,1\end{array}$ & $0,038 \pm 0,004$ (K/Ar: mtz) & Gillot et al. (1994) \\
\hline
\end{tabular}

provenientes de la región de Zarcero-Ciudad Quesada-Aguas Zarcas, resultaron muy controvertidas y de dudosa veracidad, según lo comentaba Alvarado et al. (1992) en su momento. Una de ellas corresponde con una andesita con hipersteno del cerro Pital (29,0 Ma), un flujo de pómez con biotita meteorizado, recolectada cerca del hospital de Ciudad Quesada (28,8 Ma), otra con un depósitos de flujo de pómez riodacítica cerca de Zarcero (11,1 Ma) y la cuarta con la colada de lava de Sucre, procedente del volcán Platanar $(1,5$ Ma). Pese a que las muestras poseen una estratigrafía relativa acorde con su orden decreciente en edad y ubicación topográfica, se consideró en ese entonces que dichas edades eran anómalas y, por lo tanto, que las muestras estaban contaminadas o meteorizadas, como en efecto lo parecen estar. Por otro lado, los flujos de pómez similares datados y mapeados suelen ser inferiores a 1,6 Ma, y la colada Sucre morfológicamente aún preservada, se ubican dentro de la caldera de Chocosuela (Alvarado \& Carr, 1993).

Sin embargo, las dataciones radiométricas realizadas para el arco de Sarapiquí (Gazel et al., 2005, 2009; presente trabajo), evidencian que no solo hay rocas de edades del finioligoceno y los albores del Mioceno, relativamente cercanas en edad al depósitos de flujo de pómez con biotita cerca del hospital de Ciudad Quesada, sino que además existen relictos antiguos cubiertos por los productos eruptivos más recientes, tal y como es el caso de las dacitas de Zarcero (16,8 Ma), o de antiguos flujos piroclásticos (4,2 - 4,1 Ma) y lahares, basculados, cubiertos a través de una discordancia angular por flujos de pómez (1,55 Ma) y lavas de Monteverde (1,57 Ma). Ver y comparar los cuadros 1,14 y 26 . Con base en lo anterior, queda en claro que la base de la cordillera Central en el occidente está edificada sobre productos volcánicos Oligo-Pliocénicos, tal y como se ha observado en otros macizos Cuaternarios en el resto del país. Estos antiguos productos aparecen como cerros aislados rodeados de lavas más recientes, tal y como es el caso del citado cerro en Zarcero, o de las rocas sedimentarias con moluscos fósiles en el Parque Nacional Braulio Carrillo (quebrada González), o varios cerros aislados de lavas antiguas y volcanoruditas de Pacacua en el pleno piso del Valle Central, a modo de ventanas estratigráficas (p.ej., La Favorita-Aeropuerto Tobías Bolaños), para citar algunos ejemplos. En fin, nuevos trabajos de detalle (mapeo y dataciones) serían necesarios, si se quiere esclarecer el problema a esta escala.

Claramente, las rocas más antiguas hasta ahora datadas por ${ }^{40} \mathrm{Ar} /{ }^{39} \mathrm{Ar}$, fuera de toda duda del macizo del Platanar-Chocosuela, lo remontan a edades que consistentemente se ubican alrededor del medio millón de años: 0,55 Ma (río Barroso), 0,51 Ma (base de la perforación cerca la confluencia 
del Río Segundo con el Toro), y 0,45 Ma (cañón del río La Vieja) y 0,43 Ma (entre Zapote y Tapesco). Los depósitos de flujos pumíceos (plag $+\mathrm{hb}$ ) en correspondencia con la localidad tipo del Miembro Palomo (cerca de Anateri, al oeste de Zarcero) y otro rico en biotita (plag + biot $+\mathrm{hb}$ ) en correspondencia con el Miembro Palmitos por Villa Blanca, reportan edades ${ }^{40} \mathrm{Ar} /{ }^{39} \mathrm{Ar}$ de $0,524 \mathrm{y}$ 0,440 Ma, en correspondencia con la estratigrafía establecida. Ambos probablemente provienen de las calderas de Chocosuela y la Picada (Alvarado \& Carr, 1993; Villegas, 2004). Otras edades de depósitos de flujos pumíceos similares a los del $\mathrm{Mb}$. Palomo, provienen del tajo La Pista, por el puente sobre el río Colorado, registrando edades de 0,582 y 0,565 Ma (presente trabajo).

Edades K/Ar de muestras recolectadas al parecer en lugares de difícil acceso, suministran datos ligeramente más jóvenes, que requieren tomarlas con cautela, puesto que se ubican en lo que se ha mapeado como parte del macizo antiguo de Chocosuela-Palmira (posiblemente $\geq 0,5 \mathrm{Ma}$ ): 0,35 Ma (fila Chocosuela) y 0,28 Ma (cerca del cerro Siete). En cambio, una edad ${ }^{40} \mathrm{Ar} /{ }^{39} \mathrm{Ar}$ (Carr et al., 2007) resulta en 0,25 Ma correspondiendo con un dique (por San Roque, carretera en construcción a ciudad Quesada), que sí estaría acorde por su ubicación intracaldérica (Cuadro 26). La colada de lava quebrada Palo, morfológicamente procedente del volcán Platanar, aporta una edad de $96 \mathrm{ka}$ (presente trabajo).

La evolución puede establecerse como sigue, aunque todavía faltan más datos para esclarecerla:

a. Presencia de un basamento volcánico antiguo (coladas de lava, depósitos de flujos piroclásticos, lahares) sobre el cual creció el macizo de Palmira-Platanar, con tres rangos de edades bien diferenciables: a. 29,0? - 11,1 Ma, b. 4,2 - 4,1 Ma, y c. 1,57 - 1,55 Ma.

b. Crecimiento del paleo-volcán Chocosuela (0,55 - 0,43 Ma).

c. Colapsos del o de los volcanes con la generación de depósitos de flujos piroclásticos: 0,58 - 0,44 Ma.

d. Posible edificación de edificios eruptivos menores (?): ¿0,35 - 0,25? Ma.

e. Crecimiento de los volcanes Platanar y Porvenir: <0,2 Ma?

\section{Volcán Poás}

Todas las lavas del Poás y sus conos satelitales han sido datadas mediante ${ }^{40} \mathrm{Ar} /{ }^{39} \mathrm{Ar}$ (Carr et al., 2007; Ruiz et al., 2010a; presente trabajo). Las coladas de lava más antiguas del llamado PaleoPoás, se extienden de 0,61 a 0,51 Ma, es decir que la pila efusiva se forma en $100 \mathrm{ka}$, macroscópica y cronológicamente muy similar a Colima Inferior (Cuadro 27). Una datación aislada de la unidad Achiote del Paleo-Poás aporta una edad de 0,283 $\mathrm{Ma}$, que o bien constituye el techo de un rejuvenecimiento de Paleo-Poás (Ruiz et al., 2010a) o podría corresponder con parte de Neo-Poás. Después de una pausa efusiva de casi $300 \mathrm{ka}$, se reinició el vulcanismo efusivo con las andesitas basálticas afíricas aflorantes en los alrededores de Río Cuarto datadas en 0,20 Ma, hasta culminar con las coladas de lava antiguas del Neo-Poás datadas en 0,14 Ma, así como las del cono Von Frantzius con 61 - 42 ka y el estravolcán del cerro Congo, los conos de escorias de Sabana Redonda $\mathrm{y}$, finalmente, con el vulcanismo Holoceno de los maares de Hule, Río Cuarto, Votos (Botos) y del Cráter Principal (Ruiz et al., 2010a).

Con base en el estudio detallado de Ruiz et al. (2010a), la historia eruptiva del Poás se puede resumir en:

a. Desarrollo del Paleo-Poás, predominantemente entre 0,61 y $0,51 \mathrm{Ma}$, y quizás extensivo hasta algo más joven como $0,2 \mathrm{Ma}$.

b. Desarrollo del neovulcanismo con la formación de los centros eruptivos de Neo-Poás $(0,14$ $0 \mathrm{Ma})$, incluyendo la cima del Poás con Botos y Cráter Principal ( $56-0 \mathrm{ka})$, Von Frantzius ( 41 ka), Sabana Redonda ( $40 \mathrm{ka})$, cerro Congo ( 35 ka), laguna Hule (6,2 ka), laguna Río Cuarto (¿5 - 4 ka?) y Pata de Gallo (2,8 ka).

\section{Volcán Barva}

La colada de lava más antigua del Barva fue reportada por Alvarado (1990) en 1,2 Ma (K/Ar). Dataciones más recientes y con el método ${ }^{40} \mathrm{Ar} /{ }^{39} \mathrm{Ar}$ son aquellas realizadas en los cerros Zurquí, que se extienden desde 0,9 hasta 0,4 Ma (correspondiente a un lapso de 0,5 Ma), 
Cuadro 26

Dataciones radiométricas del macizo volcánico de Chocosuela y Platanar

\begin{tabular}{|c|c|c|c|c|}
\hline MUESTRA & LITOLOGIA & UBICACIÓN & EDAD (Ma) & REFERENCIA \\
\hline \multicolumn{5}{|c|}{ PALEO-PLATANAR (CHOCOSUELA) } \\
\hline CR-PP-02-27 & Lava & $\begin{array}{l}\text { R. Toro, camino a casa de Máquinas Toro } \\
\text { 2, H. Quesada, 507,566-251,756 }\end{array}$ & $\begin{array}{c}0,554 \pm 0,020 \\
\left({ }^{40} \mathrm{Ar} /{ }^{39} \mathrm{Ar}: \text { mtz: plat. }\right)\end{array}$ & Carr et al. (2007) \\
\hline CR-245 & Andesita & $\begin{array}{l}\text { Garganta del R. La Vieja, H. Quesada, } \\
\qquad 489,150-250,025\end{array}$ & $\begin{array}{c}0,459 \pm 0,006 \\
\left({ }^{40} \mathrm{Ar} /{ }^{39} \mathrm{Ar}: \mathrm{mtz}\right)\end{array}$ & Presente trabajo \\
\hline CR-246 & Andesita basáltica & $\begin{array}{l}\text { R. Tapesco, entre Zapote y La Brisa, H. } \\
\text { Quesada, 491,100-245,050 }\end{array}$ & $\begin{array}{c}0,436 \pm 0,006 \\
\left({ }^{40} \mathrm{Ar} /{ }^{\beta 9} \mathrm{Ar}: \mathrm{mtz}\right)\end{array}$ & Presente trabajo \\
\hline MZ-72 & Andesita basáltica & C. El Avión, H. Quesada, 504,6-251,5 & $0,35 \pm 0,06(\mathrm{~K} / \mathrm{Ar})$ & ICE-ENEL (1988) \\
\hline CR-PP-02-22 & $\begin{array}{l}\text { Posible dique de } \\
\text { basalto alumínico }\end{array}$ & $\begin{array}{l}\text { Por San Roque, Ca. nueva a San Ramón, } \\
\text { H. Aguas Zarcas, } 487,656-257,869\end{array}$ & $\begin{array}{c}0,252 \pm 0,030 \\
\left({ }^{40} \mathrm{Ar}{ }^{39} \mathrm{Ar}: \text { mtz: plat. }\right)\end{array}$ & Carr et al. (2007) \\
\hline \multicolumn{5}{|c|}{ FM. ALTO PALOMO (MB. PALOMO) } \\
\hline CR-058 & $\begin{array}{l}\text { Depósito de flujo de } \\
\text { pómez no soldado }\end{array}$ & $\begin{array}{l}\text { Tajo La Pista, puente R. Colorado, H. } \\
\text { Naranjo, } 497.00 \mathrm{E}-222.25 \mathrm{~N}\end{array}$ & $\begin{array}{c}0,582 \pm 0,020 \\
\left({ }^{40} \mathrm{Ar} /{ }^{39} \mathrm{Ar}: \text { plag }\right)\end{array}$ & Presente trabajo \\
\hline $990712-2 c$ & $\begin{array}{l}\text { Depósito de flujo de } \\
\text { pómez no soldado }\end{array}$ & $\begin{array}{l}\text { Tajo La Pista, puerte R. Colorado, H. } \\
\text { Naranjo, 497,00-222,25 }\end{array}$ & $\begin{array}{c}0,565 \pm 0,030 \\
\left({ }^{40} \mathrm{Ar} /{ }^{/ 9} \mathrm{Ar}: \text { plag }\right)\end{array}$ & Presente trabajo \\
\hline $990712-6 b$ & $\begin{array}{l}\text { Depósito de flujo de } \\
\text { pómez no soldado }\end{array}$ & $\begin{array}{l}\text { Alto Palomo, camino a Bajos del Toro, H. } \\
\text { Quesada, 502,298-241,302 }\end{array}$ & $\begin{array}{c}0,524 \pm 0,022 \\
\left({ }^{40} \mathrm{Ar}{ }^{39} \mathrm{Ar}: \mathrm{plag}\right)\end{array}$ & Presente trabajo \\
\hline \multicolumn{5}{|c|}{ FM. ALTO PALOMO (MB. PALMITOS) } \\
\hline CR-217 & $\begin{array}{l}\text { Depósito de flujo de } \\
\text { pómez no soldado }\end{array}$ & $\begin{array}{l}\text { Finca Julieta, cerca de Villa Blanca, H. } \\
\text { Quesada, 484,261-241,639 }\end{array}$ & $\begin{array}{c}0,440 \pm 0,010 \\
\left({ }^{40} \mathrm{Ar} /{ }^{39} \mathrm{Ar}: \text { plat.: }\right. \\
\text { plag })\end{array}$ & Presente trabajo \\
\hline \multicolumn{5}{|c|}{ NEO-PLATANAR } \\
\hline CR-244 & Andesita & $\begin{array}{c}\text { Colada Queb. Palo, flanco WNW Platanar, } \\
\text { H. Aguas Zarcas, 492,575-258,925 }\end{array}$ & $\begin{array}{c}0,096 \pm 0,002 \\
\left({ }^{40} \mathrm{Ar} /{ }^{39} \mathrm{Ar}: \mathrm{mtz}\right)\end{array}$ & Presente trabajo \\
\hline
\end{tabular}

separado por tres grandes eventos ignimbríticos (entre muchos otros menores): 0,50 - 0,49 (Bajo La Hondura), 0,44 (Fm. Puente de Mulas) y 0,32 (Fm. Tiribí). Una gran centro efusivo post-Puente de Mulas y pre-Tiribí, está representado por unos $800 \mathrm{~m}$ de espesor de coladas de lava delgadas, de composición basáltica y andesítico basáltica $(0,5$ - $2 \mathrm{~m}$ de espesor individual) aflorantes a lo largo del río Lajas, en el flanco oeste del cerro Zurquí, con una inclinación primaria de unos $20^{\circ}$ al SW. Todo este conjunto parece haberse originado rápidamente alrededor de los $427 \mathrm{ka}$ en un lapso inferior a unos $15 \mathrm{ka}$, al grado que las muestras tomadas estratigráficamente (de más antigua a más joven: CR-6, 5B, 4 y 9) se traslapan (Cuadro 28).

Así, la historia eruptiva del Barva se puede resumir en:

a. Crecimiento del Proto-Barva (Bajo Hondura): 1,2 - 0,89 Ma.

b. b. Crecimiento de nuevos focos efusivos o Paleo-Barva (cerros Zurquí): 0,57 - 0,40 Ma.

c. Posibles varios colapsos caldéricos con depósitos de flujos ignimbríticos: 0,50 - 0,49, 0,44 y $0,32 \mathrm{Ma}$.

d. Neo-Barva: 0,26 - 0 Ma. 


\section{Volcanes Irazú y Turrialba}

El Irazú y Turrialba comparten no solo el mismo basamento, sino gran parte de su plataforma eruptiva, constituyendo volcanes hermanos.

La andesita con anfíbol de la base del volcán Turrialba, datada por K/Ar en 2,15 $\pm 0,3 \mathrm{Ma}$ (Bellon \& Tournon, 1978), posiblemente no guarda ninguna relación con los estratovolcanes, dado que su edad es significativamente más antigua y debido a que casi todas sus lavas son del tipo piroxénico (ver Cuadro 17). Esta andesita hornbléndica podría pertenecer con las rocas calcoalcalinas del Grupo Aguacate, por su abundancia en hornblendas (Kussmaul et al., 1991).

Las dataciones radiométricas ${ }^{40} \mathrm{Ar} /{ }^{39} \mathrm{Ar}$ hasta el momento disponibles, relacionadas con ambos macizos volcánicos, agrupan los productos efusivos en tres grandes grupos de edades (Cuadros 29 y 30): el Proto-Irazú/Turrialba en 0,98 Ma (andesita río Siquirres) o 0,85 Ma (ignimbrita de San Jerónimo), seguido por la fase constructiva propiamente dicha del Paleo-Irazú-Turrialba a los 0,59 - 0,45 Ma, en correspondencia con los edificios erosionados y plataformas de lava (de similar edad a las lavas del Zurquí). Y finalmente, tenemos los productos efusivos y explosivos más recientes que $0,25 \mathrm{Ma}$, culminando con los dos grandes campos de lava de Cervantes y varias coladas de lava en bloques del Turrialba. Allegre y Condomines (1976) calcularon la edad del magma reciente del Irazú bajo un equilibrio radioactivo en $0,14 \mathrm{Ma}$.

La historia crono-eruptiva del Irazú-Turrialba se puede resumir en:

a. Presencia de un basamento volcánico y sedimentario pre-Pleistoceno, incluyendo al vulcanismo coetáneo del Grupo Aguacate o Fm. Grifo Alto: 2,15 Ma.

b. Vulcanismo efusivo y explosivo muy localizada o que no está expuesto por formar parte del núcleo del Proto-Irazú/Turriabla: 0,98 - 0,85 Ma. c. Crecimiento del paleo-volcán(es): 0,59 $0,45 \mathrm{Ma}$.

d. Neovulcanismo: 0,25 - 0 Ma.

\section{Volcanismo del piso volcánico del Valle Central: desde el valle del Guarco hasta Orotina}

Acá se va a englobar todas las dataciones que se encuentran dentro de las depresiones tectónicas e intermontanas (p.ej., Turrialba, Guarco y Valle Central), valles fluviales (cañones de los ríos Grande y Reventazón) y la planicie costera (meseta de Esparza-Orotina).

Ignimbritas con y sin minerales hidroxilados (biotita y anfíbol), con pómez, escorias o fiammes, afloran en la meseta de Esparza y alrededores, así como productos erosivos asociados a ellas, presentes como bloques en los aluviones y depósitos debris avalanches (Marshall, 2000; presente trabajo). Sus edades ${ }^{40} \mathrm{Ar} /{ }^{39} \mathrm{Ar}$ varían entre 1,91 y 0,92 Ma (Cuadro 31).

La ignimbrita aflorante bajo conglomerados escoriáceos (ignimbríticos) en el puente sobre la quebrada Paso Agres (Pérez, 2000), se trató de datar $\operatorname{con}^{40} \mathrm{Ar} /{ }^{39} \mathrm{Ar}$ en el presente trabajo, pero al parecer posee muchos xenocristales y su edad no se logró determinar, siendo similar o más joven que 1,2 Ma. Marshall (2000) data mediante ${ }^{40} \mathrm{Ar} /{ }^{39} \mathrm{Ar}$ la matriz de un lahar en 1,66 $\pm 0,16 \mathrm{Ma}$ cerca del puente Agres sobre el Tárcoles, puente de hamaca que trágicamente colapsó en el 2009 (pero difiere del otro puente cercano y más pequeño sobre la quebrada Paso Agres), y unos guijarros pumíceos en de la Unidad Tigre en 1,12 $\pm 0,13$ Ma. Dicha edad es similar al resultado K/Ar de $1,28 \pm 0,26 \mathrm{Ma}$, reportado por Bergoeing (1982), para la misma localidad, pero presumiblemente asociada a una ignimbrita. La ignimbrita descrita por Bergoeing posee un 24\% de líticos (andesitas angulares hasta redondeadas, escorias y rocas plutónicas), fenocristales (10\% plag, 1,5\% px, 1\% 
Cuadro 27

Dataciones radiométricas de volcán del Poás

\begin{tabular}{|c|c|c|c|c|}
\hline MUESTRA & LITOLOGIA & UBICACIÓN & $\operatorname{EDAD}(\mathrm{Ma})$ & REFERENCIA \\
\hline \multicolumn{5}{|c|}{ LAVAS PALEO-POÁS } \\
\hline CR-148 & Andesita & $\begin{array}{l}\text { Perforación P.H.C. 28TUN, prof. 138,8 } \\
\text { m (=913 m s.n.m.), 1,5 km al N de I. } \\
\text { Bonita, H. Poás, 517,377-247,943 }\end{array}$ & $\begin{array}{c}0,610 \pm 0,0360,590 \pm 0,020 \\
\left({ }^{40} \mathrm{Ar}{ }^{39} \mathrm{Ar}: \mathrm{mtz}\right)\end{array}$ & Presente trabajo \\
\hline CR-146 & Andesita & $\begin{array}{l}\text { Perforación P.H.C. } 28 T U N, \text { prof. } 111,3 \\
\text { m (=939 m s.n.m.), 1,5 km al N de I. } \\
\text { Bonita, H. Poás, 517,377-247,943 }\end{array}$ & $\begin{array}{c}0,607 \pm 0,020\left({ }^{40} \mathrm{Ar} /{ }^{39} \mathrm{Ar}:\right. \\
\mathrm{mtz})\end{array}$ & Presente trabajo \\
\hline CR-153 & $\begin{array}{l}\text { Andesita (bloque } \\
\text { dentro de bre- } \\
\text { cha?) }\end{array}$ & $\begin{array}{l}\text { Perforación P.H.C. } 28 T U N \text {, prof. } 182 \\
\text { m (=871 m s.n.m.), 1,5 km al N de I. } \\
\text { Bonita, H. Poás, } 517,377-247,943\end{array}$ & $\begin{array}{c}0,588 \pm 0,0120,585 \pm 0,016 \\
\left({ }^{40} \mathrm{Ar}{ }^{\beta 9} \mathrm{Ar}: \mathrm{mtz}\right)\end{array}$ & Presente trabajo \\
\hline ATN-58 & Andesita basáltica & $\begin{array}{l}\text { R. San Juan, flanco S del Poás, H. } \\
\text { Naranjo, 503,517-234,834 }\end{array}$ & $\begin{array}{c}0,538 \pm 0,015\left({ }^{40} \mathrm{Ar} /{ }^{39} \mathrm{Ar}:\right. \\
\mathrm{mtz})\end{array}$ & Ruiz et al. (2010a) \\
\hline CR-012 & $\begin{array}{l}\text { Andesita basáltica } \\
\text { porfirítica (pórfi- } \\
\text { do andesítico) }\end{array}$ & $\begin{array}{l}\text { Cuesta Montaña Azul, cerca Catarata } \\
\text { La Paz, H. Poás, 518,727-243,519 }\end{array}$ & $\begin{array}{c}0,527 \pm 0,006\left({ }^{40} \mathrm{Ar} /{ }^{39} \mathrm{Ar}:\right. \\
\mathrm{mtz})\end{array}$ & Presente trabajo \\
\hline CR-144 & Andesita & $\begin{array}{l}\text { Perforación P.H.C. } 28 \mathrm{TUN} \text {, prof. 77,5 } \\
\text { m (=975 m s.n.m.), 1,5 km al N de I. } \\
\text { Bonita, H. Poás, 517,377-247,943 }\end{array}$ & $\begin{array}{c}0,517 \pm 0,0100,490 \pm 0,020 \\
\left({ }^{40} \mathrm{Ar} /{ }^{39} \mathrm{Ar}: \mathrm{mtz}\right)\end{array}$ & Presente trabajo \\
\hline CR-141 & Andesita & $\begin{array}{l}\text { Perforación P.H.C. 28TUN, sección } \\
\text { superior, } 1,5 \text { km al N de I. Bonita, } \\
\text { H. Poás, } 517,377-247,943\end{array}$ & $\begin{array}{c}0,520 \pm 0,0200,515 \pm 0,010 \\
0,514 \pm 0,024\left({ }^{40} \mathrm{Ar} /{ }^{39} \mathrm{Ar}:\right. \\
\text { mtz, plag })\end{array}$ & Presente trabajo \\
\hline CR-100 & Andesita o bloque & $\begin{array}{l}\text { Perforación, sección basal, confluen- } \\
\text { cia del R. Segundo con el río Toro, } \\
\text { H. Quesada, 505,725-247,150 }\end{array}$ & $\begin{array}{c}0,516 \pm 0,012\left({ }^{40} \mathrm{Ar} /{ }^{39} \mathrm{Ar}:\right. \\
\mathrm{mtz})\end{array}$ & Presente trabajo \\
\hline ACH-01 & Andesita & $\begin{array}{l}\text { Queb. Achiote, H. Barva, 510,300- } \\
\qquad 236,950\end{array}$ & $\begin{array}{c}0,283 \pm 0,015\left({ }^{40} \mathrm{Ar} /{ }^{39} \mathrm{Ar}:\right. \\
\mathrm{mtz})\end{array}$ & Ruiz et al. (2010a) \\
\hline \multicolumn{5}{|c|}{ LAVAS RÍO CUARTO (PALEO-POÁS?) } \\
\hline CR-PO-02-28 & $\begin{array}{l}\text { Andesita basáltica } \\
\text { afirica }\end{array}$ & $\begin{array}{c}\text { Tajo artesanal abandonado a 1,5 km } \\
\text { al WNE laguna de R. Cuarto, H. Río } \\
\text { Cuarto, 510,664-260,358 }\end{array}$ & $\begin{array}{c}0,201 \pm 0,03(40 \mathrm{Ar} / 39 \mathrm{Ar}: \\
\text { mtz: iso.) }\end{array}$ & Carr et al. (2007) \\
\hline CR-PO-02-29 & $\begin{array}{l}\text { Andesita basáltica } \\
\text { afirica }\end{array}$ & $\begin{array}{l}\text { Tajo abandonado cerca del borde } \\
\text { cratérico W laguna de R. Cuarto, H. } \\
\text { Río Cuarto, } 512,074-259,530\end{array}$ & $\begin{array}{c}0,201 \pm 0,03(40 \mathrm{Ar} / 39 \mathrm{Ar}: \\
\text { mtz: iso.) }\end{array}$ & Carr et al. (2007) \\
\hline \multicolumn{5}{|c|}{ NEO-POÁS } \\
\hline CR-097 & Andesita & $\begin{array}{l}\text { Perforación, sección media, con- } \\
\text { fluencia del R. Segundo con el R. } \\
\text { Toro, H. Poás, } 505.725-247.150\end{array}$ & $\begin{array}{l}0,140 \pm 0,0500,130 \pm 0,050 \\
(40 \mathrm{Ar} / 39 \mathrm{Ar}: \mathrm{mtz})\end{array}$ & Presente trabajo \\
\hline CR-013 & $\begin{array}{l}\text { Andesita afírica } \\
\text { bandeada }\end{array}$ & $\begin{array}{c}\text { A unos } 100 \mathrm{~m} \text { del puente, catarata } \\
\text { La Paz Grande, H. Poás, aprox. } \\
\text { 518.3-243.3 }\end{array}$ & $\begin{array}{c}0,061 \pm 0,002(40 \mathrm{Ar} / 39 \mathrm{Ar}: \\
\mathrm{mtz})\end{array}$ & Presente trabajo \\
\hline
\end{tabular}


Cuadro 27 (continuación)

Dataciones radiométricas de volcán del Poás

\begin{tabular}{ccccc}
\hline MUESTRA & LITOLOGIA & UBICACIÓN & EDAD (Ma) & REFERENCIA \\
\hline $\begin{array}{c}\text { PO-08/01/09- } \\
\text { 01/ }\end{array}$ & Andesita & $\begin{array}{c}\text { Colada del cono Botos, Queb. Pulga, } \\
\text { H. Poás, 516,901-240,800 }\end{array}$ & $\begin{array}{c}0,056 \pm 0,004\left({ }^{40} \mathrm{Ar} /{ }^{39} \mathrm{Ar}:\right. \\
\mathrm{mtz})\end{array}$ & Ruiz et al. (2010a) \\
CR-095 & Andesita & $\begin{array}{c}\text { Perforación, sección superior, con- } \\
\text { fluencia del R. Segundo con el R. } \\
\text { Toro, H. Poás, 505,725-247,150 }\end{array}$ & $0,042 \pm 0,004\left({ }^{40} \mathrm{Ar} /{ }^{39} \mathrm{Ar}:\right.$ & Presente trabajo \\
& & $\mathrm{mtz})$ & Presente trabajo \\
CR-014B & $\begin{array}{c}\text { Andesita basáltica } \\
\text { porfirítica }\end{array}$ & $\begin{array}{c}\text { Colada de 25 m de espesor, R. y Cuesta } \\
\text { Ángel, H. Poás, 517,121-248,942 }\end{array}$ & $0,041 \pm 0,002\left({ }^{40} \mathrm{Ar} /{ }^{39} \mathrm{Ar}:\right.$ & $\mathrm{mtz})$ \\
\hline
\end{tabular}

$\mathrm{hb}, 1 \% \mathrm{mt}$, y trazas de cuarzo \pm xenocristales de olivino) en una matriz (62\%) vítreo-cristalina (vidrio, plag $+\mathrm{px}+\mathrm{mt} \pm \mathrm{hb} \pm$ biot $\pm \mathrm{ap})$. Aunque en ese sector afloran tanto ignimbritas pumíceas amarillentas como el depósito del debris avalanchel flow de Tivives, la descripción petrográfica de clastos redondeados, ausencia de pómez juvenil y su geoquímica (basáltica y no ácida en contraposición a la petrografía), nos pone en duda de si se dató una ignimbrita o más bien el depósito del debris de Fm. Tivives que se describe en este apartado.

La ignimbrita de San Jerónimo, al pie del Irazú (Cuadro 32), posee una edad ${ }^{40} \mathrm{Ar} /{ }^{39} \mathrm{Ar}$ media de 0,859 Ma (Alvarado et al., 2006), contemporánea con los eventos reportados en Orotina, indicando tan solo la persistencia de un vulcanismo explosivo poco conocido en su geoquímica, distribución y fuente de origen.

Las secuencias efusivas más antiguas hasta ahora datadas de la cordillera Central y formado parte de ella corresponde con las lavas de la Estación Biológica La Selva (K/Ar 1,2 $\pm 0,1 \mathrm{Ma}$, Alvarado, 1990), cuya edad merece verificarse, aunque existen dataciones ${ }^{40} \mathrm{Ar} /{ }^{39} \mathrm{Ar}$ que nos hablan de edades similares, tales como las de la colada andesítica de Siquirres (0,98 Ma) y la del Zurquí de 0,89 Ma (presente trabajo). Esto sería, lo que a criterio de Gans et al. (2003), se le podría asociar con la Proto-Cordillera.

Como se observa, se tienen productos explosivos ignimbríticos por Orotina, extremo oriental de la cordillera de Tilarán y dentro de la cordillera Central con edades entre 1,91 y 0,89 Ma, contemporáneos en parte con el vulcanismo de Monteverde (definido cronológicamente entre 2,1 y $1,1 \mathrm{Ma}$ ), por lo que correspondería con un vulcanismo transicional entre Monteverde y el vulcanismo que dio origen a la PaleoCordillera. Las calderas que dieron origen a las diversas ignimbritas datadas (Cuadros 31 y 32) estarían cubiertas por los productos efusivos de Monteverde y de la cordillera Central subsiguiente, particularmente la Proto-Cordillera $(1,2$ - 0,89 Ma) y la Paleo-Cordillera $(0,75-$ $0,40 \mathrm{Ma}$ ). Ya Alvarado (1984, p. 115, 140, 141) había hipotetizado sobre la existencia de una cordillera antigua, tanto en Guanacaste como en la Central, sobre la cual se desarrollaron los volcanes más recientes.

Colima Inferior es una secuencia espesa (al menos $160 \mathrm{~m}$ ) de coladas de lava, rocas piroclásticas y epiclásticas, con edades comprobadas de $0,75-0,59 \mathrm{Ma}$, pero que puede extenderse más en el tiempo (Cuadro 33). Las coladas de lava de Colima se les ha explicado por como efusiones fisurales (Protti, 1986; Kussmaul, 1988), aunque podrían ser algunas de ellas parte del vulcanismo distal/media de la Paleo-Cordillera. Efectivamente, en el cauce del río Virilla a la altura de la Reforma, se observó un gran dique o chimenea que cortaba a una mesobrecha (depósito de debris flow o debris avalanche, Miembro 
Cuadro 28

Dataciones radiométricas del volcán Barva

\begin{tabular}{|c|c|c|c|c|}
\hline MUESTRA & LITOLOGIA & UBICACIÓN & $\operatorname{EDAD}(\mathrm{Ma})$ & REFERENCIA \\
\hline \multicolumn{5}{|c|}{ PROTO-BARVA } \\
\hline PV-1950 & Andesita afírica & $\begin{array}{l}\text { Queb. El Salto, Finca La Selva, H. Río Cuarto, } \\
535,7-267,6\end{array}$ & $1,2 \pm 0,1(\mathrm{~K} / \mathrm{Ar})$ & Alvarado (1990) \\
\hline CR-233 & $\begin{array}{c}\text { Andesita rica en } \\
\text { plagioclasa }\end{array}$ & $\begin{array}{l}\text { Ca. Braulio Carrillo, H. Carrillo, } \\
539,675-232,550\end{array}$ & $\begin{array}{c}0,889 \pm 0,012 \\
\left({ }^{40} \mathrm{Ar} /{ }^{39} \mathrm{Ar}: \mathrm{mtz}\right)\end{array}$ & Presente trabajo \\
\hline \multicolumn{5}{|c|}{ PALEO-BARVA } \\
\hline CR-231 & $\begin{array}{l}\text { Andesita vítreo- } \\
\text { porfirítica }\end{array}$ & $\begin{array}{l}\text { Ca. Braulio Carrillo, H. Carrillo, } \\
\text { 538,325-230,400 }\end{array}$ & $\begin{array}{c}0,570 \pm 0,020 \\
\left({ }^{40} \mathrm{Ar} /{ }^{39} \text { Ar: plag }\right)\end{array}$ & Presente trabajo \\
\hline \multicolumn{5}{|c|}{ IGNIMBRITAS DEL BAJO LA HONDURA Y DE PUENTE DE MULAS } \\
\hline CR-102 & $\begin{array}{l}\text { Ignimbrita bajo } \\
\text { Tiribí }\end{array}$ & $\begin{array}{l}\text { Perforación 4, P.H. Virilla, esquina S de La } \\
\text { Reforma, H. Abra, 512,025-215,339 }\end{array}$ & $\begin{array}{c}0,505 \pm 0,010 \\
0,480 \pm 0,020 \\
\left({ }^{40} \mathrm{Ar} /{ }^{39} \mathrm{Ar}: \text { plag }\right)\end{array}$ & Presente trabajo \\
\hline CR-228 & Ignimbrita & $\begin{array}{l}\text { Cerca Túnel Zurquí, camino antiguo Braulio } \\
\text { Carrillo, H. Carrillo, 538,150-228,000 }\end{array}$ & $\begin{array}{c}0,501 \pm 0,010 \\
0,501 \pm 0,024 \\
\left({ }^{40} \mathrm{Ar} /{ }^{39} \mathrm{Ar}: \text { plag }\right)\end{array}$ & Presente trabajo \\
\hline CR-018 & Ignimbrita & $\begin{array}{l}\text { Tajo Pedregal, ignimbrita inferior poco soldada, } \\
1,25 \mathrm{~km} \text { al W de la Planta Brasil, H. Abra, } \\
5 \text { 516,940-216,912 }\end{array}$ & $\begin{array}{c}0,496 \pm 0,016 \\
\left({ }^{40} \mathrm{Ar} /{ }^{39} \mathrm{Ar}: \text { plag }\right)\end{array}$ & Presente trabajo \\
\hline CR-057A & Ignimbrita negra & $\begin{array}{l}\text { Tajo La Pista, puente R. Colorado, H. Naranjo, } \\
\text { 497,00-222,25 }\end{array}$ & $\begin{array}{c}0,490 \pm 0,015 \\
\left({ }^{40} \mathrm{Ar} /{ }^{39} \mathrm{Ar}: \mathrm{plag}\right)\end{array}$ & Presente trabajo \\
\hline CR-229 & $\begin{array}{l}\text { Ignimbrita no } \\
\text { soldada }\end{array}$ & $\begin{array}{l}\text { Cerca Túnel Zurquí, camino antiguo Braulio } \\
\text { Carrillo, H. Carrillo, 538,100-228,100 }\end{array}$ & $\begin{array}{c}0,439 \pm 0,025 \\
\left(4^{40} \mathrm{Ar} /{ }^{39} \mathrm{Ar}: \text { plag }\right)\end{array}$ & Presente trabajo \\
\hline \multicolumn{5}{|c|}{ LAVAS CERROS ZURQUÍ (PALEO-BARVA, POST-IGNIMBRITAS) } \\
\hline B-48 & & Flanco SW C. Tibás, H. Barva, 529,4-227,4 & $\begin{array}{l}0,5 \pm 0,075 \\
\quad(\mathrm{~K} / \mathrm{Ar})\end{array}$ & $\begin{array}{l}\text { Bellon \& Tour- } \\
\text { non (1978) }\end{array}$ \\
\hline CR-009 & Basalto olivínico & $\begin{array}{l}\text { Tope Sección, R. Lajas, C. Zurquí, H. Barva, } \\
\text { 531,950-225,800 }\end{array}$ & $\begin{array}{c}0,427 \pm 0,008 \\
\left({ }^{40} \mathrm{Ar} /{ }^{39} \mathrm{Ar}: \mathrm{mtz}\right)\end{array}$ & Presente trabajo \\
\hline CR-006 & Basalto olivínico & $\begin{array}{l}\text { Sección basal, R. Lajas, C. Zurquí, H. Barva, } \\
\qquad 531,950-225,100\end{array}$ & $\begin{array}{c}0,427 \pm 0,006 \\
\left({ }^{40} \mathrm{Ar} /{ }^{39} \mathrm{Ar}: \mathrm{mtz}\right)\end{array}$ & Presente trabajo \\
\hline CR-004 & Basalto olivínico & $\begin{array}{l}\text { Sección media, R. Lajas, C. Zurquí, H. Barva, } \\
\qquad 531,950-225,350\end{array}$ & $\begin{array}{c}0,426 \pm 0,014 \\
\left({ }^{40} \mathrm{Ar} /{ }^{39} \mathrm{Ar}: \mathrm{mtz}\right)\end{array}$ & Presente trabajo \\
\hline CR-005B & Basalto olivínico & $\begin{array}{l}\text { Sección media, R. Lajas, C. Zurquí, H. Barva, } \\
\qquad 531,950-225,350\end{array}$ & $\begin{array}{c}0,405 \pm 0,020 \\
\left({ }^{40} \mathrm{Ar} /{ }^{39} \mathrm{Ar}: \mathrm{mtz}\right)\end{array}$ & Presente trabajo \\
\hline CR-230 & Basalto olivínico & $\begin{array}{l}\text { Tope de la sección, C. Zurquí, H. Barva, } \\
\qquad 531,950-225,800\end{array}$ & $\begin{array}{c}0,400 \pm 0,040 \\
\left({ }^{40} \mathrm{Ar} /{ }^{39} \mathrm{Ar}: \mathrm{mtz}\right)\end{array}$ & Presente trabajo \\
\hline \multicolumn{5}{|c|}{ NEO-BARVA } \\
\hline CR-B-02-8 & Andesita basáltica & $\begin{array}{c}\text { Colada de lava columnar espesa, cerca puente } \\
\text { sobre el R. Volcán, entre San Miguel y Ángeles, } \\
\text { H. Poás, } 517,987-256,225\end{array}$ & $\begin{array}{l}0,262 \pm 0,010 \\
\left({ }^{40} \mathrm{Ar} / 39\right. \\
\mathrm{Ar}: \mathrm{mtz}: \\
\quad \text { iso. })\end{array}$ & Carr et al. (2007) \\
\hline CR-B-02-15 & $\begin{array}{l}\text { Bloques vesicu- } \\
\text { lares }\end{array}$ & $\begin{array}{l}\text { Bijagual, a } 4 \text { km de Magsasay, H. Río Cuarto, } \\
\text { 527,472-264,585 }\end{array}$ & $\begin{array}{c}0,259 \pm 0,009 \\
\left({ }^{40} \mathrm{Ar}{ }^{\beta 9} \mathrm{Ar} \text { mtz: plat. }\right)\end{array}$ & Carr et al. (2007) \\
\hline
\end{tabular}


Cuadro 28 (continuación)

Dataciones radiométricas del volcán Barva

\begin{tabular}{|c|c|c|c|c|}
\hline MUESTRA & LITOLOGIA & UBICACIÓN & EDAD (Ma) & REFERENCIA \\
\hline CR-B-02-16 & Andesita basáltica & $\begin{array}{l}\text { Colada de lava, a } 3 \mathrm{~km} \text { de Magsasay, H. Río } \\
\text { Cuarto, } 528,026-265,418\end{array}$ & $\begin{array}{c}0,246 \pm 0,017 \\
\left({ }^{40} \mathrm{Ar} /{ }^{39} \mathrm{Ar}: \mathrm{mtz}:\right. \\
\quad \text { iso. })\end{array}$ & Carr et al. (2007) \\
\hline CR-B-02-9 & $\begin{array}{l}\text { Bloque en espeso } \\
\text { depósito aluvial? }\end{array}$ & Ángeles, Queb. Lajas, H. Poás, 519,973-255,527 & $\begin{array}{c}0,201 \pm 0,020 \\
\left({ }^{40} \mathrm{Ar} /{ }^{39} \mathrm{Ar}: \text { plag: }\right. \\
\text { plat. })\end{array}$ & Carr et al. (2007) \\
\hline \multicolumn{5}{|c|}{ LAVAS POST-IGNIMBRITAS (BARVA) } \\
\hline CR-038 & $\begin{array}{c}\text { Colada andesítica } \\
\text { basáltica }\end{array}$ & $\begin{array}{l}\text { Bajo el puente del ferrocarril, cercaTajo Pedre- } \\
\text { gal, H. Abra, } 514,750-217,750\end{array}$ & $\begin{array}{c}0,270 \pm 0,006 \\
\left({ }^{40} \mathrm{Ar} /{ }^{39} \mathrm{Ar}: \mathrm{mtz}\right)\end{array}$ & $\begin{array}{l}\text { Pérez et al. } \\
\quad(2006)\end{array}$ \\
\hline CR-052 & $\begin{array}{c}\text { Colada andesítico } \\
\text { basáltica }\end{array}$ & $\begin{array}{c}\text { Por el Aeropuerto Juan Santa María, autopista, } \\
\text { H. Barva, } 512,7-220,3\end{array}$ & $\begin{array}{c}0,258 \pm 0,005 \\
\left({ }^{40} \mathrm{Ar} /{ }^{39} \mathrm{Ar}: \mathrm{mtz}\right)\end{array}$ & $\begin{array}{l}\text { Pérez et al. } \\
\text { (2006) }\end{array}$ \\
\hline
\end{tabular}

Nuestro Amo), desde donde se derramaban las lavas a ambos lados. Las lavas de Colima Inferior en el Valle Central como las lavas de La Selva, presentan composiciones químicas diferentes a la de los estratovolcanes actuales o a la NeoCordillera (Kussmaul, 1988; Alvarado, 1990; Pérez et al., 2006).

El Miembro Nuestro Amo fue enmarcado dentro de la Fm. Tiribí (Echandi, 1981) y definido originalmente como "lodos toba" y "lodos toba lapillíca" (Brenes, 1967) o "avalanchas frías" y "tobas caóticas" (Fernández, 1969). Aunque Echandi (1981) lo pone como la unidad basal de Tiribí, a la hora de analizar con detalle las perforaciones aportadas por él, se le ve sobreyaciendo a las lavas del Miembro Belén (= Colima Inferior) pero nunca a las lavas de Colima Superior, por lo que parece ser más antiguo, incluso que la ignimbrita de Puente de Mulas; por lo tanto, no es la base de Tiribí. Ya Pérez (2000) lo había excluido como parte de Fm. Tiribí. El Mb. Nuestro Amo consiste en una brecha polimíctiva (lavas, pómez) de diversos tamaños, mal seleccionada, localmente con alteración hidrotermal, matriz tobácea, dura, densa, y con supuestas coladas de lava intercaladas, que perfectamente podrían ser megabloques. Su espesor máximo en las perforaciones es de $178 \mathrm{~m}$, pero por lo general varía entre 5 y $50 \mathrm{~m}$. Varios clastos de lava fueron tomados para datación ${ }^{40} \mathrm{Ar} /{ }^{39} \mathrm{Ar}$ de productos epiclásticos que posiblemente corresponden con Nuestro Amo, dando edades de 0,63 - 0,61 Ma (Cuadros 31 y 32). Los nuevos cortes a lo largo de la carretera a Caldera, así como el tajo Colorado (cerca del puente principal sobre el río del mismo nombre), dejan entrever lo que se puede correlacionar con Nuestro Amo y que corresponde con al menos 4 depósitos de debris avalanche y debris flows. Si tomamos en cuenta lo que se mencionó antes, de que una colada de Colima Inferior intruyó y se derramó sobre una mesobrecha, asociada con Nuestro Amo a la altura de La Reforma, y que dichas lavas se dataron en 0,61 $0,59 \mathrm{Ma}$, entonces se podría pensar perfectamente que Nuestro Amo como depósito ha de tener una edad de $\sim 0,61 \mathrm{Ma}$.

Aunque en las inmediaciones del embalse de La Garita y entre el aeropuerto Juan Santa María y Manolos, afloran megabrechas relacionadas con un depósito de debris avalanche, también existen afloramientos que nos sugieren la presencia de verdaderas coladas de lava, como la llamada colada de Cebadilla $(0,75$ - 0,53 Ma). Sin embargo, todavía falta mapeo de detalle para dilucidar la estratigrafía y su interpretación, de si se trata de verdaderas coladas de lava (= Fm. Colima Inferior) o de megabloques tipo toreva, dentro de los lapsos previamente descritos. 
Cuadro 29

Dataciones radiométricas del volcán Irazú

\begin{tabular}{|c|c|c|c|c|}
\hline MUESTRA & LITOLOGÍA & UBICACIÓN & EDAD (Ma) & REFERENCIA \\
\hline \multicolumn{5}{|c|}{ LAVAS PALEO-IRAZÜ (CABEZA DE VACA) } \\
\hline CR-IZ-02-05 & Bloque de andesita & $\begin{array}{c}\text { Santa María (antiguo Infiernillo), } \\
\text { Juan Viñas, H. Istarú, 563,116- } \\
207,334\end{array}$ & $\begin{array}{c}0,594 \pm 0,016 \\
\left({ }^{40} \mathrm{Ar} /{ }^{39} \mathrm{Ar}: \text { mtz: plat. }\right)\end{array}$ & $\begin{array}{l}\text { Alvarado et al. (2006), } \\
\text { Carr et al. (2007) }\end{array}$ \\
\hline CR-IZ-02-20 & Andesita & $\begin{array}{l}\text { Las Nubes, Hacienda Abigail, C. } \\
\text { Pico de Piedra, H. Istarú, 542,743- } \\
218,854\end{array}$ & $\begin{array}{c}0,544 \pm 0,03\left({ }^{40} \mathrm{Ar} /{ }^{39} \mathrm{Ar}:\right. \\
\text { mtz: plat. })\end{array}$ & $\begin{array}{l}\text { Alvarado et al. (2006), } \\
\text { Carr et al. (2007) }\end{array}$ \\
\hline $\mathrm{RCR}$ & $\begin{array}{l}\text { ¿Lava traquiandesí- } \\
\text { tica o bloque dentro } \\
\text { de debris avalanche? }\end{array}$ & $\begin{array}{l}\text { R. Costa Rica, Guápiles, H. Guá- } \\
\text { piles, 551,4-243,0 }\end{array}$ & $0,450 \pm 0,1(\mathrm{~K} / \mathrm{Ar})$ & $\begin{array}{l}\text { Nieuwenhuyse et al. } \\
\qquad(2000)\end{array}$ \\
\hline \multicolumn{5}{|c|}{ NEO-IRAZÚ } \\
\hline CR-001 & Andesita basáltica & $\begin{array}{l}\text { Cuesta Chinchilla, flanco SW del } \\
\text { Irazú, H. Istarú, 548,151-207,545 }\end{array}$ & $\begin{array}{c}0,176 \pm 0,002 \\
\left({ }^{40} \mathrm{Ar} /{ }^{39} \mathrm{Ar}: \text { plat.: } \mathrm{mtz}\right)\end{array}$ & Presente trabajo \\
\hline CR-IZ-02-19 & Andesita con biotita & $\begin{array}{l}\text { Entre Corralillo y Laguna, R. Tiri- } \\
\text { bí, H. Istarú, 544,328-215,008 }\end{array}$ & $\begin{array}{c}0,137 \pm 0,005 \\
\left({ }^{40} \mathrm{Ar} /{ }^{39} \mathrm{Ar}: \text { biot: plat. }\right)\end{array}$ & $\begin{array}{l}\text { Alvarado et al. (2006), } \\
\text { Carr et al. (2007) }\end{array}$ \\
\hline CA-2 & Andesita & $\begin{array}{l}\text { Tierra Blanca, H. Istarú, aprox. } \\
\qquad 548,0-212,0\end{array}$ & $\begin{array}{l}0,110 \pm 0,016 \\
\left({ }^{238} \mathrm{U} /{ }^{230} \mathrm{Th}\right)\end{array}$ & $\begin{array}{l}\text { Allegre \& Condomi- } \\
\text { nes (1976) }\end{array}$ \\
\hline CA-12 & Andesita & Volcán Irazú & $\begin{array}{l}0,068 \pm 0.026 \\
\quad\left({ }^{238} \mathrm{U} /{ }^{230} \mathrm{Th}\right)\end{array}$ & $\begin{array}{l}\text { Allegre \& Condomi- } \\
\text { nes (1976) }\end{array}$ \\
\hline CR-IZ-02-1 & Basalto & $\begin{array}{l}\text { Boquerón, colada de Cervantes W, } \\
\text { H. Istarú, 552.462-208.193 }\end{array}$ & $\begin{array}{c}0,057 \pm 0,013 \\
\left({ }^{40} \mathrm{Ar} /{ }^{39} \mathrm{Ar}: \text { mtz: iscrona }\right)\end{array}$ & $\begin{array}{l}\text { Alvarado et al. (2006), } \\
\text { Carr et al. (2007) }\end{array}$ \\
\hline CA-7 & Andesita & Volcán Irazú & $0,05\left({ }^{238} \mathrm{U} /{ }^{230} \mathrm{Th}\right)$ & $\begin{array}{l}\text { Allegre \& Condomi- } \\
\text { nes (1976) }\end{array}$ \\
\hline 14 & Andesita & Volcán Irazú & $\begin{array}{l}0,036 \pm 0,014 \\
\left({ }^{238} \mathrm{U} /{ }^{230} \mathrm{Th}\right)\end{array}$ & $\begin{array}{l}\text { Allegre \& Condomi- } \\
\text { nes (1976) }\end{array}$ \\
\hline $\mathrm{C}$ & Andesita & Colada Cervantes (E?), H. Istarú & $0,023\left({ }^{238} \mathrm{U} /{ }^{230} \mathrm{Th}\right)$ & $\begin{array}{l}\text { Allegre \& Condomi- } \\
\text { nes (1976) }\end{array}$ \\
\hline CR-IZ-02-02 & Andesita basáltica & $\begin{array}{l}\text { Colada de Cervantes E, Oratorio, } \\
\text { H. Istarú, 554,401-209,175 }\end{array}$ & $\begin{array}{c}0,020 \pm 0,012 \\
\left({ }^{40} \mathrm{Ar} /{ }^{39} \mathrm{Ar}: \text { mtz: plat. }\right)\end{array}$ & $\begin{array}{l}\text { Alvarado et al. (2006), } \\
\text { Carr et al. (2007) }\end{array}$ \\
\hline
\end{tabular}

En los cerros Tacares se presentas al menos dos, quizás tres tipos de lavas basálticas hasta andesítico-basálticas alumínicas (Kussmaul, 1988; presente trabajo) envueltas en un profundo suelo residual. Dos de ellas están datadas en 0,62 $\mathrm{Ma}$ (Cuadro 32). Aunque las exposiciones no son buenas, de igual manera, los indicios de campo apuntan hacia relictos de antiguas coladas de lava más que de lomas (hummocks) de un depósito de debris avalanche.

Por otro lado tenemos, que gran parte de las ignimbritas antiguas en Orotina están cubiertas parcialmente por el abanico epiclástico (depósito de debris avalanche transformado a debris flow), que está representado por guijarros y grandes bloques de lava y de ignimbritas antiguas, en una matriz lítico-cristalina. Su edad máxima se estimó con base en la edad ${ }^{40} \mathrm{Ar} /{ }^{39} \mathrm{Ar}$ más joven de los bloques o matriz datados, correspondientes a $0,63 \pm 0,26$ Ma (Gans et al., 2003; presente trabajo), más joven que las determinaciones previas de Marshall (2000). Esta unidad corresponde a la Fm. Tivives.

Resulta interesante, por no decir que muy casual, que el depósito de debris avalanche/debris flow de Tivives, puede presentar una correlación temporal y espacial con el depósito de debris avalanche de Nuestro Amo en el Valle Central occidental y a lo que también se llamó la Avalancha de 
Cuadro 30

Dataciones radiométricas del macizo del Turrialba

\begin{tabular}{|c|c|c|c|c|}
\hline MUESTRA & LITOLOGÍA & UBICACIÓN & $\operatorname{EDAD}(\mathrm{Ma})$ & REFERENCIA \\
\hline \multicolumn{5}{|c|}{ PROTO-TURRIALBA? } \\
\hline CR-234 & Andesita basáltica & $\begin{array}{l}\text { Lava sobre conglomerado de Suretka, puente } \\
\text { sobre el R. Siquirres, entre Coco y Siquirres, } \\
\text { H. Bonilla, } 586,85-230,65\end{array}$ & $\begin{array}{c}0,983 \pm 0,008 \\
\left({ }^{40} \mathrm{Ar} /{ }^{39} \mathrm{Ar}: \mathrm{mtz}\right)\end{array}$ & Presente trabajo \\
\hline \multicolumn{5}{|c|}{ PALEO-TURRIALBA } \\
\hline TUR-38 & $\begin{array}{c}\text { Colada de lava } \\
\text { andesítico-basáltica }\end{array}$ & $\begin{array}{l}\text { Entre Finca Convenio y Esperanza, V. Finca } \\
\text { Liebres ,H. Istarú, 559,140-218,464 }\end{array}$ & $\begin{array}{c}0,251 \pm 0,004 \\
\left({ }^{40} \mathrm{Ar}{ }^{/ 39} \mathrm{Ar}: \text { mtz: plat. }\right)\end{array}$ & Ruiz et al. (2010b) \\
\hline \multicolumn{5}{|c|}{ NEO-TURRIALBA } \\
\hline TUR-30 & Colada andesítica & $\begin{array}{c}\text { Bajos de Bonilla, H. Bonilla, } \\
565,810-224,136\end{array}$ & $\begin{array}{l}0,099 \pm 0,003 \\
\left({ }^{40} \mathrm{Ar} /{ }^{39} \mathrm{Ar}: \mathrm{mtz}:\right. \\
\text { integrated age })\end{array}$ & Ruiz et al. (2010b \\
\hline TUR-19 & $\begin{array}{l}\text { Colada andesítico- } \\
\text { basáltica }\end{array}$ & $\begin{array}{c}\text { Flanco SE Turrialba, H. Bonilla, } \\
567,641-220,599\end{array}$ & $\begin{array}{c}0,090 \pm 0,004 \\
\left({ }^{40} \mathrm{Ar} /{ }^{39} \mathrm{Ar}: \text { mtz: plat. }\right)\end{array}$ & Ruiz et al. (2010b) \\
\hline TUR-32 & Colada andesítica & $\begin{array}{l}\text { Santa Cruz, flanco SE Turrialba, H. Tucurri- } \\
\text { que, } 565,604-216,502\end{array}$ & $\begin{array}{c}0,062 \pm 0,002 \\
\left({ }^{40} \mathrm{Ar} /{ }^{39} \mathrm{Ar}: \text { mtz: plat. }\right)\end{array}$ & Ruiz et al. (2010b) \\
\hline TUR-33 & $\begin{array}{l}\text { Colada andesítico- } \\
\text { basáltica }\end{array}$ & $\begin{array}{l}\text { Colada del cono satelite Armado, H. Istarú, } \\
\qquad 561,547-216,494\end{array}$ & $\begin{array}{c}0,061 \pm 0,006 \\
\left({ }^{40} \mathrm{Ar} /{ }^{39} \mathrm{Ar}: \text { mtz: plat. }\right)\end{array}$ & Ruiz et al. (2010b) \\
\hline TUR-12 & Colada de dacita & $\begin{array}{l}\text { Buenos Aires, flanco SE Turrialba, H. Istarú, } \\
\qquad 565,928-219,047\end{array}$ & $\begin{array}{c}0,0256 \pm 0,0019 \\
\left({ }^{40} \mathrm{Ar} /{ }^{39} \mathrm{Ar}: \text { mtz: plat. }\right)\end{array}$ & Ruiz et al. (2010b) \\
\hline TUR-36 & $\begin{array}{l}\text { Colada andesítico- } \\
\text { basáltica }\end{array}$ & Flanco S, H. Istarú, 562,091-219,040 & $\begin{array}{c}0,0100 \pm 0,003 \\
\left({ }^{40} \mathrm{Ar} /{ }^{39} \mathrm{Ar}: \text { mtz: plat. }\right)\end{array}$ & Ruiz et al. (2010b) \\
\hline TUR-08 & Colada de dacita & $\begin{array}{c}\text { Por Finca Silvia y La Picada, W Turrialba, H. } \\
\text { Carrillo, 560,222-222,798 }\end{array}$ & $\begin{array}{c}0,0003 \pm 0,0003 \\
\left({ }^{40} \mathrm{Ar}{ }^{39} \mathrm{Ar}: \text { mtz: plat. }\right)\end{array}$ & Ruiz et al. (2010b) \\
\hline
\end{tabular}

El Coyol (Méndez \& Hidalgo, 2004). Entonces, el Mb. Nuestro Amo podría ser equivalente a la Unidad Coyol (facies medias de un debris avalanche) y la Fm. Tivives correspondería con la facies distal, todas ellas con edades de $\sim 0,61 \mathrm{Ma}$.

Por tanto, las lavas de Colima Inferior $(0,75$ - 0,59 Ma) son, en parte, contemporáneas con otras lavas aflorantes en Cebadilla (0,75 - 0,53 Ma), en Bajos del Toro o Chocosuela (0,55 - 0,43 Ma), Paleo-Poás (principalmente 0,61 - 0,51 Ma), Paleo-Barva o Zurquí (0,57 - 0,40 Ma), Paleo-Irazú $(0,59-0,45 \mathrm{Ma})$ y con los cerros de Tacares $(0,62$ $\mathrm{Ma})$, así como productos epivolcánicos de Nuestro Amo-Coyol-Tivives ( 0,61 Ma). Todo ello se podría enmarcar dentro del vulcanismo de la PaleoCordillera Central, mayoritariamente 0,75 - 0,40 Ma, quizás tan joven como 0,2 Ma?. Gran parte de este vulcanismo está caracterizado por potentes y extensas coladas de lava, muy porfiríticas, ricas en megafenocristales de plagioclasas (andesitas porfídicas).

Un vulcanismo explosivo, caracterizado por varios depósitos de flujos de pómez (Fm. Alto Palomo), se registró con fuente de origen en el extremo occidental de la cordillera volcánica Central, específicamente en los cerros de Palmira-Chayote-Chocosuela (Alvarado \& Carr, 1993; Villegas, 1997, 2004). Depósitos de flujos similares, en el piso volcánico del Valle Central, están representados por depósitos de flujos de pómez datados en 0,58 - 0,56 Ma, pero más cerca hacia su fuente de origen, se presentan otros flujos más jóvenes entre 0,52 y $0,44 \mathrm{Ma}$ (Cuadro 26), indicando que dicho vulcanismo explosivo se extendió entre 0,58 y $0,44 \mathrm{Ma}$, asociado a varios colapsos caldéricos, tal y como en efecto lo parece sugerir las diversas estructuras de colapso cartografiadas en los cerros Palmira. 
Cuadro 31

Dataciones radiométricas de las ignimbritas de Tilarán, Aguacate y Tivives

\begin{tabular}{|c|c|c|c|c|}
\hline MUESTRA & LITOLOGÍA & UBICACIÓN & $\operatorname{EDAD}(\mathrm{Ma})$ & REFERENCIA \\
\hline \multicolumn{5}{|c|}{ IGNIMBRITAS Y RETRABAJO DE TILARÁN-AGUACATE-OROTINA } \\
\hline CR-060 & $\begin{array}{l}\text { Ignimbrita intruida por } \\
\text { dique basáltico olivínico }\end{array}$ & $\begin{array}{l}\text { C. Macho Chingo, Atenas, H. Río } \\
\text { Grande, 497,050-218,400 }\end{array}$ & $\begin{array}{c}6,05 \pm 0,04\left({ }^{40} \mathrm{Ar} /{ }^{39} \mathrm{Ar}:\right. \\
\text { plag })\end{array}$ & Presente trabajo \\
\hline CR-182 & $\begin{array}{l}\text { Depósito de flujo de pó- } \\
\text { mez con hb. entre lavas } \\
\text { del Aguacate }\end{array}$ & $\begin{array}{l}\text { C. Peña Blanca, Ca. Interame- } \\
\text { ricana, H. Abangares, 422,800- } \\
252,750\end{array}$ & $\begin{array}{c}5,20 \pm 0,30\left({ }^{40} \mathrm{Ar} /{ }^{39} \mathrm{Ar}:\right. \\
\text { plag })\end{array}$ & Presente trabajo \\
\hline CR-216 & $\begin{array}{l}\text { Ignimbrita inferior bas- } \\
\text { culada interestratificada } \\
\text { entre lahares }\end{array}$ & $\begin{array}{l}\text { R. Balsa, P.H. Daniel Gutiérrez, } \\
\text { H. San Lorenzo, 479,250-248,575 }\end{array}$ & $\begin{array}{l}4,20 \pm 0,104,10 \pm 0,10 \\
\quad\left({ }^{40} \mathrm{Ar} /{ }^{39} \mathrm{Ar}: \text { plag }\right)\end{array}$ & Presente trabajo \\
\hline $\begin{array}{c}\text { CR-041 } \\
(9907-14-2)\end{array}$ & Ignimbrita rica en biotita & $\begin{array}{c}\text { Entre San Mateo y Esparza, R. } \\
\text { Surubres (similar localidad que CR- } \\
\text { 94-18), H. Barranca, 473,85-215,35 }\end{array}$ & $\begin{array}{c}1,91 \pm 0,06\left({ }^{40} \mathrm{Ar} /{ }^{39} \mathrm{Ar}:\right. \\
\text { biot })\end{array}$ & Presente trabajo \\
\hline CR-214 & $\begin{array}{l}\text { Depósito de flujo de } \\
\text { pómez rico en biotita } \\
\text { bajo colada CR-213 }\end{array}$ & $\begin{array}{l}\text { P.H. Daniel Gutiérrez, H. San } \\
\text { Lorenzo, 479,850-246,900 }\end{array}$ & $\begin{array}{c}1,55 \pm 0,02\left({ }^{40} \mathrm{Ar} /{ }^{39} \mathrm{Ar}:\right. \\
\text { plag })\end{array}$ & Presente trabajo \\
\hline CR94-18 & $\begin{array}{c}\text { Arenas pumíticas } \\
\text { andesíticas, sección } \\
\text { superior (Unidad Tigre) }\end{array}$ & $\begin{array}{l}\text { Entre Calle Tigre y Puente Agres, } \\
\text { Orotina, H. Barranca, 478,3-207,3 }\end{array}$ & $\begin{array}{c}1,12 \pm 0,13\left({ }^{40} \mathrm{Ar} /{ }^{39} \mathrm{Ar}:\right. \\
\text { iso.: plag })\end{array}$ & $\begin{array}{c}\text { Marshall (2000), } \\
\text { Marshall et al. (2003) }\end{array}$ \\
\hline CR93-18 & $\begin{array}{l}\text { Ignimbrita moderada- } \\
\text { mente soldada, rosada- } \\
\text { blancuzca, rica en biotita }\end{array}$ & $\begin{array}{l}\text { Pequeño tajo, W R. Surubres (si- } \\
\text { milar localidad que CR-041), H. } \\
\text { Barranca, aprox. 473,85-215,35 }\end{array}$ & $\begin{array}{c}0,673 \pm 0,092 \\
\left({ }^{40} \mathrm{Ar} /{ }^{39} \mathrm{Ar}: \text { pómez }\right)\end{array}$ & $\begin{array}{l}\text { Fisher et al. (1994), } \\
\text { Marshall (2000) }\end{array}$ \\
\hline \multicolumn{5}{|c|}{ BLOQUES DE IGNIMBRITA Y MATRIZ DEL DEBRIS AVALANCHE DE TIVIVES } \\
\hline CR94-16 & $\begin{array}{l}\text { Matriz del lahar, unidad } \\
\text { basal }\end{array}$ & $\begin{array}{c}\text { Puente Agres, camino a Orotina, } \\
\text { H. Barranca, 478,7-207,0 }\end{array}$ & $\begin{array}{c}1,66 \pm 0,16\left({ }^{40} \mathrm{Ar} /{ }^{39} \mathrm{Ar}:\right. \\
\text { iso.: plag })\end{array}$ & $\begin{array}{c}\text { Marshall (2000), } \\
\text { Marshall et al. (2003) }\end{array}$ \\
\hline CR-162 & $\begin{array}{l}\text { Bloque de ignimbrita } \\
\text { rica en biotita }\end{array}$ & $\begin{array}{l}\text { P. Carrizal, Pl. Guacalillo, H. } \\
\text { Barranca, 462,638-201,753 }\end{array}$ & $\begin{array}{c}1,52 \pm 0,02\left({ }^{40} \mathrm{Ar} /{ }^{39} \mathrm{Ar}:\right. \\
\text { plat.: plag })\end{array}$ & Presente trabajo \\
\hline CR-165 & $\begin{array}{l}\text { Matriz anaranjada rica } \\
\text { en plagioclasa del depó- } \\
\text { sito de debris flow }\end{array}$ & $\begin{array}{l}\text { P. Carrizal, Pl. Guacalillo, H. } \\
\text { Barranca, 462,638-201,753 }\end{array}$ & $\begin{array}{l}1,50 \pm 0,10\left({ }^{40} \mathrm{Ar} /{ }^{39} \mathrm{Ar}:\right. \\
\text { plat. irregular: plag })\end{array}$ & Presente trabajo \\
\hline $\begin{array}{c}\text { CR94-38 } \\
(=\text { CR93-20) }\end{array}$ & $\begin{array}{l}\text { Ignimbrita moderada- } \\
\text { mente soldada, color } \\
\text { rosado claro con biotita }\end{array}$ & $\begin{array}{l}\text { C. Tamarindo, } 3 \text { km SW, H. } \\
\text { Barranca, 467,2-207,3 }\end{array}$ & $\begin{array}{c}1,45 \pm 0,07\left({ }^{40} \mathrm{Ar} /{ }^{39} \mathrm{Ar}:\right. \\
\text { iso: biot) } \\
1,91 \pm 0,03\left({ }^{40} \mathrm{Ar} /{ }^{39} \mathrm{Ar}:\right. \\
\text { plat.: biot })\end{array}$ & $\begin{array}{c}\text { Marshall (2000), } \\
\text { Marshall et al. (2003) }\end{array}$ \\
\hline CR94-9 & $\begin{array}{l}\text { Matriz del lahar, unidad } \\
\text { superior }\end{array}$ & $\begin{array}{l}\text { R. Jesús María, H. Barranca, } \\
\text { 462,7-210,5 }\end{array}$ & $\begin{array}{l}1,45 \pm 0,05\left({ }^{40} \mathrm{Ar} /{ }^{39} \mathrm{Ar}:\right. \\
\text { iso.: plag) }\end{array}$ & $\begin{array}{c}\text { Marshall (2000), } \\
\text { Marshall et al. (2003) }\end{array}$ \\
\hline CR93-12 & Matriz del lahar & $\begin{array}{l}\text { Alto de las Mesas, H. Barranca, } \\
\qquad 460,4-211,0\end{array}$ & $\begin{array}{c}1,42 \pm 0,13\left({ }^{40} \mathrm{Ar} /{ }^{39} \mathrm{Ar}:\right. \\
\text { iso.: biot })\end{array}$ & $\begin{array}{c}\text { Marshall (2000), } \\
\text { Marshall et al. (2003) }\end{array}$ \\
\hline $\begin{array}{l}\text { BBCR-4 } \\
(\mathrm{B}-5)\end{array}$ & $\begin{array}{l}\text { Toba lítica ( } 24 \% \text { clastos) } \\
\text { basáltica de flujo piro- } \\
\text { clástico }\end{array}$ & $\begin{array}{c}\text { Márgen derecha R. Tárcoles, } \\
\text { Puente Agres, H. Barranca, aprox. } \\
\text { 478,5-207,1 }\end{array}$ & $\begin{array}{l}1,28 \pm 0,27 \\
(\mathrm{~K} / \mathrm{Ar})\end{array}$ & Bergoeing (1982) \\
\hline CR94-7b & $\begin{array}{c}\text { Matriz del lahar, facies } \\
\text { distal }\end{array}$ & $\begin{array}{l}\text { Bajamar, H. Barranca, 462,4- } \\
201,9\end{array}$ & $\begin{array}{c}1,10 \pm 0,07\left({ }^{40} \mathrm{Ar} /{ }^{39} \mathrm{Ar}:\right. \\
\text { iso.: plag) }\end{array}$ & $\begin{array}{c}\text { Marshall (2000), } \\
\text { Marshall et al. (2003) }\end{array}$ \\
\hline CR-164 & $\begin{array}{l}\text { Bloque de ignimbríta } \\
\text { riolítica pobre en cristales }\end{array}$ & $\begin{array}{l}\text { P. Carrizal, Pl. Guacalillo, H. } \\
\text { Barranca, 462,638-201,753 }\end{array}$ & $\begin{array}{c}0,919 \pm 0,012 \\
\left({ }^{40} \mathrm{Ar} /{ }^{39} \mathrm{Ar}: \text { plat.: plag }\right)\end{array}$ & Presente trabajo \\
\hline
\end{tabular}


Cuadro 32

Dataciones radiométricas del piso volcánico antiguo del Valle Central

\begin{tabular}{|c|c|c|c|c|}
\hline MUESTRA & LITOLOGÍA & UBICACIÓN & $\operatorname{EDAD}(\mathrm{Ma})$ & REFERENCIA \\
\hline \multicolumn{5}{|c|}{ SAN JERÓNIMO, REVENTAZÓN $(0,859 \pm 0,003)$} \\
\hline CR-IZ-02-17 & Ignimbrita & $\begin{array}{c}\text { Joya, San Jerónimo, H. Istarú, } \\
559,024-205,015\end{array}$ & $\begin{array}{c}0,868 \pm 0,009 \\
0,862 \pm 0,009 \\
0,861 \pm 0,006 \\
0,855 \pm 0,006 \\
0,853 \pm 0,011 \\
0,847 \pm 0,011 \\
\left({ }^{40} \mathrm{Ar} /{ }^{39} \mathrm{Ar}: \text { biot }\right. \\
\text { plag: plat. e iso. })\end{array}$ & $\begin{array}{l}\text { Alvarado et al. (2006), } \\
\text { Carr et al. (2007) }\end{array}$ \\
\hline \multicolumn{5}{|c|}{ CERROS TACARES, CEBADILLA, COLIMA INFERIOR Y CLASTOS ASOCIADOS } \\
\hline CR95-6 & Andesita basáltica & $\begin{array}{c}\text { Calle Tamarindo, cerca de Ce- } \\
\text { badilla de Turrúcares, H. Río } \\
\text { Grande, aprox. 499,5-213,0 }\end{array}$ & $\begin{array}{c}0,758 \pm 0,016 \\
\left({ }^{40} \mathrm{Ar} /{ }^{39} \mathrm{Ar}: \text { iso.: } \mathrm{mtz}\right)\end{array}$ & $\begin{array}{l}\text { Marshall (2000), Mar- } \\
\text { shall et al. (2003) }\end{array}$ \\
\hline CR-163 & $\begin{array}{c}\text { Clasto andesítico basáltico, } \\
\text { dentro de debris avalanche } \\
\text { de Tivives }\end{array}$ & $\begin{array}{l}\text { P. Carrizal, Pl. Guacalillo, H. } \\
\text { Barranca, 462,638-201,753 }\end{array}$ & $\begin{array}{c}0,632 \pm 0,260 \\
\left({ }^{40} \mathrm{Ar} /{ }^{39} \mathrm{Ar}: \mathrm{mtz}\right)\end{array}$ & Presente trabajo \\
\hline CR-055C & $\begin{array}{c}\text { Bloque de lava infrayacien- } \\
\text { do a Tiribí }\end{array}$ & $\begin{array}{l}\text { Margen derecha puente } \\
\text { sobre el R. Poás, H. Naranjo, } \\
\text { 502,200-220,300 }\end{array}$ & $\begin{array}{c}0,629 \pm 0,018 \\
\left({ }^{40} \mathrm{Ar} /{ }^{39} \mathrm{Ar}: \mathrm{mtz}\right)\end{array}$ & Presente trabajo \\
\hline CR-069 & $\begin{array}{l}\text { Brecha monomíctica de } \\
\text { andesitas basálticas, bajo } \\
\text { ignimbrita Tiribí }\end{array}$ & $\begin{array}{c}\text { R. Siquiares, } 2,5 \text { km WNW } \\
\text { de Turrúcares, H. Río Grande, } \\
498,750-216,750\end{array}$ & $\begin{array}{c}0,628 \pm 0,012 \\
\left({ }^{40} \mathrm{Ar} /{ }^{39} \mathrm{Ar}: \mathrm{mtz}\right)\end{array}$ & Presente trabajo \\
\hline CR-219 & Basalto olivínico & $\begin{array}{c}\text { C. de Tacares, H. Naranjo, } \\
\text { 499,338-223,237 }\end{array}$ & $\begin{array}{c}0,625 \pm 0,015 \\
\left({ }^{40} \mathrm{Ar} /{ }^{39} \mathrm{Ar}: \mathrm{mtz}\right)\end{array}$ & Presente trabajo \\
\hline CR-218 & Basalto olivínico & $\begin{array}{c}\text { C. de Tacares, H. Naranjo, } \\
\text { 498,381-223,682 }\end{array}$ & $\begin{array}{c}0,622 \pm 0,014 \\
\left({ }^{40} \mathrm{Ar} /{ }^{39} \mathrm{Ar}: \mathrm{mtz}\right)\end{array}$ & Presente trabajo \\
\hline CR-059 & $\begin{array}{l}\text { Canto basáltico en aluvio- } \\
\text { nes, bajo depósito de flujo } \\
\text { de pómez }\end{array}$ & $\begin{array}{c}\text { Tajo La Pista, puente sobre } \\
\text { el R. Colorado, H. Naranjo, } \\
496,95-222,25\end{array}$ & $\begin{array}{c}0,616 \pm 0,010 \\
\left({ }^{40} \mathrm{Ar} /{ }^{39} \mathrm{Ar}: \mathrm{mtz}\right)\end{array}$ & Presente trabajo \\
\hline CR-108 & Andesita porfirítica & $\begin{array}{l}\text { Base de la perforación 2, P.H. } \\
\text { Virilla, H. Abra, 509,300-214,100 }\end{array}$ & $\begin{array}{c}0,614 \pm 0,006 \\
\left({ }^{40} \mathrm{Ar} /{ }^{39} \mathrm{Ar}: \mathrm{mtz}\right)\end{array}$ & Presente trabajo \\
\hline CR-103 & Andesita porfirítica & $\begin{array}{l}\text { Base de perforación 4, P.H. Vi- } \\
\text { rilla, H. Abra, 512,025-215,339 }\end{array}$ & $\begin{array}{c}0,594 \pm 0,010 \\
\left({ }^{40} \mathrm{Ar} /{ }^{39} \mathrm{Ar}: \mathrm{mtz}\right)\end{array}$ & Presente trabajo \\
\hline CR-070 & Andesita rica en plagioclasa & $\begin{array}{l}\text { 0,8 km de Cebadilla, H. Río } \\
\text { Grande, } 499,462-215,940\end{array}$ & $\begin{array}{c}0,535 \pm 0,015 \\
\left({ }^{40} \mathrm{Ar} /{ }^{39} \mathrm{Ar}: \mathrm{mtz}\right)\end{array}$ & Presente trabajo \\
\hline
\end{tabular}

Una pausa de unos 100 - 90 ka se dio entre Colima Inferior y las ignimbritas de Puente de Mulas, datadas en el piso del Valle Central en 0,50 - 0,49 Ma, pero en el Zurquí facies ignimbríticas petrográficamente similares y coetáneas, se extienden entre 0,50 y 0,44 Ma (Cuadro 28). Este lapso permitió el desarrollo de un paleosuelo bien desarrollado. Así, lo que se incluye como Colima
Inferior, abarca a una serie de volcanitas depositadas en facies proximales y distales de la PaleoCordillera Central a lo largo de casi medio millón de años, eruptadas a través de fisuras paralelas a la cordillera actual.

Nuevamente, una fase efusiva muy extensa (Colima Superior) se registró hace $331 \pm 2$ ka sobre el piso volcánico del Valle Central, seguida casi sin 
Cuadro 33

Dataciones radiométricas del piso volcánico subreciente del Valle Central

\begin{tabular}{|c|c|c|c|c|}
\hline MUESTRA & LITOLOGÍA & UBICACIÓN & $\operatorname{EDAD}(\mathrm{Ma})$ & REFERENCIA \\
\hline \multicolumn{5}{|c|}{ LAVAS INTRACAÑÓN (FM. COLIMA SUPERIOR) $0,331 \pm 0,002$} \\
\hline $\begin{array}{l}\text { CR94-34 } \\
\text { CR94-33 }\end{array}$ & $\begin{array}{l}\text { Andesita, autobrecha } \\
\text { superior }\end{array}$ & $\begin{array}{c}\text { Tajo Pedregal, San Antonio } \\
\text { de Belén, H. Abra, 516,940- } \\
216,912\end{array}$ & $\begin{array}{c}0,371 \pm 0,049 \\
\left({ }^{40} \mathrm{Ar} /{ }^{39} \mathrm{Ar}: \text { iso.: } \mathrm{mtz}\right) \\
\\
0,337 \pm 0,07 \\
\left({ }^{40} \mathrm{Ar} /{ }^{39} \mathrm{Ar}: \text { iso.: } \mathrm{mtz}\right)\end{array}$ & $\begin{array}{c}\text { Marshall (2000), } \\
\text { Marshall et al. (2003) }\end{array}$ \\
\hline CR-011 & Andesita afírica & $\begin{array}{l}\text { Tajo Colima, R. Virilla, H. } \\
\text { Abra, 527,381-218,222 }\end{array}$ & $\begin{array}{c}0,338 \pm 0,002 \\
\left({ }^{40} \mathrm{Ar} /{ }^{39} \mathrm{Ar}: \mathrm{mtz}\right)\end{array}$ & Pérez et al. (2006) \\
\hline CR-039 & Andesita afírica & $\begin{array}{l}\text { Bolsón, H. Río Grande, } \\
486,119-210,954\end{array}$ & $\begin{array}{c}0,331 \pm 0,002 \\
\left({ }^{40} \mathrm{Ar}{ }^{39} \mathrm{Ar} \text { : plat.: } \mathrm{mtz}\right)\end{array}$ & Pérez et al. (2006) \\
\hline CR-019 & Andesita afírica & $\begin{array}{l}\text { Tajo Pedregal, H. Abra, } \\
516,940-216,912\end{array}$ & $\begin{array}{c}0,331 \pm 0,004 \\
\left({ }^{40} \mathrm{Ar}{ }^{39} \mathrm{Ar}: \mathrm{mtz}\right)\end{array}$ & Pérez et al. (2006) \\
\hline & & & $\begin{array}{c}0,321 \pm 0,018 \\
\left({ }^{40} \mathrm{Ar} /{ }^{39} \mathrm{Ar}: \text { plag }\right)\end{array}$ & \\
\hline BA-100 & $\begin{array}{l}\text { Lava afanítica gris con } \\
\text { estructura de flujo }\end{array}$ & $\begin{array}{l}\text { Puente sobre Queb. Turú, } 200 \\
\text { m al NW, cerca de Anonos, H. } \\
\text { Barva, 530,240-224,830 }\end{array}$ & $0,29 \pm 0,02(\mathrm{~K} / \mathrm{Ar})$ & $\begin{array}{l}\text { G.J. Soto (com. } \\
\text { escrita, 2009) }\end{array}$ \\
\hline \multicolumn{5}{|c|}{ TIRIBÍ-OROTINA $0,322 \pm 0,002$} \\
\hline CR94-35 & $\begin{array}{l}\text { Ignimbrita soldada prismáti- } \\
\text { ca sobre Colima Superior }\end{array}$ & $\begin{array}{c}\text { Tajo Pedregal, San Antonio de } \\
\text { Belén, H. Abra, 516,940-216,912 }\end{array}$ & $\begin{array}{c}0,390 \pm 0,017 \\
\left({ }^{40} \mathrm{Ar} /{ }^{39} \mathrm{Ar}: \text { iso.: plag }\right)\end{array}$ & $\begin{array}{c}\text { Marshall (2000), } \\
\text { Marshall et al. (2003) }\end{array}$ \\
\hline CR95-26 & $\begin{array}{l}\text { Ignimbrita soldada sobre } \\
\text { toba pumícea }\end{array}$ & $\begin{array}{l}\text { San Pedro, Turrubares, H. Río } \\
\text { Grande, aprox. 485,3-207,1 }\end{array}$ & $\begin{array}{c}0,373 \pm 0,019 \\
\left({ }^{40} \mathrm{Ar} /{ }^{39} \mathrm{Ar}: \text { iso.: plag }\right)\end{array}$ & $\begin{array}{l}\text { Marshall (2000), } \\
\text { Marshall et al. (2003) }\end{array}$ \\
\hline CR93-13 & $\begin{array}{l}\text { Ignimbrita soldada sobre } \\
\text { toba pumícea }\end{array}$ & $\begin{array}{l}\text { Queb. Santa Rita, C. Chayote, } \\
\text { Ca. Interamericana, misma } \\
\text { muestra CR-61787-8, H. Ba- } \\
\text { rranca, 473,549-206,162 }\end{array}$ & $\begin{array}{c}0,352 \pm 0,040 \\
\left({ }^{40} \mathrm{Ar}{ }^{39} \mathrm{Ar}: \text { iso.: plag }\right)\end{array}$ & $\begin{array}{l}\text { Marshall (2000), } \\
\text { Marshall et al. (2003) }\end{array}$ \\
\hline CR96-1 & Ignimbrita soldada & $\begin{array}{l}\text { R. Picagres, Picagres de Mora, } \\
\text { H. Río Grande, 498,9-211,6 }\end{array}$ & $\begin{array}{c}0,331 \pm 0,023 \\
\left({ }^{40} \mathrm{Ar}{ }^{39} \mathrm{Ar}: \text { iso.: plag }\right)\end{array}$ & $\begin{array}{l}\text { Marshall (2000), } \\
\text { Marshall et al. (2003) }\end{array}$ \\
\hline CR-021 & Ignimbrita & $\begin{array}{c}\text { Tajo Pedregal, H. Abra, } \\
516,940-216,912\end{array}$ & $\begin{array}{c}0,332 \pm 0,012 \\
\left({ }^{40} \mathrm{Ar} /{ }^{39} \mathrm{Ar}: \text { plat.: plag }\right)\end{array}$ & Pérez et al. (2006) \\
\hline CR96-2 & Ignimbrita soldada & $\begin{array}{l}\text { Queb. Honda, Ciudad Colón, } \\
\text { H. Abra, 510,1-209,8 }\end{array}$ & $\begin{array}{c}0,320 \pm 0,010 \\
\left({ }^{40} \mathrm{Ar} /{ }^{39} \mathrm{Ar}: \text { plat.: biot }\right)\end{array}$ & $\begin{array}{c}\text { Marshall (2000), } \\
\text { Marshall et al. (2003) }\end{array}$ \\
\hline CR-053-1,2 & Ignimbrita & $\begin{array}{l}\text { Puente sobre el R. Poás, des- } \\
\text { pués de Manolos, H. Naranjo, } \\
\text { 502.2E-220.3N }\end{array}$ & $\begin{array}{l}0,331 \pm 0,0060,326 \pm \\
0,008\left({ }^{40} \mathrm{Ar} /{ }^{39} \mathrm{Ar}: \text { plag }\right)\end{array}$ & Pérez et al. (2006) \\
\hline CR94-32 & $\begin{array}{l}\text { Ignimbrita soldada sobre } \\
\text { toba pumícea }\end{array}$ & $\begin{array}{l}\text { Sitio El Túnel, H. Barranca, } \\
\text { 466,0-206,3 }\end{array}$ & $\begin{array}{c}0,326 \pm 0,018 \\
\left({ }^{40} \mathrm{Ar} /{ }^{39} \mathrm{Ar}: \text { plat.: plag }\right)\end{array}$ & $\begin{array}{c}\text { Marshall (2000), } \\
\text { Marshall et al. (2003) }\end{array}$ \\
\hline CR-067 & Ignimbrita & $\begin{array}{l}\text { Puente de ferrocarril sobre el } \\
\text { R. Grande, H. Río Grande, } \\
\text { 498,141-216,321 }\end{array}$ & $\begin{array}{c}0,325 \pm 0,008 \\
\left({ }^{40} \mathrm{Ar} /{ }^{39} \mathrm{Ar}: \text { plag }\right)\end{array}$ & Pérez et al. (2006) \\
\hline $\begin{array}{l}\text { CR-056A } \\
\text { c.g. }\end{array}$ & Pómez en ignimbrita & $\begin{array}{c}\text { Tajo La Pista, H. Naranjo, } \\
497,142-222 ., 051\end{array}$ & $\begin{array}{c}0,321 \pm 0,004 \\
\left({ }^{40} \mathrm{Ar} /{ }^{39} \text { Ar: plag }\right)\end{array}$ & Pérez et al. (2006) \\
\hline CR-101A & Ignimbrita & $\begin{array}{l}\text { Perforación 4, P.H. Virilla, H. } \\
\text { Abra, 512.,025-215,339 }\end{array}$ & $\begin{array}{c}0,317 \pm 0,006 \\
\left({ }^{40} \mathrm{Ar} /{ }^{39} \mathrm{Ar}: \text { plag }\right)\end{array}$ & Pérez et al. (2006) \\
\hline
\end{tabular}


Cuadro 33 (continuación)

Dataciones radiométricas del piso volcánico subreciente del Valle Central

\begin{tabular}{|c|c|c|c|c|}
\hline MUESTRA & LITOLOGÍA & UBICACIÓN & $\operatorname{EDAD}(\mathrm{Ma})$ & REFERENCIA \\
\hline CR-56A f.g. & Pómez en ignimbrita & $\begin{array}{c}\text { Tajo La Pista, H. Naranjo, } \\
497,142-222,051\end{array}$ & $\begin{array}{c}0,317 \pm 0,006 \\
\left({ }^{40} \mathrm{Ar} /{ }^{39} \mathrm{Ar}: \text { plag }\right)\end{array}$ & Pérez et al. (2006) \\
\hline CR-61787-8 & $\begin{array}{c}\text { Ignimbrita sobre sedimentos } \\
\text { Miocenos }\end{array}$ & $\begin{array}{c}\text { C. Coyote, camino a Jacó, } \\
\text { similar localidad CR93-13, H. } \\
\text { Barranca, 473,6- 205,8 }\end{array}$ & $\begin{array}{c}0,275 \pm 0,005 \\
\left({ }^{40} \mathrm{Ar} /{ }^{39} \mathrm{Ar}: \mathrm{mtz} \text { desvi- }\right. \\
\text { trificada })\end{array}$ & $\begin{array}{c}\text { Gardner \& Turrin } \\
\text { (com. escrita 1990, } \\
\text { en Alvarado et al., } \\
\text { 1992) }\end{array}$ \\
\hline$?$ & $\begin{array}{c}\text { Capa de pómez pliniana } \\
\text { (capa Tibás) Infrayaciendo } \\
\text { a Tiribí }\end{array}$ & $\begin{array}{c}\text { Tajo Zamora, H. Abra, aprox. } \\
526,300-216,550\end{array}$ & $\begin{array}{c}0,273 \pm 0,04 \\
\left({ }^{40} \mathrm{Ar} /{ }^{39} \mathrm{Ar}\right)\end{array}$ & $\begin{array}{l}\text { Woodward-Clyde } \\
\text { (1993) }\end{array}$ \\
\hline $\begin{array}{l}\text { CR-61787-9 } \\
\text { (CR93-23 y } \\
\text { CR96-8) }\end{array}$ & Ignimbrita soldada & $\begin{array}{l}\text { San Pablo de Turrubares, } \\
\text { catarata queb. Limón, H. Río } \\
\text { Grande, aprox. 487,6-210,8 }\end{array}$ & $\begin{array}{c}0,25 \pm 0,052 \\
\left({ }^{40} \mathrm{Ar} /{ }^{39} \mathrm{Ar}: \mathrm{mtz}\right)\end{array}$ & $\begin{array}{c}\text { Gardner \& Turrin } \\
\text { (com. escrita 1990, } \\
\text { en Alvarado et al., } \\
\text { 1992) }\end{array}$ \\
\hline $\begin{array}{l}\text { CR-61787-4 } \\
\text { (CR90- } \\
\text { SNAK, } \\
\text { CR94-27) }\end{array}$ & Ignimbrita (matriz) & $\begin{array}{c}\text { Tajo Jesús María, Ca. Inte- } \\
\text { ramericana, puente sobre R. } \\
\text { Jesús María, H. Río Grande, } \\
\text { 463,0- } 210,5\end{array}$ & $\begin{array}{l}0,201 \pm 0,016 \\
\quad\left({ }^{40} \mathrm{Ar} /{ }^{39} \mathrm{Ar}\right)\end{array}$ & $\begin{array}{c}\text { Gardner \& Turrin } \\
\text { (en Alvarado et al., } \\
\text { 1992) }\end{array}$ \\
\hline
\end{tabular}

la formación de suelo por la capa de pómez de caída de Tibás y la concomitante ignimbrita asociada de Tiribí a los $322 \pm 2$ ka (Pérez et al., 2006). Es decir, entre las lavas y los productos ignimbríticos transcurrió un lapso de entre 5 y $13 \mathrm{ka}$, con probabilidad unos pocos miles de años ante la ausencia de un desarrollo edafológico (Cuadro 33). Un afloramiento "aislado" de una andesita afírica, cronológica y litoestratigráficamente correlacionable con Colima Superior, aflora por Bolsón-Turrúcares (muestra CR-039), muy alejada de los afloramientos más extendidos de Colima Superior. Toda esta secuencia $(0,62$ - 0,33 Ma) se asociaría a la Paleo-Cordillera Central.

Nuevas extensas lenguas de lava, las coladas de Ojo de Agua-Río Segundo, se extendieron de manera serpenteante por el piso volcánico, directamente sobre la ignimbrita Tiribí $(322 \pm 2 \mathrm{ka})$ o sobre los depósitos del debris avalanches/debris flow del Coyol, tal y como se observa en la carretera 27 camino a Caldera o en la carretera a San Antonio de Belén. Estas lavas están datadas por ${ }^{40} \mathrm{Ar} /{ }^{39} \mathrm{Ar}$ en 0,27 - 0,26 Ma (Cuadro 28). La NeoCordillera se empezaría a desarrollar hace aproximadamente 0,27 Ma, e incluye la Fm. Barva y a los depósitos piroclásticos (tefras de caída y de flujo) y epiclásticos (la "Lavina") distales del Valle Central.

La edad relativa del depósito lacustre de Palmares (50 - $90 \mathrm{~m}$ de espesor), se puede establecer geocronológica y biocronológicamente, aunque desgraciadamente ambas antagónicas. Las nuevas dataciones ${ }^{40} \mathrm{Ar} /{ }^{39} \mathrm{Ar}$ (presente trabajo) y una estratigrafía más controlada con base en las unidades que lo encierran, permiten establecer una edad geocronológica precisa. Los sedimentos lacustrinos sobreyacen directa y concordantemente a un flujo de pómez rico en biotita, sin ningún paleosuelo, siendo los sedimentos lacustrinos ricos en estos componentes, correlacionables con el Miembro Palmitos (Villegas, 1997, 2004), datado en 0,440 $\pm 0,01$ $\mathrm{Ma}$ (presente trabajo). Otras edades de ignimbritas infrayacentes y de depósitos de flujos de escombros, soportan que la edad de Palmitos está bien establecida. Por otro lado, el lacustre está sobreyacido por una ignimbrita correlacionable con la Fm. Tiribí (Villegas, 1997; Pérez, 2000), datada en 0,322 $\pm 0,002 \mathrm{Ma}$ (Pérez et al., 2006), y existen evidencias claras de que la ignimbrita 
ingresó al lago, como lo son la gradación inversa en la pómez y la presencia de clastos de tobitas deformados plásticamente, contenidos en la base del depósitos del flujo piroclástico. Facies lacustrinas muy locales, sobreyacen a dicha ignimbrita como evidencia de una persistencia efímera del paleolago (Villegas, 1997; Pérez, 2000). Así, la edad del lago estaría comprendida en algún momento entre $0,45-0,43$ y $0,324-0,320 \mathrm{Ma}$, es decir Pleistoceno Medio.

Sin embargo, la megafauna extinta determinada como Pachyarmatherium leiseyi y Glyptotherium cf. arizonae, le permiten concluir a Laurito et al. (2005) y a Valerio \& Laurito (2011) que la edad del lacustre ha de corresponder con los periodos de megafauna del Blancano Tardío al Irvingtoniano Temprano, por lo que le asignan una edad entre 2,6 y 1,6 Ma (cf., Laurito et al., 2005, p. 89). El Pachyarmatherium leiseyi posee una distribución bioestratigrafica bien determinada como del Plioceno Tardío al Pleistoceno Temprano en EE.UU., mientras que el Glyptotherium sp. cf. arizonae como del Pleistoceno Temprano a Medio (ver trabajos citados en Laurito et al., 2005; Valerio \& Laurito, 2011), lo que es equivalente a las edades paleomastozoológicas de Blancano Tardío al Irvingtoniano Temprano, que más bien abarcan entre $\sim 2,8$ y 1 Ma (sensu Woodburne, 2004, 2010). Entonces, el rango bioestratigráfico del lacustre de Palmares, con base en las determinaciones paleomastozoológicas, no concuerda con el rango de edad geocronológico atribuible al depósito lacustre de Palmares de 0,44 - 0,32 Ma (Irvingtoniano Tardío). ¿Estarán las determinaciones isotópicas y sus correlaciones estratigráficas erradas? o ¿merecerán revisarse las determinaciones paleomastozoológicas y/o sus rangos biocronológicos no estarán bien establecidos? Varias líneas de evidencia (controles cruzados, trabajo de campo, etc.) sugieren que las edades radiométricas están bien establecidas. Sin embargo, el problema bioestratigráfico y paleontológico anterior, está fuera de los objetivos del presente trabajo.

Puesto que el lacustre de Turrúcares sobreyace a los depósitos de debris avalanches antiguos y a las coladas de lava de Colima Inferior e infrayace a la ignimbrita de Tiribí, podemos igualmente establecer un rango de edad entre 0,53 y $0,32 \mathrm{Ma}$, muy similar y sugestivo de su contemporaneidad con el lacustre de Palmares, tal y como Alvarado (1986) ya lo había hipotetizado. Los depósitos de diatomitas, en ambos lagos, fueron disparados por la abundancia de sílice en las aguas, procedente de la pómez, siendo a su vez indicadores de un clima más frío.

En fin, la historia cuaternaria del piso volcánico del Valle Central se puede resumir en:

a. Vulcanismo explosivo con varias ignimbritas (presentes como bloques dentro de Tivives o como afloramientos) y fases epiclásticas en los alrededores de Orotina: 1,91 - 0,92 Ma. La ignimbrita de San Jerónimo, corresponde con una de las más antiguas en el Valle del Guarco-Turrialba $(0,86 \mathrm{Ma})$ y en posición in situ.

b. Coladas de andesíticas porfiríticas, o como clastos contenidos en los depósitos aluviales, laháricos y de debris avalanches, todo como parte de la Paleo-Cordillera: 0,75 - 0,40 Ma.

d. Una serie de eventos de debris avalanche cubrieron gran parte del piso occidental del Valle Central hasta Orotina: 0,61 Ma.

e. Flujos púmiticos asociados con la Fm. Alto Palomo: 0,58 - 0,44 Ma.

f. Las ignimbritas de Puente de Mulas y Bajo La Hondura: 0,50 - 0,43 Ma.

g. Paleo-lago de Palmares, contemporáneo con el de Turrúcares: en algún momento entre 0,44 y $0,32 \mathrm{Ma}$.

h. Las coladas de andesitas afíricas (Colima Superior): 0,33 Ma.

i. Ignimbrita de Tiribí-Orotina: 0,32 Ma.

j. Coladas de lava de andesitas basálticas de Ojo de Agua-Río Segundo: 0,27 - 0,26 Ma.

$\mathrm{k}$. Lahares/debris avalanches (La Lavina del Valle Central): ¿0,3 - 0,1 Ma?

1. Cenizas: $\sim 0,1-0$ Ma.

\section{MAGMATISMO ALCALINO DEL OLIGOCENO AL CUATERNARIO}

\section{Magmatismo alcalino continental}

El magmatismo alcalino de Costa Rica fue por primera vez citado por Wolf (1896) para una teralita (= grabo nefelínico) recolectada durante 
la construcción del ferrocarril al Caribe. No fue hasta 74 años después cuando se volvió a comentar sobre la existencia de rocas alcalinas, algunas de ellas denominadas con la clasificación antigua de "Serie Atlántica", mediante estudios petrográficos, geoquímicos y mapeos (Malavassi \& Chaves, 1970; Tournon, 1972; Pichler \& Weyl, 1976; Azambre \& Tournon, 1977; Bellon \& Tournon, 1978). Varios otros trabajos le siguieron con detalles mineralógicos, petroquímicos e isotópicos (p.ej., Tournon, 1984; Stack, 1991; Alvarado \& Carr, 1993; Abratis, 1998; Gazel et al., 2011).

La posible existencia de un vulcanismo alcalino, está evidenciado de modo indirecto por la presencia de piroxenos ricos en aluminio y titanio en sedimentos clásticos dentro de la Fm. Térraba (Yuan, 1984). Sin embargo, sus afloramientos no se han reportado y perfectamente podrían ser el producto de la erosión de las lavas alcalinas en almohadilla del Eoceno, tal y como se mencionó previamente en el apartado del vulcanismo basáltico submarino de Talamanca (ver Tournon \& Alvarado, 1997, y referencias allí citadas).

Los basaltos alcalinos Neógenos más antiguos, hasta ahora fechados, corresponden con los del puente de La Garita, con edades ${ }^{40} \mathrm{Ar} /{ }^{39} \mathrm{Ar}$ de 6,47 - 6,1 Ma (Marshall et al., 2003; Gazel et al., 2009; presente trabajo, Cuadro 34). La geoquímica nos dice que se trata de basanitas, traquibasaltos y basaltos alcalinos (Gazel, 2003). Aunque la geología del antiguo tajo, hoy día abandonado, no es clara, al parecer se trata de uno o varios sills o de varias coladas de lava con analcima, en su mayoría porfiríticas, aunque también las hay afaníticas e incluso brechas monomícticas. En el cauce del río Grande, al lado del tajo, aflora un depósito de flujo de pómez, que posiblemente rellenó un antiguo cauce y podría correlacione con la Fm. Alto Palomo. Un dique de basalto olivínico, petrográficamente muy similar a los del puente La Garita, aflora en los cerros Macho Chingo, a tan solo 1,6 km de distancia, cortando a una ignimbrita antigua (Alvarado, 1984), datada en el presente trabajo en 6,05 Ma (ver Cuadro 31, Figs. 2 y 7). Lavas similares afloran localmente en la ruta 27.

Al otro lado de la divisoria continental, se tiene un basalto alcalino como parte del enjambre de diques Victoria, originalmente mapeados por Dengo (1962) en Baja Talamanca, que aportan una edad de 6,49 Ma (Gazel et al., 2011). Otro dique del lado Caribe, localizado en la margen izquierda del río Sixaola (Sapper, 1905), al límite con la frontera con Panamá, posee una edad de 5,82 Ma, correspondiendo con una traquiandesita basáltica con feldespatoides (Abratis \& Wörner, 2001).

Cuadro 34

Dataciones radiométricas de las rocas ígneas alcalinas hipoabisales de Baja Talamanca y Valle Central occidental

\begin{tabular}{|c|c|c|c|c|}
\hline MUESTRA & LITOLOGÍA & UBICACIÓN & $\operatorname{EDAD}(\mathrm{Ma})$ & REFERENCIA \\
\hline \multicolumn{5}{|c|}{ PUENTE LA GARITA } \\
\hline P-95 & Dique basáltico & $\begin{array}{l}\text { Puente La Garita, H. Río } \\
\text { Grande, 498,598-218,916 }\end{array}$ & $\begin{array}{c}6,47 \pm 0,21 \\
\left({ }^{40} \mathrm{Ar} /{ }^{39} \mathrm{Ar}: \mathrm{mtz}\right)\end{array}$ & Gazel et al. (2009) \\
\hline CR-065 & Basanita analcímica & $\begin{array}{l}\text { Puente La Garita, H. Río } \\
\text { Grande, 498,598-218,916 }\end{array}$ & $\begin{array}{c}6,10 \pm 0,15 \\
\left({ }^{40} \mathrm{Ar} /{ }^{39} \mathrm{Ar}: \mathrm{mtz}\right)\end{array}$ & Presente trabajo \\
\hline CR93-24 & Feno-Traquita & $\begin{array}{l}\text { Puente La Garita, H. Río } \\
\text { Grande, 498,598-218,916 }\end{array}$ & $\begin{array}{c}5,52 \pm 0,08 \\
\left({ }^{40} \mathrm{Ar} /{ }^{/ 9} \mathrm{Ar}: \text { iso.: } \mathrm{plag}\right)\end{array}$ & $\begin{array}{c}\text { Marshall (2000), } \\
\text { Marshall et al. (2003) }\end{array}$ \\
\hline \multicolumn{5}{|c|}{ DIQUES DE BAJA TALAMANCA } \\
\hline ES-081606-2 & Dique basalto alcalino & $\begin{array}{c}\text { Cerca de Victoria, H. Telire, } \\
636,674-188,560\end{array}$ & $\begin{array}{c}6,49 \pm 0,03 \\
\left({ }^{40} \mathrm{Ar} /{ }^{39} \mathrm{Ar}: \mathrm{mtz}\right)\end{array}$ & Gazel et al. (2011) \\
\hline BRI 25 & $\begin{array}{c}\text { Dique de traquiandesita } \\
\text { basáltica con feldespatoides }\end{array}$ & $\begin{array}{l}\text { Piedra Grande, Cerca de } \\
\text { Chase, R. Sixaola, H. Amu- } \\
\text { bri, 586,300-393,755 }\end{array}$ & $\begin{array}{c}5,82 \pm 0,09 \\
\left({ }^{40} \mathrm{Ar} /{ }^{39} \mathrm{Ar}: \text { Laser }\right. \\
\text { weighted mean: hb) }\end{array}$ & $\begin{array}{l}\text { Abratis (1998), Abra- } \\
\text { tis \& Wörner (2001) }\end{array}$ \\
\hline
\end{tabular}




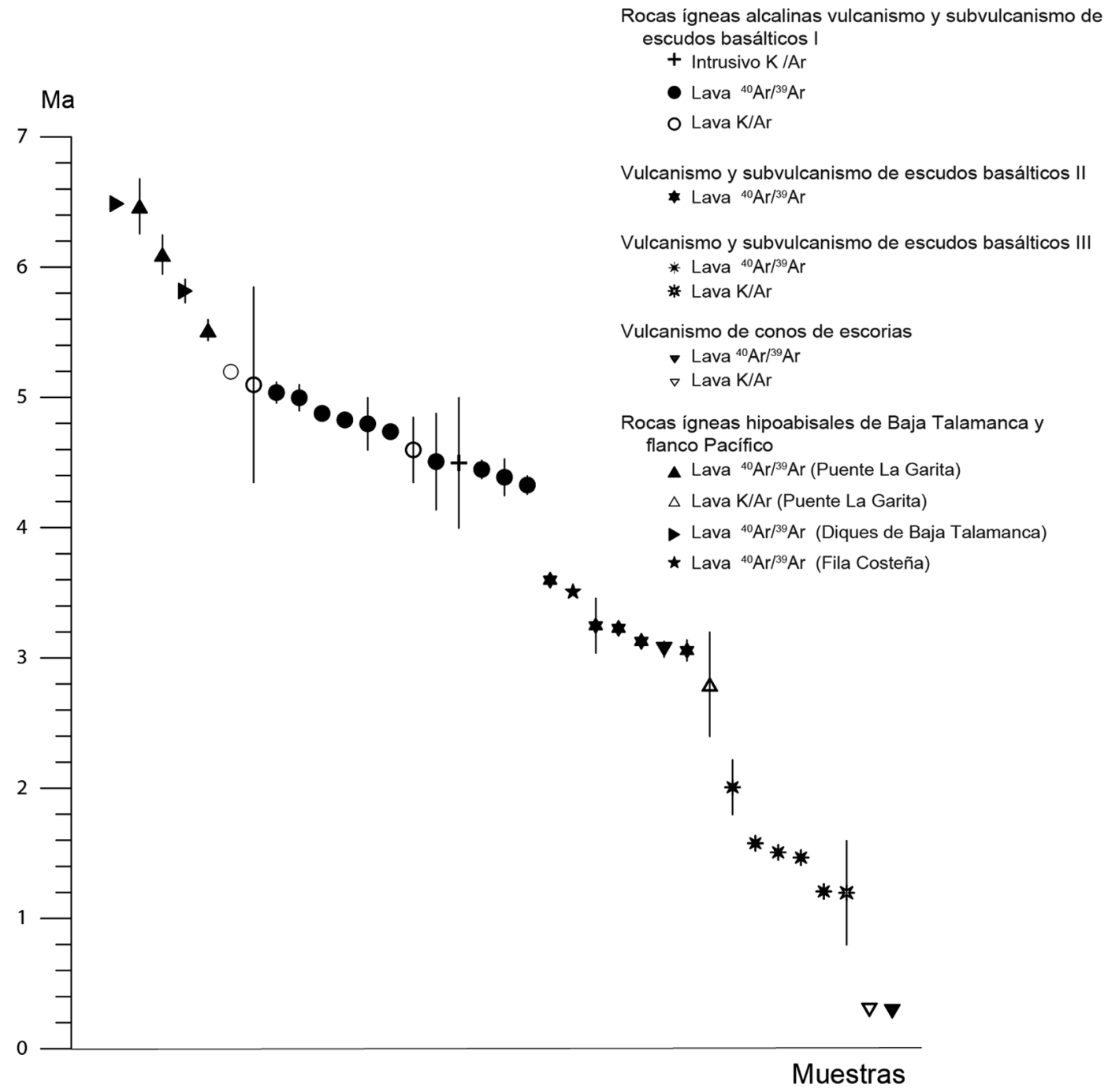

Fig. 7: Número de dataciones de las rocas ígneas alcalinas, ordenados de mayor a menor edad.

La relación genética y el contexto geotectónico del cuerpo hipoabisal de La Garita con los diques alcalinos del lado Caribe se desconoce, pero en tal caso son coetáneos (Cuadro 34).

En el sitio de presa de Siquirres sobre el río Pacuare, aflora una secuencia de al menos 27 coladas de lava de basanitas separadas por paleosuelos, con espesores individuales entre 1,2 y 21,3 $\mathrm{m}$, para un espesor total de $256 \mathrm{~km}$ (Stack, 1991), que poseen edades de 5,04 Ma en la base hasta
4,74 Ma, evidenciando que dicho escudo basáltico se originó en un lapso de $300 \mathrm{ka}$. Estas edades ${ }^{40} \mathrm{Ar} /{ }^{39} \mathrm{Ar}$ están en concordancia con la edad $\mathrm{K} / \mathrm{Ar}$ suministrada por Bellon \& Tournon (1978) de 4,6 Ma (Guayacán de Siquirres) y para el substrato del volcán Turrialba de 5,1 Ma (río Guayabo), o con las dataciones de Gazel et al. (2011) de 4,51 Ma (río Rubio, Siquirres) o incluso para la nefelinita del río Chirripó de 5,2 Ma (Tournon, 1984), al parecer la única roca de este tipo $(\mathrm{ol}+\mathrm{cpx}+$ ne 
+ mt) conocida en América Central (J. Tournon, com. escrita, 2010). Ello nos hace pensar en un período caracterizado por un vulcanismo de escudos basálticos pequeños, desarrollados principalmente entre 5,2 y 4,33 Ma, mientras que los cuerpos intrusivos del tipo gabros (teschenitas), monzogabros feldespatoídicos, sienitas analcímica y monzosienitas nefelínicas (Tournon, 1984; Cassell, 1986; Tournon \& Alvarado, 1997; Abratis, 1998) son contemporáneos (4,39 - 5,2 $\mathrm{Ma})$, siendo la expresión subvolcánica somera -algunas intrusiones poseen incluso vesículas ( $\mathrm{J}$. Tournon, com. verbal, 2011)- de este vulcanismo mediana a muy alcalino, ahora parcialmente denudado por la erosión (Cuadro 35).

En las llanuras del Caribe, se tienen las lomas Azules o de Sierpe, las lomas de Colorado y el cerro Coronel, datados entre 3,60 y 3,06 Ma (Gazel et al., 2011). En general, todas las lavas del Caribe corresponden con basanitoides (basaltos alcalinos, tefritas y basanitas). Un vulcanismo más reciente se tienen cerca de la frontera con Nicaragua en donde afloran basaltos alcalinos Cuaternarios de 2,0 - 1,2 Ma, representados por las coladas de lava presentes en el delta del río San Juan (2,01 Ma), o a las lavas basálticas más recientes en los alrededores de Crucitas, tales como los cerros Níspero (1,58 - 1,47 Ma) y Las Mercedes (1,21 Ma). Esta última es la única basanita leucítita conocida en el país (Tournon \& Alvarado, 1997), que posee abundantes xenolitos de peridotitas (lherzolitas y harzburgitas), piroxenitas (clinopiroxenitas con olivino, websteritas, algunas olivínicas), y muestras del manto litosférico actual bajo Costa Rica (Lindsay, 2009).

Un vulcanismo alcalino, más reciente, está representado por conos de piroclásticos de Tortuguero y Aguas Zarcas, algunos de los cuales todavía conservan restos de cráteres (Tournon, 1972; Alvarado, 2009). En efecto, una datación realizada por Gazel et al. (2011) resultó ser de "cero" para el cono del Tortuguero en el litoral Caribe e igualmente "cero" para el cono Buenos Aires, en Aguas Zarcas (edades no incluidas en el cuadro 35 por estar por debajo del método de detección analítico). El cono estromboliano de Altamira-que igualmente forma parte del campo de conos de Aguas Zarcas- fue datado en $295 \mathrm{ka}$ por ${ }^{40} \mathrm{Ar} /{ }^{39} \mathrm{Ar}$ (presente trabajo), muy concordante con la edad de $\sim 300$ ka reportada por Poncia (1993) con base en K/Ar (Cuadro 35).

El magmatismo alcalino continental posee fases claramente establecidas, muy posiblemente relacionadas con un régimen extensivo local. $\mathrm{Su}$ historia se puede resumir como:

a. Vulcanismo intracontinental, representado por los cuerpos hipoabisales medianamente alcalinos de la Garita, Victoria y Sixaola: 6,49 - 5,52 Ma.

b. Vulcanismo basanítico que genera escudos en la llanura del Caribe (cerro Coronel, río Colorado) y piedemonte (Siquirres) y sus raíces hipoabisales (mediana a altamente alcalinas) en la región de Guayacán y río Chirripó: 5,2 - 4,33 Ma.

c. Escudos basálticos pequeños (lomas Azules y lomas de Colorado, cerro Coronel): 3,60 - 3,06 Ma.

d. Nuevamente un vulcanismo de escudos y pequeños cuerpos lávicos cerca de la frontera con Nicaragua (delta del San Juan, cerros Níspero y Mercedes): 2,01 - 1,21 Ma.

e. Conos estrombolianos de Aguas Zarcas y Tortuguero: 0,3 - $0 \mathrm{Ma}$.

\section{Volcanismo en la placa del Coco}

En la placa del Coco se presentan volcanes submarinos en territorio marítimo costarricense, algunos aislados sobre la placa, otros en como volcanes gemelos, o bien conformando grupos o más extensamente como filas, sierras y mesetas, muchos de ellos como parte de la cordillera volcánica submarina del Coco. En realidad, el número de estos volcanes submarinos extintos o no, aún no se conoce, y podría superar la centena entre nuestras costas y la isla del Coco. Sus formas varían desde cónicas típicas hasta mesetas y crestas alargadas con alturas desde unas pocas decenas de metros hasta $2 \mathrm{~km}$ o más, a partir del fondo oceánico (Alvarado, 2000). Debido a su 
Cuadro 35

Dataciones radiométricas de las rocas ígneas alcalinas del Caribe

\begin{tabular}{|c|c|c|c|c|}
\hline MUESTRA & LITOLOGÍA & UBICACIÓN & $\operatorname{EDAD}(\mathrm{Ma})$ & REFERENCIA \\
\hline \multicolumn{5}{|c|}{ VULCANISMO Y SUBVULCANISMO DE ESUCUDOS BASÁLTICOS I } \\
\hline $\mathrm{CH}-14$ & Nefelinita & $\begin{array}{l}\text { Confluencia R. Jetyujuluri con el Chirri- } \\
\text { pó, H. Chirripó, 603,0-193,3 }\end{array}$ & $5,2(\mathrm{~K} / \mathrm{Ar})$ & Tournon (1984) \\
\hline TU-13 & Basalto alcalino & $\begin{array}{l}\text { R. Guayabito, H. Tucurrique, 569,7- } \\
215,9\end{array}$ & $5,1 \pm 0,75(\mathrm{~K} / \mathrm{Ar})$ & $\begin{array}{l}\text { Bellon \& Tour- } \\
\text { non (1978) }\end{array}$ \\
\hline CR-130 & Basanita & $\begin{array}{l}\text { Parte basal de las perforaciones, P.H. } \\
\text { Siquirres, H. Matina, aprox. 591,4-228,0 }\end{array}$ & $\begin{array}{c}5,04 \pm 0,08 \\
\left({ }^{40} \mathrm{Ar} /{ }^{39} \mathrm{Ar}: \mathrm{mtz}\right)\end{array}$ & Presente trabajo \\
\hline CR-127 & Basanita & $\begin{array}{l}\text { Parte media de las coladas, P.H. Siqui- } \\
\text { rres, H. Matina, aprox. 591,4-228,0 }\end{array}$ & $\begin{array}{c}5,00 \pm 0,10 \\
\left({ }^{40} \mathrm{Ar} /{ }^{39} \mathrm{Ar}: \mathrm{mtz}\right)\end{array}$ & Presente trabajo \\
\hline CR-120 & Basanita & $\begin{array}{l}\text { Parte media de las coladas, P.H. Siqui- } \\
\text { rres, H. Matina, aprox. 591,4-228,0 }\end{array}$ & $\begin{array}{c}4,88 \pm 0,04 \\
\left({ }^{40} \mathrm{Ar} /{ }^{39} \mathrm{Ar}: \mathrm{mtz}\right)\end{array}$ & Presente trabajo \\
\hline CR-109 & Basanita & $\begin{array}{c}\text { Tope de las coladas perforadas, P.H. } \\
\text { Siquirres, H. Matina, aprox. 591,4-228,0 }\end{array}$ & $\begin{array}{c}4,83 \pm 0,04 \\
\left({ }^{40} \mathrm{Ar} /{ }^{39} \mathrm{Ar}: \mathrm{mtz}\right)\end{array}$ & Presente trabajo \\
\hline CR-116 & Basanita & $\begin{array}{c}\text { Parte media, coladas perforadas, P.H. } \\
\text { Siquirres, H. Matina, aprox. 591,4-228,0 }\end{array}$ & $\begin{array}{c}4,80 \pm 0,20 \\
\left({ }^{40} \mathrm{Ar} /{ }^{39} \mathrm{Ar}: \mathrm{mtz}\right)\end{array}$ & Presente trabajo \\
\hline CR-110 & Basanita & $\begin{array}{c}\text { Tope de la pila de coladas, P.H. Siquirres, } \\
\text { H. Matina, Aprox. 591,4-228,0 }\end{array}$ & $\begin{array}{c}4,74 \pm 0,04 \\
\left({ }^{40} \mathrm{Ar} /{ }^{39} \mathrm{Ar}: \mathrm{mtz}\right)\end{array}$ & Presente trabajo \\
\hline S-25 & Basanita & Guayacán, H. Bonilla, 586,5-224,5 & $4,6 \pm 0,25(\mathrm{~K} / \mathrm{Ar})$ & $\begin{array}{l}\text { Bellon \& Tour- } \\
\text { non (1978) }\end{array}$ \\
\hline P145 & Basanita & R. Rubio, H. Bonilla, 582,784-228,303 & $\begin{array}{c}4,51 \pm 0,37 \\
\left({ }^{40} \mathrm{Ar} /{ }^{39} \mathrm{Ar}: \mathrm{mtz}\right)\end{array}$ & $\begin{array}{l}\text { Gazel et al. } \\
\quad(2011)\end{array}$ \\
\hline$?$ & $\begin{array}{l}\text { Sill de "teschenita" } \\
\text { ("gabro alcalino") }\end{array}$ & $\begin{array}{l}\text { Queb. Terciopelo, H. Bonilla, aprox. } \\
585,650-222,800 . \text { Misma localidad que } \\
\text { GUA } 28 ?\end{array}$ & $4,5 \pm 0,5(\mathrm{~K} / \mathrm{Ar})$ & Cassell (1986) \\
\hline BO-062206-2 & Tefrita & R. Rubio, H. Bonilla, 582,289-228,772 & $\begin{array}{c}4,45 \pm 0,07 \\
\left({ }^{40} \mathrm{Ar} /{ }^{39} \mathrm{Ar}: \mathrm{mtz}\right)\end{array}$ & $\begin{array}{l}\text { Gazel et al. } \\
\text { (2011) }\end{array}$ \\
\hline GUA 28 & $\begin{array}{l}\text { Monzosienita } \\
\text { nefelínica }\end{array}$ & $\begin{array}{l}\text { Queb. Terciopelo, Bajo Tigre, H. Bonilla, } \\
5585,650-222,800\end{array}$ & $\begin{array}{c}4,39 \pm 0,14 \\
\left({ }^{40} \mathrm{Ar} /{ }^{39} \text { Ar: Furnace- }\right. \\
\text { largest step: } \mathrm{hb})\end{array}$ & $\begin{array}{l}\text { Abratis (1998), } \\
\text { Abratis \& Wör- } \\
\quad \text { ner (2001) }\end{array}$ \\
\hline BO-062306-8 & Basalto alcalino & $\begin{array}{l}\text { Queb. Guayacán, H. Bonilla, 584,800- } \\
\qquad 228,407\end{array}$ & $\begin{array}{c}4,33 \pm 0,07 \\
\left({ }^{40} \mathrm{Ar} /{ }^{39} \mathrm{Ar}: \mathrm{mtz}\right)\end{array}$ & $\begin{array}{l}\text { Gazel et al. } \\
\text { (2011) }\end{array}$ \\
\hline \multicolumn{5}{|c|}{ VULCANISMO DE ESCUDOS BASÁLTICOS II } \\
\hline AF-070306-3 & Basalto alcalino & $\begin{array}{l}\text { Lomas Sierpe, H. Guácimo, } \\
583,235-254,759\end{array}$ & $\begin{array}{c}3,60 \pm 0,03 \\
\left({ }^{40} \mathrm{Ar} /{ }^{39} \mathrm{Ar}: \mathrm{mtz}\right)\end{array}$ & $\begin{array}{l}\text { Gazel et al. } \\
\text { (2011) }\end{array}$ \\
\hline P163B & Basalto alcalino & $\begin{array}{l}\text { Afluente R. Indio, Lomas, Lomas de } \\
\text { Sierpe, H. Agua Fría, 581,953-259,667 }\end{array}$ & $\begin{array}{c}3,25 \pm 0,21 \\
\left({ }^{40} \mathrm{Ar} /{ }^{39} \mathrm{Ar}: \mathrm{mtz}\right)\end{array}$ & $\begin{array}{l}\text { Gazel et al. } \\
\quad(2011)\end{array}$ \\
\hline AF-070306-8 & Basalto alcalino & $\begin{array}{l}\text { Lomas Azules o de Sierpe, H. Agua Fría, } \\
\qquad 582,247-260,276\end{array}$ & $\begin{array}{c}3,23 \pm 0,03 \\
\left({ }^{40} \mathrm{Ar} /{ }^{39} \mathrm{Ar}: \mathrm{mtz}\right)\end{array}$ & $\begin{array}{l}\text { Gazel et al. } \\
\quad(2011)\end{array}$ \\
\hline TO-070106-1 & Basanita & $\begin{array}{l}\text { Lomas de Colorado, H. Tortuguero, } \\
570,487-291,784\end{array}$ & $\begin{array}{c}3,13 \pm 0,06( \\
\left.{ }^{40} \mathrm{Ar} /{ }^{39} \mathrm{Ar}: \mathrm{mtz}\right)\end{array}$ & $\begin{array}{l}\text { Gazel et al. } \\
\quad(2011)\end{array}$ \\
\hline TO-070106-3 & Basalto alcalino & $\begin{array}{l}\text { Lomas de Colorado, H. Colorado, } \\
\text { 572,866-294,784 }\end{array}$ & $\begin{array}{c}3,07 \pm 0,06 \\
\left({ }^{40} \mathrm{Ar} /{ }^{39} \mathrm{Ar}: \mathrm{mtz}\right)\end{array}$ & $\begin{array}{l}\text { Gazel et al. } \\
\text { (2011) }\end{array}$ \\
\hline CO-070206-2 & Basanita & $\begin{array}{l}\text { C. Coronel, H. Colorado, } \\
575,399-296,990\end{array}$ & $\begin{array}{c}3,06 \pm 0,08 \\
\left({ }^{40} \mathrm{Ar} /{ }^{39} \mathrm{Ar}: \mathrm{mtz}\right)\end{array}$ & $\begin{array}{l}\text { Gazel et al. } \\
\quad(2011)\end{array}$ \\
\hline
\end{tabular}


Cuadro 35

Dataciones radiométricas de las rocas ígneas alcalinas del Caribe

\begin{tabular}{|c|c|c|c|c|}
\hline MUESTRA & LITOLOGÍA & UBICACIÓN & $\operatorname{EDAD}(\mathrm{Ma})$ & REFERENCIA \\
\hline \multicolumn{5}{|c|}{ VULCANISMO DE ESUCUDOS BASÁLTICOS III } \\
\hline P-128 & Basalto alcalino & $\begin{array}{l}\text { R. San Juan (margen de Nicaragua), } 2,5 \\
\text { km del poblado Delta del San Juan, H. } \\
\text { Trinidad, 558,11-305,58 }\end{array}$ & $\begin{array}{c}2,01 \pm 0,21 \\
(40 \mathrm{Ar} / 39 \mathrm{Ar}: \mathrm{mtz})\end{array}$ & $\begin{array}{l}\text { Gazel et al. } \\
\quad(2011)\end{array}$ \\
\hline CR-275 & Basalto olivínico & C. Níspero, H. Pocosol, 506,925-315,075 & $\begin{array}{c}1,58 \pm 0,05 \\
(40 \mathrm{Ar} / 39 \mathrm{Ar}: \mathrm{mtz})\end{array}$ & Presente trabajo \\
\hline CR-277 & $\begin{array}{l}\text { Basalto olivínico } \\
\text { (bloque en que- } \\
\text { brada) }\end{array}$ & $\begin{array}{l}\text { C. Níspero, flanco NW, H. Pocosol, } \\
506,450-315,725\end{array}$ & $\begin{array}{c}1,51 \pm 0,02 \\
(40 \mathrm{Ar} / 39 \mathrm{Ar}: \mathrm{mtz})\end{array}$ & Presente trabajo \\
\hline CR-269 & Basalto olivínico & $\begin{array}{l}\text { Colada del C. Níspero, a } 4 \text { km al SSE de } \\
\text { Crucitas, H. Pocosol, 501,350-315,500 }\end{array}$ & $\begin{array}{c}1,470 \pm 0,040 \\
(40 \mathrm{Ar} / 39 \mathrm{Ar}: \mathrm{mtz})\end{array}$ & Presente trabajo \\
\hline CR-285 & $\begin{array}{l}\text { Leucitita con } \\
\text { olivino }\end{array}$ & $\begin{array}{l}\text { C. Las Mercedes, H. Pocosol, 498,300- } \\
\text { 327,450 }\end{array}$ & $\begin{array}{c}1,210 \pm 0,020 \\
(40 \mathrm{Ar} / 39 \mathrm{Ar}: \mathrm{mtz})\end{array}$ & Presente trabajo \\
\hline \multicolumn{5}{|c|}{ VULCANISMO DE CONOS DE ESCORIAS } \\
\hline CRC8 & Basalto alcalino & $\begin{array}{l}\text { Cono Loma Morena, H. Aguas Zarcas, } \\
\text { aprox. 500,8-260,6 }\end{array}$ & $0,3(\mathrm{~K} / \mathrm{Ar})$ & Poncia (1993) \\
\hline CR-241 & Basalto alcalino & $\begin{array}{l}\text { Cono Chiles (Altamira), H. Aguas Zar- } \\
\text { cas, 499,000-270,750 }\end{array}$ & $\begin{array}{c}0,295 \pm 0,025 \\
(40 \operatorname{Ar} / 39 \operatorname{Ar}: \mathrm{mtz})\end{array}$ & Presente trabajo \\
\hline
\end{tabular}

poca sismicidad y a que no es una dorsal medio oceánica (mid-ocean ridge), se le asignó el nombre de dorsal asísmica (aseismic ridge) del Coco por los geotectonistas, a una cadena de montes y volcanes submarinos que se extiende por espacio de $1200 \mathrm{~km}$ en forma más o menos continua desde las islas Galápagos (Ecuador) hasta el frente de nuestras costas, justo en la denominada Fosa Mesoamericana. Sin embargo, desde el punto de vista geográfico y vulcanológico, es mejor llamarla cordillera del Coco, constituyendo así la cordillera más grande de América Central y de Costa Rica, con unos $780 \mathrm{~km}$ de longitud en aguas territoriales (Alvarado, 2009). La isla del Coco es el único afloramiento de dicha cadena volcánica, ubicado sobre la placa tectónica del Coco, muy cerca de la dorsal de las Galápagos (Hey, 1977).

Dentro de los primeros estudios batimétricos acerca del fondo oceánico, pueden mencionarse los de Hey (1977) y Hey et al. (1977), quienes los asocian con rocas dentro de la placa del Coco y que se debieron de haber originado cerca de las Galápagos, entre 15 y 10 Ma atrás. Fueron transportados y hasta subducidos bajo el territorio costarricense actual, a lo largo de varios millones de años, mediante el proceso aún activo de la tectónica de placas. Los estudios vulcanológicos recientes evidencian que los volcanes más antiguos tienen edades entre 30 y 19 millones de años (p. ej., la serranía Fisher), mientras que los más recientes, situados más hacia la cordillera del Coco, frente a nuestras costas, poseen edades entre 14,5 y 13 millones de años (Werner et al., 1999). Debido a que en el fondo oceánico la erosión es casi nula, gran parte de la morfología de estos conos volcánicos ha quedado prácticamente congelada en el tiempo, y algunos de ellos hasta exhiben hasta su cráter perfectamente conservado.

Las dataciones radiométricas de rocas volcánicas dragadas en la placa del Coco o tomadas en la cordillera e isla del Coco, se distribuyen en 9 grupos (Cuadros 36 y 37): a) $30 \mathrm{Ma}$, b) $19 \mathrm{Ma}$, c) $14,46-10,0 \mathrm{Ma}$, d) $8,8-8,3 \mathrm{Ma}$, e) $5,7-5,2$ Ma, f) 4,2 - 3,4 Ma, g) 2,2 - 1,9 Ma, h) 1,5 e i) 0,6 $\mathrm{Ma}$, que representan diferentes pulsos magmáticos (Dalrymple \& Cox, 1968; Bellon et al., 1983; Werner et al., 2003; Harpp et al., 2005; O'Connor et al., 2007).

Las lavas en la cordillera del Coco son basaltos y andesitas basálticas toleíticas, mientras que 
Cuadro 36

Dataciones radiométricas de las rocas volcánicas submarinas de la cordillera del Coco y otros volcanes submarinos

\begin{tabular}{|c|c|c|c|c|}
\hline MUESTRA & LITOLOGÍA & UBICACIÓN & $\operatorname{EDAD}(\mathrm{Ma})$ & REFERENCIA \\
\hline DK28 & Basalto toleítico & $\begin{array}{l}\text { Flanco NE sierra Fisher, } \\
08^{\circ} 56.10^{\prime} \mathrm{N}-085^{\circ} 34.11^{\prime} \mathrm{W}\end{array}$ & $\begin{array}{c}29,96 \pm 0,48\left({ }^{40} \mathrm{Ar} /{ }^{39} \mathrm{Ar}:\right. \\
\text { iso.: vidrio })\end{array}$ & Werner et al. (1999) \\
\hline SO81-6 & Basalto toleítico & $\begin{array}{l}\text { Flanco S sierra Fisher, } \\
\sim 08^{\circ} 48^{\prime} \mathrm{N}-085^{\circ} 38^{\prime} \mathrm{W}\end{array}$ & $\begin{array}{c}19,19 \pm 0,31\left({ }^{40} \mathrm{Ar} /{ }^{39} \mathrm{Ar}:\right. \\
\text { iso.: plag) }\end{array}$ & Werner et al. (1999) \\
\hline$?$ & Basalto alcalino & $\begin{array}{c}\text { V. Eva } 2,08^{\circ} 47.64^{\prime} \mathrm{N}- \\
085^{\circ} 12.99^{\prime} \mathrm{W}\end{array}$ & $\begin{array}{c}14,46 \pm 0,32\left({ }^{40} \mathrm{Ar} /{ }^{39} \mathrm{Ar}:\right. \\
\text { iso.: plag })\end{array}$ & Werner et al. (1999) \\
\hline SO81-10 & $\begin{array}{c}\text { Basalto con fenocristales } \\
\text { de plag }\end{array}$ & $\begin{array}{c}\text { Plat. de Quepos, } \\
08^{\circ} 39.6^{\prime} \mathrm{N}-84^{\circ} 39.6^{\prime} \mathrm{W}\end{array}$ & $\begin{array}{c}14,02 \pm 0,34\left({ }^{40} \mathrm{Ar} /{ }^{39} \mathrm{Ar}:\right. \\
\text { iso.: plag })\end{array}$ & Werner et al. (1999) \\
\hline 81 & Traquiandesita basáltica & $\begin{array}{l}\text { Cordillera del Coco, } \\
08^{\circ} 31.6^{\prime}-085^{\circ} 09.0^{\prime}\end{array}$ & $13,8 \pm 0,2\left({ }^{40} \mathrm{Ar} /{ }^{39} \mathrm{Ar}\right)$ & O'Connor et al. (2007) \\
\hline DK30 & Basalto alcalino & $\begin{array}{l}\text { V. Monte Fisher, } \\
09^{\circ} 03.47^{\prime} \mathrm{N}-085^{\circ} 28.49^{\prime} \mathrm{W}\end{array}$ & $\begin{array}{c}13,76 \pm 0,24\left({ }^{40} \mathrm{Ar} /{ }^{39} \mathrm{Ar}:\right. \\
\text { iso.: plag })\end{array}$ & Werner et al. (1999) \\
\hline $54 \mathrm{a}$ & Basalto & $\begin{array}{l}\text { Cordillera del Coco, } \\
08^{\circ} 02.1^{\prime}-083^{\circ} 26.2^{\prime}\end{array}$ & $13,4 \pm 0,4\left({ }^{40} \mathrm{Ar} /{ }^{39} \mathrm{Ar}\right)$ & O'Connor et al. (2007) \\
\hline 51 & Basalto afanítico & $\begin{array}{l}\text { Cordillera del Coco, } \\
07^{\circ} 00.0^{\prime}-082^{\circ} 51.9^{\prime}\end{array}$ & $13,2 \pm 0,3\left({ }^{40} \mathrm{Ar} /{ }^{39} \mathrm{Ar}\right)$ & O'Connor et al. (2007) \\
\hline 84 & Basalto afanítico & $\begin{array}{l}\text { Cordillera del Coco, } \\
08^{\circ} 31.8^{\prime}-085^{\circ} 38.3^{\prime}\end{array}$ & $13,2 \pm 0,3\left({ }^{40} \mathrm{Ar} /{ }^{39} \mathrm{Ar}\right)$ & O’Connor et al. (2007) \\
\hline $63 a$ & Basalto afanítico & $\begin{array}{l}\text { Cordillera del Coco, } \\
07^{\circ} 01.4^{\prime}-086^{\circ} 00.8^{\prime}\end{array}$ & $13,1 \pm 0,4\left({ }^{40} \mathrm{Ar} /{ }^{39} \mathrm{Ar}\right)$ & O'Connor et al. (2007) \\
\hline DK23 & Traquibasalto & $\begin{array}{c}\text { V. Eva } 1,08^{\circ} 52.35^{\prime} \mathrm{N}-085- \\
{ }^{\circ} 08.30^{\prime} \mathrm{W}\end{array}$ & $\begin{array}{c}13,09 \pm 0,36\left({ }^{40} \mathrm{Ar} /{ }^{39} \mathrm{Ar}:\right. \\
\text { iso.: plag })\end{array}$ & Werner et al. (1999) \\
\hline SO81-2 & Basalto olivínico & $\begin{array}{l}\text { Cordillera del Coco, } \\
08^{\circ} 01.7^{\prime} \mathrm{N}-083^{\circ} 51.1^{\prime} \mathrm{W}\end{array}$ & $\begin{array}{c}12,97 \pm 0,21\left({ }^{40} \mathrm{Ar} /{ }^{39} \mathrm{Ar}:\right. \\
\text { iso.: plag })\end{array}$ & Werner et al. (1999) \\
\hline 78 & Basalto & $\begin{array}{l}\text { Cordillera del Coco, } \\
08^{\circ} 06.9^{\prime}-085^{\circ} 47.5^{\prime}\end{array}$ & $12,9 \pm 0,3\left({ }^{40} \mathrm{Ar} /{ }^{39} \mathrm{Ar}\right)$ & O'Connor et al. (2007) \\
\hline 79 & Basalto afanítico & $\begin{array}{l}\text { Cordillera del Coco, } \\
07^{\circ} 58.5^{\prime}-085^{\circ} 33.7^{\prime}\end{array}$ & $12,9 \pm 0,3\left({ }^{40} \mathrm{Ar} /{ }^{39} \mathrm{Ar}\right)$ & O’Connor et al. (2007) \\
\hline 62 & Basalto afanítico & $\begin{array}{l}\text { Cordillera del Coco, } \\
07^{\circ} 30.9^{\prime}-085^{\circ} 32.1^{\prime}\end{array}$ & $12,7 \pm 0,2\left({ }^{40} \mathrm{Ar} /{ }^{39} \mathrm{Ar}\right)$ & O'Connor et al. (2007) \\
\hline 80 & Basalto & $\begin{array}{l}\text { Cordillera del Coco, } \\
08^{\circ} 17.0^{\prime}-085^{\circ} 08.9^{\prime}\end{array}$ & $12,5 \pm 0,3\left({ }^{40} \mathrm{Ar} /{ }^{39} \mathrm{Ar}\right)$ & O'Connor et al. (2007) \\
\hline 82 & Basalto traquítico afanítico & $\begin{array}{l}\text { Cordillera del Coco, } \\
08^{\circ} 33.7^{\prime}-085^{\circ} 27.5^{\prime}\end{array}$ & $12,4 \pm 0,2\left({ }^{40} \mathrm{Ar} /{ }^{39} \mathrm{Ar}\right)$ & O’Connor et al. (2007) \\
\hline 60 & Basalto traquítico & $\begin{array}{l}\text { Cordillera del Coco, } \\
07^{\circ} 23.2^{\prime}-085^{\circ} 11.3^{\prime}\end{array}$ & $12,4 \pm 0,2\left({ }^{40} \mathrm{Ar} /{ }^{39} \mathrm{Ar}\right)$ & O'Connor et al. (2007) \\
\hline 56 & Basalto picrítico & $\begin{array}{l}\text { Cordillera del Coco, } \\
07^{\circ} 52.1^{\prime}-084^{\circ} 26.4^{\prime}\end{array}$ & $12,1 \pm 0,3\left(4^{40} \mathrm{Ar} /{ }^{39} \mathrm{Ar}\right)$ & O'Connor et al. (2007) \\
\hline 53 & Basalto afanítico & $\begin{array}{l}\text { Cordillera del Coco, } \\
07^{\circ} 36.4^{\prime}-083^{\circ} 25.2^{\prime}\end{array}$ & $11,7 \pm 0,5\left({ }^{40} \mathrm{Ar} /{ }^{39} \mathrm{Ar}\right)$ & O'Connor et al. (2007) \\
\hline 48 & Basalto & $\begin{array}{l}\text { Cordillera del Coco, } \\
06^{\circ} 47.5^{\prime}-085^{\circ} 22.9^{\prime}\end{array}$ & $11,5 \pm 0,3\left({ }^{40} \mathrm{Ar} /{ }^{39} \mathrm{Ar}\right)$ & O'Connor et al. (2007) \\
\hline 55 & Basalto afanítico & $\begin{array}{l}\text { Cordillera del Coco, } \\
07^{\circ} 52.7^{\prime}-083^{\circ} 59.6^{\prime}\end{array}$ & $11,2 \pm 0,6\left({ }^{40} \mathrm{Ar} /{ }^{39} \mathrm{Ar}\right)$ & O'Connor et al. (2007) \\
\hline
\end{tabular}


Cuadro 36 (continuación)

Dataciones radiométricas de las rocas volcánicas submarinas de la cordillera del Coco y otros volcanes submarinos

\begin{tabular}{|c|c|c|c|c|}
\hline MUESTRA & LITOLOGÍA & UBICACIÓN & $\operatorname{EDAD}(\mathrm{Ma})$ & REFERENCIA \\
\hline 73 & Basalto picrítico & $\begin{array}{l}\text { Cordillera del Coco, } \\
07^{\circ} 05.4^{\prime}-086^{\circ} 23.9^{\prime}\end{array}$ & $11,2 \pm 0,3\left({ }^{40} \mathrm{Ar} /{ }^{39} \mathrm{Ar}\right)$ & O'Connor et al. (2007) \\
\hline 74 & Basalto afanítico & $\begin{array}{l}\text { Cordillera del Coco, } \\
07^{\circ} 23.2^{\prime}-086^{\circ} 31.0^{\prime}\end{array}$ & $10,8 \pm 0,3\left({ }^{40} \mathrm{Ar} /{ }^{39} \mathrm{Ar}\right)$ & O'Connor et al. (2007) \\
\hline $77 \mathrm{a}$ & Basalto afanítico & $\begin{array}{l}\text { Cordillera del Coco, } \\
07^{\circ} 45.9^{\prime}-085^{\circ} 55.5^{\prime}\end{array}$ & $10,8 \pm 0,2\left({ }^{40} \mathrm{Ar} /{ }^{39} \mathrm{Ar}\right)$ & O'Connor et al. (2007) \\
\hline $45 \mathrm{a}$ & Basalto & $\begin{array}{l}\text { Cordillera del Coco, } \\
06^{\circ} 15.8^{\prime}-084^{\circ} 53.3^{\prime}\end{array}$ & $10,0 \pm 0,4\left({ }^{40} \mathrm{Ar}{ }^{39} \mathrm{Ar}\right)$ & O'Connor et al. (2007) \\
\hline 41 & Basalto picrítico & $\begin{array}{l}\text { Cordillera del Coco, } \\
04^{\circ} 40.3^{\prime}-087^{\circ} 54.4^{\prime}\end{array}$ & $8,8 \pm 0,2\left({ }^{40} \mathrm{Ar} /{ }^{39} \mathrm{Ar}\right)$ & O'Connor et al. (2007) \\
\hline $49 \mathrm{a}$ & Basalto afanítico & $\begin{array}{l}\text { Cordillera del Coco, } \\
06^{\circ} 56.1^{\prime}-084^{\circ} 14.9^{\prime}\end{array}$ & $8,3 \pm 0,4\left({ }^{40} \mathrm{Ar} /{ }^{39} \mathrm{Ar}\right)$ & O'Connor et al. (2007) \\
\hline $70 \mathrm{~b}$ & Traquita & $\begin{array}{l}\text { Cordillera del Coco, } \\
05^{\circ} 34.5^{\prime}-088^{\circ} 13.7^{\prime}\end{array}$ & $5,7 \pm 0,1\left({ }^{40} \mathrm{Ar} /{ }^{39} \mathrm{Ar}\right)$ & O'Connor et al. (2007) \\
\hline 33 & Basaltos picríticos & $\begin{array}{l}\text { Cordillera del Coco, } \\
03^{\circ} 53.7^{\prime}-089^{\circ} 13.6^{\prime}\end{array}$ & $5,5 \pm 0,3\left(\left(^{40} \mathrm{Ar} /{ }^{39} \mathrm{Ar}\right)\right.$ & O'Connor et al. (2007) \\
\hline 69 & Basalto alcalino & $\begin{array}{l}\text { Cordillera del Coco, } \\
05^{\circ} 12.2^{\prime}-087^{\circ} 56.8^{\prime}\end{array}$ & $5,2 \pm 0,2\left({ }^{40} \mathrm{Ar} /{ }^{39} \mathrm{Ar}\right)$ & O'Connor et al. (2007) \\
\hline 64 & Basalto traquítico afanítico & $\begin{array}{l}\text { Cordillera del Coco, } \\
05^{\circ} 45.3^{\prime}-086^{\circ} 54.1^{\prime}\end{array}$ & $4,2 \pm 0,1$ & O'Connor et al. (2007) \\
\hline 71 & Traquiandesita basáltica & $\begin{array}{c}\text { Cordillera del Coco, } \\
05^{\circ} 30.7^{\prime}-088^{\circ} 34.8^{\prime}\end{array}$ & $3,9 \pm 0,1\left({ }^{40} \mathrm{Ar} /{ }^{39} \mathrm{Ar}\right)$ & O'Connor et al. (2007) \\
\hline $65 \mathrm{a}$ & Basalto picrítico & $\begin{array}{l}\text { Cordillera del Coco, } \\
05^{\circ} 44.1^{\prime}-086^{\circ} 48.4^{\prime}\end{array}$ & $3,8 \pm 0,2\left({ }^{40} \mathrm{Ar} /{ }^{39} \mathrm{Ar}\right)$ & O'Connor et al. (2007) \\
\hline $71 \mathrm{a}$ & Basalto alcalino & $\begin{array}{l}\text { Cordillera del Coco, } \\
05^{\circ} 28.5^{\prime}-088^{\circ} 36.4^{\prime}\end{array}$ & $3,7 \pm 0,1\left({ }^{40} \mathrm{Ar} /{ }^{39} \mathrm{Ar}\right)$ & O'Connor et al. (2007) \\
\hline 65 & Basalto afanítico & $\begin{array}{l}\text { Cordillera del Coco, } \\
05^{\circ} 44.2^{\prime}-086^{\circ} 47.9^{\prime}\end{array}$ & $3,6 \pm 0,1\left({ }^{40} \mathrm{Ar} /{ }^{39} \mathrm{Ar}\right)$ & O'Connor et al. (2007) \\
\hline 47 & Basalto afanítico & $\begin{array}{l}\text { Cordillera del Coco, } \\
06^{\circ} 38.2^{\prime}-085^{\circ} 44.5^{\prime}\end{array}$ & $3,4 \pm 0,1\left({ }^{40} \mathrm{Ar} /{ }^{39} \mathrm{Ar}\right)$ & O'Connor et al. (2007) \\
\hline 46 & Basalto traquítico & $\begin{array}{l}\text { Cordillera del Coco, } \\
06^{\circ} 29.4^{\prime}-085^{\circ} 34.8^{\prime}\end{array}$ & $1,9 \pm 0,1\left({ }^{40} \mathrm{Ar} /{ }^{39} \mathrm{Ar}\right)$ & O’Connor et al. (2007) \\
\hline 32 & Basaltos picríticos & $\begin{array}{l}\text { Cordillera del Coco, } \\
03^{\circ} 27.6^{\prime}-090^{\circ} 36.8^{\prime}\end{array}$ & $1,8 \pm 0,4\left({ }^{40} \mathrm{Ar} /{ }^{39} \mathrm{Ar}\right)$ & O'Connor et al. (2007) \\
\hline 67 & Basalto traquítico & $\begin{array}{l}\text { Cordillera del Coco, } \\
05^{\circ} 30.5^{\prime}-087^{\circ} 15.4^{\prime}\end{array}$ & $1,3 \pm 0,2\left({ }^{40} \mathrm{Ar} /{ }^{39} \mathrm{Ar}\right)$ & O'Connor et al. (2007) \\
\hline 42 & Traquiandesita basáltica & $\begin{array}{l}\text { Cordillera del Coco, } \\
05^{\circ} 08.5^{\prime}-087^{\circ} 32.6^{\prime}\end{array}$ & $1,2 \pm 0,1\left({ }^{40} \mathrm{Ar} /{ }^{39} \mathrm{Ar}\right)$ & O'Connor et al. (2007) \\
\hline $72 \mathrm{a}$ & Basalto & $\begin{array}{l}\text { Cordillera del Coco, } \\
05^{\circ} 52.0^{\prime}-087^{\circ} 34.4^{\prime}\end{array}$ & $1,2 \pm 0,1\left({ }^{40} \mathrm{Ar} /{ }^{39} \mathrm{Ar}\right)$ & O'Connor et al. (2007) \\
\hline 38 & Basalto traquítico & $\begin{array}{l}\text { Cordillera del Coco, } \\
04^{\circ} 21.8^{\prime}-085^{\circ} 47.2^{\prime}\end{array}$ & $0,6 \pm 0,1\left({ }^{40} \mathrm{Ar} /{ }^{39} \mathrm{Ar}\right)$ & O'Connor et al. (2007) \\
\hline 40 & Basalto traquítico & $\begin{array}{l}\text { Cordillera del Coco, } \\
04^{\circ} 38.2^{\prime}-087^{\circ} 22.0^{\prime}\end{array}$ & $0,6 \pm 0,1\left({ }^{40} \mathrm{Ar} /{ }^{39} \mathrm{Ar}\right)$ & O'Connor et al. (2007) \\
\hline
\end{tabular}


Cuadro 37

Dataciones radiométricas de la isla del Coco

\begin{tabular}{|c|c|c|c|c|}
\hline MUESTRA & LITOLOGÍA & UBICACIÓN & $\operatorname{EDAD}(\mathrm{Ma})$ & REFERENCIA \\
\hline \multicolumn{5}{|c|}{ ESCUDOS OCEÁNICOS DE LA I. DEL COCO } \\
\hline 5 & Mugearita & 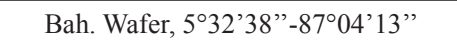 & $2,28 \pm 0,11(\mathrm{~K} / \mathrm{Ar})$ & Bellon et al. (1983) \\
\hline $\mathrm{C}-35$ & Basalto & $\begin{array}{c}\text { Bah. Wafer, ladera E del río, cerca del } \\
\text { margen W de un dique, que corta la co- } \\
\text { lada inferior (C-33), aprox. } 5^{\circ} 32^{\prime} 40^{\prime \prime}- \\
87^{\circ} 04^{\prime} 30^{\prime \prime}\end{array}$ & $2,2 \pm 0,3\left({ }^{40} \mathrm{Ar}{ }^{\beta 9} \mathrm{Ar}\right)$ & O’Connor et al. (2007) \\
\hline $\mathrm{C}-26$ & Basalto traquítico & $\begin{array}{l}\text { Bah. Chatham, ladera W río, colada } \\
\text { central de } 3 \text { aflorantes en la costa, } \\
\text { aprox. } 5^{\circ} 33^{\prime} 05^{\prime \prime}-87^{\circ} 030^{\prime} 10^{\prime \prime}\end{array}$ & $2,2 \pm 0,1\left({ }^{40} \mathrm{Ar} /{ }^{\beta 9} \mathrm{Ar}\right)$ & O'Connor et al. (2007) \\
\hline $\mathrm{C}-33$ & Basalto alcalino & $\begin{array}{l}\text { Bah. Wafer, ladera E del río, lava infe- } \\
\text { rior de } 3 \text {, aprox. } 5^{\circ} 32^{\prime} 40^{\prime \prime}-87^{\circ} 04^{\prime} 30^{\prime \prime}\end{array}$ & $2,2 \pm 0,1\left({ }^{40} \mathrm{Ar} /{ }^{39} \mathrm{Ar}\right)$ & O'Connor et al. (2007) \\
\hline $\mathrm{C}-15$ & Basalto & 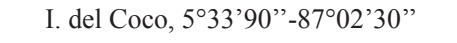 & $2,2 \pm 0,03\left({ }^{40} \mathrm{Ar} /{ }^{39} \mathrm{Ar}\right)$ & O’Connor et al. (2007) \\
\hline $\mathrm{C}-24$ & Traquita & $\begin{array}{l}\text { Bah. Chatham, ladera E, colada en } \\
\text { la catarata detrás de la playa, aprox. } \\
5^{\circ} 32^{\prime} 55^{\prime \prime}-87^{\circ} 03^{\prime} 20^{\prime \prime}\end{array}$ & $2,1 \pm 0,03\left({ }^{40} \mathrm{Ar} /{ }^{39} \mathrm{Ar}\right)$ & O’Connor et al. (2007) \\
\hline $4 \mathrm{C} 400$ & Traquita & $\begin{array}{l}\text { Bah. Chatham, sector W, aprox. } \\
5^{\circ} 33^{\prime} 05^{\prime \prime}-87^{\circ} 022^{\prime} 56^{\prime \prime}\end{array}$ & $\begin{array}{c}2,09 \pm 0,04 \text { Edad } \\
\text { calibrada: } 2,10 \pm 0,00 \\
(\mathrm{~K} / \mathrm{Ar})\end{array}$ & $\begin{array}{l}\text { Dalrymple \& Cox } \\
\qquad(1968)\end{array}$ \\
\hline $4 \mathrm{C} 401$ & Basalto alcalino & $\begin{array}{l}\text { Bah. Chatham, sector W, aprox. } \\
5^{\circ} 33^{\prime} 12^{\prime \prime}-87^{\circ} 02^{\prime} 83^{\prime \prime}\end{array}$ & $\begin{array}{c}2,03 \pm 0,06 \text { Edad } \\
\text { calibrada: } 2,04 \pm 0,00 \\
(\mathrm{~K} / \mathrm{Ar})\end{array}$ & $\begin{array}{l}\text { Dalrymple \& Cox } \\
\qquad(1968)\end{array}$ \\
\hline 4 & Mugearita afírica & 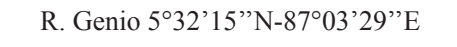 & $1,97 \pm 0,10(\mathrm{~K} / \mathrm{Ar})$ & Bellon et al. (1983) \\
\hline $4 \mathrm{C} 402$ & Basalto alcalino & $\begin{array}{l}\text { Bah. Chatam, sector W, aprox. } \\
5^{\circ} 33^{\prime} 12^{\prime \prime}-87^{\circ} 02^{\prime} 83^{\prime \prime}\end{array}$ & $\begin{array}{l}1,93 \pm 0,09(\mathrm{~K} / \mathrm{Ar}) \\
\text { Edad calibrada: } 1,93 \pm \\
0,00\end{array}$ & $\begin{array}{l}\text { Dalrymple \& Cox } \\
\text { (1968) }\end{array}$ \\
\hline 7 & $\begin{array}{l}\text { Basalto (bloque } \\
\text { dentro de toba) }\end{array}$ & I. del Coco, $5^{\circ} 32^{\prime} 35^{\prime \prime} \mathrm{N}-87^{\circ} 04^{\prime} 13^{\prime \prime} \mathrm{E}$ & $1,91 \pm 0,10(\mathrm{~K} / \mathrm{Ar})$ & Bellon et al. (1983) \\
\hline $\mathrm{C}-11$ & $\begin{array}{l}\text { Traquiandesita } \\
\text { con piroxenos }\end{array}$ & $\begin{array}{l}\text { Colada en la ladera W del río hacia la } \\
\text { Bah. Wafer, } 1 \mathrm{~km} \text { de la casa del Parque, } \\
5^{\circ} 32^{\prime} 30^{\prime \prime}-87^{\circ} 04^{\prime} 30^{\prime \prime}\end{array}$ & $1,9 \pm 0,04\left({ }^{40} \mathrm{Ar}{ }^{39} \mathrm{Ar}\right)$ & O'Connor et al. (2007) \\
\hline $\mathrm{C}-13$ & Basalto & $\begin{array}{c}\text { Ladera W del río hacia la Bah. Wafer, } \\
\text { sendero al C. Iglesias, aprox. } 1 \mathrm{~km} \\
\text { de la casa del Parque, } 5^{\circ} 32^{\prime} 20^{\prime \prime}-87 \text { - } \\
{ }^{\circ} 04{ }^{\prime} 20^{\prime}\end{array}$ & $1,5 \pm 0,1\left({ }^{40} \mathrm{Ar} r{ }^{39} \mathrm{Ar}\right)$ & O'Connor et al. (2007) \\
\hline
\end{tabular}

las lavas y rocas piroclásticas de la isla del Coco y los montes submarinos, presentes hasta nuestras costas, poseen un carácter principalmente alcalino: hawaitas, traquiandesitas basálticas, traquiandesitas hasta traquitas (Werner et al., 1999; Harpp et al., 2005).

Según el modelo de Hey et al. (1977), el basamento de la isla se encuentra ubicada entre los isocronas de 15 y 10 millones de años (principalmente en el Mioceno Medio). En efecto la rocas que conforman la cordillera del Coco suelen tener edades de hasta $14 \mathrm{Ma}$, sin embargo, las dataciones radiométricas de la isla del Coco (2,2 - 1,5 Ma), así como para los volcanes submarinos circundantes $(1,3$ - 0,6 Ma, por ejemplo), aportan edades anómalamente jóvenes (Dalrymple \& Cox, 1968; Bellon et al., 1983; O'Connor et al., 2007). Lo anterior sugiere que la isla es producto de un vulcanismo local (Pleistoceno Inferior), en ese momento -y aún 
hoy día- no fácil de relacionarla directa y cronológicamente con el vulcanismo que dio origen a la cordillera del Coco. En efecto, el origen de este vulcanismo relativamente joven, dentro de los paradigmas de la tectónica de placas, es un tema aún abierto a discusión y fuera de los objetivos del presente artículo, pero en síntesis varía desde un punto caliente (Burke \& Wilson, 1976), una línea caliente (Alvarado, 1984), la reactivación en bajo grado de la pluma mantélica del punto caliente de las Galápagos (Castillo et al., 1988), un vulcanismo de dorsal oceánica o un punto caliente secundario (Meschede et al., 1998), el rejuvenecimiento del vulcanismo post-escudo y post-erosional con cierto control tectónico (Werner et al., 1999; Harpp et al., 2005), o una amplia anomalía del manto de gran longevidad (O'Connor et al., 2007; Gazel et al., 2011). Todos concuerdan en mayor o menor grado y de modo simplificado, en que corresponde con una anomalía térmica del manto que se manifestó mediante vulcanismo a través de una zona de debilidad cortical.

\section{CRONOLOGÍA DEL METAMORFISMO, ALTERACIÓN HIDROTERMAL Y LAS MINERALIZACIONES METÁLICAS}

Todavía se está en pañales en Costa Rica en lo referente a la geocronología del metamorfismo, la alteración hidrotermal y las mineralizaciones metálicas asociadas. Sin embargo, el presente apartado permite realizar algunas inferencias con base en algunas edades y relaciones de campo, así como plantear hipótesis para futuras investigaciones (Cuadro 38).

El metamorfismo puede ser definido como la adaptación mineral, química y estructural de las rocas en estado sólido a condiciones físico-químicas (ya sea temperatura, presión y/o ambiente químico) diferentes de aquellas donde se formaron originalmente las rocas, exceptuando procesos de intemperismo, cementación y diagénesis, aunque en realidad la frontera no es siempre clara o nítida. Pese a ello, el metamorfismo tradicional o sensu stricto es, esencialmente, isoquímico, cuya recristalización ocurre en un sistema cerrado, aunque puede haber modificaciones sustanciales en volátiles como la introducción de $\mathrm{H}_{2} \mathrm{O}$, $\mathrm{CO}_{2}$ y otras especies fluidas, la deshidratación y la descarbonatación. Si está relacionado con un sistema abierto con modificaciones importantes en la química de la roca (= aloquímico), entonces los procesos se denomina metasomatismo y metamorfismo hidrotermal, conocido este último más como alteración hidrotermal (Tyrrel, 1929; Turner, 1968; Aubouin et al., 1968; Frey \& Robinson, 1999; Smulikowski et al., 2007).

\section{Metamorfismo}

En Costa Rica no hay expuesto ningún cinturón metamórfico regional, derivado de una orogenia (llamado orogénico), por lo que para muchos geólogos nacionales casi resulta más apropiado decir que no existen rocas metamórficas. Otro tipo particular metamorfismo, que puede ser regional y local, corresponde con el metamorfismo/ metasomatismo, o la alteración hidrotermal de rocas ígneas relativamente frías $\left(\leq 300{ }^{\circ} \mathrm{C}\right)$ generado por la circulación de fluidos calientes a través de rocas permeables (porosas y fracturadas). Este proceso es debido a su sepultamiento (metamorfismo de hundimiento o carga) o al abrupto gradiente geotérmico creado cerca de los focos volcánicos submarinos (metamorfismo del fondo oceánico) (Coleman, 1977; Smulikowski et al., 2007).

Este tipo de proceso produjo, en parte, la serpentinización de las peridotitas de Santa Elena, la uralitización de los piroxenos en los gabros, doleritas y basaltos en Santa Elena, así como la albitización de los basaltos (espilitas) y doleritas de Nicoya. Sin embargo, todavía faltan estudios de detalle al respecto, en particular para distinguir entre el metamorfismo de bajo grado y la alteración hidrotermal (p.ej., Martens et al., 2007), por lo general inferior a los $400{ }^{\circ} \mathrm{C}$ (Frey \& Robinson, 1999). Pese a ello, seis facies metamórficas principales se logran reconocer en el territorio nacional:

Facies de las zeolitas: Corresponde con un metamorfismo débil entre 50 y $250{ }^{\circ} \mathrm{C}$ y presiones 
Cuadro 38

Dataciones radiométricas de rocas con eventos metamórficos y de alteración hidrotermal

\begin{tabular}{|c|c|c|c|c|}
\hline MUESTRA & LITOLOGÍA & UBICACIÓN & $\operatorname{EDAD}(\mathrm{Ma})$ & REFERENCIA \\
\hline \multicolumn{5}{|c|}{ INTRUSIONES EN LA PERIDOTITA ALÓCTONA Y FACIES DE ANFIBOLITA } \\
\hline SE 10 & $\begin{array}{l}\text { Anfibolita gnéis- } \\
\text { sica (anfibolita } \\
\text { foliada, gabro con } \\
\text { anfíbol) }\end{array}$ & $\begin{array}{l}\text { R. Murciélago, H. Murciélago, } \\
\text { 347,65-318,8 }\end{array}$ & $\begin{array}{c}101,3 \pm 2,5 \\
98,8 \pm 3,6(\mathrm{~K} / \mathrm{Ar}: \mathrm{hb}) \\
88,8 \pm 4,5(\mathrm{~K} / \mathrm{Ar}: \mathrm{wr}) \\
78,8 \pm 2,3 \text { (K/Ar: plag) }\end{array}$ & $\begin{array}{l}\text { Bellon \&Tournon, } \\
\text { (1978), Tournon \& } \\
\text { Bellon (2009) }\end{array}$ \\
\hline CR 316 & $\begin{array}{l}\text { Dolerita anfibo- } \\
\quad \text { lítica }\end{array}$ & H. Murciélago, 357,50-321,30 & $92,7 \pm 2,9$ (K/Ar: wr) & $\begin{array}{l}\text { Tournon \& Bellon } \\
\text { (2009) }\end{array}$ \\
\hline CR 745 & $\begin{array}{l}\text { Anfibolita (gneiss } \\
\text { anfibolítico) }\end{array}$ & H. Sta. Elena, 330,00-322,30 & $83,4 \pm 2,4$ (K/Ar: wr) & $\begin{array}{l}\text { Tournon \& Bellon } \\
\qquad(2009)\end{array}$ \\
\hline SE 4 & $\begin{array}{l}\text { Dolerita con } \\
\text { anfíbol }\end{array}$ & H. Murciélago, 347,40-319,80 & $80,1 \pm 1,7$ (K/Ar: wr) & $\begin{array}{l}\text { Tournon \& Bellon } \\
\qquad(2009)\end{array}$ \\
\hline \multicolumn{5}{|c|}{ BASALTOS CON EVENTO TÉRMICO (METABASALTOS)? } \\
\hline NIC-037 & Basalto & H. Juntas, 428,3-206,1 & $64,9 \pm 4,4(\mathrm{~K} / \mathrm{Ar})$ & Appel (1990) \\
\hline NIC-038 & Basalto & $\begin{array}{l}\text { Intersección camino Pl. del Coco con Pl. } \\
\text { Hermosa, H. Carrillo Norte, 353,4-280,2 }\end{array}$ & $57,2 \pm 6,9(\mathrm{~K} / \mathrm{Ar})$ & Appel 1990 \\
\hline NIC-045 & $\begin{array}{l}\text { Basalto en almo- } \\
\text { hadilla }\end{array}$ & $\begin{array}{l}\text { Lomas Pochotada, } 2 \text { km N de Bolsón y } \\
\text { Ortega, H. Tempisque, 377,0-262,9 }\end{array}$ & $53,6 \pm 11,1(\mathrm{~K} / \mathrm{Ar})$ & Appel (1990) \\
\hline $\mathrm{R}-243$ & Basalto o dolerita & $\begin{array}{c}\text { Intersección camino Pl. del Coco con Pl. } \\
\text { Hermosa, H. Carrillo Norte, } 353,40- \\
280,30\end{array}$ & $46,0 \pm 4,0(\mathrm{~K} / \mathrm{Ar})$ & $\begin{array}{l}\text { Berrangé et al. } \\
\text { (1989) }\end{array}$ \\
\hline PAV-030 & $\begin{array}{l}\text { Rodado de picrita } \\
\text { con cloritas y biot } \\
\text { secundarias }\end{array}$ & $\begin{array}{l}\text { Pavón (P. Burica), cerca de Queb. Man- } \\
\text { gle, H. Pavón, 560,8-263,3 }\end{array}$ & $17,5 \pm 3,3(\mathrm{~K} / \mathrm{Ar})$ & Appel (1990) \\
\hline \multicolumn{5}{|c|}{ ESQUISTOS DE TALAMANCA } \\
\hline SL25 & $\begin{array}{l}\text { Micaesquisto con } \\
\text { muscovita, andalu- } \\
\text { sita y cuarzo }\end{array}$ & $\begin{array}{l}\text { F. Bugú, Alto Chinagucha, cuenca R. } \\
\text { Coén, H. Siola, 552,3-377,4 }\end{array}$ & $4,95 \pm 0,17(\mathrm{~K} / \mathrm{Ar})$ & $\begin{array}{c}\text { Montigny, com } \\
\text { pers. en Tournon } \\
\text { (1984), Tournon \& } \\
\text { Alvarado (1997) } \\
\end{array}$ \\
\hline \multicolumn{5}{|c|}{ CRUCITAS-CONCHUDITA } \\
\hline $\begin{array}{l}\text { CO-261 } \\
\text { UDac-m }\end{array}$ & $\begin{array}{l}\text { Dacita con adularia } \\
\text { y alteración seri- } \\
\text { cítica }\end{array}$ & $\begin{array}{c}\text { Conchudita, Perforación CO-261, } 110 \text { m, } \\
\text { H. Cutris, 509,610-309,720 }\end{array}$ & $22,9 \pm 0,6(\mathrm{~K} / \mathrm{Ar})$ & Sigarán (2001) \\
\hline Adularia-1 & $\begin{array}{l}\text { Concentrado adula- } \\
\text { ria en brecha hidro- } \\
\text { termalizada }\end{array}$ & $\begin{array}{l}\text { Prospecto aurífero Crucitas, H. Pocosol, } \\
\qquad 500,600-315,950\end{array}$ & $16,4 \pm 0,4(\mathrm{~K} / \mathrm{Ar})$ & Obando (1995) \\
\hline DH-31-104 & $\begin{array}{l}\text { Concentrado de } \\
\text { adularia en brecha } \\
\text { hidrotermalizada }\end{array}$ & $\begin{array}{l}\text { Prospecto aurífero Crucitas, cerca del C. } \\
\text { 152, Perforación DDH94-31 (104 m), H. } \\
\text { Pocosol, 500,650-315,900 }\end{array}$ & $15,3 \pm 0,4(\mathrm{~K} / \mathrm{Ar})$ & Obando (1995) \\
\hline \multicolumn{5}{|c|}{ MONTES DEL AGUACATE } \\
\hline CR-159 & $\begin{array}{l}\text { Meta-andesita } \\
\text { porfirítica con } \mathrm{hb}\end{array}$ & $\begin{array}{l}\text { Cerca de Atenas, H. Río Grande, 486,281- } \\
\qquad 216,565\end{array}$ & $\begin{array}{c}3,37 \pm 0,06 \\
\left({ }^{40} \mathrm{Ar} /{ }^{39} \mathrm{Ar}: \mathrm{mtz}\right)\end{array}$ & Presente trabajo \\
\hline
\end{tabular}


inferiores a $3 \mathrm{kbar}$ (menos de $10 \mathrm{~km}$ ), por lo que se le suele asociar con el metamorfismo de hundimiento o de carga (Coombs, 1960, en Frey \& Robinson, 1999; Smulikowski et al., 2007). Suele estar representado en metaígneas y grauwacas por heulandita + analcima $+\mathrm{qz} \pm$ minerales de arcilla o por laumontita + albita $+\mathrm{qz} \pm$ clorita, y en las metapelitas por muscovita + clorita + albita + qz (Turner, 1968; Aubouin et al., 1975; Smulikowski et al., 2007).

Se le reconoce ampliamente en la península de Nicoya (Kuypers, 1979; Levi, 1981; Beccaluva et al., 1999) y en el terreno de Osa en donde el mélange debió de estar sepultado entre 4 y $8 \mathrm{~km}$ con temperaturas mínimas de $150-200{ }^{\circ} \mathrm{C}$ (Vannucchi et al., 2006; Buchs et al., 2009), o en Quepos (analcima + esmectita \pm plag \pm natrolita). En Nicoya es probable que este metamorfismo sea del finicretácico con base en el evento térmico que afectó a los basaltos (metabasaltos datados), mientras que en Osa y Quepos puede ser del final del Paleoceno, puesto que no se le observa en las rocas sedimentarias sobreyacentes.

Facies de subesquistos verdes: Corresponde con un metamorfismo débil con una temperatura de 100 a $300{ }^{\circ} \mathrm{C}$, pero una presión entre 3 y $6 \mathrm{kbar}$ en correspondencia con $10-20 \mathrm{~km}$ de profundidad. Se le reconoce en metabasitas y grauwacas por la presencia de prehnita/pumpelleyita, pumpelleyita/actinolita y prehnita/actinolita, además de clorita + epidota + cuarzo + albita, etc., y en las ultramáficas por minerales del grupo de la serpentinita, normalmente crisotilo-lizardita (Turner, 1968; Aubouin et al., 1975; Smulikowski et al., 2007).

Estas facies se reconoce regionalmente en las serpentinitas de península Santa Elena y Tiricias por el río San Juan, localmente en la costa oeste de la península de Santa Elena, en donde las doleritas poseen prehnita + zeolitas (Tournon \& Azéma, 1980; Tournon, 1984; Tournon \& Alvarado, 1997; Gazel et al., 2006), península de Nicoya (Kuypers, 1979; Levi, 1981; Beccaluva et al., 1999), quizás en el bloque de Herradura (Rodríguez et al., 1996) y en la parte interna de la península de Osa (Buchs et al., 2009) y punta Burica. Es probable que sus edades sean del Cretácico Superior al Paleoceno Inferior, con base en la edad de las rocas ígneas afectadas y de las rocas sobreyacentes sin metamorfismo.

Facies de esquistos verdes: Corresponde con un metamorfismo moderado con límites entre 280 y $480{ }^{\circ} \mathrm{C}$ y presiones de $1-8 \mathrm{kbar}$, es decir, entre 3,3 y $26,4 \mathrm{~km}$, y caracterizado en metabasitas y metagrauwacas por epidota + albita + cloritas + actinolita, aunque puede contener pumpelleyita, carbonatos así como esfena y cuarzo (Turner, 1968; Coleman, 1977; Frey \& Robinson, 1999; Smulikowski et al., 2007).

En los casos reportados en Costa Rica, se caracteriza por la presencia de epidota + cloritas \pm albita \pm calcita \pm cuarzo y su presencia se ha reportado en el extremo sur de la península de Nicoya (Levi, 1981), pero también en gabros, ferrogabros, dioritas y ferrodioritas de la parte central de la península de Nicoya (Beccaluva et al., 1999), en la costa oeste de la península de Santa Elena, en donde doleritas y gabros pegmatíticos poseen cloritas + epidota (zoisita) + actinolita + albita, y rodingitas con zoisita + glosularia + clorita (Tournon, 1984; Beccaluva et al., 1999; Gazel et al., 2006), estas últimas como producto de un metamorfismo del fondo oceánico. En la península de Osa, se reportan metabasitas, mármoles y en general metapelitas (Berrangé \& Thorpe, 1988; Vannucchi et al., 2006; Buchs et al., 2009); los metabasaltos en almohadilla de la desembocadura del río Sierpe, reportan en los analisis difractométricos, cuarzo + epidota + actinolita \pm laumontita \pm albita \pm clinocloro \pm magnetita.

El inicio del vulcanismo andesítico, relacionado con el establecimiento de una nueva zona de subducción, dio inicio en el Campaniano (Kuypers, 1979). Por ello, un evento termal pudo presentarse entre 71 y $50 \mathrm{Ma}$, lo cual podría explicar las edades anómalamente jóvenes de los basaltos del Complejo de Nicoya (Cuadro 38), producto de pérdida de argón en los minerales ígneos y/o crecimiento de secundarios (arcillas, 
sericita, carbonatos, cloritas, epidotas, cuarzo, zeolitas y raramente biotita) (Appel, 1990; Appel et al., 1994).

Facies de anfibolitas: Corresponde con un metamorfismo local o regional, de temperatura moderada a alta entre unos 480 y $780{ }^{\circ} \mathrm{C}$ y presión moderada entre 2 y 12 kbar o 6,6 - 40 km (Turner, 1968; Smulikowski et al., 2007).

En Costa Rica, las ortoanfibolitas y anfibolitas gneísicas de Santa Elena (plag $\mathrm{Ca}+\mathrm{hb}+\mathrm{mt}$, plag $\mathrm{Ca}+\mathrm{hb}+\mathrm{mt}+$ diópsido \pm titanita), se presentan dentro de las peridotitas y serpentinitas con cierta o poca esquistosidad. Provienen más bien de un metasomatismo cálcico de alta temperatura (metamorfismo del fondo oceánico) en donde intruyeron doleritas y gabros a lo largo de las zonas de cizalla. Por ello, son clasificadas como la facies de anfibolita con hornblenda y plagioclasa cálcica, que aportan edades para los eventos metasomáticos (Martens et al., 2007; Tournon \& Bellon, 2009), posiblemente en algún momento entre 84,3 y 76,5 Ma (Cuadro 38), edad de las rocas metamorfizadas y restringidas por las rocas sobreyacentes. Cantos aislados de anfibolitas foliadas fueron hallados en los ríos Madrigal (Tournon, 1984) y Claro (Krawinkel \& Seyfried, 1994) en península de Osa, donde aflora el mélange de Osa (Di Marco, 1994), pero sus afloramientos todavía permanecen desconocidos, lo mismo que su edad, aunque con base en el contexto regional, podrían ser del Cretácico.

Facies de granulitas: Corresponden con rocas de presión y temperaturas muy altas $>700$ ${ }^{\circ} \mathrm{C}$ pero presiones muy variadas $(2-14 \mathrm{kbar})$ en correspondencia con metamorfismo de alto grado (Smulikowski et al., 2007).

En las tefras del volcán Arenal se reportaron bloques de posibles gneisses, pero principalmente algunas granulitas básicas con espinelas, clasificándose como del tipo pyriclasita espinelífera, con una presión de equilibrio a 5 kbar (Sachs \& Alvarado, 1993), es decir unos $16,5 \mathrm{~km}$, justo en la parte media-superior de corteza costarricense en ese punto. En el volcán Poás, xenocristales (anortita + opx + cpx con bordes de salitas) con relaciones de isótopo de estroncio diferentes con respecto a las lavas huésped, fueron igualmente interpretados como restos de metagabros de la facies de granulitas (Cigolini et al., 1991) y quizás de igual modo ocurre en el Irazú (Alvarado, 1993). Posiblemente son producto de un metamorfismo de raíz del arco volcánico, relacionado con la acreción magmática en profundidad del frente volcánico (A. García, com. escrita, 2011).

\section{Metamorfismo de contacto}

Cornubianitas: Las cornubianitas son producto de un termometamorfismo de contacto muy extendido como aureolas alrededor de los cuerpos intrusivos, debido a la transmisión térmica a las rocas caja, por lo que se desarrolla a temperaturas entre 250 y $800{ }^{\circ} \mathrm{C}$ y presiones normalmente inferiores a $2 \mathrm{kbar}(\leq 6,6 \mathrm{~km}$ de profundidad), similares a las del hidrotermalismo, y produce corneanas o cornubianitas (Smulikowski et al., 2007). El tiempo de duración de la elevación de la temperatura varía en función del grosor del cuerpo intrusivo variando entre 3 días $(1 \mathrm{~m})$, un año $(10 \mathrm{~m})$, un siglo $(100 \mathrm{~m})$ hasta 10000 años (1 $\mathrm{km}$ ), etc. (Aubouin et al., 1975).

Muchos trabajos han reportado rocas de metamorfismo de contacto en Costa Rica (Gabb, 1874; Kussmaul, 1987; Rivier, 1979; Obando, 1983, 1985; Barrantes, 1991; Tournon \& Alvarado, 1997, entre muchos otros).

Dentro de los estudios de detalle, existen claros indicios de metamorfismo de contacto generado por la intrusión de basaltos hasta gabros en las radiolaritas del Complejo de Nicoya y en menor grados en calizas silíceas, fenómeno que debió de ocurrir en cuatro fases principales: 139 - $133 \mathrm{Ma}$, 119 - 110 Ma, 95 - 88 Ma y 85 - 83 Ma (Denyer \& Baumgartner, 2006; Denyer \& Gazel, 2009; presente trabajo). Varían desde paragénesis de baja temperatura, inferior a $200{ }^{\circ} \mathrm{C}$ (illita-esmectita, clinoptilolita-zeolita, barita, dentro de ellas heulandita), de baja a media temperatura, quizás alta (piemontita, granate, diópsido), y de alta temperatura (escapolita) cerca de los contactos ígneos (Gursky \& Gurshy, 1989; Halbach et al., 1992).

Rivier (1979) y Obando $(1983,1985)$ reportan para las cornubianitas de Escazú, minerales tales como calcita, cuarzo criptocristalino, epidota (zoisita), actinolita y localmente cordierita, y al contacto 
con el intrusivo, hedenbergita y diópsido. Valverde (1989) describe las cornubianitas aflorantes en los alrededores del túnel de Pejibaye, relacionadas con el intrusivo de Tapantí. Presentan epidota, clorita, sericita, biotita, prehnita, cuarzo, carbonatos y biotita secundaria. Barrantes (1991) igualmente describe las cornubianitas de Monterrey, relacionadas con el stock en forma de manto de Candelaria. Poseen textura porfiroblástica, poikiloblástica, blastofídica, granoblástica y xenoblástica. En algunas cornubianitas de Talamanca se ha observado asociaciones de albita-actinolita (Levi, 1981), granate y cordierita (Kussmaul, com. verbal, 1981, 2010), así como metasomatismo cálcico rico en epidota, llegando a producir epidotitas (Weyl, 1957; Kussmaul, 1987; Valverde, 1986). Otro ejemplo de metasomatismo, relacionado con las intrusiones ácidas, es la turmalinización descrita en el cerro de la Muerte (Kussmaul, 1987), generando turmalinitas.

Otro de los estudios detallados se llevó a cabo en los alrededores del intrusivo de Guacimal (cordillera de Tilarán), donde se han observado aureolas de cornubianitas en las lavas con minerales metamórficos tales como epidota (clinozoisita), clinopiroxeno (diópsido), anfíbol (actinolita), prehnita, smectita, clorita, feldespato potásico, plagioclasa, wollastonita, granate (andradita), cuarzo, calcita y pirita, típico de un metasomatismo rico en calcio (Žáček et al., 2011).

Un caso todavía enigmático es el hallazgo en la cordillera de Talamanca (fila Bugú, cuenca del río Coen), de bloques aislados de micaesquistos con muscovita, andalucita y cuarzo. La muscovita ha dado una edad K/Ar (Cuadro 38) de 4,95 \pm 0,17 Ma (Montigny, com verb., 1992, en Tournon, 1984). Sin embargo, se desconoce si estos micaesquistos son el producto de un metamorfismo de contacto de elevada temperatura y presión baja (tipo facies de corneana anfibólica) debido a los batolitos, o si corresponden con testigos o bloques de un basamento metamórfico regional, rejuvenecido por las intrusiones (Tournon, 1984 y Tournon \& Alvarado, 1997). En tal caso, ya Gabb (1875, p. 201) habla de haber hallado un canto de pizarra con mica, en un afluente importante del río Coen. Al parecer no se trata de una mala interpretación o traducción del término (mica slate), que podría interpretarse quizás como lutitas, debido a que el mismo Gabb recalca: “..., yo encontré un único bloque de pizarra con mica, pero yo no pude trazar éste hasta su fuente.". Lo que sí es claro, es que mucho de las rocas que Gabb llamó "shale", no eran esquistos sino más bien lutitas (Denyer \& Soto, 2000). De existir relictos de un basamento metamórfico (serie andalucita-silimanita), habría que estudiar las relaciones espaciales, pero en el caso de ser producto de una intrusión, la pirofilita, por ejemplo, se puede transformar en andalucita y cuarzo a temperaturas cercanas a los 500 ${ }^{\circ} \mathrm{C}$ (Aubouin et al., 1975). Esto quedará como una tarea para generaciones futuras.

La mayoría de las rocas intrusivas ácidas neógenas cristalizaron entre 715 y $860^{\circ} \mathrm{C}$ y a una profundidad $\leq 3-5 \mathrm{~km}$ (Drummond et al., 1995; Gräfe, 1988; Gräfe et al., 2002; Ulloa \& Delgado, 2010; Žáček et al., 2011). Como producto de su intrusión, tendríamos representadas en nuestro país las tres facies de corneanas (Winkler, 1965; Smulikowski et al., 2007) en las rocas caja, ya sean sedimentarias o volcánicas: facies de albita-epidota $\left(250-450{ }^{\circ} \mathrm{C}\right)$ presentes en Talamanca, Monterrey, Tapantí, Escazú y Guacimal; facies anfibólicas (unos $300-600{ }^{\circ} \mathrm{C}$ ) en Nicoya, Talamanca, Escazú y Guacimal; así como facies piroxénicas $\left(580-700^{\circ} \mathrm{C}\right)$ en Nicoya, Escazú y Guacimal.

Pirometamorfismo (cáustico, opalítico): Corresponde con casos locales de termometamorfismo de superficie, producto de la onda térmica limitada, que se da cuando una lava o ignimbrita discurre sobre la superficie de un suelo. En nuestro país, se le suele hallar en muchas partes, generando los llamados ladrillos naturales bajo coladas de lava y en ciertos casos pequeños prismas en los suelos cocidos bajo ignimbritas.

\section{Metamorfismo en zonas de cizalla}

Mucha de la textura de las serpentinitas de Santa Elena son porfiroclásticas, en donde los cristales y fragmentos de la peridotita han sobrevivido a la granulación cataclástica, también se han reportado microgabros con deformación plástica, generando texturas flaser y blastomilonítica (Beccaluva 
et al., 1999) o textura cataclástica en punta Salsipuedes, en Osa (Tournon \& Bellon, 2009). En Quepos, los autores han observado lo que podrían corresponder con protocataclasitas (protoclastitas). Barrantes (1991), por su parte, reporta una tectonita con metamorfismo cataclástico asociada a la falla Delicias, en la hoja Caraigres.

\section{Metamorfismo de impacto}

En nuestro país no se tienen registros de metamorfismo por impacto de meteoritos. Sin embargo, en las bombas y bloques procedentes de los flujos piroclásticos históricos del Arenal, se observan impactos entre ellas que han dejado superficies pulidas con estrías, muescas y brechiación. Estudios de detalle, en otros lugares, han evidenciado que son producto de impactos cataclásticos, presentado las superficies estriadas, vidrios seudotaquilíticos, producto de una fusión instantánea (p.ej., Schwarzkoft et al., 2001). Algunos deslizamiento de gran velocidad y ricos en bloques, como el de Piedras de Fuego, por Ánimas de Turrialba, también presentan este tipo de estructuras.

\section{Síntesis del Metamorfismo}

En resumen, las facies metamórficas regionales suelen acompañar las fases de plegamiento u orogénesis, mientras que las locales (corneanas y pirometamorfismo) con fases magmáticas. Se pueden resumir que ocurrieron principalmente en los siguientes periodos:

a. Cretácico Inferior (139 - 133 y $119-110$ Ma) y Cretácico Superior Temprano $(95-88$ y 85 - $83 \mathrm{Ma}$ ): Facies de corneana con anfíbol y con piroxeno en las pelagitas (posiblemente $\leq 860^{\circ} \mathrm{C}$ y $1-3 \mathrm{~km}$ de profundidad) debido a las múltiples intrusiones.

b. Santoniano-Campaniano Medio: Facies de anfibolitas (probablemente 84,3 - 76,5 Ma), presentes en la península de Santa Elena, Nicoya y Osa, originadas posiblemente entre $480-780^{\circ} \mathrm{C}$. Estas condiciones fueron seguidas por el emplazamiento tectónico con metamorfismo de cizalla, y precedidas por autometamorfismo y metamorfismo del fondo oceánico de las rocas básicas y ultrabásicas con facies de zeolitas, de subesquistos verdes y en menor grado de esquistos verdes, posiblemente entre 150 y unos $350^{\circ} \mathrm{C}$. Dado que el metamorfismo suele ser bajo, las profundidades posiblemente fueron someras o a lo sumo unos 10 $\mathrm{km}$ de profundidad.

c. Maastrichtiano-Eoceno Medio: Facies de zeolitas hasta esquistos verdes, relacionadas con el establecimiento de un arco volcánico, relacionado con la zona de subducción -y su anomalía térmica- y los emplazamientos tectónicos de complejos ígneos básicos y mélanges en un margen convergente con metamorfismo de cizalla, presentes en Nicoya, Herradura, Quepos y Osa, con temperaturas posiblemente entre 150 y unos 350 ${ }^{\circ} \mathrm{C}$ y profundidades variables pero posiblemente inferiores a $10 \mathrm{~km}$.

d. Mioceno al Cuaternario: Facies de corneanas de albita-epidota, anfibólica y piroxénica (principalmente entre 15 y $5 \mathrm{Ma}$ ) en rocas del eje magmático con temperaturas posiblemente entre $200 \mathrm{y}$ $860^{\circ} \mathrm{C}$ y profundidades inferiores a $5 \mathrm{~km}$, mientras que para el pirometamorfismo, las temperaturas estimadas son de $700-900{ }^{\circ} \mathrm{C}$ y presión baja, en pocos casos quizás moderada. Unos pocos ejemplos, muy localizados, de metamorfismo de cizalla, cataclástico y de impacto, han sido descritos.

\section{Alteraciones hidrotermales}

El metasomatismo hidrotermal se origina en rocas que son infiltradas por fluidos calientes (hidrotermalismo: ca. 50 hasta $>500{ }^{\circ} \mathrm{C}$ ) y a profundidades inferiores a los $10 \mathrm{~km}$ (unos $3 \mathrm{kbar}$ ). Diversos tipos de alteración hidrotermal se han reportado en el territorio nacional, que constituye un tipo de metamorfismo de baja-alta temperatura pero en un sistema no cerrado y a relativa baja presión. La alteración suele variar con la distancia desde las facies proximales (silicificación y alteración potásica), seguida por la filítica/sercítica, argilítica y finalmente la propilítica (Pirajno, 1992). Muchos otros tipos de alteraciones y subdivisiones se pueden establecer (p. ej., Thompson \& Thompson, 1996), pero las principales reportadas son: 
Silicificación: Se caracteriza por una destrucción parcial a total de la textura de la roca y un reemplazamiento por cuarzo granular, tridimita, cristobalita, calcedonia y/o jaspe, acompañado de manera subordinada por sericita, pirita, hematita. Se trata de una alteración muy proximal de fuerte temperatura, con adición de sílice y lixiviación de álcalis y aluminio. La roca puede tener forma bandeada o vesicular.

Excelentes ejemplos de silicificaciones se encuentran en el cerro Pelado por Cañas y en los cerros Pelón y Mondongo por San Ramón (Alvarado, 1984; USGS-DGGMH-UCR, 1987), en donde se logra reconocer el caparazón silíceo conformado por rocas de sílice oquerosa o vesicular, presente en los relictos volcánicos silicificados, siendo la alteración de tipo epitermal de alta sulfuración. Otros ejemplos son descritos con detalle mineralógico en la cordillera de Tilarán (Mixa et al., 2011). Caso locales son descritos para Talamanca (Berrangé \& Whittaker, 1977; Valverde, 1986, entre otros), Escazú (Obando, 1983), entre otros. Vega (2000) reporta para el Miravalles posibles ejemplos de silicificación geotermal de baja sulfuración. Otros ejemplos más aislados son camino al indómito cerro Kámuk (E. Vega, com. escrita, 1996), así como el presente ambiente hiperácido de la laguna caliente del Poás y alrededores.

Alteración potásica: La asociación característica es la biotita anhedral secundaria usualmente omnipresente junto con feldespato potásico (microclina), sulfuros (calcopirita, pirita, molibdenita) con clorita subordinada y que puede estar acompañada de rutilo, magnetita, albita, sericita, cuarzo y anhidrita (Thompson \& Thompson, 1996). Suele corresponder con un evento inicial con condiciones de temperatura superiores a los $300{ }^{\circ} \mathrm{C}$ (Beane \& Titley, 1981). Está estrechamente relacionada con el emplazamiento de intrusivos portadores de mineralizaciones de cobre en los sistemas porfiríticos, y de oro en los epitermales (Gustafson \& Hunt, 1975; Sillitoe, 2000).

Ejemplos los tenemos en la cordillera de Talamanca (Kussmaul, 1987; Valverde, 1986; Ulloa \& Delgado, 2010), en las cornubianitas de Escazú (Rivier, 1979; Obando, 1983), y quizás en el prospecto minero de Conchudita (Sigarán, 2001). Picrita con clorita y biotita secundarias sin deformar (Appel, 1990), se encontraron por Pavones en punta Burica y fueron asociadas a un posible evento de esquistos verdes del Mioceno (Appel et al., 1994), aunque más bien podría corresponder con un evento de alteración hidrotermal potásica.

Alteración filítica o sericítica: Se caracteriza como su nombre lo indica por la presencia de sericita (sericitización -muscovita-illita- de todos los silicatos excepto el cuarzo), algo de clorita y cuarzo (Thompson \& Thompson, 1996).

Hidrotermalismo del tipo seritización se ha reportado en Talamanca, particularmente en el tajo Fuentes (Kussmaul, 1987), Tapantí (Valverde, 1986), en prospecto aurífero de Conchudita (Sigarán, 2001), en la cordillera de Tilarán (Mixa et al., 2011) y en el campo geotérmico de Miravalles (Milodowski et al., 1989).

Alteración argílica: Se caracteriza por la formación de minerales arcillosos en medios ácidos y a unos $100-300{ }^{\circ} \mathrm{C}$ (principalmente caolinita y montmorillonita, haloisita, halofana, etc.), además de clorita y, en menor cantidad, sericita, hematita y jarosita, entre muchos otros en función del tipo del grado de alteración y ambiente (Thompson \& Thompson, 1996).

Se le ha reportado en prospecto aurífero de Conchudita (Sigarán, 2001), en Tilarán (Mixa et al., 2011) y en las partes superficiales de la zona de alteración hidrotermal en el campo geotérmico de Miravalles (Milodowski et al., 1989; Vega, 2000), y entre Macacona y San Ramón.

Alteración propilítica: Es una alteración importante en yacimientos epitermales relacionados con andesitas orogénicas. Corresponde con la asociación mineralógica de epidota (cuanto mayor sea su presencia, particularmente clinozoisita, más cerca del centro intrusivo o subvolcánico), clorita, calcita y albita, además de cantidades subordinadas de actinolita y magnetita, así como la pirita, que se le suele encontrar muy relacionada y diseminada; otros minerales asociados y subordinados son cuarzo, adularia, montmorillonita, sericita, zeolitas, pirrotina, magnetita e ilmenita (Thompson \& Thompson, 1996). La roca generada suele llamarse propilita, aunque la misma paragénesis de minerales puede darse en lo que se denomina saussuritización de 
rocas volcánicas (sausssurita: albita + oligoclasa + epidota o zoisita \pm clorita \pm actinolita \pm ortosa \pm prehnita \pm glosularia) o por metamorfismo regional de facies de esquistos verdes. Suele ser de menor temperatura que la alteración potásica, por lo que generalmente define sus límites en la partes más externas (Sillitoe, 2000). La alteración clorítica puede ser un caso particular pero carece de epidota (Gómez-Gutiérrez \& MolanoMendoza, 2009).

En el antiguo sitio de presa Pirrís, las lavas en almohadillas y los gabros presentan prehnita + clorita + zeolitas + zoisita + cuarzo, que se encuentran como rellenos de fracturas, amígdalas como reemplazando minerales primarios. Esta paragénesis no se presenta en las rocas sedimentarias sobreyacientes, indicando que es pre-Oligocena. La forma en esquirlas de los componentes de ciertas brechas cementadas principalmente por prehnita, sugiere que son el resultado de fracturación hidráulica causada por sistemas de fluidos hidrotermales. La paragénesis prehenita + clinozoisita/zoisita + cuarzo + calcita + epidota + zeolitas + albita + pirita + cloritas sugiere que la temperatura debió de ser $\leq 300{ }^{\circ} \mathrm{C}$ y la presión posiblemente no superó los 2 - 3 kbar. Aunque complicado por varias fases de cristalización, el orden de aparición de los minerales fue: (1) grupo epidota (zoisita seguida después por clinozoisita), (2) cuarzo en vetas, (3) prehnita, y (4) cuarzo en vetas y rellenando cavidades así como cloritas (Rodríguez et al., 1996).

En algunas cornubianitas de Talamanca se ha observado metasomatismo e hidrotermalismo rico en epidota y propilítico (Weyl, 1957; Berrangé \& Whittaker, 1977; Levi, 1981; Kussmaul, 1987). Sin embargo, los mejor ejemplos de propilitización se encuentran en la cordillera de Tilarán y los montes del Aguacate (Levi, 1981; Alvarado, 1984; USGS-DGGMH-UCR, 1987; Mixa et al., 2011; Žáček et al., 2011), y en los prospectos auríferos de Conchudita (Sigarán, 2001) y Crucitas. Otros ejemplos de alteración clorítica y propilítica se pueden evidenciar en los estudios mineralógicos y petrográficos de detalle del campo geotérmico de Miravalles (Milodowski et al., 1989; Vega, 2000).

\section{Mineralizaciones}

Una de las primeras mineralizaciones corresponde con aquellas relacionadas con las cromititas podiformes en la península de Santa Elena, los nódulos de manganeso y los hallazgos locales de sulfuros de cobre tipo Chipre en las ofiolitas del Complejo de Nicoya (ver detalles en USGS-DGGMH-UCR, 1987). Las cromititas podiformes de Santa Elena, están relacionadas con la diferenciación de un magma, posiblemente boninítico, inyectado en la cuña astenosférica en una zona de subducción (Zaccarini et al., 2011).

Las mineralizaciones de oro de en las llanuras de San Carlos (Cuadro 38), parecen estar asociadas con cuerpos hipoabisales criptodómicos (De la Cruz, 1994; Sigarán, 2001). Concentrados de adularia suministran edades de 16,4 - 15,3 Ma (Obando, 1995), aunque algunas mineralizaciones podrían ser inclusive de unos $22 \mathrm{Ma}$ (Sigarán, 2001). Por su parte, las mineralizaciones de cobre (porfídico y nativo) así como las vetas polimetálicas $(\mathrm{Cu}, \mathrm{Pb}, \mathrm{Zn})$, tanto en Talamanca como en sus estribaciones, parecen estar asociado con las rocas volcánicas antiguas (Fm. La Cruz) o volcano-sedimentarias (p.ej., Fm. Pacacua), por lo que podría pensarse en un asocio con los intrusivos antiguos ácidos de Talamanca o, más probablemente, con el mismo magmatismo que dio origen a dichas formaciones. Por ello, serían contemporáneas con los yacimientos epitermales de San Carlos. Así, los yacimientos auríferos de San Carlos, representan los niveles metalo-estructurales más superiores de los complejos epitermales mineralizados, mientras que las mineralizaciones cupríferas (cobre porfídico y nativo) y polimetálicas, corresponderían con niveles epitermales más profundos, expuestos por la erosión. En las llanuras de San Carlos, el nivel estructural de erosión es relativamente poco (quizás $1-2 \mathrm{~km}$ como máximo), influenciado por una relativa subsidencia del graben de Nicaragua, mientras que en Talamanca, el nivel estructural de erosión es más intenso, exponiendo las raíces del magmatismo Oligo-Mioceno, producto del acortamiento y levantamiento cortical, al interactuar la microplaca 
de Panamá con la zona de subducción, particularmente en su dominio de montes submarinos del Coco. Se puede estimar una erosión de al menos $2-3 \mathrm{~km}$.

En Tilarán, Schuls et al. (1987) describen numerosos cuerpos subvolcánicos (muchos de ellos, sin embargo, confundidos con silicificaciones) de composición riolítica, los cuales relacionan con las mineralizaciones $(\mathrm{Au}+\mathrm{Ag} \pm \mathrm{Pb} \pm \mathrm{Cu} \pm \mathrm{Zn})$ en la Fm. Grifo Alto (ver estudio de detalle en Mixa et al., 2011). La edad de las riolitas es de 7,3 - 6,5 Ma (presente trabajo) o 4,41 Ma, pero las mineralizaciones nunca se presentan en la Fm. Monteverde (Kycl et al., 2010; Žaček et al., 2011; Mixa et al., 2011), datada entre 2,1 y 1,1 Ma (Gillot et al., 1994; Carr et al., 2007; presente trabajo). La edad de 7,3 - 6,5 Ma parece ser muy antigua dado que rocas de diversa edad (predominantemente entre 8,7 y 3,3 Ma) en los Montes del Aguacate y Tilarán parecen mineralizadas, por ello podría pensarse más bien que la mineralización es producto del magmatismo de Grifo Alto en sus fases hidrotermales, principalmente entre 6,0 y 3,3 Ma, particularmente cerca de centro de emisión volcánica (calderas, estratovolcanes, maares). Similar cronología de alteración hidrotermal, pero sin mineralizaciones auríferas, se suelen encontrar asociadas con los intrusivos de Río Macho y Escazú (5,9 - 4,0 Ma).

Un yacimiento muy controversial hasta el presente es la proveniencia del oro de placer en la península de Osa, Golfito y punta Burica. Aunque varios trabajos han propuesto que proviene de la denudación de posibles yacimientos epitermales en Talamanca (p.ej., Anónimo, 1978; Shatwell, 2004), claramente al ser las molasas o paleo-aluviones del Valle del General y de Baja Talamanca (Fms. Valle del General y Suretka) estériles en este elemento, no puede proceder el oro del pie de monte de Talamanca ni de la propia cordillera. Lew (1983) y Corrigan (1986) igualmente piensan a la hora de estudiar la petrografía de las areniscas que contienen el oro, que provienen de la erosión de Talamanca, dado que poseen una cierta cantidad de cuarzo y feldespatos, que a criterio de ellos le hacen acreedor de esta fuente plutónica. Sin embargo, los conglomerados cargados de clastos ígneos presentes en Osa, son fundamente de carácter básico (gabros y basaltos) o a lo sumo con calizas y radiolaritas, pero los granitoides son en extremo raros, como sería de esperarse de una erosión desde Talamanca, hecho que sí se observa en cambio en las molasas provenientes de esta cordillera (Fms. Valle del General y Suretka). En efecto, para otros autores, los sedimentos recientes (Plioceno-Cuaternario) son exclusivamente producto de la erosión del basamento ígneo o del mélange (Berrangé, 1992; Berrangé \& Thorpe, 1988; Kriz, 1990; Vannucchi et al., 2006; presente trabajo). Los análisis de minerales pesados de los sedimentos asociados con el placer sugieren más bien una fuente cercana y no apoya un origen desde una fuente magmática ácida, ya sea granitoide o riolítica (Berrangé, 1992). Aunque Kriz (1990) critica la posibilidad de una fuente cercana con base en el ejemplo del yacimiento de placer de Tipuani en Bolivia, donde el oro fue transportado desde su "posible" (sic) fuente unos $76 \mathrm{~km}$, este autor concuerda en el oro de osa proviene de una fuente siempre circunscrita a la provincia geológica de Osa-Golfito-Burica. Adicionalmente, si nos basamos en el trabajo de Townley et al. (2003), la morfológica y composición de las pepitas sugiere fuentes variables entre más de un kilómetro hasta unos pocos cientos o decenas de metros.

La edad de los placeres auríferos es claramente del Plioceno (predominantemente Plioceno Superior basal) al Cuaternario (Berrangé, 1992; Lew, 1983), pero la edad de las secreciones cuarzo-auríferas no está aún establecida, aunque para Berrangé (1992) debe de corresponder con alguno de los tres eventos magmáticos principales presentes en Osa entre el Campaniano Medio y el Eoceno Medio; Kriz (1990) similarmente piensa que debió de ocurrir entre el Paleoceno Temprano y el Eoceno Medio. Según Buchs et al. (2010) sobre las rocas ofiolíticas antiguas se estableció un arco primitivo de islas durante el Campaniano Tardío-Maastrichtiano. De comprobarse, parte de los fluidos de esta zona de subducción podrían provenir de dicho vulcanismo. Otra posibilidad, es que a la acreción de los diferentes complejos ofiolíticos, quizás desde el Maastrichtiano, pero principalmente desde el Oligoceno al Mioceno, 
fuese la responsable de la subida de fluidos mineralizados. Así, se podría tratar-tesis por demostrar- de lo que se denomina oro orogénico (p.ej., Pettke \& Diamond, 1997), en donde la mineralización aurífera en forma de vetas de cuarzo puede perfectamente estar relacionada con los fluidos hidrotermales de estos sistemas acrecionales en una zona orogénica activa, con predominancia de facies de esquistos verdes. Y por qué no, que se deba a un único evento debido a la concatenación del magmatismo de arco con la acreción, posiblemente durante el Paleoceno Inferior, hipótesis escogida en el presente trabajo.

Por otro lado, queda por investigar si gran parte de las pepitas poseen un crecimiento secundario por acción bacteriana (p.ej., ver Southam et al., 2009, y referencias allí citadas), por lo que suelen ser de tamaños variados, incluso gigantes (hasta 7,7 kg, Berrangé, 1987, 1992), aspecto más difícil de explicar si uno ve que las vetas son escasamente centimétricas, a menos que se aduzca que ya se erosionaron las bonanzas. Sin embargo, las tendencias recientes no apoyan lo anterior. Tal y como se mencionó, si tomamos la morfología y mineralogía de las pepitas (sensu Berrangé, 1987, 1992) y la comparamos con el trabajo de Townley et al. (2003), tenemos que nos indicaría una fuente muy cercana. Este hecho apoyaría más bien que la forma original de las pepitas fue alterada y engrosada por actividad bacteriana.

En síntesis, la propuesta más plausible y geológicamente apropiada es la de Berrangé (1987, 1992) y Berrangé \& Thorpe (1988), incluso apoyada por Kriz (1990), de que el oro proviene de vetas de cuarzo epitermal (unos $200{ }^{\circ} \mathrm{C}$ ) con cierto enriquecimiento aurífero de hasta $510 \mathrm{ppb}$, hecho que debió de ocurrir en algún momento entre el Maastrichtiano y el Eoceno (posiblemente Paleoceno Inferior). Debido a la erosión y actividad bactariana, se tradujo en un yacimientos de placer.

Con base en todo lo anterior podemos concluir 6 fases de mineralizaciones metálicas importantes:

A. Mineralizaciones Mesozoicas:

a. Cromita podiforme de Santa Elena: ¿Jurásico?

b. Sulfuros masivos (yacimientos tipo Chipre) y mineralizaciones de manganeso hidrotermal y sedimentario (nódulos) en Nicoya: Paleozoico, principalmente del Bajociano al Albiano (Halbach et al., 1992; Denyer \& Baumgartner, 2006): 170 - $95 \mathrm{Ma}$.

B. Mineralizaciones Cenozoicas:

a. Mineralización aurífera (tipo orogénica?) en Golfito-Osa-Burica: ¿64? Ma.

b. Mineralización aurífera epitermal, cuprífera y polimetálica: 22,9 - 22,2 Ma.

c. Mineralización aurífera epitermal, cuprífera y polimetálica: 16,4 - 15,3 Ma.

d. Mineralización epitermal (Au-Ag-Pb) de Tilarán-Aguacate: 5,6 - 3,3 Ma.

e. Oro y magnetita de placer: 3,6 - 0 Ma.

\section{DISCUSIÓN}

Hoy día existen un buen número de estudios petrológicos y geocronológicos recientes en los países vecinos de Nicaragua (Ehrenborg, 1996; Elming, 1998; Plank et al., 2002; Carr et al., 2007; Saginor et al., 2011a) y de Panamá (de Boer et al., 1988; Wegner et al., 2011) o compartiendo regiones Costa Rica-Panamá (Defant et al., 1992; Drummond et al., 1995; de Boer et al., 1995; Hoernle et al., 2002, 2004) y Costa Rica-Nicaragua (Carr et al., 2007; Hoernle et al., 2008; Gazel et al., 2009; Lindsay, 2009). Sin embargo, falta control y mapeo estratigráfico. Las comparaciones que acá se realizan, son relativamente generales. No obstante, como fue planteado previamente por Alvarado et al. (2007), al quitar los nombres locales de unidades, se puede establecer una comparación y similitudes relativamente buenas entre los países de América Central.

\section{Las ofiolitas en Costa Rica y Panamá, su acreción y el inicio del magmatismo de arco en América Central Austral (200- 20 Ma)}

La historia se inicia en el Jurásico Inferior con la sedimentación de radiolaritas pelágicas en el paleopacífico en conexión con el Tethys (Denyer \& Baumgartner, 2006). Un complejo ígneo-sedimentario acrecionado o mélange, el de Santa Rosa, se forma al margen del bloque más 
austral de Chortis, englobando clastos del Jurásico Medio hasta el Cenomaniano, con la intrusión de sills alcalinos dentro de las radiolaritas, posiblemente alrededor de 159 - $150 \mathrm{Ma}$, con basaltos y traquitas más jóvenes entre 127 y unos $85 \mathrm{Ma}$ (Tournon \& Bellon, 2009). Las intrusiones ácidas a ultrabásicas cumuladas y estratificadas de bahía Nancite presentan edades compartidas entre el lapso de 133 y 140 Ma y una afinidad de arco de islas (Hauff et al., 2000; Tournon \& Bellon, 2009). Varias intrusiones tardías dentro de la peridotita, tales como diques doleríticos y algunas anfibolítas gneísicas, ambas de toleitas de arco a calcoalcalinos, cuya fase magmática quizás se remonta entre 101 y $93 \mathrm{Ma}$, mientras que las traquitas de Respingue aportan edades alrededor de los 86,5 Ma (Tournon \& Bellon, 2009). Cuerpos contemporáneos de picritas komatíticas $(88,4 \mathrm{Ma})$ intruidos por diques alcalinos (Alvarado et al., 1997; Sinton et al., 2009), ocurren posiblemente relacionados con el magmatismo y geotectonismo de Santa Elena (Hauff et al., 2000). Finalmente, el emplazamiento (obducción) de la peridotita de Santa Elena ocurre en algún momento entre el post-Cenomaniano y el Maastrichtiano (Tournon \& Bellon, 2009).

En otro contexto geotectónico, pero siempre en el paleo-Pacífico, se presentaron efusiones basálticas a los 139 - 133 y a los 119 - $110 \mathrm{Ma}$, con intrusiones subvolcánicas de magmas basálticos a los 92 - $88 \mathrm{Ma}$, mientras que las intrusiones gabroicas y plagiograníticas, intruyen a los $87-80$ Ma (Hoernle et al., 2004; Denyer \& Baumgartner, 2006), lo que hoy día define al Complejo de Nicoya. Esta fase final del magmatismo tiene características de intraplaca, del tipo punto Caliente de las Galápagos, conformando una amalgamación de diversos plateaus oceánicos de la Gran Provincia Ígnea del Caribe (con sus siglas CLIP: Caribbean Large Igneous Province) o incluso fases pre-CLIP desde 139 a $69 \mathrm{Ma}$ (Hoernle et al., 2004; Denyer \& Baumgartner, 2006; Geldmacher et al., 2008).

La presencia de sedimentos volcaniclásticos desde Guatemala hasta Panamá, durante el Albiano al Campaniano, han servido de base para postular que el magmatismo de arco pudo darse a lo largo de toda esa faja (Pindell et al., 2006; ver referencias adicionales en Alvarado et al., 2007 y Geldmacher et al., 2008). Sin embargo, los estudios de detalle refuerzan que, el establecimiento cuasi in situ de la zona de subducción, al menos en Costa Rica y Panamá, y quizás la parte sur de Nicaragua y su arco respectivo, ocurrió en el Campaniano Tardío en el caso de Costa Rica, cuando los sedimentos volcánicos subalcalinos suelen ser abundantes (Küypers, 1979; Denyer \& Alvarado, 2007; Buchs et al., 2010). Una situación similar se presenta en Panamá a los $71 \mathrm{Ma}$ (Campaniano terminal), es decir, posiblemente en coincidencia con el cese del vulcanismo del CLIP (Wegner et al., 2011). Los sedimentos ricos en detritos volcánicos, posiblemente de arco, del Albiano al Campaniano, mezclados con lutitas carbonosas -incluso también presentes en las Antillas-, al parecer son más bien restos de una antigua zona de subducción establecida cerca de los bloques Maya y Chortis, transportados y adosados algunos de ellos por la tectónica, en la parte austral de América Central. Más estudios son necesarios para establecer su verdadero rol y contexto geotectónico (ver Alvarado et al., 2007; Geldmacher et al., 2008). De este arco ancestral en Costa Rica, prácticamente no quedan rocas ígneas in situ -tan solo posiblemente las rocas básicas que afloran por Golfito descritas por Buchs et al. (2010)-, siendo en su mayoría solo los productos de su erosión en los sedimentos turbidíticos.

En Panamá, algunas rocas con características de arco se ubican dentro de lo que se ha agrupado de manera generalizada como perteneciente a los terrenos del CLIP, tanto en la parte central como oeste de Panamá (Soná-Azuero), como al NE del Canal de Panamá (Chagres-Bayano). Así, una segunda fase del magmatismo regional está presente en las penínsulas de Azuero y Soná, con características de arco originado entre 71 y 69 Ma. El magmatismo de arco continuó en ChagresBayano, representado por una secuencia submarina de lavas, diques y brechas con cuerpos intrusivos hipoabisales (gabros hasta granitos), originados entre 68 y $40 \mathrm{Ma}$ (mayoritariamente 68 - 60 y entre 50 - $40 \mathrm{Ma}$ ) es decir Maastrichtiano hasta Eoceno Superior Temprano. Ambos arcos, SonáAzuero y Chagres-Bayano, poseen en su mayoría contenidos pobres a ligeramente intermedios 
en $\mathrm{K}$ y son principalmente toleíticos con algunas muestras calco-alcalinas (Wegner et al., 2011). De igual modo, entre 60 y 50 Ma existe un profuso vulcanismo de arco que se extiende al menos desde Honduras hasta Nicaragua y, claramente, en Panamá. En Costa Rica, al parecer, existe un hiato en rocas volcánicas in situ de arco, estando tan solo representadas por sedimentos volcaniclásticos marinos (Alvarado et al., 2007, y referencias allí citadas).

La historia continúa en lo que hoy día se conoce como Costa Rica, pero ahora con el emplazamiento y adosamiento de montes submarinos entre el Maastrichtiano y el Eoceno Medio al margen continental activo costarricense. No obstante en Panamá se extiende hasta el Mioceno Inferior, bajo la forma de terrenos acrecionados más jóvenes, enriquecidos en elementos trazas que indican un magmatismo de islas oceánicas acrecionadas y amalgamadas entre 70 y $20 \mathrm{Ma}$ (Hauff et al., 2000; Hoernle et al., 2002, 2004; Buchs et al., 2010).

El establecimiento del arco al final del Cretácico y su continuidad durante el PaleocenoEoceno, en su mayor parte evidenciado por los sedimentos volcaniclásticos (ver Alvarado et al., 2007), debió de incrementar en el gradiente térmico de la corteza continental, lo que favoreció su cambio a un estado más frágil y dúctil, fomentando su fallamiento incluso a nivel de basamento $y$, con ello, los prismas acrecionales. Así, diferentes factores pudieron ser los responsables de la migración que se dio en los arcos centroamericanos, principalmente debido a: a) cambios en la geometría (ángulo) de la zona de subducción, b) migración de zonas de fracturas. Todos ellos se han reportado al menos en la parte austral de América Central (Bundschuh \& Alvarado, 2007).

\section{El Proto-Arco del Oligoceno al Mioceno Supe- rior (35 - 8 Ma)}

Desde que los primeros exploradores recorrieron América Central Austral, se dieron cuenta de la existencia de cordilleras volcánicas profundamente erosionadas hasta sus raíces (Sapper,
1905). Los estudios recientes nos hablan que están conformadas por coladas de lava, diques, rocas piroclásticas e intrusivos con variables grados de alteración y mineralizaciones, observándose la continuidad espacial de dicho vulcanismo a lo largo de toda América Central (Fig. 8), principalmente entre 25 y $12 \mathrm{Ma}$ (Alvarado et al., 2007).

Después de un vulcanismo basáltico y andesítico (alcalino hasta subalcalino) de fondo oceánico aflorante en algunos puntos de Talamanca (ver Tournon \& Alvarado, 1997; Tournon \& Bellon, 2009), se tiene la conformación del Proto-Arco del Oligoceno o el establecimiento del frente volcánico más antiguo. Las primeras rocas datadas corresponden con intrusiones aisladas con cierto grado de duda por su alteración o bajo contenido en $\mathrm{K}(35,6$ - 25,7 Ma). El primer vulcanismo calcoalcalino (andesitas hasta riolitas) claramente in situ y bien establecido, se tiene a los 24,3 - $21 \mathrm{Ma}$, bien desarrollado en las llanuras de San Carlos (Fm. Cureña) y más pobremente preservado en Talamanca, seguido por un episodio similar a los 18 - $11 \mathrm{Ma}$, tanto en las llanuras de San Carlos, como en Talamanca y fila Costeña. Geoquímicamente, el Proto-Arco está representado en Costa Rica por basaltos hasta riolitas pobres a ricas en $\mathrm{K}$, toleíticas hasta calcoalcalinas y sus equivalentes intrusivos (Gazel et al., 2005, 2011).

Diques andesíticos hasta diabásicos y stocks gabroicos aparecen a los 18,3 - 16,8 y 14,8 - 11,1 Ma en la fila Costeña. Los plutones en Talamanca bien desarrollados se inician a los 12,4 Ma y se extienden hasta más recientes que los $8 \mathrm{Ma}$.

En Panamá fue agrupado todo este tipo de rocas ígneas dentro del llamado arco Cordillerano, descrito por de Boer et al. (1988) y Drummond et al. (1995) con afinidad toleítica y calco-alcalina, manifestándose principalmente entre los 22 y $7 \mathrm{Ma}$, aunque existe un hiato en el vulcanismo en Panamá entre 11 y $6 \mathrm{Ma}$ (Wegner et al., 2011). Dicha brecha cronológica, en el vulcanismo, fue reportada para el sur de Costa Rica, quizás por profusa denudación de los macizos eruptivos, pero que en su lugar está substituida por la abundante presencia de rocas 
intrusivas expuestas por el abrupto levantamiento de Talamanca (MacMillan et al., 2004).

Mientras que el vulcanismo de arco en Panamá está agrupado entre 22 y $5 \mathrm{Ma}$, en Costa Rica y Nicaragua existen subdivisiones más acusadas para todo este periodo. En el caso de Nicaragua, todavía falta trabajo de mapeo para hacer coincidir la geocronología con la geoquímica y la geología. En Costa Rica existe un mejor control; un avance al respecto fue el mapa de Denyer \& Alvarado (2007).

En Nicaragua, se tiene ahora un mejor panorama geocronológico y petrológico del Grupo Coyol y Fm. Tamarindo, pero todavía falta mucho del mapeo volcánico y su sinopsis dentro de la triada mapeo-edad-petroquímica. Se logra reconocer un arco relativamente continuo desde Guatemala hasta Panamá, entre 25 y $13 \mathrm{Ma}$ (Alvarado et al., 2007), soportado incluso por trabajos más recientes (Hoernle et al., 2008; Janoušek et al., 2009; Saginor et al., 2011a). Y es justo este arco, el que aprovechó la fauna y flora para migrar de Norteamerica al extremo sur de America Central, particularmente a partir de los $12 \mathrm{Ma}$ (Woodburne, 2010).

\section{EI Paleo- (8 - 2,2 Ma) y Neo-Arco (2,1 - 0 Ma)}

En Costa Rica las rocas plutónicas intruyeron a Talamanca en forma continua al menos desde los $24 \mathrm{Ma}$ (posición del Proto-Arco) y continuaron hasta con seguridad hasta los 6 - 4 Ma en sus estribaciones, por Tapantí y Escazú (MacMillan et al., 2004; presente trabajo), caso contrario a lo ocurrido en Panamá en donde las rocas intrusivas más jóvenes que 7 Ma suelen estar ausentes (Wegner et al., 2011).

En el Mioceno Superior, existió un cambio abrupto en la orientación del arco magmático costarricense, rotando $20^{\circ}$ en sentido opuesto a las manecillas del reloj, para establecerme en Costa Rica de forma más o menos paralela al presente frente volcánico activo desde hace unos $8 \mathrm{Ma}$ (Gans et al., 2002, 2003; Alvarado et al., 2007). Tanto en Costa Rica como en Nicaragua, se nota que el arco del Mioceno Superior al presente ha sufrido una serie de migraciones, acercándose a la presente fosa mesoamericana (Alvarado et al., 2007). Las causas pueden ser variadas (p. ej. migración al oriente de la zona de fractura, hoy día conocida como de Panamá, cambio en el ángulo de la subducción, etc.), pero todavía merecen un análisis (Fig. 8).

Sin embargo, al parecer el arribo de la cordillera del Coco a la fosa mesoamericana puedo ser el disparador de una serie de procesos en cadena. Aunque existe una discusión en la que no hay acuerdo sobre si esto se inició hace unos $8 \mathrm{Ma}$, o en su defecto tan joven como menos de $1 \mathrm{Ma}$ (ver discusión en Alvarado et al., 2007, p. 376), los autores del presente trabajo están a favor de una edad aproximada de $7 \mathrm{Ma}$, basado en: a) Existe una rica paleofauna de vertebrados terrestres en la fila Costeña con afinidad norteamericana, que nos indica la existencia de tierras ya emergidas hace unos $7 \mathrm{Ma}$ (Laurito \& Valerio, 2008; Lucas \& Alvarado, 2010), b) los sedimentos Pliocenos están restringidos en la fila Costeña (Tournon \& Alvarado, 1997), c) la rápida erosión de la cordillera de Talamanca a partir de los 5 Ma (Gräfe, 1998; Gräfe et al., 2002), y d) la paulatina inhibición del vulcanismo calcoalcalino hace $5 \mathrm{Ma}$ (retardada debido al tiempo que se requiere para que la cordillera se subduzca y se manifiesten sus efectos) hasta su extinción hace 3,5 Ma, promoviéndose la aparición de magmatismo adakítico y alcalino, hace 6,5 Ma (McMillan et al., 2004; Gazel et al., 2011).

Así, se tiene que partir de los 8 Ma hasta los 2,2 Ma, se establece el Paleo-Arco (Fig. 8), representado por la Fm. Grifo Alto, las ignimbritas de Bagaces y los intrusivos de Tapantí, Escazú, la Carpintera, Desmonte y Guacimal. Este arco, favoreció el gran intercambio biótico de las Américas (Alvarado et al., 2007; Lucas \& Alvarado, 2010; Woodburne, 2010, y referencias allí citadas).

Después se estableció el Neo-Arco, iniciando por las lavas de Fm. Monteverde (2,1 - 1,1 Ma) y finalmente, los volcanes activos (estratovolcanes y escudos andesíticos), además de los abanicos ignimbríticos y de flujos de escombros (depósitos de debris avalanches y debris flows) del Pleistoceno Medio y Superior. Geoquímicamente, el Paleo-Arco y el Neo-Arco están representados por basaltos hasta riolitas pobres a ricas en $\mathrm{K}$, 


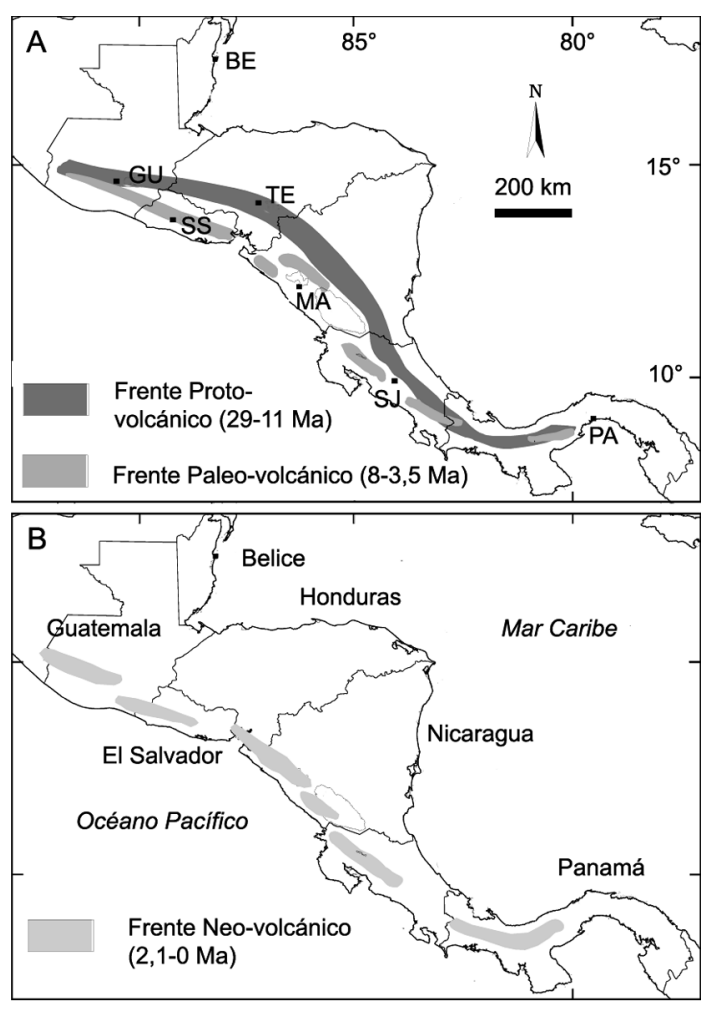

Fig. 8: Los diferentes frentes volcánicos y su migración. Las capitales son: Gu: Guatemala, SS: San Salvador, TE: Tegucigalpa, MA: Managua, SJ: San José, PA: Panamá.

en su mayoría calco-alcalinas, siendo las toleitas de arco más abundantes en rocas más antiguas y subordinadas en las más recientes (Tournon, 1984; Kussmaul et al., 1994). Dado que las lavas de Monteverde no están enriquecidas en oro y su petrología es similar a los estratovolcanes, siendo en muchos casos indistinguibles en el campo, aunado a su edad Pleistocena Inferior y coexistencia espacial cercana con la cordillera de Guanacaste y la parte occidental de la cordillera Central, se les agrupó como parte del Neo-Arco.

Rocas cronológicamente similares a las Fms. Grifo Alto y Monteverde se han encontrado en Nicaragua (Saginor et al., 2011a), pero queda para estudios posteriores una comparación entre el quimismo de éstas y otras unidades. De igual modo resulta enigmático que en la cordillera de
Tilarán se tenga un vulcanismo del Pleistoceno Inferior (Fm. Monteverde), pero que no existan rocas más jóvenes, solamente solventado por la existencia de los domos Los Perdidos y de los estratovolcanes Chato y Arenal. ¿Habrá disminuido el ángulo de la zona de subducción en el último millón de años?.

El arco volcánico activo en Costa Rica (Fig. 8 ), aunque posee ciertas diferencias geoquímicas, morfológicas, volumétricas y en grado de actividad con respecto al de Nicaragua, en términos generales se origina de modo similar hace $0,6 \mathrm{Ma}$ (Alvarado et al., 1992; Carr et al., 2007).

Claramente la brecha de unos $175 \mathrm{~km}$ en el vulcanismo de tipo estratovolcán entre el IrazúTurrialba (Costa Rica) y el Barú (Panamá), se debe al arribo de la cordillera del Coco y el acortamiento cortical del bloque de Panamá contra la zona de subducción, acelerando la orogénesis que formó la cordillera de Talamanca y la fila Costeña.

Como se dijo, todo ello desfavoreció la generación del vulcanismo calcoalcalino y, en su lugar, promovió la fusión de la placa subducida, generando magmas adakíticos que fueron subordinados en Costa Rica hasta su extinción (McMillan et al., 2004; Alvarado et al., 2007; Gazel et al., 2011). En cambio, las adakitas son abundantes en Panamá y aún en sus estratovolcanes dormidos (de Boer et al., 1988; Drummond et al., 1995; Wegner et al., 2011). En efecto, desde los inicios de las décadas de los noventas, se reconocieron rocas geoquímicamente anómalas del Plioceno-Pleistoceno, tanto en Talamanca, punta Burica del lado panameño (como bloques dentro del depósito de debris flows/debris avalanches, Morell et al., 2011) como al oeste de Panamá. Las adakitas corresponde con un término petroquímico más no petrográfico, al referirse a andesitas hasta dacitas normalmente con anfíbol, minoritariamente basaltos y andesitas basálticas, poseen fuertes pendientes en los patrones normalizados a condritos de los elementos REE desde el $\mathrm{Sm}$ al $\mathrm{Yb}$, razones $\mathrm{Sm} / \mathrm{Yb}$ de 2,47 - 10,3, alto $\mathrm{Sr} / \mathrm{Y}$, alto $\mathrm{Pb}$ y $\mathrm{Sr}$; y bajo $\mathrm{Y}$, Lu e $\mathrm{Yb}$, lo cual es diagnóstico de una fuente magmática residual con granate y originados por la fusión de la placa subducida. 
Las adakitas en Panamá suelen estar asociadas con estratovolcanes y domos en diferentes grados de erosión, incluyendo los volcanes Barú y La Yeguada, activos durante el Holoceno, mientras que en Costa Rica están presentes como domos extintos y sedimentos fragmentarios de diversa índole, incluyendo avalanchas de escombros volcánicos y aluviones (Drummond et al., 1995; Abratis \& Wörner, 1991; MacMillan et al., 2004, Hoernle et al., 2008; Wegner et al., 2011, Gazel et al., 2011). Sin embargo, las andesitas basálticas y basaltos de Paso Real poseen una tendencia adakítica, por lo que la generación de adakitas debió de generarse desde hace por lo menos de 6,5 Ma (Gazel et al., 2009, 2011).

\section{Magmatismo alcalino continental (6,49 - 0 Ma)}

El magmatismo alcalino, mayoritariamente tras-arco, ocurre en Costa Rica en cinco fases principales: 6,49 - 5,82 Ma, 5,3 - 4,4 Ma, 3,51 - 3,2 Ma, 2,0 - 1,2 Ma y 0,6 - 0 Ma, muy posiblemente relacionadas con un régimen extensivo. Algunos cuerpos se presentan en posición anómala, tales como las rocas medianamente alcalinas de $\mathrm{La}$ Garita (6,47 - 5,52 Ma), pero que se pueden agrupar dentro de los rangos previamente indicados.

Las rocas alcalinas del Cuaternario poseen una característica geoquímica mayoritariamente controlada por las descompresión del manto y su ascenso, en parte mezclada por fluidos migratorios provenientes de la placa subduccida (Hoernle et al., 2008; Gazel et al., 2011). Las rocas, que están más cerca de la proyección de la placa subduccida, son medianamente alcalinas (sin cuarzo ni feldespatoides normativos) y con más influencia de los fluidos relacionados con la subducción, que aquellas más alejadas, las cuales a su vez suelen tener feldespatoides normativos y modales.

Aspectos interesantes, aún por investigar, son las rocas alcalinas pliocenas que se encuentran en Alta y Baja Talamanca, algunas incluso bajo los productos calco-alcalinos del Plioceno Superior o del volcán Turrialba, dado que probablemente conformaron con una geometría diferente de la placa subducida durante el Plioceno, que originó a su vez el vulcanismo de Grifo Alto.

En Nicaragua, las rocas alcalinas (traquibasaltos) se presentan en Pearl Lagoon, Kukra Hill y volcán Azul con edades K/Ar entre 3,24 y 1,41 $\mathrm{Ma}$, que incluso resultan más jóvenes con el método ${ }^{40} \mathrm{Ar} r{ }^{39} \mathrm{Ar}$ entre 0,74 y $0 \mathrm{Ma}$ (Gazel et al., 2011). Algunos pequeños conos se presentan en el lado Caribe de Panamá cerca de Colombia, pero se desconoce si son alcalinos (Alvarado et al., 2007).

\section{Volcanismo en la placa del Coco (30 - 0,6 Ma)}

En la placa del Coco se presentan más de un centenar de volcanes submarinos, algunos aislados, otros en como volcanes gemelos, en grupos o conformando la cordillera volcánica submarina del Coco. La cordillera del Coco es una cadena de montes y volcanes submarinos que se extiende por espacio de $780 \mathrm{~km}$ en frente de nuestras costas, constituyendo la cordillera centroamericana más extensa; la isla del Coco es el único afloramiento subaéreo.

Las dataciones radiométricas publicadas de la cordillera del Coco se distribuyen en 9 grupos de edades: a) Oligoceno Inferior (30 Ma), b) Mioceno Inferior (19 Ma), c) Mioceno MedioMioceno Inferior Temprano (14,46 - 10,0 Ma), d) Mioceno Superior Temprano (8,8 - 8,3 Ma), e) Mioceno Superior Tardío-Plioceno Inferior Temprano (5,7 - 5,2), f) Plioceno (4,2 - 3,4 Ma), g) Pleistoceno Inferior $(2,2$ - 1,9 y 1,5 Ma) y h) Pleistoceno Medio Temprano (0,6 Ma), que representan diferentes pulsos magmáticos en diferentes partes de la placa (Dalrymple \& Cox, 1968; Bellon et al., 1983; Werner et al., 2003; O'Connor et al., 2007). No pbstante, tomados como un todo, casi representan un vulcanismo continuo en el tiempo -no en el espacio- para los últimos $15 \mathrm{Ma}$.

Las rocas en la cordillera del Coco son basaltos y andesitas basálticas toleíticas, mientras que las coladas de lava y rocas piroclásticas de la isla del Coco y de los montes submarinos que 
se extiende hasta nuestras costas (= cordillera del Coco), poseen un carácter petroquímico principalmente alcalino: hawaitas, traquiandesitas basálticas hasta traquitas (Werner et al., 2003; Harpp et al., 2005).

Las dataciones radiométricas de la isla del Coco (2,2 - 1,5 Ma) así como las de los volcanes submarinos circundantes (1,3 - 0,6 Ma, por ejemplo), aportan edades anómalamente jóvenes (Dalrymple \& Cox, 1968; Bellon et al., 1983; O'Connor et al., 2007). Lo anterior, sugiere, que la isla es producto de un vulcanismo local (Pleistoceno Inferior), no relacionado directa y cronológicamente con el vulcanismo del punto caliente de Galápagos, por lo que originalmente se propuso una "línea caliente' (Alvarado, 1984), aunque sus orígenes aún están en discusión (ver Werner et al., 2003; Harpp et al., 2005; O'Connor et al., 2007).

\section{RECOMENDACIONES}

Todavía existen algunas brechas en los muestreos geocronológicos, tales como en gran parte de la península de Santa Elena, promontorio de Herradura, Osa y punta Burica. Tampoco existen edades publicadas de las vulcanitas (tobitas y brechas) Cretácicas de las formaciones Loma Chumico y Berrugate. En el núcleo de Talamanca falta por demostrar si existen rocas intrusivas oligocenas y corroborar si algunas de las plataformas de vulcanitas en Talamanca son relativamente jóvenes (Plioceno?), o establecer si la Fm. Doán es pliocena, al igual que las brechas del río Pey (ver Tournon \& Alvarado, 1997; Alvarado \& Pérez, 1998). De igual modo, todavía se requiere demostrar si existe una brecha real en las edades entre 16,8 y 14,8 Ma o se debe a la falta de muestras en la Fm. Puerto Nuevo. Similar hiato se presenta en la Fm. Bagaces entre los 8 y los casi 5 Ma. Varias ignimbritas en la cordillera de Tilarán y los Montes del Aguacate aún carecen de dataciones. Estos son trabajos idóneos para generaciones venideras.
Una comparación petrológica entre las lavas de los Proto-, Paleo- y Neo-Arcos es fundamental para poder establecer las semejanzas y diferencias, y poder así establecer una mejor correlación estratigráfica y evolución petrogenética, al menos entre Nicaragua, Costa Rica y Panamá para los últimos 30 Ma.

También se tiene un faltante en dataciones para establecer mejor la edad de las mineralizaciones, hidrotermalismo y del metamorfismo.

Referente a los yacimientos de oro de placer de Osa-Golfito-Burica, queda por demostrar en qué momento ocurrió la mineralización y con qué evento tectono-magmático se asocia. Tambien hay que estudiar si la actividad bacteriana modificó el tamaño de las pepitas. Las dataciones de $\mathrm{Rh} / \mathrm{Os}$ pueden ayudar en ese sentido, e incluso a diferenciar de si se trata de un oro epitermal u orogénico.

Nuevas edades serán aportadas con seguridad en los próximos años, complementando o reforzando las conclusiones acá aportadas, o incluso descubriéndose nuevas fases magmáticas, extendiéndolas o acortándolas en el tiempo, $\mathrm{y}$ afinando las edades del hidrotermalismo y del metamorfismo.

\section{AGRADECIMIENTOS}

Resulta difícil establecer una lista de colaboradores de este proyecto que se inició a finales de 1998. Su financiamiento estuvo sustentado por el proyecto NSF-EAR 9975339 y por el Instituto Costarricense de Electricidad, a quien se les agradece profundamente por su aporte económico y logístico, respectivamente. El presente trabajo es una contribución al proyecto Fortalecimiento de la investigación en Estratigrafía y Tectónica, 830B0-242, del Centro de Investigaciones Geológicas de la Universidad de Costa Rica.

Debemos agradecer las colaboraciones, ya sea en el laboratorio y/o en el campo o por suministrar información, a Ian McMillan, Andy Calvert, Esteban Gazel, Percy Denyer, Pablo Ruiz, Kaj Hoernle, Reinhard Werner, Ken 
Heydolph, Thomas Vogel, David Szymanski, Wendy Pérez, Jean Tournon, Jeffrey S. Marshall, Carl Nelson, Christopher W. Sinton, Vladimír Žaček, Sofía Huanpaya, Andrés Ulloa, Spencer G. Lucas, Folkmar Hauff, Gerardo Soto, Alfredo Mainieri, Alberto Vargas, Carolina Sigarán, Rodrigo Vásquez, Eduardo Vega y Maricruz Saborío.

Carl E. Nelson, Christian Corrales, Wilbert Siles, Monserrat Cascante, Ana M. Barber, Sonia Serrano, Ana C. González y Ana E. Vega, asistieron en diversas etapas del proyecto.

Esteban Gazel, Antonio García, Percy Denyer y Jean Tournon, tuvieron la paciencia de leer el documento y de contribuir sustancialmente a su mejoramiento con sus críticas y comentarios. Pablo Ruiz revisó el apartado sobre los volcanes Poás, Barva, Irazú y Turrialba, al igual que Uwe Martens el apartado sobre metamorfismo.

A todos ellos, gracias.

\section{REFERENCIAS BIBLIOGRÁFICAS}

ABRATIS, M., 1998: Geochemical variations in magmatic rocks from southern Costa Rica as a consequence of Cocos Ridge subduction and uplift of the Cordillera de Talamanca.- vi +148 págs. Univ. Göttingen [Tesis Ph.D].

ABRATIS, M. \& WÖRNER, G., 2001: Ridge collision, slab-window formation and the flux of Pacific asthenophere into the Caribbean realm.- Geology, 29 (2): 127-130.

ALLEGRE, C.J. \& CONDOMINES, M., 1976: Fine chronology of volcanic processes using 238U- 230Th systematics.- Earth and Planetary Sci. Letters, 28: 395-406.

ALVARADO, G.E., 1984: Aspectos PetrológicosGeológicos de los Volcanes y Unidades Lávicas del Cenozoico Superior de Costa Rica.- xii +183 págs. Escuela Centroamericana de Geología Univ. Costa Rica, San José [Tesis Lic.].
ALVARADO, G.E., 1986. Hallazgos de megamamíferos fósiles en Costa Rica.- Rev. Geol. Amér. Central, 4: 1-46; San José.

ALVARADO, G. E., 1990: Características geológicas de la Estación Biológica La Selva, Costa Rica.- Tecnología en Marcha, 10 (3): 11-22.

ALVARADO, G.E., 1993: Volcanology and Petrology of Irazú Volcano, Costa Rica.-xxv + 261 págs. Univ. Kiel, Alemania [Tesis Ph. D.].

ALVARADO, G.E., 2009: Los volcanes de Costa Rica: Geología, historia, riqueza natural y su gente [ $3^{\mathrm{a}}$ ed.].- xxviii +335 págs. EUNED, San José.

ALVARADO, G.E. \& CARR, M.J., 1993: The Platanar-Aguas Zarcas volcanic centers, Costa Rica: Spatial-temporal association of Quaternary calc-alkaline and alkaline volcanism.- Bull. Volcanol., 55: 443-453.

ALVARADO, G.E. \& DENYER, P., 1998: Implications for the Caribbean region of the high-Mg volcanic rocks in the Costa Rican ophiolitic complexes: The case of the Tortugal komatiitic-like suite.- Zbl. Geol. Paläont. I(3-6): 409-429.

ALVARADO, G.E. \& PÉREZ, W., 1998: The Doán Formation (Pliocene) of Costa Rica: An overview on its description, origin, lateral equivalents, and further implications on the closing of the Central America Seaway.- En: NISHIMURA, S. \& TSUCHI, R. (eds.): Proceedings of the Sixth International Congress on Pacific Neogene Stratigraphy and IGCP-355: 150-167.

ALVARADO, G.E. \& AGUILAR, T. 2008. Buzamientos en rocas volcánicas? Sí pero por qué y su importancia.- Bol. Colegio Geólogos de Costa Rica, 14 (1): 11-14. 
ALVARADO, G.E. \& GAMBOA, D.G., 2008: Las lavas del Cerro Minas (Mioceno Inferior): Un ejemplo de cuerpos subvolcánicos coetáneos con la sedimentación de la Fm. Pacacua.- Memoria: Programa y Resúmenes, IX Congreso Geológico de América Central y VI Congreso Geológico Nacional (documento digital), San José.

ALVARADO, G.E., KUSSMAUL, S., CHIESA, S., GILLOT, P.-Y., WÖRNER, G. \& RUNDLE, C., 1992: Cuadro cronoestratigráfico de las rocas ígneas de Costa Rica basado en dataciones radiométricas.- J. South. Amer. Earth Sci., 6(3): 151-168.

ALVARADO, G.E., DENYER, P. \& SINTON, C.W., 1997: The 89 Ma Tortugal komatiitic suite, Costa Rica: Implications for a common geological origin of the Caribbean and Eastern Pacific region from a mantle plume.- Geology, 25: 439-442.

ALVARADO, G.E., CARR, M.J., TURRIN, B.D., SWISHER, C., SCHMINCKE, H.-U. \& HUDNUT, K.W., 2006: Recent volcanic history of Irazú volcano, Costa Rica: Alternation and mixing of two magma batches, implying at least tow intracrustal chambers.- En: ROSE, W.I., BLUTHB, G.J.S., CARR, M.J., Ewert, J., PATINO, L.C. \& VALLANCE, J. (eds): Natural Hazards in Central America. Geol. Soc. Am. Spc. Paper, 412: 259-276, DOI: 10.1130/2006.2412(14).

ALVARADO, G.E., DENGO, C., MARTENS, U., BUNDSCHUH, J., AGUILAR, T. \& BONIS, S.B., 2007: Stratigraphy and geologic history.- En: BUNDSCHUH, J. \& ALVARADO, G.E. (eds.): Central America: Geology, Resources and Hazards. Taylor \& Francis, Londres/ London. 1: 345-394.

ALVARADO, G.E., DENYER, P. \& GAZEL, E., 2009a: Endeavor research into evolving paradigms around ophiolites: the case of the oceanic igneous complexes of Costa Rica.Rev. Geól. Amér. Central, 40: 49-73.

ALVARADO, G.E., BARQUERO, R, TAYLOR, W., LÓPEZ, A., CERDAS, A. \& MURILLO, J., 2009b. Geología de la hoja General, Costa Rica.- Rev. Geól. Amér. Central, 40: 99-109.

AMOS, B.J. \& ROGERS, P.J., 1983: The Geology and Exploration Geochemistry of the Cordillera Tilarán-Montes del Aguacate Gold Field, Costa Rica.- 33 págs. Inst. of Geol. Sci. Overseas Division, Londres [Inf. interno].

ANÓNIMO, 1978: Diagnóstico del Sector Minero de Costa Rica.- 91 págs. República de Costa Rica, Organización de los Estados Americanos, Washington D.C.

APPEL, H., 1990: Geochemie und K/ArDatierung an Magmatiten in Costa Rica, Zentralamerika.- 153 págs. Univ. Mainz, Alemania [Tesis de Diploma].

APPEL, H., WÖRNER, G., ALVARADO, G.E., RUNDLE, C. \& KUSSMAUL, S., 1994: Age relations in igneous rocks from Costa Rica.- Profil 7: 63-69.

ARIAS, M., 2002: Petrografía y gequímica de las rocas del Complejo Ígneo Estratificado de Bahia Nancite y su relacion con los filones basalticos, Península de Santa Elena, Costa Rica.- 94 págs. Univ. de Costa Rica, San José [Tesis Lic.].

ARIAS, O., 2003: Redefinicion de la Formacion Tulín (Mastrichtiano-Eoceno Inferior) del Pacífico Central de Costa Rica.- Rev. Geol. Amér. Central, 28: 47-68.

AUBOUIN, J., BROUSE, R. \& LEHMAN, J.P., 1975: Précis de Geología, t. 1. Pétrologie.Ed. Bordas. Trad. Español: Tratado de Geología, t. 1. Petrología.- 602 págs. Ed. Omega, S.A., Madrid, 1981. 
AZAMBRE, B. \& TOURNON, J., 1977: Les instrusions basique alcalines du Rio Reventazón (Costa Rica).- C.R. Somm. (Compte Rendu Sommaire) Soc. Géol. France, 2: 104-107.

AZEMA, J., GLAÇON, G., TOURNON, J. \& VILA, J.-M., 1979: Precisiones acerca del Paleoceno de Puerto Quepos y sus alrededores, provincia de Puntarenas, Costa Rica.- Inf. Sem. IGN, 2: 77-78.

BARR, K.W. \& ESCALANTE, G., 1969: Contribución al esclarecimiento del problema de la edad del Complejo de Nicoya, Costa Rica.- Publicaciones Geológicas ICAITI, 2: 43-47.

BARRANTES, M., 1991: Comentarios petrográficos de algunas rocas aflorantes en la región Central de Costa Rica.- Rev. Geol. Amér. Central, 12: 75-82.

BAUMGARTNER, P.O. \& DENYER, P., 2006: Evidence for middle Cretaceous accretion at Santa Elena Peninsula (Santa Rosa Accretionary Complex), Costa Rica.- Geol. Acta, 4(1-2): 179-191.

BAUMGARTNER, P.O., MORA, C.R., BUTTERLIN, J., SIGAL J., GLACON, G., AZÉMA, J. \& BOURGOIS, J., 1984: Sedimentación y paleogeografía del Cretácico y Cenozoico del litoral pacífico de Costa Rica.- Rev. Geol. Amér. Central, 1: $57-136$.

BAUMGARTNER, P.O., FLORES, K., BANDINI, A.N., GIRAULT, G. \& CRUZ, D., 2008: Upper Triassic to Cretaceous radiolarian from Nicaragua and northern Costa Rica -the Mesquito Composite Oceanic Terrane.- Ofioliti, 33(1): 1-19.

BEANE, R.E \& TITLEY, S.R., 1981: Porphyry copper deposits. Part II. Hydrothermal alteration and mineralization.- Economic Geol., $75^{\text {th }}$ Anniversary Vol.: 235-263.
BEAUDET, G., GABERT, P. \& BERGOEING, J.P., 1982: La Cordillère de Talamanca et son Piémont (Néotectonique et variations morpho-climatiques dans le Sud-Ouest du Costa Rica).- Colloque sur les Piédemonts, Toulouse, Francia: 121-134.

BECCALUVA, L., CHINCHILLA-CHAVES, A.L., COLTORTI, M., GIUNTA, G., SIENA, F. \& VACCARO, C., 1999: Petrological and structural significance of the Santa Elena-Nicoya ophiolitic complex in Costa Rica and geodynamic implications.- Eur. J. Mineral., 11(6): 1091-1107.

BELLON, H. \& TOURNON, J., 1978: Contribution de la géochronométrie $\mathrm{K} / \mathrm{Ar}$ l' étude du magmatisme de Costa Rica, Amérique Central.- Bull. Soc. Geól. de France, 20(6): 955-959.

BELLON, H., QUOC BUÜ, N., CHAUMONT, J. \& PHILIPPET, J.C., 1981: Implantation ionique d'argon dans une cible support: application au traçage isotopique de l'argon contenu dans les minéraux et les roches.C.R. Acad. Sci., Paris, 292: 977-980.

BELLON, H., SAENZ, R. \& TOURNON, J., $1983:$ K/Ar radiometric ages of lavas from Cocos Island (eastern Pacific).- Marine Geol. 54: M17-M23.

BERGOEING, J.P., 1982: Dataciones radiométricas de algunas muestras de Costa Rica.IGN, Informes Semestrales, 28: 71-86.

BERGOEING, J.P., 1998: Geomorfología de Costa Rica.- xvi +423 págs. IGN, San José.

BERRANGÉ, J.P., 1992: Gold from the Golfo Dulce Placer Province, Southern Costa Rica.- Rev. Geol. Amér. Central, 14: 1337.

BERRANGÉ, J.P. \& WHITTAKER, J.E., 1977: Reconnaissance Geology of the Tapantí 
Quadrangle, Talamanca Cordillera, Costa Rica.- 73 págs +2 láminas. Inst. Geol. Sciences; Report 37, Londres.

BERRANGÉ, J.P. \& THORPE, R. S., 1988: The geology, geochemistry and emplacement of the Cretaceous-Tertiary ophiolitic Nicoya Complex of the Osa Península, southern Costa Rica.- Tectonophysics, 147: 193-220.

BERRANGÉ, J.P., BRADLEY, D.R. \& SNELLING, N.J., 1989: K/Ar age dating of the ophiolitic Nicoya Complex of the Osa Peninsula, southern Costa Rica.- J. South Amer. Earth Sci., 2(1): 49-59.

BUCHS, D.M., BAUMGARTNER, P.O., BAUMGARTNER-MORA, C., BANDINI, A.N., JACKETT, S.-J., DISERENS, M.-O. \& STUCKI, J., 2009: Late Cretaceous to Miocene seamount accretion and mélange formation in the Osa and Burica Peninsulas (Southern Costa Rica): episodic growth of a convergent margin.- En: JAMES, K.H., LORENTE, M.A. \& PINDELL, J.L. (eds): The Origin and Evolution of the Caribbean Plate.- Geol. Soc., London, Sp. Publ. 328: 411-456.

BUCHS,D.M.,ARCULUS,R.,BAUMGARTNER, P.O., BAUMGARTNER-MORA, C., ULIANOV, A., 2010: Late Cretaceous arc development on the SW margin of the Caribbean Plate: Insights from the Golfito, Costa Rica, and Azuero, Panama, complexes.- Geochem. Geophys. Geosyst. 11(7), DOI: 10.1029/2009GC002901.

BUNDSCHUH, J. \& ALVARADO, G.E. (eds.) 2007: Central America: Geology, Resources and Hazards.- Vol. $1+2$ : lix +1311 págs. Taylor \& Francis, Londres.

BURKE, K.C. \& WILSON, J.T., 1976: Hot Spots on the Earth's surface.- Scientific Amer., August: 46-57.
CALVO, C. \& BOLZ, A., 1987: La secuencia de Venado, un estuario lagunar tropical del Mioceno Medio, San Carlos, Costa Rica.Rev. Geol. Amér. Central, 6: 1-24.

CARR, M.J., SAGINOR, I. ALVARADO, G.E. BOLGE, L.L. LINDSAY, F.N. , MILIDAKIS, K., TURRIN, B.D., FEIGENSON, M.D. \& SWISHER, III., C.C., 2007: Element fluxes from the volcanic front of Nicaragua and Costa Rica.Geochem. Geophys. Geosyst. 8, Q06001, DOI: $10.1029 / 2006$ GC001396.

CASSELL, D.T., 1986: Neogene Foraminifera of the Limon Basin of Costa Rica.- xii +323 págs. Lousiana State University, Lousiana. [Tesis Ph.D. ]

CASTILLO, P., BATIZA, R., VANKO, D., MALAVASSI, R.E., BARQUERO, J. \& FERNÁNDEZ, E., 1988: Anomalously young and old hot-spot traces: I. Geology and petrology of Cocos Island.- Bull. Geol. Soc. Amer. 100: 1400-1414.

CHÁVES, R. \& SÁENZ, R., 1974: Geología de la Cordillera de Tilarán (Proyecto Aguacate 2a fase).- Informes Técnicos y Notas Geológicas, 53: 2-49.

CHIESA, S., 1991: El flujo de pómez biotítico del Río Liberia (Guanacaste, Costa Rica, América Central).- Rev. Geol. Amér. Central, 13: 73-84.

CHIESA, S., CIVELli, G., GILlOT, P.-Y., MORA, O. \& ALVARADO G.E., 1992: Rocas piroclásticas asociadas a la formación de la Caldera de Guayabo, Cordillera de Guanacaste, Costa Rica.- Rev. Geol. Amér. Central, 14: 59-75.

CHIESA, S., CONFORTINI, F. \& MADESANTI, R., 1998: Geología del Área de Conservación Guanacaste.- Rothschildia, 5(2): 1-35. 
CHIESA, S., CORELLA, M. \& MORA, O., 1987: Geología de la Meseta Ignimbrítica de Santa Rosa, Guanacaste, Costa Rica.- 133 págs. Inst. Costarricense de Electricidad, Proyecto Geotérmico Miravalles [Inf. interno].

CIGOLINI, C. \& CHÁVES, R., 1986: Geological, petrochemical and metallogenic characteristics of the Costa Rican gold belt: Contribution to new explorations.- Geol. Rundschau, 75(3): 737-754.

CIGOLINI, C., KUDO, A.M., BROOKINS, D.G. \& WARD, D., 1991: The petrology of Poas Volcano lavas: basalt-andesite relationship and their petrogenesis within the magmatic arc of Costa Rica.- J. Volcanol. Geotherm. Res., 48: 367-384.

COLEMAN, R.G., 1977: Ophiolites. Ancient Oceanic Lithosphere?.- ix + 229 págs. Springer-Verlag, Berlín.

CORRIGAN, J., 1986: Geology of the Burica peninsula, Panamá- Costa Rica: Neotectonic implications for the southern middle America convergent margin.- 152 págs. Univ. Costa Rica, San José [Tesis M. Sc.].

DALRYMPLE, G. \& COX, A., 1968: Paleomagnetism, Potassium-Argon Ages and Petrology of some Volcanic Rocks.Nature, 217: 323-326.

DE BOER, J.Z., DEFANT, M.J. STEWART, R., RESTREPO, J.F., CLARK, L.F. \& RAMÍREZ, A.H. 1988: Quaternary calcalkaline volcanism in westerm Panamá: Regional variation and implication for the plate tectonic framework.- J. South Amer. Earth Sci. 1(3): 275-293.

DE BOER, J.Z., DRUMMOND, M.S., NORDELON, M.J., DEFANT, M.J., BELLON, H. \& MAURY, R.C., 1995: Cenozoic magmatic phases of the Costa
Rican island arc (Cordillera de Talamanca).En: MANN, P. (ed.), Geologic and Tectonic Development of the Caribbean Plate Boundary in Southern Central America. Spec. Pap., Geol. Soc. Amer. Special Paper, 295: 35-55.

DEFANT, M.J., JACKSON, T.E., DRUMMOND, M.S., DE BOER, J.Z., BELLON, H., FEIGENSON, M.D., MAURY, R.C. \& STEWART, R.H., 1992: The geoquemistry of Young volcanism throughout western Panama and southeastern Costa Rica: An overview.- J. Geol. Soc. London, 149(4): 569-579.

DE LA CRUZ, R., 1994: Estudio de secciones estratigraficas. Sondajes CP-1 a CP-24, Proyecto Crucitas.- 68 págs. Placer Dome, San José [Inf. interno].

DENGO, G., 1962: Tectonic-igneous sequence in Costa Rica.- En: ENGEL, A.E.J., JAMES, H.L. \& LEONARD, B.F. (eds): A Volume to Honor A.F. Budinton. GSA Spec.Vol. Geol. Soc. Amer.: 133-161.

DENYER, P. \& ARIAS, O., 1991: Estratigrafía de la región Central de Costa Rica.- Rev. Geol. Amér. Central, 12: 1-59.

DENYER, P. \& SOTO, G.J., 2000: Análisis de los trabajos geológicos de William M. Gabb sobre Costa Rica, a la luz del paradigma geológico del siglo XX.- Rev. Geol. Amér. Central, 23: 97-118.

DENYER, P. \& BAUMGARTNER, P.O., 2006: EmplacementofJurassic-LowerCretaceous radiolarites of the Nicoya Complex (Costa Rica).- Geologica Acta, 4(1-2): 203-218.

DENYER, P. \& BAUMGARTNER, P.O. \& GAZEL, E., 2006: Characterizacion and tectonic implications of Mesozoic-Cenozoic oceanic assemblages of Costa Rica and Western Panama.- Geologica Acta, 4(1-2): 219-235. 
DENYER, P. \& ALVARADO, G.E., 2007: Mapa Geológico de Costa Rica 2007.-Escala 1: 400 000, Librería Francesa S.A.

DENYER, P. \& GAZEL, E., 2009: The Costa Rican Jurassic to Miocene oceanic complexes: Origin, tectonics and relations.- J. South Amer. Earth Sciences, 28: 429-422.

DE WEVER, P., AZÉMA, J., TOURNON, J. \& DESMET, A., 1985: Découverte de matérial oceánique du Lias-Dogger inférieur dans la péninsula de Santa Elena (Costa Rica, Amérique Centrale).- C.R. Acad. Sci., París 300(II, 15): 759-764.

DI MARCO, G., 1994: Les terrains accrétés du sud du Costa Rica.- Mémoires de Géologia (Lausanne), 20: 1-184.

DI MARCO, G., BAUMGARTNER, P.O. \& CHANNELL, J.E.T., 1995: Late Cretaceousearly Tertiary paleomagnetic data and revised tectonostratigraphy subdivision of Costa Rica and western Panama.- En: MANN, P. (ed.): Geological and tectonic development of the Caribbean Plate Boundary in Southern Central America. Geol. Soc. Amer. Bull. Spec. Paper, 295: 1-27.

DILEK, Y. \& FURNES, H., 2011: Ophiolite genesis and global tectonics: Geochemical and tectonic fingerprinting of ancient oceanic lithosphere.- Geol. Soc. Amer. Bull., 123 (3/4): 387-411.

DRUMMNOD, M.S., BORDELON, M., DE BOER, J.Z., DEFANT, M.J., BELLON, H. \& FEIGENSON, M.D., 1995: Igneous petrogenesis and tectonic setting of plutonic and volcanic rocks of the Cordillera de Talamanca, Costa Rica-Panama, Central American Arc.Am. J. Science, 295: 875-919.

DUFFIELD, W.A. \& DALRYMPLE, G.B., 1990: The Taylor Creek Rhyolite of New Mexico: a rapidly emplaced field of domes and lava flows.- Bull. Volcanol., 52: 475-478.
ECHANDI, E., 1981: Unidades volcánicas de la vertiente norte de la Cuenca del Río Virilla.$\mathrm{x}+123$ págs +1 mapa. Univ. de Costa Rica, San José [Tesis Lic.].

EHRENBORG, J., 1996: A new stratigraphy for the Tertiary volcanic rocks of the Nicaraguan Highland.- Geol. Soc. Amer. Bull., 108 (7): 830-842.

ELMING, S.-Å., 1998: A paleomagnetic study and $\mathrm{K}-\mathrm{Ar}$ determinations of Tertiary rocks in Nicaragua, Central America.- En: ELMING, S.-Å., WINDENFALK, L. \& RODRIGUEZ, D. (eds): Geoscientific Research in Nicaragua. A Swedish-Nicaraguan joint project during the period 1981-1991.- Lulea Univ. Technology, Sweden: 1-19.

FAURE, G., 1986: Principles of Isotope Geology ( 2 ed.).- $x v+589$ págs. John Wiley \& Sons. New York.

FERNÁNDEZ, M., 1968: Las unidades hidrogeológicas y los manantiales de la vertiente norte de la cuenca del Río Virilla.- Inf. Técnico Ministerio Agricultura y Ganadería, 27: 1-44.

FISHER, D.M., GARDNER, T.W., MARSHALL, J.S. \& MONTERO, W., 1994: Kinematics associated with late Cenozoic deformation in central Costa Rica: Western boundary of the Panama microplate.- Geology, 22: 263-266.

FREY, M. \& ROBINSON, D., 1999: Low-Grade Metamorphism.- $\mathrm{x}+313$ págs. Blackwell Sci. Ltd., Londres.

FRISCH, W., MESCHEDE, M. \& SICK, M., 1992: Origin of the Central American ophiolites: Evidence from paleomagnetic results.- Geol. Soc. Amer. Bull., 104: 1301-1314.

GABB, W.M., 1874: On the Geology of the Republic of Costa Rica.- Manustrito inédito, biblioteca U.S.G.S., transcrito por O.H. Lücke, V. Gutiérrez \& G. Soto (2007): Rev. Geol. Amér. Central, 37 Especial: 103-118. 
GABB, W.M., 1875: Notes on the Geology of Costa Rica.- Amer. J. Sci. 9: 198-204.

GANS, P.B., MACMILLAN, I., ALVARADOINDUNI, G., PÉREZ, W. \& SIGARÁN, C., 2002: Neogene evolution of the Costa Rica arc. Geol. Soc.America, 2002 Annual Meeting (Oct. 27-30, Denver), Abstracts with Programs.- Geol. Soc. Amer. 34(6): 513.

GANS, P.B., ALVARADO-INDUNI, G., PEREZ, W., MACMILLAN, I., CALVERT, A., 2003: Neogene evolution of the Costa Rican arc and development of the Cordillera Central.- Geol. Soc. Amer., Cordilleran Section, 99 $9^{\text {th }}$ annual meeting, Abstracts with Programs (April 1-3, Puerto Vallarta).- Geol. Soc. Amer., 35(4): 74.

GAZEL, E., 2003: Las series alcalinas del Plioceno de Costa Rica: Distribución especial y relación con una fuente mantélica tipo OIB.- Rev. Geol. Amér. Central, 29: 87-94.

GAZEL, E., ALVARADO, G.E., OBANDO, J. \& ALFARO, A., 2005: Evolución magmática del arco de Sarapiquí, Costa Rica.- Rev. Geól. Amér. Central, 32: 13-31.

GAZEL, E., DENYER, P. \& BAUMGARTNER, P.O., 2006: Magmatic and geotectonic significance of Santa Elena Peninsula, Costa Rica.- Geologica Acta, 4(1-2): 193-202.

GAZEL, E., CARR, M.J., HOERNLE, K., FEIGENSON, M.D., SZYMANSKI, D., HAUFF, F. \& VAN DER BOGAARD, P., 2009: Galapagos-OIB signature in southern Central America: Mantle refertilization by arc-hot spot interaction.- Geochemistry, Geophysics and Geosystems, DOI: 10.1029/2008GC002246.

GAZEL, E., HOERNLE, K., CARR, M.J., HERZBERG, C., SAGINOR, I., VAN DEN BOGAARD, P., HAUFF, F., FEIGENSON, M. \& SWISHER III, C., 2011: Plume- subduction interaction in southern Central America: Mantle upwelling and slab melting.- Lithos, 121: 117-134.

GELDMACHER, J., HOERNLE, K., VAN DEN BOGAARD, P., HAUFF, F. \& KLUGEL, A., 2008: Age and Geochemistry of the Central American Forearc Basement (DSDP Leg 67 and 84): Insights into Mesozoic Arc Volcaninism and Seamount Accretion on the Fringe of the Caribbean LIP.- J. Petrol., 49(10): 1781-1815.

GIBBARD, P.L., HEAD, M., WALKER, M.J.C. $\&$ the Subcommission on Quaternary Stratigraphy, 2010: Quaternary Stratigraphy.- J. Quaternary Sci., 25(2): 96-102.

GILLOT, P.-Y. \& CORNETTE, Y., 1986: The Cassignol technique for potassim-argon dating, precision and accuracy: Examples from the Late Pleistocene to Recent volcanics from suthern Italy.- En: ODIN, G.S. (ed.): Calibration of the Phanerozoic Time Scale. Chem. Geol. (Isot. Geosci. Sect.), 59: 205-222.

GILLOT, P.-Y., CHIESA, S. \& ALVARADO, G.E., 1994: Chronostratigraphy of Upper MioceneQuaternary volcanism in northern Costa Rica.- Rev. Geol. Amér. Central, 17: 45-53.

GÓMEZ-GUTIÉRREZ， D.F. \& MOLANOMENDOZA, J.C., 2009: Evaluación de zonas de alteración hidrotermal y fases intrusivas, para el prospecto "Stock Porfirítico de Piedra Sentada" (Vereda Santa Lucía), Cauca, Colombia.- Geol. Colombiana, 34: 75-94.

GRÄFE, K., 1998: Exhumation and thermal evolution of the cordillera de Talamanca (Costa Rica): Constraints from fission track analysis, 40Ar-39Ar, and 87Rb-87Sr chronology.- ii + 113 págs. Tübinger Geowisenschafliche Arbeiten, Reihe A, Band 9. 
GRÄFE, K., FRISCH, W., VILLA, I.M. \& MESCHEDE, M., 2002: Geodynamic evolution of southern Costa Rica related to low-angle subduction of the Cocos Ridge: constraints from thermochronology.Tectonophysics, 348: 187-204.

GURSKY, H.G. \& GURSKY, M.M., 1989: Thermal Alteration of Chert in the Ophiolite Basement of Southern Central America.En: HEIN, J.R. \& OBRADOVIĆ, J. (eds): Siliceous Deposits of the Tethys and Pacific Regions, Springer, Berlín.: 217-233.

GUSTAFSON, L.B. \& HUNT, J.P., 1975: The Porphyry Copper Porphyry deposits at El Salvador, Chile.- Economy Geol. 70: 857912.

HALBACH, P., GURSKY, H.-J., GURSKY, M.M., SCHMIDT-EFFING, R. \& MARESCH, W.V., 1992: Composition and formation of fossil manganese nodules in Jurassic to Cretaceous radiolarites from the Nicoya Ophiolite Complex (NW Costa Rica).Mineral. Deposita, 27: 153-160.

HANES, J.A., 1987: Dating of Precambrian Mafic Dykes Swarms by the Rb-Sr, K-Ar and $\mathrm{Sm}-\mathrm{Nb}$ methods.- En: HALLS, H.C. \& FAHRIG, W.F. (eds.): Mafic dyke swarms. Geol. Assoc. Canada Sp. Paper, 34: 137146.

HARPP, K.S., WANLESS, V.D., OTTO, R.H., HOERNLE, K. \& WERNER, R., 2005: The Cocos and Carnegie aseismic ridges: a trace element record of long-term plumespreading center interaction.- J. Petrol., 46: 109-133.

HAUFF, F., HOERNLE, K., VAN DEN BOGAARD, P., ALVARADO, G. \& GARBE-SHÖNBERG, D., 2000: Age and Geochemistry of Basaltic Complexes in Western Costa Rica: Contributions to the Geotectonic Evolution of Central America.- Geochem. Geophys.
Geosyst. 1(5): 1999GC000020, DOI: 10.1029/1999GC000020.

HENNINGSEN, D., 1965 [Ed. espec. 1969]: La fila costeña del Pacífico en Costa Rica y su posición dentro del sistema montañoso centroamericano meridional.- 94 págs. Direc. Gral. Geol. Min. Petról., Ministerio de Industria y Comercio, San José.

HEY, R., 1977: Tectonic evolution of the CocosNazca Spreading.- Geol. Soc. Amer. Bull. 88: 1404-1420.

HEY, R., JOHNSON, G. L. \& LOWRIE. A., 1977: Recent plate motions in the Galápagos area.- Bull. Geol. Society Amer. 88: 13851403.

HOERNLE, K., VAN DEN BOOGARD, P., WERNER, R., LISSINA, B., HAUFF, F., ALVARADO, G.\&GARBE-SCHÖNBERG, D., 2002: Missing history (16-71 Ma) of the Galápagos hotspot: Implications for the tectonic and biological evolution of the Americas.- Geology, 30: 795-798.

HOERNLE, K., HAUFF, F., VAN DEN BOOGARD, P., 2004: 70 m.y. history (139-69 Ma) for the Caribbean Large igneous province.- Geology, 32: 697-700.

HOERNLE, K., ABT, D.L., FISHER, K.M., NICOLS, H., HAUFF, F., ABERS, G.A., VAN DEN BOGAARD, P., HEYDOLPH, K., ALVARADO, G., PROTTI, M. \& STRAUCH, W., 2008: Arc-parallel flow in the mantle wedge beneath Costa Rica and Nicaragua.- Nature, 451: 1094-1097.

HOLDEN, N.E., BONARDI, M.L., DE BRIEVRE, P., RENNE, P.R. \& VILLA, I.M., 2011: IUPAC-IUGS common definition and convention o the use of the year as a derived unit of time (IUPAC Recommendations 2011).- Pure Appl. Chem., 83 5): 1159-1162, DOI: 10.1351/ PAC-REC-09-01-22. 
ICE, 1985: Dataciones K/Ar del Volcán Miravalles realizadas por la Universidad de Bern (Suiza).- Sección Recursos Geotérmicos, Instituto Costarricense de Electricidad, San José [Info. interno].

ICE, 1987: Dataciones Radiométricas de la Región de Palmira-Platanar.- Geochron Lab. Inc., Archivo Oficina de Sismología y Vulcanología, Departamento de Geología, San José, Costa Rica.

ICE-ELC, 1983: Proyecto Geotérmico Miravalles. Investigaciones Adicionales.- Inst. Costarricense de Electricidad, San José, Costa Rica [Reporte interno GMV-D5834].

ICE-ENEL, 1988: Estudio de Reconocimiento y Prefactibilidad Geotermica en la República de Costa Rica, Fase I.- 337 págs. Ente Nazionale per 1'Energia Electtrica, Inst. Costarricense de Electricidad [Inf. Interno].

ICE-ENEL, 1989: Estudio de Reconocimiento y Prefactibilidad Geotérmica en la República de Costa Rica, Fase I. Informe final, anexos 1 y 2.- 486 págs. Ente Nazionale por 1' Energía Elettica, Inst. Costarricense de Electricidad [Inf. interno].

ICE-ENEL, 1990: Estudios de reconocimiento y prefactibilidad geotérmica en la república de Costa Rica. Fase II, estudio de prefactibilidad del área del Tenorio, Informe geovulcanológico.- 124 págs +6 planos. Proyecto COS/83/T01, marzo 1990 [Inf. interno].

JANOUŠEK, V., ERBAN, V., HOLUB, F.V., MAGNA, T., BELLON, H., MLČOCH, B., WIECHERT, V. \& RAPPRICH, V., 2010. Geochemistry and genesis of behind-arc basaltic lavas from eastern Nicaragua.- J. Volcanol. Geotherm. Res., 192: 232-256.
JACKSON, T.E., 1991: Neogene geochemistry of the Central American Arc: Western Panama and Southern Costa Rica.- ix + 109 págs. Univ. South Florida [Tesis M.Sc.].

KENNETT, J.P., MCBIRNEY,A. R. \& THUNELL, R. C., 1977: Episodios of Cenozoic volcanism in the circum-Pacific region.- J. Volcanol. Geotherm. Res. 2: 145-163.

KESEL, R.H., 1983: Quaternary History of the Río General Valley, Costa Rica.- Nat. Geo. Soc. Res. Reports, 15: 339-358.

KRIZ, S., 1977: Tectonic evolution and origin Golfo Dulce gold placers.- Rev. Geol. Amér Central, 11: 27-40.

KRAWINKEL, J. \& SEYFRIED, H., 1994: A review of plate-tectonic processes involved in the formation of southwestern edge of the Caribbean Plate.- Profil, 7: 47-61.

KRUSHENSKY, R.D., 1972: Geology of Istarú Quandrangle, Costa Rica.- 46 págs. U.S.G.S. Bull. 1368.

KUSSMAUL S., 1987: Petrología de las rocas instrusivas neógenas de Costa Rica.- Rev. Geol. Amér. Central, 7: 83-11.

KUSSMAUL, S., 1988: Comparación petrológica entre el piso volcánico del Valle Central y la Cordillera Central de Costa Rica.- Rev. Ciencia y Tecnología, 12(1-2): 109-116.

KUSSMAUL, S., TOURNON, J. \& ALVARADO, G.E., 1991: Evolución de las rocas plutónicas y volcánicas subalcalinas del Neógeno y Cuaternario de Costa Rica.Memorias Simposio sobre Magmatismo y Andino y su marco tectónico, Manizales, Colombia, 1: 23-44.

KUSSMAUL, S., TOURNON, J. \& ALVARADO, G., 1994: Evolution of the Neogene to Quaternary igneous rocks of Costa Rica.Profil, 7: 97-123. 
KUYPERS, E.P., 1979: La Geología del Complejo Ofiolítico de Nicoya, Costa Rica.- Informe Semestral Julio-Diciembre, pp. 15-75.

KYCL, S., ŽÁČEK, V., ČECH, S., GRYGAR, R., HRAZDÍRA, P., HUAPAYA, S., KARENOVÁ, J., KONDROVÁ, L., MENDOZA, E.Q., METELKA, V., MIXA, P., ŠERČIK, J., VOREL, T., HRADECKÁ, L., REJCHRT, M. \& ŠVÁBENICKÁ, L., 2010: Informe Final, Estudio Geológico 3246 II-Miramar, 3246 III-Chapernal, 3246 IV-Juntas, Costa Rica.- 263 págs. Servicio Geológico Checo y Dirección Geol. Minas, PragaSan José.

LAURITO, C. \& VALERIO, A.L., 2008: The first record of Gaviolosuchus americanus Sellards (1915) $\dagger$ (Eusuchia: Crocodylidae, Tomistominae) for the Late Tertiary of Costa Rica and Central America.- Rev. Geol. Amér. Central, 39: 107-115.

LAURITO, C., VALERIO, A.L. \& PÉREZ, E.A., 2005: Los Xenarthras fósiles de la localidad de Buenos Aires de Palmares (Blancano Tardío-Irvingtoniano Temprano), Provincia de Alajuela, Costa Rica.- Rev. Geol. Amér. Central, 33: 83-90.

LE MAITRE, R.W., 1989: A Classification of Igneous Rocks and Glossary of Terms.xi +193 págs. Blackwell Sic. Pub., Oxford

LEVI, B., 1981: Low-grade non-deformational metamorphism in the Mesozoic and Tertiary sequences of Costa Rica.- Pacific Geol. 15: 65-70.

LEW, L.R., 1983: The geology of the Osa Peninsula, Costa Rica: Observations and speculation of the outer arc of the southern Central American Orogen.- 128 págs. Pennsylvania State University, Pennsylvania [Tesis M.Sc.].
LINDSAY, F.N., 2009: Geochemistry of lavas from Southeastern Nicaragua and of Mantle Xenoliths from Cerro Mercedes, Costa Rica.- xiii +289 págs. The State Univ. New Jersey, New Jersy [Tesis Ph.D.].

LONG, A. \& RIPPETEAU, B., 1974. Testing Contemporaneity and Averaging Radiocarbon Dates.- Amer. Antiquity, 39(2): 205-215.

LUCAS, S.G. \& ALVARADO, G.E., 2010: Fossil Proboscidea from the Upper Cenozoic of Central America: Taxonomy, evolutionary and peleobiogeographic significance.- Rev. Geol. Amér. Central, 42: 9-42.

MACMILLAN, I., GANS, P.B. \& ALVARADO, G., 2004: Middle Miocene to present plate tectonic history of the southern Central American Volcanic Arc.- Tectonophysiscs, 392: 325-348.

MAHOOD, G. \& DRAKE, R.E., 1982: K/Ar dating young rhyolite rocks: a case study of the Sierra La Primavera, Jalisco, Mexico.Geol. Soc. Amer. Bull., 93: 1232-1241.

MAINIERI, A., 1976: Proyecto Geotérmico de Guanacaste.- 99 págs. +32 gráficos +11 planos. Inst. Costarricense de Electricidad [Inf. Previabilidad Técnica, Geología].

MALAVASSI, E. \& CHÁVEZ, R., 1970: Estudio Geológico Regional de la Zona Atlántica Norte de Costa Rica.- Dirección de Geol. Min. Petról., Inf. Técn. Not. Geol., 9 (35): 1-16.

MALAVASSI, E., LAMBERT, A. \& WEYL, R., 1971: Excursión a Talamanca.- 35 págs. San José [Inf. Interno inédito].

MALAVASSI, E. \& MADRIGAL, R., 1970: Reconocimiento Geológico de la Zona Norte de Costa Rica.- Inf. Técn. Not. Geol., (38): 1-18. 
MARSHALL, J.S., 2000: Active tectonics and Quaternary landscape evolution across the western Panama block, Costa Rica, Central America.- xiii + 304 págs. The Pennsylvania State Univ., Pennsylvania [Ph.D. tesis].

MARSHALL, J.S.,IDLEMAN,B.D., GARDNER, T.W. \& FISHER, D.M., 2003: Landscape evolution within a retreating volcanic arc, Costa Rica, Central America.- Geology, 31(5): 419-422.

MARTENS, U., ORTEGA-OBREGÓN, C., ESTRADA, J. \& VALLE, M., 2007: Metamorphism and metamorphic rocks.En: BUNDSCHUH, J. \& ALVARADO, G.E. (eds.): Central America: Geology, Resources and Hazards. Taylor \& Francis, Londres, 1: 485-522.

MÉNDEZ, J. \& HIDALGO, P.J., 2004: Descripción geológica del depósito de debris avalanche El Coyol, Formacion Barva, Costa Rica.- Rev. Geol. Amér. Central, 30: 41-58.

MESCHEDE, M., BARCKHAUSEN, U. \& WORM, H.-U., 1998: Extinct spreading on the Cocos Ridge.- Terra Nova, The European J. Geosci. 10(4): 211-216.

MILODOWSKI, A.E., SAVAGE, D., BATH, A.H., FORTEY, N.J., NANCARROW, P.H.A. \& SHEPHERD, T.J., 1989: Hydrothermal Mineralogy in Geothermal Assessment: Studies of Miravalles Field, Costa Rica and Experimental Simulations of Hydrothermal Alteration.- British Geol. Surv., Nottinghan, NG 125 GG: 39-70 [Inf. Interno inédito].

MIXA, P., DOBEŠ, P., ŽÁČEK, V., LUKEŠ P. \& QUINTANILLA, E.M., 2011: Epithermal gold mineralization in Costa Rica, Cordillera de Tilarán -exploration geoche- mistry and genesis of gold deposits.- J. Geosci. 56: 81-104.

MORA, S., 1979: Estudio Geológico de una Parte de la Región Sureste del Valle del General, Provincia de Puntarenas, Costa Rica.- 188 págs. (vol. 1). Univ. de Costa Rica, San José [Tesis Lic.].

MORELL, K.D., FISHER, D.M., GARDNER, T.W., LA FEMINA, P., DAVIDSON, D. \& TELETZKE, A., 2011: Quaternary outer fore-arc deformation and uplift inboard of the Panama Triple Junction, Burica Peninsula.- J. Geophys. Res. 116, B05402, DOI: 10.1029/2010JB007979.

NIEWENHUYSE, A., VERBURG, P.S.J. \& JONGMANS, A.G., 2000: Mineralogy and soil chronosequence on andesitic lava in humid tropical Costa Rica.- Geoderma, 98: 61-82.

OBANDO, L.G., 1983: Estratigrafia y Petrografia de las Rocas Aflorantes al Sur del Valle Central (Tarbaca).- 138 págs, +1 mapa. Univ. de Costa Rica, San José [Tesis Lic.].

OBANDO, L.G., 1985: Petrografía del intrusivo de Escazú (Valle Central, Costa Rica, América Central).- Brenesia, 24: 1-18.

OBANDO, L.G., 1986: Estratigrafía de la Formación Venado y rocas sobreyacentes (Mioceno-Reciente); Provincia de Alajuela, Costa Rica.- Rev. Geol. Amér. Central, 5: 73-104.

OBANDO, L.G., 2011: Estratigrafía y tectónica de la parte noreste de la hoja Dota (1: 50 000), Costa Rica.- Rev. Geol. Amér. Central, 44: 71-82.

OBANDO, J., 1995: Estudio geológico del Arco de Sarapiquí: Contribución a las nuevas exploraciones mineras de la región.- 74 págs.Placer Dome de Costa Rica [Inf. Interno]. 
O'CONNOR, J.M., STOFFERS, P., WIJBRANS, J.R. \& WORTHINGTON, T.R., 2007: Migration of widespread long-lived volcanism across the Galapagos Volcanic Province: Evidence for a braod hotspot melting anomaly?- Earth and Planetary Sci. Lett. 263: 339-354.

PÉREZ, W., 2000: Vulcanología y petroquímica del evento ignimbrítico del Pleistoceno Medio (0,33 M.a.) del Valle Central de Costa Rica.- xvi +192 págs. Univ. de Costa Rica, San José [Tesis Lic.].

PÉREZ, W. ALVARADO, G.E. \& GANS, P.B., 2006: The 322 ka Tiribí Tuff: stratigraphy, geochrology and mechanisms of deposition of the largest and most recent ignimbrite in the Valle Central, Costa Rica.- Bull. Volcanol. 69: 25-40.

PETTKE, T. \& DIAMOND, L.W., 1997: Oligocene gold quartz veins at Brusson, NW Alps: Sr isotopes trace the source of ore-bearing fluid to over a $10-\mathrm{km}$ depth.Econ. Geol. Bull. Soc. Econ. Geol. 92(4): 389-406.

PICHLER, H. \& WEYL, R., 1976: Magmatism and crustal evolution in Costa Rica (Central America).- Geol. Rundsch. 64: 457-475.

PINDELL, J., KENNAN, L., STANEK, K.P., MARESCH, M.W. \& DRAPER, G., 2006: Foundation of Gulf of Mexico and Caribbean evolution: Eight controversies resolved.- Geol. Acta, 4: 303-341.

PIRAJNO, F., 1992: Hydrothermal Mineral Deposits. Principles and Fundamental Concepts for the Exploration Geologist.xviii +709 págs. Springer-Verlag, Berlín.

PIZARRO, D., 1993: Los pozos profundos perforados en Costa Rica: Aspectos litológicos y bioestratigráficos.- Rev. Geol. Amér. Central, 15: 81-85.
PLANK, T., BALZER, V. \& CARR, M.J., 2002: Nicaraguan volcanoes record paleomagnetic changes accompanaying closure of the Panama gateway.- Geology, 30(12): 10871090.

PONCIA, C., 1993: Il complexo alcalino-subalcalino Platanar-Aguas Zarcas (Costa Rica): genesi dei magmi e relaizione tra tettonica e vulcanismo.- 79 págs. Univ. degli Studi dei Milano, Dipt. Science della Terra [Tesis Laurea].

PROTTI, R., 1986: Geología del flanco sur del volcán Barva, Heredia, Costa Rica.- Bol. Vulcanol. 17: 23-31.

REAGAN, M., DUARTE, E., SOTO, G.J. \& FERNÁNDEZ, E., 2006: The eruptive history of Turrialba volcano, Costa Rica, and potential hazards from future eruptions.- En: ROSE, W.I., BLUTHB, G.J.S., CARR, M.J., EWERT, J., PATINO, L.C. \& VALLANCE, J. (eds): Natural Hazards in Central America.- Geol. Soc. Am. Spc. Paper, 412: 235-257, DOI: 10.1130/2006.2412(14).

REINERS, P.W., EHLERS, T.A. \& ZEITLER, P.K., 2005: Past, Present and Future of Thermochronology.- Rev. Mineralogy \& Geochemistry, 58: 1-18, DOI: 10.2138/ rmg.2005.58.1.

RIVIER, F., 1979: Geología del área norte de los Cerros de Escazú, Cordillera de Talamanca, Costa Rica.- Inst. Geogr. Nacional, Inf. Semestral: 99-137.

RODRÍGUEZ, C., SÁENZ, L.F., CERVANTES, F., ALVARADO, G., CHAVEZ, J., LEANDRO, G., VALVERDE, M. \& SALAZAR, J., 1996: Informe geológicogeotécnico de avance para el diseño básico del P.H. Pirrís.- 119 págs + Anexos A hasta E, (Tomo I). ICE, Dirección de Ing. Civil, [Inf. Interno]. 
RUIZ, P., GAZEL, E., ALVARADO, G.E., CARR, M.J. \& SOTO, G.J., 2010a: Caracterización geoquímica y petrográfica de las unidades geológicas del macizo del volcán Poás, Costa Rica.- Rev. Geol. Amér. Central, 43: 37-66.

RUIZ, P., TURRIN, B.D., SOTO, G.J., DEL POTRO, R., GAGNEVIN, D., GAZEL, E., MORA, M., CARR, M.J. \& SWISHER, C.C., 2010b: Unveilling Turrialba (Costa Rica) volcano's latest geological evolution through new ${ }^{40} \mathrm{Ar} /{ }^{39} \mathrm{Ar}$, ages.- Abstract, AGU Fall Meeting, San Francisco.

SACHS, P. M. \& ALVARADO, G.E., 1996: Mafic metaigneous lower crust beneath Arenal volcano (Costa Rica): Evidence from xenoliths.- Bol. Obs. Vulc. Arenal, 6(11-12): 71-78.

SÁENZ, R., 1982: Edades radiométricas de algunas rocas de Costa Rica.- Bol. Vulcanol. 12: 8-10.

SAGINOR, I., GAZEL, E., CARR, M.J., SWISHER III, C.C. \& TURRIN, B., 2011a: New Pliocene-Pleistocene ${ }^{40} \mathrm{Ar} /{ }^{39} \mathrm{Ar}$ ages fill in temporal gaps in the Nicaraguan volcanic record.- J. Volcanol. Geotherm. Res. 202: 143-152.

SAGINOR, I., GAZEL, E., CARR, M.J., SWIHER III, C.C. \& TURRIN, B., 2011b: Progress and challenger using ${ }^{40} \mathrm{Ar} /{ }^{39} \mathrm{Ar}$ geochronology in Costa Rica and Nicaragua.- Rev. Geol. Amer. Central, 45: 75-85.

SAPPER, K., 1905: Gebirgsbau und Boden des südlichen Mittelamerika.- $\mathrm{v}+82$ págs. Justus Perthes en Gotha, 151.

SAPPER, K., 1937: Mittelamerika.- 160 págs. Handbuch der Regionalen Geologie, 8(4), Carl Winter's Universitatsbüchhandlung, Heidelberg.
SCHULZ, K., KOEPPEN, R., LUDINGTON, S., KUSSMAUL, S., \& GRAY, K., 1987: Volcanological framework for the gold deposits in the Cordillera de Tilarán and Montes del Aguacate, Costa Rica.En: U.S. GEOLOGICAL SURVEY: DIRECCIÓN DE GEOLOGÍA, MINAS E HIDROCARBUROS \& UNIV. COSTA RICA(eds): Mineral Resource Assessment of the Republic of Costa Rica.- U.S.G.S. Miscellaneous Investigation Series, Map I-1865: 34-43.

SCHWARZKOFT, L.M., SCHMINCKE, H.-U. \& TROLL, V.R., 2001: Pseudotachylite on impact marks of block surfaces in blockand-ash flows at Merapi volcano, Central Java, Indonesia.- Int. J. Earth Sci. (Geol. Rundsch.), 90: 769-775.

SEN GUPTA, B.K., MALAVASSI, L. R. \& MALAVASSI, E., 1986: Late Miocene shore in northern Costa Rica: Benthic foraminiferal record.- Geology, 14(3): 218-219.

SHATWELL, D., 2004: Subducted Ridges, Magmas, Differential Uplift and Gold Deposits: Examples from South and Central America.- The Ishihara Symposium: Granites and Associated Metallogenesis, Geoscience, Australia: 115-120.

SIGARÁN, C., 2001: Caracterización vulcanológica y alteración hidrotermal del yacimiento aurífero Conchudita (Zona Norte, Costa Rica).- 223 págs. Univ. Costa Rica, San José [Tesis Lic.].

SILLITOE, R., 2000: Gold-rich porphyry deposits: descriptive and genetic models and their role in exploration and discovery.Reviews in Economic Geol. 13: 315-345.

SINTON, C.W., DUNCAN, R.A. \& DENYER, P., 1997: Nicoya Peninsula, Costa Rica: A single suite of Caribbean oceanic plateau magmas.- J. Geophy. Res. 102: 15507-15520. 
SINTON, C.W., PYLE, D.G., HANAN, B.B., DENYER, P. \& ALVARADO, G.E., 2009: Distinct Mantle Source for the Caribbean Large Igneous Province Ultramafic of Tortugal, Costa Rica.- GSA Annual Meeting, Portland, OR, Abstract with Programs: 41(7).

SMULIKOWSKI, W., DESMONS, J., FETTES, D.J., HARTE, B., SASSI, F.P. \& SCHMID, R., 2007: A systematic nomenclature for metamorphic rocks: 2 . Types, grade and facies of metamorphism. Recommendations by the IUGS Subcommission on the Systematics of Metamorphic Rocks.- Web version 01.02.07, http://www.bgs.ac.uk/ SCMR/products.html [4/8/11].

SOUTHAM, G., LENGKE, M.F., FAIRBROTHER, L. \& REITH, F.., 2009: The Biogeochemistry of Gold.- Elements, 5: 303-307.

STACK, C.M., 1991: Inverse modeling of alkaline lavas from Guayacán, Costa Rica.- viii +52 págs. The State University of New Jersey, New Jersey [Tesis M.Sc.].

STEIGER, R.H. \& JÄGER, E., 1977: Subcommission on geochronology: convention on the use of decay constants in geo and cosmochronology.- Earth Plan. Sci. Letters, 36(3): 359-362.

THOMPSON, A.J.B. \& THOMPSON, J.F.H. (eds.). 1996: Atlas of Alteration. A Field and Petrographic Guide to HydrothermalAlteration Minerals.- vi +119 págs. Geol. Assoc. Canada, Mineral Deposits Div., Canadá.

TOURNON, J., 1972: Présence de basaltes alcalíns récents au Costa Rica (Amérique Centrale).- Bull. Volcanol., 36: 140-147.

TOURNON, J., 1984: Magmatismes du Mesozoique a l' Actuel en Amerique Centrale: L'example de Costa Rica, des
Ophiolites aux Andesites.- 335 págs. Univ. Curie, París [Tesis doctoral].

TOURNON, J. \& ALVARADO, G.E., 1997: Carte géologique du Costa Rica: notice explicative; Mapa geológico de Costa Rica: folleto explicativo, échelle-escala 1500 000.- Ed. Tecnológica de Costa Rica, 80 págs. + mapa geológico de Costa Rica.

TOURNON, J. \& AZÉMA, J., 1980: Sobre la estructura y la petrología del macizo ultrabásico de Santa Elena (Provincia de Guanacaste, Costa Rica).- Inst. Geogr. Nacional, Inf. Semestral, 26: 17-54.

TOURNON, J. \& BELLON, H., 2009: The southern Central America puzzle: Chronology and structure. A review.- Rev. Geol. Amér. Central, 40: 11-47.

TOWNLEY, B.K., HÉRAIL, G., MAKSAEV, V., PALACIOS, C., PARSEVAL, P., SEPULVEDA, F., ORELLANA, R., RIVAS, P. \& ULLOA, C., 2003: Gold grain morphology and composition as an exploration tool: application to gold exploration in covered areas.- Geochemistry: Exploration, Enviroment, Analysis, Geol. Soc. London, 1: 29-38.

TURNER, F.J., 1968: Memorphic petrology, mineral and field aspects.- 403 págs. McGraw-Hill, New York.

TYRRELL, G.W., 1929: The Principles of Petrology.- Trad. Español: Principios de Petrología. Introducción al estudio de la ciencia de las rocas.- 369 págs. Companía Ed. Continental, S.A., México.

UlloA, A. \& DELGADO, C., 2010: Características geoquímicas y mineralogía del flanco pacífico central de la cordillera de Talamanca.- 170 págs +2 mapas. Univ. de Costa Rica, San José [Tesis Lic.]. 
USGS-DGGMH-UCR, 1987: Mineral Resource Assessment of the Republic of Costa Rica/ Evaluacion de los Recursos Minerales de la Republica de Costa Rica.- 75 págs. U.S.G.S, Dirección General de Geología, Minas e Hidrocarburos \& Univ. Costa Rica, Miscellaneous Investigations Series Map I-1865, Reston, Virginia.

VALERIO, A.L. \& LAURITO, C.A., 2011: Nuevos hallazgos de Mammalia, Xenarthra (Cingulata) y confirmación del registro de Pachyarmatherium leiseyi Downing \& White, 1995 en la localidad de Buenos Aires de Palmares, provincia de Alajuela, Costa Rica.Rev. Geol. Amér. Central, 44: 131-139.

VALVERDE, R., 1989: Investigación GeológicoAmbiental del Proyecto Túnel de Pejibaye, Cartago, Costa Rica.- 190 págs (Tomo I). Univ. de Costa Rica, San José [Tesis Lic.].

VANNUCCHI, P., FISHER, D.M., BIER, S. \& GARDNER, T.W., 2006: From seamount accretion to tectonic erosion: Formation of Osa Mélange and the effects of Cocos Ridge subduccion in southern Costa Rica.- Tectonics, 25, TC2004, DOI: 10.1029/2005TC001855.

VEGA, E., 2000: Patrones de Alteracion Hidrotermal en el Campo Geotérmico Miravalles y su Correlación con la Temperatura.- ix + 79 págs. Escuela Centroamericana de Geología, Univ. Costa Rica [Tesis Lic.].

VILLEGAS, A., 1997: Geodinámica de la Cordillera de Tilarán, relación entre la volcanología y la tectónica.- $\mathrm{v}+182$ págs. +2 mapas. Escuela Centroamericana de Geología, Univ. Costa Rica [Tesis Lic.].

VILLEGAS, A., 2004: La Formación Alto Palomo: Flujos pumíticos de la cordillera volcánica Central, Costa Rica.- Rev. Geol. Amér. Central, 30: 73-81.
VOGEL, T.A., PATINO, L.C., ALVARADO, G.E. \& GANS, P.B., 2004: Silicic ignimbrites within the Costa Rican volcanic front: evidence for the formation of continental crust.- Earth Planetary Sci. Letters, 226: 149-159

WALKER, J.D. \& GEISSMAN, J.W. (eds), 2009: Geological Time Scala.- Geol. Soc. Amer. 60-61, DOI: 10.1130/2009.CTS004R2C.

WERNER, R., HOENLE, K, VAN DEN BOGAARD, P., RANERO, C. \& VON HUENE, R., 1999: Drowned 14 m.y.-old Galápagos archipielago off the coast of Costa Rica: Implications for tectonic and evolutionary models.- Geology, 27(6): 499-502.

WEGNER, W., WÖRNER, G., HARMON, R. \& JICHA, B.R., 2011: Magmatic history and evolution of the Central American Land Bridge in Panama since Cretaceous times.Geol. Soc. Amer. Bull. 123(3/4): 703-724, DOI: 10.1130/B30109.1.

WEYL, R., 1957: Contribución a la geología de la Cordillera de Talamanca de Costa Rica (Centro América).- 77 págs. Inst. Geogr. Costa Rica, San José.

WEYL, R., 1980: Geology of Central America.371 págs. Borntraeger, Berlín.

WINKLER, H.G.F., 1965: Petrogenesis of Metamorphic Rocks.- viii + 220 págs. Springer-Verlag, Berlín.

WOLF, J.W., 1896: On the occurence of theralite in Costa Rica, Central America.- Amer. J. Sci. 1: 271-272.

WOODBURNE, M.O., 2004: Global Events and the North American Mammalian Biochronology.- En: WOODBURNE, M.O. (ed.): Late Cretaceous and Cenozoic Mammals of North America. Biostratigraphy and Geochronology, Columbia Univ. Press, New York: 315-343. 
WOODBURNE, M.O., 2010: The Great American Biotic Interchange: Dispersals, Tectonic, Climate, Sea Level and Holding Pens.- J. Mammal Evol., 17: 245-264, DOI: 10.1007/ s10914-010-9144-8.

WOODCOCK, N.H. \& MORT, K., 2008: Classification of fault breccias and related fault rocks.- Geol. Mag. 145(3): 435-440.

WOODWARD-CLYDE, 1993: A preliminary evaluation of earthquake and volcanic hazards significant to the major population centers of Central Valley, Costa Rica.66 págs. Ret. Coorporation-WoodwardClyde.

YUAN, P.B., 1984: Stratigraphy, Sedimentalogy, and Geologic Evolution of Eastern Terraba Trough, Southwestern Costa Rica.- x +89 págs. Lousiana State University, Lousiana [Tesis M.Sc.].
ZACCARINI, F., GARUTI, G., PROENZA, J.A., CAMPOS, L., THALHAMMER, O.A.R., AIGSPELRGER, T. \& LEWIS, J.F., 2011: Chromite and platinum group elements mineralization in the Santa Elena Ultramafic Nappe (Costa Rica): geodynamic implications.- Geol. Acta, 9 (3-4): 407-423.

ŽÁČEK, V., JANOUŠEK, V., ULLOA, A., KOŠLER, J., HUAPAYA, S., MIXA, P., VONDROVICOVÁ, L. \& ALVARADO, G.E., 2011: The Late Miocene Guacimal Pluton in the Cordillera de Tilarán, Costa Rica: its nature, age and pretogenesis.- J. Geosciences, 56(1): 51-79.

ZAMORA, N, MÉNDEZ, J., BARAHONA, M. \& SJÖBOHM, L., 2004: Volcanoestratigrafía asociada al campo de domos de Cañas Dulces, Guancaste, Costa Rica.Rev. Geol. Amér. Central, 30: 41-58. 